\title{
DESENVOLVIMENTO DE UM SISTEMA ADAPTATIVO DE DETECÇÃO DE INTRUSOS EM REDES DE COMPUTADORES
}

OK

Adriano Mauro Cansian

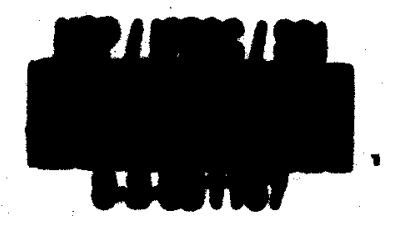

Tese apresentada ao Instituto de Física de São Carlos, da Universidade de São Paulo, para obtenção do título de Doutor em Física Aplicada, sub-área Física Computacional.

Orientador: Prof. Dr. Edson dos Santos Moreira

\section{São Carlos}

1997 


\section{Cansian, Adriano Mauro}

Desenvolvimento de um Sistema Adaptativo de Detecção de Intrusos em Redes de Computadores / Adriano Mauro Cansian São Carlos, 1997.

$154 \mathrm{p}$.

Tese (Doutorado) - Instituto de Física de São Carlos, USP 1997.

Orientador: Prof. Dr. Edson dos Santos Moreira

1.Redes de Computadores. 2. Segurança 3.Redes Neurais I. Título. 
MEMBROS DA COMISSÃO JULGADORA DA TESE DE DOUTORADO DE ADRIANO MAURO CANSIAN APRESENTADA AO INSTITUTO DE FÍSICA DE SÃO CARLOS, UNIVERSIDADE DE SÃO PAULO, EM 18/04/1997.

COMISSÃO JULGADORA:

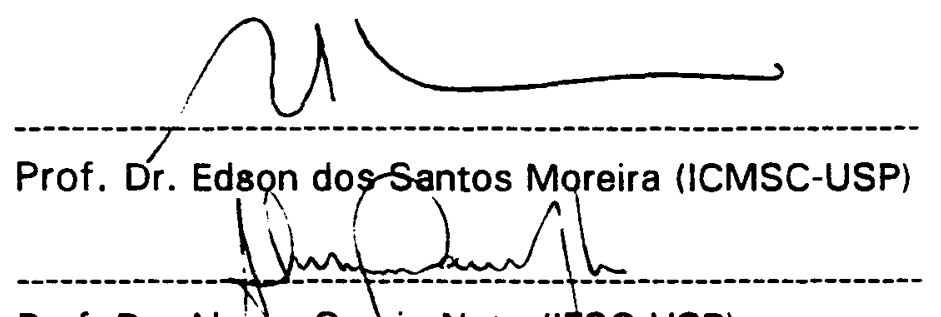

Prof. Dr. Alvało Garcia Neto (IFSC-USP)

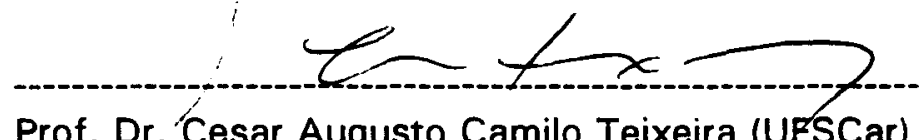

Prof. Dr. Cesar Augusto Camilo Teixeira (UFSCar)

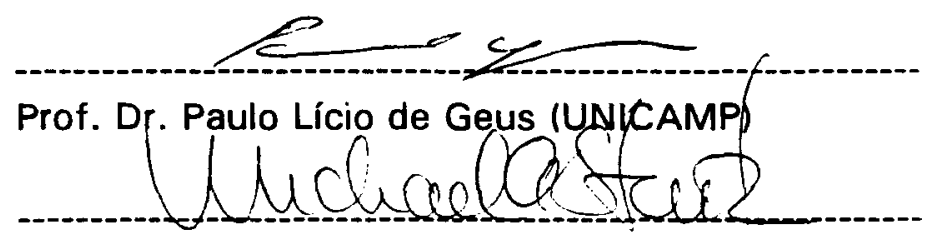

Prof. Dr. Michel Stanton (PUC-RJ) Michael Anthony Stanto. 
Para Cecilia, por tudo.

IFGC ULD SERVICOODE 310LOOTECA

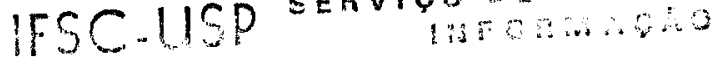




\section{Agradecimentos}

* Ao Prof. Edson dos Santos Moreira, meu orientador, pela incansável e valiosa orientação, e principalmente pelo apoio, amizade e confiança ao longo deste tempo.

* A meus pais, pela minha formação e pelo estímulo nos momentos mais dificeis.

* A meus amigos Aleck Zander Tomé de Souza, Sérgio Antonio Leugi Filho e José Maurício Bonifácio Júnior, que trabalharam direta e intensivamente neste projeto.

* Ao Prof. Dr. André de Carvalho, do ICMSC/USP, pela grande orientação com relação ao uso das redes neurais.

* Ao Dr. Steve McCanne, do Lawrence Berkeley National Laboratory, USA, pela documentação e informações relevantes sobre a biblioteca de captura de pacotes libpcap.

* A Rogério Borges Mouro, por valiosas discussões sobre os temas deste trabalho.

* À Profa. Adriana Cardoso de Moraes, pela revisão gramatical dos originais deste texto.

* A Cristiano Nunes Pereira e Romildo Olier Rodrigues, técnicos do IBILCE/UNESP em São José do Rio Preto, por manterem sintonizadas as redes utilizadas nos ensaios deste trabalho.

* Às secretárias Sandra e Olga, do IBILCE/UNESP em São José do Rio Preto, por cuidarem de tudo na minha ausência.

* A todos os colegas do Grupo de Intermídia, do ICMSC/USP, pela amizade e carinho com que sempre me trataram.

* À CAPES - Coordenadoria de Aperfeiçoamento de Pessoal de Ensino Superior, e à FAPESP - Fundação de Amparo à Pesquisa do Estado de São Paulo, pelo apoio financeiro na realização deste projeto. 
Esta pesquisa foi financiada por intermédio de bolsa de estudos do PICD - Programa Institucional de Capacitação à Docência, patrocinado pela CAPES - Coordenadoria de Aperfeiçoamento de Pessoal de Ensino Superior. 
“ I'm sorry Dave, I'm afraid I can't let you do that. " 


\section{Sumário}

Sumário ___ $i$

Lista de Figuras___ v

Lista de Tabelas__ vi

Lista de Abreviaturas e Siglas___ vii

RESUMO _ _ viii

ABSTRACT _ ix

1. Introdução ___ 1

1.1 Os riscos envolvidos ___ 1

1.2 Segurança de computadores e redes __ 3

1.3 Detectando atacantes _ 4

1.40 que é deteção de intrusão __ 6

1.4.1 Considerações Gerais _ 6

1.4.2 Classificação dos principais tipos de ataque ___ 7

1.5 Classificação dos métodos de detecção de intrusão __ 8

1.5.1 Deteç̧ão de anomalia —_ 8

1.5.2 Deteç̧ão por abusos 9

1.5.3 Classificação por tipo de análise __ 10

1.6 Terminologia __ 10

1.7 Casos e exemplos utilizados neste trabalho 12

1.8 Propósitos e esboço geral deste trabalho ___ 13

2. Modelos Atuais de Deteç̧ão de Intrusão ___ 14

2.1 Introdução __ 14

2.2 Detecção de intrusos por anomalia ___ 15

2.2.1 Método estatístico ___ 15

2.2.2 Gerador de prognósticos de padrões ___ 17

2.2.3 Classificação Bayesiana ___ 18

2.3 Deteç̧ão de intrusos por abusos __ 19

2.3.1 Características gerais _ـ 19

2.3.2 Uso de sistemas especialistas em detecção de intrusão ___ 20

2.3.3 Deteç̧ão por modelamento _____ 21

2.4 Sistema híbridos 22

2.4.1 Intrusion Detection Expert System (IDES) ___ 22

2.5 Sistemas de deteç̧ão de intrusão baseados em redes __ 23

2.5.1 Network Security Monitor (NSM) ___ 24

2.6 Situação geral das técnicas de detecção de intrusão _ 27 
3.1 Redes de computadores com protocolo TCP/IP $\quad 30$

3.1.1 Características básicas do protocolo TCP/IP — 30

3.1.2 Problemas de segurança envolvendo redes T $\overline{\mathrm{CP} / \mathrm{IP}} \_35$

3.2 Captura e tratamento de pacotes de rede ___ 38

3.3 Uso de redes neurais no reconhecimento de padrões __ 40

3.3.1 Introdução —u 40

3.3.2 Caracteristicas gerais _ 41

3.3.3 A aprendizagem da rede neural ___ 44

3.3.4 Regras de correção de erro___ 45

3.3.5 Redes feedforward multicamada 46

3.3.6 O re-treinamento e adaptabilidade da rede ___ 48

4. Um Modelo Adaptativo de Deteç̧ão de Intrusos __ 49

4.1 Introdução _ 49

4.2 Descrição inicial____ 49

4.3 Ambiente de abrangência ___ 51

4.4 Estrutura do modelo _ 53

4.4.1 Estrutura geral _ 53

4.4.2 Estrutura modular do sistema __ 54

4.4.3 Módulo de captura e o módulo de pré-seleção___ 55

4.4.4 Módulo de conexão __ 57

4.4.5 O analisador semântico e o vetor de estímulo _ 59

4.4.6 Obtenção do nivel de suspeita da sessão ___ 61

5. Implementação de um Protótipo do Sistema ___ 63

5.1 Introdução _ 63

5.1.1 Equipamento utilizado _ 64

5.20 módulo de captura de pacotes ___ 64

5.2.1 Características gerais ___ 64

5.2.2 A biblioteca de captura de pacotes__ 65

5.2.3 As funções principais da biblioteca de captura libpcap___ 66

$\begin{array}{ll}5.2 .4 \text { Operações de captura ___ } 67 & 67\end{array}$

5.2.5 Estruturas do sistema de captura __ 67

5.30 módulo de pré-seleção _ 69

5.3.1 Consideraçôes gerais — 69

5.3.2 Tipos de pacotes tratados 70

5.3.3 Lista de monitoração e o disparo de captura ___ 70

5.40 módulo de conexão __ 73

5.4.1 Características gerais 73

5.4.2 Mapeamento dos dados __ 74

5.50 analisador semântico e pós-processador __ 77

5.5.1 Características gerais ___ 77

5.5.2 Sub-módulo de reconhecimento de assinaturas__ 78

5.5.3 Sub-módulo de codificação binária __ 80

5.5.4 Esquemas de codificação das assinaturas para código binário ___ 81

5.5.5 O Assistente Adaptativo de Inserção de Assinaturas____ 84

5.60 simulador de rede neural ___ 85

5.6.1 Caracteristicas gerais __ 85

$5.6 .2 \mathrm{O}$ controle da rede neural no SNNS 86

$\begin{array}{ll}5.6 .3 \text { Inserindo conjuntos de dados no SNNS } & 88\end{array}$ 
5.6.4 Saída de resultados do SNNS

5.6.5 Monitoração do processo de aprendizagem

5.7 Resumo do fluxo de informaçōes ___ 91

6. Resultados Obtidos ___ 93

6.1 Introdução __ 93

6.2 Testes do módulo de captura e de conexão ___ 94

6.3 Testes do módulo de pré-seleção ___ 96

6.4 Formação das assinaturas de ataque __ 97

6.4.1 Técnicas de simulação de ataque ___ 97

6.4.2 Ambiente de testes dos ataques ___ 98

6.4.3 Formação das assinaturas _ـ 101

6.4.4 Preparação das assinaturas de ataque em vetores binários ___ 103

6.5 Dados para o treinamento da rede neural ___ 106

$\begin{array}{ll}\text { 6.6 Resultados da rede neural } & 107\end{array}$

$\begin{array}{ll}\text { 6.6.1 Rede neural utilizada } & 107\end{array}$

$\begin{array}{ll}\text { 6.6.2 Condições de aprendizagem da rede neural ___ } & 107\end{array}$

6.6.3 Procedimentos de aprendizagem e testes _ 108

$\begin{array}{ll}\text { 6.6.4 Resultados dos processos de aprendizagem e validação } & 109\end{array}$

6.6.5 Tempos de aprendizagem ___ 114

6.6.6 Resultados dos processos de teste a generalização___ 114

6.7 Resultados de generalização e adaptabilidade $\quad 115$

6.7.1 Resultados de variações de ataque 115

6.7.2 Resultados de variaçðes de um não-ataque ___ 118

6.8 0 assistente de adaptabilidade __ 120

6.9 Considerações gerais sobre os resultados das redes neurais ___ 121

7. Conclusões e Sugestões para Trabalhos Futuros __ 123

7.1 Conclusões gerais _ 123

7.2 Contribuições especificas deste trabalho $\quad 124$

7.2.1 Determinação do comportamento intrusivo 125

7.2.2 Determinação e codificação de um conjunto de assinaturas de ataque ___ 125

7.2.3 A captura e o tratamento de sessões__ 126

7.3 Sugestões para continuidade e aprimoramento deste trabalho $\quad 126$

7.3.1 Considerações gerais 126

$\begin{array}{ll}\text { 7.3.2 Sistema de Gerenciamento___ } & 127\end{array}$

$\begin{array}{ll}\text { 7.3.3 Módulo de pré-seleção } & 129\end{array}$

$\begin{array}{ll}\text { 7.3.4 Aprimoramento das assinaturas de ataque } 129 & 129\end{array}$

7.3.5 Aprimoramento da rede neural ___ 130

7.3.6 Obtenção de contra-prova ou dupla verificação (double-checking) _ـ 131

7.3.7 Determinação do sucesso de um ataque___ 131

$\begin{array}{ll}7.4 \text { Conclusão final } & 131\end{array}$

ANEXO A - Artigo publicado

ANEXO B - Artigo publicado

ANEXO C - Artigo aceito para publicação _ـ 136

ANEXO D - Artigo aceito para publicação __ 137 
Referências Bibliográficas 138

APÊNDICE A - Autômato Finito 145 APÊNDICE B - Exemplo da TSR 147 APÊNDICE C - Principais URLs utilizados 149 APÊNDICE D - Como contactar o autor 150 GLOSSARIO 151 


\section{Lista de Figuras}

Figura 2.1 - Arquitetura do modelo ICEM com as 3 primeiras camadas 24

Figura 2.2 - Representação das 3 últimas camadas do modelo ICEM 25

Figura 2.3 - Estrutura atual do sistema especialista do NSM 27

Figura 3.1 - Vários protocolos nas diferentes camadas do conjunto de protocolos TCP/IP [Ste94] _ 31

Figura 3.2 - Estrutura de um datagrama IP_ 32

Figura 3.3 - Estrutura de um datagrama TCP__ 33

Figura 3.4 - Estrutura de um datagrama UDP__ 34

Figura 3.5 - Esquema de funcionamento do BSD Packet Filtering [MJ93] __ 39

Figura 3.6 - Modelo de McCulloch-Pitts para um neurónio ___ 42

Figura 3.7 - Uma típica arquitetura de rede tipo feedforward de 3 camadas [JMM96]___ 47

Figura 4.1 - Tipos básicos de ataque. Figura adaptada da referência [KFG+93] __ 50

Figura 4.2 - Monitoração de sub-rede _ 52

Figura 4.3 - Monitoração de um backbone ___ 52

Figura 4.4 - Monitoração de backbone e linhas seriais___ 53

Figura 4.5 - Estrutura geral do modelo de segurança ___ 53

Figura 4.6 - Estrutura geral alternativa do modelo de segurança_ 54

Figura 4.7 - Estrutura dos módulos do sistema de deteç̧ão de intrusos __ 55

Figura 4.8 - Representação do vetor de monitoração ___ 56

Figura 4.9 - Esquema de formação do vetor de conexão pelo módulo de conexão___ 58

Figura 4.10 - Representação do vetor de estímulo para a rede neural ___ 61

Figura 5.1 - Ambiente onde o protótipo realiza monitoração ___ 64

Figura 5.2 - Ativação do Módulo de Conexão pelo módulo Pré-seleção_ 73

Figura 5.3 - Associação da Tabela de Símbolos Reservados com os valores binários___ 78

Figura 5.4 - Exemplo do esquema de codificação das assinaturas _________ 81

Figura 5.5 - Painel de controle do SNNS ___ 87

Figura 5.6 - Reprodução de uma tela do gráfico do erro cometido pela rede neural ___ 91

Figura 5.7 - Esquema do fluxo de informações no SADI ___ 92

Figura 6.1 - Erro ao longo dos ciclos. Conjunto de dados 1 e rede MLP126-1_ 110

Figura 6.2 - Erro ao longo dos ciclos. Conjunto de dados l e rede MLP126-10-1__ 110

Figura 6.3 - Erro ao longo dos ciclos. Conjunto de dados 2 e rede MLP126-1____ 111

Figura 6.4 - Erro ao longo dos ciclos. Conjunto de dados 2 e rede MLPI26-10-1___ 111

Figura 6.5 - Erro ao longo dos ciclos de. Conjunto de dados 3 e rede MLP126-I___ 112

Figura 6.6 - Erro ao longo dos ciclos de. Conjunto de dados 3 e rede MLPI26-10-1_ 112

Figura 6.7 - Erro ao longo dos ciclos de. Conjunto de dados 4 e rede MLPI26-1___ 113

Figura 6.8 - Erro ao longo dos ciclos de. Conjunto de dados 4 e rede MLP126-10-1_ 113

Figura 7.1 - Estrutura de funcionamento do sistema NetTracker [MMM97] ___ 128 


\section{Lista de Tabelas}

Tabela 2.1 - Principais sistemas detetores de intrusão atuais e suas características 29

Tabela 4.1 - Exemplo de conversão de cadeias de strings, formadores das assinaturas de ataque Tabela 5.1 - Valores de NS, referentes às portas

Tabela 6.1 - Eficiência da captura de pacotes 72

Tabela 6.2 - Distribuição dos ataques simulados utilizáveis, com relação às portas 95

Tabela 6.3 - Codificação em binários para as portas das sesszes 100

Tabela 6.4 - Distribuição dos dados de ataque usados na aprendizagem da rede neural 104 Tabela 6.5 - Resultados dos erros quadráticos médios 106

Tabela 6.6 - Resultados dos erros quadráticos médios, desconsiderando-se o conjunto 3 114 122 


\section{Lista de Abreviaturas e Siglas}

$\begin{array}{ll}\text { AAIA } & \text { Assistente Adaptativo de Inserção de Assinaturas } \\ \text { API } & \text { Application Program Interface } \\ \text { ARP } & \text { Address Resolution Protocol } \\ \text { BPF } & \text { BSD Packet Filtering } \\ \text { BSD } & \text { Berkeley Systems Development } \\ \text { CERT } & \text { Computer Emergency Response Team } \\ \text { CIAC } & \text { United States Dept. of Energy's Computer Incident Advisory Capability } \\ \text { CSI } & \text { Computer Security Institute } \\ \text { DNS } & \text { Domain Name System } \\ \text { FTP } & \text { File Transfer Protocol } \\ \text { HTTP } & \text { Hipertext Transfer Protocol } \\ \text { ICMP } & \text { Internet Control Message Protocol } \\ \text { ISS } & \text { Internet Security Scan } \\ \text { NIS } & \text { Network Information System } \\ \text { NIT } & \text { Network Information Tap } \\ \text { NS } & \text { Nivel de Segurança } \\ \text { NSM } & \text { Network Security Monitor } \\ \text { RARP } & \text { Reverse Address Resolution Protocol } \\ \text { RFC } & \text { Request for Comments } \\ \text { SATAN } & \text { Security Administrator's Tool for Analysing Networks } \\ \text { SDI } & \text { Sistema Detetor de Intrusão } \\ \text { SDIs } & \text { Sistemas Detetores de Intrusão } \\ \text { SMTP } & \text { Simple Mail Transfer Protocol } \\ \text { SNMP } & \text { Simple Network Management Protocol } \\ \text { SO } & \text { Sistema Operacional } \\ \text { TCP/TP } & \text { Transmission Control Protocol / Internet Protocol } \\ \text { TSR } & \text { Tabela de Simbolos Reservados }\end{array}$




\section{RESUMO}

Este trabalho apresenta o desenvolvimento de um modelo de deteç̧ão de intrusão em redes de computadores. É apresentada a construção e testes de um protótipo para um ambiente Internet. $O$ sistema, posicionado em pontos chaves da rede, examina o fluxo de dados entre as conexões, buscando por padrões de comportamento suspeito. A identificação de tais padrões é realizada por intermédio de uma rede neural. O sistema é altamente adaptativo, uma vez que novos perfis podem ser adicionados à base de dados, e assim um retreinamento da rede neural permite reconhece-los. Cerca de 240 perfis de intrusão diferentes foram analisados, dos quais 117 foram selecionados como sendo relevantes para esta implementação. Acredita-se que este conjunto represente cerca de 90 por cento do número total de tipos de ataques conhecidos na Internet. Finalmente, são relatados os procedimentos de avaliação do sistema , mostrando a eficiência do método. 


\begin{abstract}
This work presents the development of a network intrusion detection model. The building and testing of a prototype in the Internet environment is described. The system, positioned at key points of the network, examines the data flow between connections, searching for patterns of suspicious behaviour. The identification of those patterns is carried out by a neural network. The system is highly adaptive, since new profiles of intrusion can be easily added to the database, and so a retraining of the neural network enables the system to consider them. About 240 different intrusion profiles were analysed, from which 117 were elected as been relevant for this implementation. It is believed that this set currently represents around 90 percent of the total number of attacks profiles over the Internet. Finally the description of the system evaluation procedures are reported, and can show the efficience of the method.
\end{abstract}




\section{Introdução}

Este capítulo apresenta a situação atual das redes de computadores com relação à segurança, e discute a motivação para a realização desta pesquisa. São mostradas algumas definições importantes sobre a classificação dos métodos de detecção de intrusos em sistemas computacionais, e as implicações de utilização destas tecnologias. No final, o capítulo traz um esboço sobre o que este trabalho pretende mostrar.

\subsection{Os riscos envolvidos}

Com a crescente difusão das redes de dados, cresce também a preocupação com a segurança das informações armazenadas nos computadores conectados a elas. Além disso, uma quantidade cada vez maior de atividades essenciais é realizada por intermédio das redes (principalmente através da Internet), e seu funcionamento correto e confiável torna-se de fundamental importância. Paralelamente, ações de pirataria, tentativas de intrusão e invasões consumadas aumentam a cada dia, envolvendo um número cada vez maior de máquinas [Bac94, NP89 $]^{1}$. Isto faz com que técnicas especiais de segurança se tornem indispensáveis nos sistemas computacionais modernos.

A proliferação de computadores e redes com um custo mais acessível ampliou o problema de acesso não-autorizado, bem como a possibilidade de manipulação e ataque a dados e recursos. $O$ crescimento da interconexão de redes não só possibilita o rápido acesso a uma maior variedade de computadores, como também garante acesso a dados que podem vir de qualquer lugar. Com freqüência ocorrem situações onde os intrusos facilmente superam os mecanismos de autenticação de senhas, projetados para proteger os sistemas.

\footnotetext{
${ }^{1}$ Referências bibliográficas aparecem indicadas entre [ colchetes ] neste texto
} 
Além disso, expandem-se rapidamente as redes denominadas Intranets, que interligam sistemas de empresas, de corporações ou de instituições com propósitos específicos. Estas Intranets representam um papel econômico muito importante, em função da grande quantidade de atividades que delas dependem, seja do ponto de vista administrativo, seja do ponto de vista comercial. Segundo Rapalus [Rap97], uma em cada 5 corporações Norte-americanas já possui uma Intranet desenvolvida e $70 \%$ das empresas pretendem implementar uma até o final de 1997.

Em vista desta expansão, sem as devidas e apropriadas precauções, qualquer tipo de atividade eletrônica em redes pode se tornar completamente vulnerável. Alguns exemplos evidenciam tal preocupação: em 1994, no Dia de Ação de Graças, as redes da General Eletric, da IBM e da rede de televisão NBC sofreram um sério ataque de um obscuro grupo extremista denominado Internet Liberation Front, e tiveram seus sistemas temporariamente desabilitados. No final de 1995 o grupo Citibank foi atingido por intrusos, provenientes de ex-repúblicas soviéticas, que transferiram ilegalmente mais de 10 milhões de dólares para centenas de contas separadas ao redor do mundo [Pow96a].

No início de 1996, o Computer Security Institute ${ }^{1}$ (CSI, San Franciso, California, USA), em conjunto com o FBI - Federal Bureau of Investigations (USA), realizaram uma pesquisa [CSI96] com 428 instituições, entre as quais os principais bancos, agências governamentais, instituições médicas e universidades Americanas. As respostas mostraram que $42 \%$ destas instituições já teriam sido vítima de algum uso não autorizado de seu sistema de rede, nos 12 meses que precederam a pesquisa. Segundo o relatório do CSI, mais de $60 \%$ responderam que suas redes têm sido sondadas constantemente (53\% das sondagens vem dos sistemas internos; $39,4 \%$ vem de linhas discadas remotas e $37,5 \%$ são provenientes da Internet), enquanto $20 \%$ não sabem sequer se já foram atacadas.

Apesar de analistas internacionais considerarem que os crimes em redes de computador representam milhões de dólares, é muito dificil estimar qual o real montante

\footnotetext{
${ }^{1}$ Acessivel via WWW em $h t t p: / / w w w . g o c s i . c o m /$
} 
de prejuízos envolvidos anualmente, principalmente porque na grande maioria das vezes, os ataques não são relatados em função da perda de prestígio e credibilidade que eles podem representar.

Sabe-se também que o risco tende a aumentar, pois, com o passar dos anos e com a disseminação de informações (notadamente através da Internet), houve um significativo avanço no entendimento de como operam os sistemas. Isso fez com que intrusos se tornassem verdadeiros especialistas em determinar e explorar vulnerabilidades a fim de obterem acessos privilegiados. Estes mesmos intrusos também passaram a se utilizar de técnicas de intrusão de dificl de rastreamento e identificação. Freqüentemente usam diversos níveis de ocultação e dissimulação, antes de realizar o ataque. Procuram despistar o alvo, e raramente são surpreendidos, realizando ataques massivos, que evidenciem facilmente uma atividade suspeita ou anormal. Além disso costumam cobrir seus rastros, de forma que as atividades realizadas no sistema penetrado não são facilmente descobertas.

\subsection{Segurança de computadores e redes}

De uma forma abrangente, Garfinkel e Spafford [GS96] definem um sistema computacional seguro como sendo aquele que se comporta da maneira esperada. A observação do comportamento esperado, em comparação com o comportamento apresentado, pode ser entendido como o nivel de confiança do sistema e indica o quanto podemos confiar no seu funcionamento. O comportamento esperado é formalizado dentro da política de segurança do sistema, e regula as metas que este deve cumprir. Dessa forma, um evento de segurança normalmente está relacionado a uma violação de normas ou procedimentos, que dependem do sistema computacional em uso.

Uma definição mais rígida de segurança de computadores baseia-se na confidencialidade, na integridade e na disponibilidade dos recursos do sistema [RS91]. Confidencialidade requer que a informação seja acessivel somente àquelas pessoas autorizados para tal; integridade requer que a informação permaneça intacta e inalterada por acidentes ou ataques, e disponibilidade requer que o sistema computacional funcione adequadamente, sem degradação de acesso, fornecedo recursos aos usuários 
autorizados, quando eles assim necessitarem. A confidencialidade pode ser importante para o sucesso comercial ou até mesmo sobrevivência de uma empresa; integridade pode ser importante para um hospital que mantém históricos médicos de seus pacientes e os utiliza para tomadas de decisão em situações críticas. A disponibilidade de um recurso pode ser fator determinante no controle de um sistema de tráfego aéreo ou possibilidade de retaliar um ataque militar. Nesta definição, um sistema computacional que não forneça todos os recursos necessários no devido momento, é tratado como não-confiável, uma vez que o conjunto representa os requisitos de segurança.

O que se pretende mostrar aqui é que, apesar de possuir muitos pontos comuns, a definição de segurança em sistemas de computadores é extremamente flexível e dependente de uma série de fatores e características. Em resumo, um sistema seguro protege seus dados e seus recursos de acesso não-autorizado, de intromissão ou de bloqueio de uso.

\subsection{Detectando atacantes}

Com o aparecimento dos sistemas computacionais compartilhados e multiusuários, já havia uma preocupação em prover algum mecanismo de controle de acesso [Lam74] como a primeira linha de defesa. Entretanto isto somente limitava o acesso aos objetos no sistema, mas não restringia o que pode ser feito com ou pelos objetos em si [Den82]. O controle de acesso não modela, e não pode prevenir, fluxo de informação não autorizado através do sistema. Além disso, existem sistemas em que o controle de acesso é arbitrário, e a responsabilidade de proteção dos dados depende de ações do usuário final. Isto freqüentemente exige que o usuário entenda os mecanismos de proteção oferecidos pelo sistema, e como é possível obter a segurança desejada utilizando-se estes mecanismos.

Sabe-se que segurança é obtida a custo da conveniência e facilidade de uso dos sistemas. Além disso pode-se afirmar que a facilidade de conectividade de computadores é inversamente proporcional à segurança. Em geral, modelos mais antigos de segurança [BL73, Bib77] são muito rigorosos, e restringem as operações de leitura e escrita nos sistemas. Dessa forma, um sistema completamente seguro pode ser pouco útil. 
Controle de acesso e modelos de proteção não são muito úteis contra atacantes internos ou contra o comprometimento do módulo de autenticação. Se uma senha de acesso a uma conta do sistema é fraca, e foi comprometida, as medidas de controle de acesso não têm como prevenir a perda ou corrupção dos dados aos quais aquela conta tem acesso. Em geral, métodos estáticos de proteção podem simplesmente ser insuficientes ou podem tornar o sistema extremamente restritivo aos seus próprios usuários. Por exemplo, considere que uma determinada técnica de segurança não seja capaz de prevenir ou detectar violação de política de segurança resultante de buscas generalizadas em arquivos de dados; e se por essa razão o acesso a todos os arquivos tenha que ser controlado rigorosamente, o sistema pode se tornar ineficiente para o uso proposto. Dessa maneira, um método dinâmico de segurança, como por exemplo um verificador de comportamento, pode ser indicado para detectar e talvez proteger falhas de segurança.

Um outro aspecto a se considerar é que a dificuldade em se produzir softwares complexos, funcionais e isentos de erros ainda é uma questão a ser resolvida. Diversas falhas em sistemas freqüentemente se manifestam como vulnerabilidades na segurança. Há que se considerar também, que os ciclos de vida útil dos softwares estão se tornando cada vez mais curtos devido à competitividade do mercado. Isso geralmente tem como efeito colateral uma programação inadequada, ou então leva a testes e validações insuficientes ou mal planejados, o que só vem a agravar o problema. Desse modo, acredita-se que sistemas computacionais, e principalmente redes, continuarão inseguros ainda por um bom tempo. Assim, devem existir mecanismos que permitam detectar falhas de segurança, isto é, detectar intrusos e intrusões.

Os sistemas de detecção de intrusão cumprem este papel como a última linha de defesa dentro do esquema de proteção de computadores. Eles são úteis não somente para se detectar falhas de segurança que foram, ou podem, ser exploradas com sucesso, mas também para monitorar tentativas de invasão na segurança, e assim fornecerem mecanismos importantes para adoção de contra-medidas, dentro de um tempo apropriado. 
Assim, sistemas de detecção de intrusão são úteis, mesmo que fortes medidas preventivas já são usadas para controlar os sistemas que exigem alta proteção. Além disso, algumas dessas medidas preventivas, tais como ajustes e reparos de falhas em softwares, podem não ser práticas em função da relação custo-beneficio, exigência de pessoal especializado, ou mesmo podem não ser efetuadas dentro de um intervalo de tempo aceitável para muitos sistemas. Em muitos casos, estes ajustes de erros e aplicações de correções (patches) podem representar processos de instalação muito mais complexos, onerosos e perturbadores do que a atualização de uma base de dados de detecção de intrusos, especialmente quando o sistema detector de intrusão é aprimorado para o uso local e dentro de instalações individuais especializadas. De um modo mais geral, no caso de programas grandes e complexos, como por exemplo o sistema de correio eletrônico sendmai 1, pode não ser possível efetuar o ajuste apropriado do erro sem a disponibilidade do código fonte. Assim, a monitoração de métodos de ataque genéricos e conhecidos pode ser útil como uma medida preventiva.

\subsection{Oue é deteç̧ão de intrusão}

\subsubsection{Considerações Gerais}

Uma intrusão é definida [HLMS90] como " qualquer conjunto de ações que tentem comprometer a integridade, confidencialidade ou disponibilidade de um recurso computacional ". Intrusão é uma violação da política de segurança do sistema. Esta definição é geral o suficiente para abranger todo tipo de ataque. Em muitos casos as políticas de segurança não podem ser traduzidas num conjunto de regras rígido, haja vista a própria natureza mutante dos eventos de segurança. Enquanto a política de segurança define as metas que devem ser cumpridas num sistema, a deteç̧ão das violações desta politica requer conhecimento dos passos ou ações que possam resultar nesta violação.

A deteç̧ão de intrusos num sistema pode ser definida em duas categorias: detecção de intrusão por anomalia e detecção por abuso. A detecção por anomalia é baseada na determinação de comportamento anômalo no uso de recursos do sistema. Por exemplo se normalmente um determinado usuário $A$ do departamento de vendas de uma empresa somente usa sua conexão de rede de segunda a sexta-feira entre 8 e 16 horas, 
uma atividade noturna na conta deste usuário, é anormal, e pode significar uma intrusão. A detecção por anomalia tenta quantificar o comportamento usual ou aceitável, enquanto tenta indicar outros comportamentos irregulares como sendo potencialmente intrusivos.

Por outro lado, a detecção por abuso se refere a intrusões que seguem um padrão bem definido de ataque, que explora vulnerabilidades no sistema ou nos softwares aplicativos. Tais modelos podem ser prévia e precisamente escritos ou identificados. Por exemplo, encaixam-se nessa categoria a exploração das falhas de fingerd e sendmail usados no ataque conhecido como Internet Worm [Spa89]. Esta técnica representa o conhecimento sobre o comportamento impróprio ou inaceitável [Sma92] e procura localizá-lo diretamente, de maneira oposta à deteç̧ão de intrusão por anomalia, a qual busca detectar o complementar do comportamento normal. De maneira genérica, podemos dizer que a detecção por abuso trata e usa diretamente o conhecimento sobre $o$ comportamento das ações intrusivas, enquanto a deteç̧ão por anomalia usa o conhecimento sobre o comportamento normal e procura identificar o que foge a este comportamento.

A classificação apresentada baseia-se no método de deteç̧ão. Outro esquema [Sma88], discutido a seguir, classifica as intrusões em 6 tipos, agrupando-as com base em seu efeito final e no método de ação.

\subsubsection{Classificação dos principais tipos de ataque}

- Tentativa de Invasão (Attempted Break-in): freqüentemente detectado através de perfis de comportamento atípico ou tentativa de violação dos mecanismos de validação e contenção.

- Ataque Dissimulado (Masquerade Attack): também determinado através de perfis de comportamento atípico ou tentativa de violação dos mecanismos de validação e contenção, mas de determinação mais sensivel.

- Penetração do Controle de Segurança do Sistema (Penetration): usualmente detectado pela monitoração de padrões específicos de atividade.

- Escoamento (Leakage): normalmente detectado por uso atípico de recursos de entrada e saída (E/S) e que não se encaixa nos casos anteriores. 
- Comprometimento de Recursos (Denial of Services): detectado por uso atípico dos recursos do sistema, freqüentemente levando-os a se tornarem indisponiveis.

- Uso Mal-intencionado (Malicious use): normalmente relacionado a usuários legítimos do sistema que abusam de seus privilégios; pode ser detectado a partir de perfis de comportamento atípico, violações ou tentativas de violações de mecanismos de bloqueio, ou uso de privilégios especiais.

Modelos estatísticos são usados na detecção de anomalia, e a monitoração rigorosa de padrões de ataque bem conhecidos são adotados quando se usa detecção de abuso. Ambos os métodos trazem implícitas algumas suposições sobre a natureza das intrusões que podem ser detectadas por eles e, obviamente, possuem determinadas aplicações e limitações. Além disso, os métodos de detecção podem variar pela maneira como são implantados, e pelo tipo de dados ou análises que utilizam dentro dos sistemas computacionais. Estes métodos, e sua classificação, são discutidos a seguir.

\subsection{Classificação dos métodos de deteç̧ão de intrusão}

\subsubsection{Deteç̧ão de anomalia}

A consideração central da detecção por anomalia é que a atividade intrusiva é um sub-conjunto da atividade anormal. Isso é razoável, considerando que um atacante externo tem uma grande chance de possuir um comportamento anormal dentro de uma conta de um usuário do qual ele não conhece o padrão de atividades. Freqüentemente a atividade intrusiva pode ser tratada como uma soma de atividades individuais que, independentemente, podem não ser anormais. Em geral, o conjunto de atividades anormais é o mesmo conjunto de atividades intrusivas. Assim, em tese, localizando-se todas as anomalias seria possível localizar todas as atividades intrusivas. Entretanto, a atividade intrusiva nem sempre coincide com atividade anômala. Nos sistemas por deteç̧ão de anomalia há quatro casos possíveis, cada um dos quais com probabilidade diferente de zero de ocorrer [Sma88]:

- Intrusivo e anômalo. São os verdadeiros positivos: a atividade é intrusiva e é apontada como tal por ser também anômala.

- Não intrusivo e não anômalo. São verdadeiros negativos: a atividade não é anômala e não é apontada como intrusiva. 
- Intrusivo mas não anômalo. São falso negativos, isto é, a atividade é intrusiva mas, como não é anômala há uma falha em sua detecção.

- Não intrusivo mas anômalo. São os falso positivos. A atividade não é intrusiva, mas como é anormal, o sistema a aponta, erroneamente, como sendo intrusiva.

Para se eliminar ou reduzir o problema de falso-negativos, é preciso redefinir os limites que apontam a anomalia. Quando estes limites estão ajustados erroneamente, há um comprometimento da eficiência dos mecanismos automáticos de deteç̧ão, que acusam muitos casos como sendo intrusivos, os quais são descartados como tal após análise pelo pessoal de segurança. Além disso, detetores por anomalia tendem a ser computacionalmente mais dispendiosos, porque muitos parâmetros precisam ser ajustados com freqüência, dependendo do tipo de atividade do sistema [MHL94].

\subsubsection{Detecção por abusos}

A principal consideração na detecção por abuso é que há ataques que podem ser precisamente codificados, de maneira a capturar e registrar arranjos e variações acerca de atividades que exploram a mesma vulnerabilidade. Entretanto, na prática, nem todas as maneiras possiveis de se efetuar uma intrusão podem ser eficientemente capturadas e codificadas. A limitação principal desse método é que ele busca por vulnerabilidades conhecidas, e pode não ser de muita utilidade na deteç̧ão de intrusões futuras. Outra limitação deste método tem a ver com considerações práticas sobre o que é auditorado. Por exemplo, as práticas convencionais de auditoria não registram mudanças nas variáveis dos processos, devido ao impacto que isso pode causar na performance do sistema e devido às exigências de disco para armazenar os dados auditorados. Se uma intrusão só puder ser identificada a partir daqueles dados, há um comprometimento do método, ainda que alguns dados possam ser inferidos a partir de outras condições do sistema.

Por outro lado, os métodos de detecção por abuso, tem sido preferidos em muitos casos devido a seu custo computacional reduzido e pequeno comprometimento da performance. Além disso, estudos recentes [Pow96b] mostram que cerca de $93 \%$ das tentativas de intrusão ocorrem a partir de padrões bem definidos de comportamento, e que freqüentemente são de conhecimento dos administradores do sistema. 


\subsubsection{Classificação por tipo de análise}

Além das classificações apresentadas acima, segundo Mukherjee et al [MHL94], os sistemas detetores de intrusão (SDIs) podem ainda ser divididos em duas categorias mais amplas: SDIs baseados em hosts (host-based) e baseados em rede (network-based). Os sistemas host-based empregam os registros de auditoria como fonte principal para identificar intrusões, enquanto os sistemas network-based constróem seu próprio mecanismo utilizando o tráfego, acesso, ou fluxo de dados pela rede. Os sistemas network-based podem também ainda utilizar análises dos registros de auditoria dos computadores da rede sobre a qual atuam, de maneira a complementar informações ou eliminar casos duvidosos ou ambíguos. Alguns sistemas são híbridos e agregam várias técnicas. No capítulo 2 serão apresentados os SDIs mais relevantes, e aqueles que são importantes para o desenvolvimento deste trabalho.

\subsection{Terminologia}

A seguir apresentamos a terminologia principal de segurança utilizada no texto. A maioria das definições foi retirada de [LS87], ou foram adaptadas ao contexto deste trabalho. Em alguns casos, para efeito de documentação, os termos originais aparecem entre parênteses.

- Registro de auditoria (audit record): um registro de auditoria, também referenciado neste trabalho como um "evento". É cada entrada individual nos registros de um processo auditor.

- Processo auditor (audit trail): um registro cronológico de atividades do sistema, que é suficiente para permitir a reconstrução, revisão e exame de uma seqüência de atividades. Os processos auditores registram requisições de serviço que determinadas aplicações fazem ao sistema operacional, como por exemplo, operações de login ou FTP, dentre outros.

- Ataque: um conjunto de ações que resultam numa violação da política de segurança de um sistema computacional. Intrusos exploram vulnerabilidades para obter acesso não-autorizado ao sistema. Estas ações freqüentemente são codificadas como assinaturas, que podem ser localizadas junto aos processos auditores. 
- Política de Segurança: um conjunto procedimentos e normas que regulam a maneira pela qual uma organização gerencia, protege e distribui informações sensíveis através de seus sistemas computacionais.

- Atacante / Intruso: um usuário legítimo ou não, que explora ou tenta explorar alguma vulnerabilidade do sistema, de maneira a prejudicar suas operações normais ou com intenção de obter acesso indevido a informações ou recursos, em desacordo com a política de segurança. Entende-se o termo "usuário", como sendo não necessariamente um indivíduo, mas também, eventualmente, um processo ou um programa computacional.

- Assinatura: uma especificação de aspectos, condições, arranjos e inter-relações entre eventos que significam um ataque, uma violação de acesso, outro tipo de abuso ou uma tentativa destes. Neste trabalho "padrão de intrusão" possue o mesmo significado que " assinatura de intrusão".

- Vulnerabilidade: uma falha nos procedimentos automáticos de segurança, controle administrativo e controle de acesso, a qual pode ser utilizada por um atacante para obter acesso não autorizado ao sistema, às informações armazenadas ou para interromper suas operações normais. Neste trabalho considera-se uma vulnerabilidade como sendo qualquer tipo de falha ou mal funcionamento que possibilite um ataque ao sistema em questão.

- Conexão: no contexto deste trabalho, indica um conjunto de pacotes de informações cujos endereços origem-destino são os mesmos, e não possui relação com os termos "orientado a conexão" e "sem conexão", normalmente presentes na literatura especializada. Freqüentemente referenciado neste trabalho como uma " sessão".

- Domínio: indica um endereço IP, uma rede, ou uma faixa de números IP que serão considerados como pertencentes a um mesmo grupo, para ações de limitação de fronteiras de segurança. Neste trabalho o termo "domínio" não possui nenhuma função como as definidas tradicionalmente no contexto do NIS ou do DNS.

- Host: no contexto deste trabalho, significa um computador, com algum sistema operacional, e ao qual foi atribuído um número IP. 


\subsection{Casos e exemplos utilizados neste trabalho}

Neste trabalho são usados exemplos de vulnerabilidades e descrições de ambientes computacionais derivados do sistema operacional UNIX, e protocolo de rede TCP/IP. Isso é feito considerando-se que as técnicas de detecção de intrusão e princípios aplicados ao UNIX e ao TCP/IP podem ser aplicáveis a outros sistemas operacionais e sistemas de rede, ainda que alguns detalhes e características particulares possam variar. Esta escolha se deve principalmente porque o UNIX, em conjunto com o TCP/IP, além de possuir uma grande base instalada, tem suas vulnerabilidades discutidas de forma mais pública, abrangente e aberta, como por exemplo na lista de discussões eletrônica Bugtraq Mailing List ${ }^{1}$, ou na $8 \operatorname{lgm}$ Advisories $^{2}$. A escolha TCP/IP é estratégica, e se deve principalmente à importância que este protocolo de rede vem representando, em função da expansão vertiginosa da Internet e das atividades relevantes que são cada vez mais realizadas dentro dessa rede, conforme já mencionado anteriormente.

Outra razão é que organizações que fornecem alertas e agem como "conselheiros", emitindo boletins e propondo soluções técnicas para segurança, tais como o Computer Emergency Response Team $(C E R T)^{3}$ e United States Department of Energy's Computer Incident Advisory Capability $(C I A C)^{4}$, tratam predominantemente de vulnerabilidades no UNIX. Dessa forma, o acesso a estas informações é facilitado e pode ser obtido e atualizado de maneira rápida e eficaz. Outros sistemas operacionais, tais como Digital VAX VMS ou Novell Netware, não possuem seus sistemas e códigos fonte amplamente divulgados ou disponíveis. Assim, detalhes de vulnerabilidades de segurança nesses sistemas são privativos e não servem para ilustrar casos tratados por este trabalho. São necessárias situações abertamente discutidas, para que o modelo possa ser validado. Paradoxalmente, por estas mesmas razões, sabe-se que os atacantes também preferem os sistemas UNIX e as redes TCP/IP.

\footnotetext{
${ }^{1}$ Bugtraq Eletronic Mailing List. Disponivel eletronicamente em http://www.geek-girl.com/bugtraq

2 8lgm Eletronic Mailing List. Disponivel eletronicamente em http://www.8lgm.org/

${ }^{3}$ Podem ser consultados eletronicamente em $h t t p: / / w w w . c e r t . o r g /$

${ }^{4}$ Podem ser consultados eletronicamente em http://ciac.llnl.gov/ciac/
} 


\subsection{Propósitos e esboço geral deste trabalho}

O que se pretende com este trabalho é propor, desenvolver e testar um novo método de detecção de intrusos em redes de computadores. Este é baseado em técnicas de deteç̧ão por abuso e possui como mecanismo principal, um sistema de captura de pacotes sobre protocolo TCP/IP, o qual procura por assinaturas de ataque em determinadas conexões de rede. Essas assinaturas são passadas para uma rede neural que tenta prever quão intrusiva pode ser as atividades sob monitoração. São estudados os comportamentos intrusivos nas sessões de rede. As falhas de segurança, e os ataques, são tratados a partir da sua manifestação no conjunto da rede como um todo, ao invés de serem considerados em função da sua origem ou dos efeitos resultantes. Assim é desenvolvido um sistema capaz de analisar as tentativas de intrusão em tempo real, permitindo ao administrador uma tomada rápida de decisões, ou mesmo o disparo automático de procedimentos de proteção. Além disso, um sistema de rede neural dá ao modelo uma característica de grande adaptabilidade, pouco encontrada em outros mecanismos detetores ou auditores. É a primeira vez que um mecanismo de captura de pacotes, para identificação de assinatura de ataques, é utilizado em conjunto com um sistema de rede neural.

O Capítulo 2 discute os principais modelos atuais de detecção de intrusos, bem como suas vantagens e desvantagens. O Capítulo 3 faz uma revisão dos aspectos teóricos necessários para a compreensão deste trabalho. O Capítulo 4 traz o modelo de detecção de intrusão proposto, e o Capítulo 5 trata da implementação de um protótipo deste modelo. O Capítulo 6 apresenta e discute os testes realizados e os resultados obtidos com o protótipo desenvolvido. O Capítulo 7 faz uma conclusão comparativa, e propõe trabalhos para a continuação desta pesquisa. 


\section{Modelos Atuais de Detecção de Intrusão}

Este capítulo realiza uma breve apresentação dos modelos de deteç̧ão de intrusão existentes. Os modelos iniciais, projetados para atuarem em computadores isolados, empregam algoritmos básicos que incluem cálculos estatísticos, para detectar desvios do comportamento normal e, em muitos casos, sistemas especialistas para detectar violações da política de segurança. Os modelos mais recentes monitoram um grande número de computadores interconectados em rede, transferindo as informações monitoradas para processamento num equipamento centralizador, além de possuirem o fluxo de tráfego da rede como parte de seus algoritmos de deteç̧ão. Nenhum dos modelos apresentados utiliza verificação de padrões, ou seja, monitoração e análise de assinaturas de ataque, diretamente.

\subsection{Introdução}

Diversos sistemas de deteç̧ão de intrusos empregam ao mesmo tempo técnicas para detecção de anomalia e abusos. Algumas são baseadas em técnicas de prédeterminação de padrões futuros, a partir do comportamento anterior, enquanto outras, utilizam técnicas estatísticas para determinar o comportamento anômalo. Em ambos os casos, quando o comportamento monitorado não está de acordo com o comportamento esperado, pode haver um indicativo de intrusão. Os modelos são baseados na hipótese de que a exploração das vulnerabilidades de um sistema envolve algum tipo de desvio. Deste modo, violações de segurança podem ser detectadas a partir de algoritmos agindo nos computadores em questão, ou sobre a rede como um todo. A discussão apresentada a seguir não é original, mas sim baseada no trabalho de Kumar e Spafford [KS94]. 


\subsection{Deteção de intrusos por anomalia}

\subsubsection{Método estatístico}

A discussão a seguir, é baseada num sistema especialista de deteç̧ão de intrusos em tempo real, descrita em [LTG+92]. O tratamento estatístico é a característica principal destes sistemas, que são do tipo host-based. O detector de anomalia observa as atividades relevantes dos usuários ou processos, e gera perfis destes, representando seus comportamentos esperados. Estes perfis podem sofrer modificações constantes, conforme necessário e em função das alterações de atividades. À medida que os registros de auditoria são processados, o sistema periodicamente gera um valor que é um indicativo da anormalidade daquele perfil. Este valor é uma função da anormalidade de todas as atividades envolvidas no perfil. As atividades podem ser a quantidade de processamento usado, o número de arquivos abertos, a quantidade de operações de entrada e saída num período, a freqüência de logins a partir de uma localidade fisica, freqüência de uso de compiladores ou shells, dentre outros.

Assim, se $S_{1}, S_{2}, \ldots, S_{n}$ representam respectivamente os valores de anormalidade do perfil para as atividades $A_{1}, A_{2}, \ldots, A_{n}$, então um valor maior de $S_{i}$ indica uma anormalidade maior com relação àquela atividade $A_{i}$.

Uma função combinatória dos valores individuais de $S_{i}$ pode ser uma soma ponderada dos seus quadrados, tal como $a_{1} S_{1}^{2}+a_{2} S_{2}^{2}+\ldots+a_{n} S_{n}^{2}$ [LTG+92], onde o valor de $a_{i}>0$ reflete o peso relativo da atividade $A_{i}$. Em geral as medidas das atividades $A_{1}, A_{2}, \ldots, A_{n}$ não são mutuamente independentes, e podem exigir uma função mais complexa, de forma que é necessário haver um estudo teórico correto, e bem definido, para combina-las.

O comportamento padrão de cada usuário é mantido num perfil particular ou mesmo em perfis de grupo. Em intervalos regulares o perfil atual é comparado com o perfil armazenado, e assim determina-se se há um comportamento anômalo. Em alguns sistemas, tal como em [LTG+92], os perfis armazenados podem ser modificados automática e dinamicamente, de forma a refletirem mudanças graduais de 
comportamento. Por exemplo, ao longo de um projeto, um dado usuário pode passar a utilizar maior quantidade de CPU ou realizar mais operações de entrada e saída, à medida que o trabalho evolui. As variações nessas medidas podem ser percebidas $\mathrm{e}$ atualizadas no perfil do usuário, de modo que o sistema detector de intrusão não aponte essas variações como anômalas.

\section{Vantagens:}

- Existem técnicas estatísticas clássicas e bem conhecidas, que podem ser freqüentemente aplicadas aos problemas em questão. Por exemplo, dados que estejam fora de um desvio padrão, em torno de um valor médio pré-determinado, podem ser considerados anômalos.

\section{Desvantagens:}

- Sistemas de deteç̧ão de intrusão puramente estatísticos podem ser levados gradualmente para uma condição em que o comportamento, ainda que anormal, seja considerado sempre normal. Um atacante que tenha conhecimento que está sendo monitorado por detetores de anomalia, pode modificar aos poucos seu perfil de atividade. Por isso a maioria dos esquemas atuais de detecção que utilizam modelos estatístico, também utiliza algum tipo de detecção de abuso, buscando a ocorrência de padrões específicos de comportamento dentro dos eventos.

- Medidas estatísticas não são sensíveis à ordem de ocorrência dos eventos. Isto é, um sistema de detecção de intrusão puramente estatístico pode não detectar intrusões que sejam indicadas por uma seqüência de eventos interrelacionados.

- Há um limite para os tipos de comportamento que podem ser modelados usando métodos puramente estatísticos. A aplicação de técnicas estatísticas na formulação de anomalias requer que seja assumido que os dados são provenientes de um processo quase estacionário, o que freqüentemente não acontece. Em geral, modelos mais aprimorados que lidam com dados dinâmicos são mais complexos e gastam mais tempo para serem executados.

- A especificação de limites acima dos quais o comportamento anômalo deve ser considerado intrusivo é delicada. A especificação errada desses limites pode resultar em muitas ocorrências de falso positivos ou falso negativos. 


\subsubsection{Gerador de prognósticos de padrões}

Esta técnica considera que as seqüências de eventos não são aleatórias, mas seguem um padrão possível de ser previsto. Isso pode levar a um método de detecção mais aprimorado, devido ao fato de considerar inter-relações entre as atividades, bem como a ordem entre os eventos significativos, pontos estes em que os detetores estatísticos são deficientes.

Um método descrito por Teng e Chen [Che88, TCL90], utiliza regras temporais que caracterizam os padrões de comportamento normal dos usuários. As regras, geradas por indução, são modificadas dinamicamente durante uma fase de aprendizado. Somente regras que apresentem grande precisão de prognóstico com alto grau de confiança, permanecem no sistema. Uma regra possui grande precisão de prognóstico se ela prediz resultados corretos na maioria das vezes, e tem alto grau de confiança se ela pode ser aplicada com sucesso diversas vezes nos conjuntos de dados monitorados. Um exemplo de regra gerada por este modelo [TCL90] pode ser:

$$
A_{1} \rightarrow A_{2} \rightarrow A_{3} \Rightarrow\left(A_{4}=90 \%, A_{5}=10 \%\right)
$$

onde os $A_{i}$ são atividade que podem ser eventos de segurança. Esta notação significa o seguinte: se ocorre a atividade $A_{1}$ seguida da atividade $A_{2}$, por sua vez seguida da atividade $A_{3}$, então há $90 \%$ de probabilidade que, logo a seguir, ocorra uma determinada atividade $A_{4}$ e apenas $10 \%$ de ocorrer uma outra atividade $A_{5}$. As regras são baseadas nos dados previamente observados.

Por exemplo, considere uma ação que explora uma vulnerabilidade do programa /bin/mail em algumas versões mais antigas dos sistemas UNIX, e que permite obter um acesso (especificamente um shell) de root. Esta vulnerabilidade se baseia no fato de que o sistema local de envio de mensagens / bin/mail muda o userid do arquivo de mensagem para o userid do destinatário, mas falha ao remover o bit de setuid anterior do arquivo, que pertence a root. Um script para explorar esta vulnerabilidade poderia ser o seguinte:

\& cp /bin/sh / var/spool/mail/root

\& chmod 4755 /var/spool/mail/root 
\& touch 1 ixo

o mail root $<$ lixo

Neste caso, através de prognóstico de padrões, é possível prever que existe uma grande probabilidade de ocorrer a atividade mail root $<$, logo após a ocorrência, em seqüência, das ações:

$$
\text { cp } \rightarrow \text { chmod } 4755 \rightarrow \text { touch }
$$

Em resumo, o perfil do usuário consiste em um conjunto de regras gerado pela observação do comportamento, e uma anomalia pode ser detectada em função da maneira como a seqüência de eventos observados ocorre.

\section{Vantagens:}

- Possibilidade de concentrar esforços sobre uma quantidade menor de eventos relevantes, ao invés de observar e analisar todo o andamento das sessões ou processos suspeitos.

- Melhor tratamento em casos onde os usuários possuem uma variação muito grande de comportamento, mas que possuem fortes características seqüenciais.

- Melhor sensibilidade na detecção de violação de políticas. Atacantes que tentem dissimular o sistema durante o processo de treinamento podem ser detectados em função das características semânticas envolvidas nas regras.

\section{Desvantagens:}

- Padrões de comportamento desconhecidos podem não ser detectados como anômalos, porque eles podem não coincidir com nenhuma das regras previamente estabelecidas.

- Só é possível reconhecer os padrões que tenham sido previamente identificados.

\subsubsection{Classificação Bayesiana}

A Classificação Bayesiana [CHS91] trata-se de uma técnica de classificação de dados não supervisionada. Sua implementação, denominada Autoclass [CKS+88], busca por classes num conjunto de dados, e tenta determinar qual foi o processo mais provável a tê-los gerado. Isto é feito a partir da definição de uma função probabilística de participação de cada um dos dados [Cha91], que os relaciona às classes mais prováveis. 
$\mathrm{Na}$ detecção de intrusão estatística há uma peocupação com a classificação do comportamento observado. As técnicas usadas até o momento concentram-se sobre uma classificação supervisionada, na qual os perfis de usuários ou grupos são criados baseados no comportamento observado de cada usuário, havendo sempre ajustes supervisionados. $O$ método de classificação Bayesiana permite a determinação, através de cálculos probabilísticos, de um número de classes otimizado, agrupando usuários com perfis semelhantes, produzindo assim uma classificação natural de um conjunto de usuários.

\section{Vantagens:}

- É possível determinar quais são as classes mais prováveis a que pertencem os eventos, dado um conjunto de dados relacionados a um usuário.

- Não há necessidade de arranjos seqüenciais de medidas ou eventos similares.

- Existe possibilidade de se utilizar atributos que sejam discretos e contínuos, em conjunto.

\section{Desvantagens:}

- Dificuldades de especificação de limiares para as anomalias.

- Possibilidade do atacante dissimular o sistema, mudando gradualmente seu comportamento.

Não há notícia de que este método tenha sido implementado e testado em algum sistema de deteç̧ão de intrusos, apesar de haver algumas propostas nesse sentido [CKS+88].

\subsection{Detecção de intrusos por abusos}

\subsubsection{Características gerais}

Técnicas baseadas em abusos estão relacionadas à definição e observação precisa dos comportamentos intrusivos, comumente chamados de assinaturas de intrusão. É importante ressaltar que há sempre um componente de deteç̧ão por abuso na maioria dos sistemas de detecção, haja visto que técnicas estatísticas isoladas não são adequadas 
para determinar todos os eventos de segurança, em razão das limitações já discutidas nas sessões anteriores.

Assinaturas de intrusão especificam os aspectos, condições, posicionamento e inter-relações entre os eventos que levam a uma intrusão ou outro abuso. Assinaturas não são apenas úteis para se detectar intrusões, mas também para localizar tentativas de quebra de segurança, de forma que a confirmação parcial da ocorrência de uma assinatura pode indicar uma tentativa de intrusão. A seguir são apresentadas as técnicas de detecção por abuso mais importantes.

\subsubsection{Uso de sistemas especialistas em detecção de intrusão}

O fator mais importante relacionado ao uso de sistemas especialistas é a separação entre o método de controle e a formulação da solução do problema. Um exemplo do uso desses sistemas na detecção de intrusos é descrito por Snapp e Smaha [SS92]. Utilizando linguagem CLIPS [Gia92], este sistema codifica, em regras de estruturas de decisão tipo "se-então" (if-then), o conhecimento sobre ataques, declarando e associando fatos correspondentes nos eventos dos processos auditores. Através da parte "se" (if), as regras são codificadas para especificar as condições que indicam um ataque. Quando todas as condições do lado esquerdo da regra são satisfeitas, então as ações do lado direito (then) são executadas.

\section{Vantagens:}

- Conjunto de regras bem definidas reduz os problemas de sobrecarga (overhead) no sistema de análise.

- Vários parâmetros de comportamento de intrusão podem ser combinados para construir um quadro coeso e certo acerca dos acontecimentos

- É possível, em tese, deduzir simbolicamente a ocorrência de uma intrusão baseada apenas nos dados recebidos.

\section{Desvantagens:}

- Esta técnica somente pode detectar vulnerabilidades conhecidas. 
- O conhecimento incorporado nos sistemas especialistas é limitado ao mesmo nível do humano no qual as regras foram modeladas [Lun93], as quais freqüentemente não são completamente abrangentes. $\mathrm{O}$ problema aumenta quando não há disponibilidade de especialistas em segurança, que possam codificar seus conhecimentos dentro de um conjunto de regras compreensível.

- Há dificuldades em concluir sobre situações que são identificadas como ambíguas, devido a fatos previamente assumidos nas regras.

\subsubsection{Detecção por modelamento}

Este método [GL91] é uma variação de detecção por abuso, que combina modelos de comportamento e comparações entre evidências, para concluir sobre a ocorrência de um evento de segurança. Existe uma base de dados de situações, cada uma das quais contendo uma seqüência de comportamento do ataque. A ocorrência de um subconjunto dessas situações, pode indicar que o sistema está sob ataque. Então é feita uma tentativa de verificar essas situações, através de cruzamento de informações dos registros de auditoria, de modo a substanciar a suspeita, ou descarta-la. Este processo, denominado Anticipator em [GL91], gera os próximos conjuntos de comportamentos a serem verificados no processo auditor, baseando-se nos modelos atuais existentes. Esses conjuntos são enviados para outro módulo, que determina quanto do comportamento hipotético está realmente refletido nos dados auditores, gerando um valor que indica o nível desta concordância. Este mapeamento do comportamento para atividade deve se realizar de forma a ser facilmente reconhecido dentro do processo auditor.

À medida que as evidências de algumas situações de intrusão se somam, enquanto outras diminuem, a lista de padrões de atividade se mantém atualizada. $O$ cálculo da razão entre as evidências, embutida no sistema, permite a manutenção atualizada da probabilidade de ocorrência de uma situação de ataque, dentro da lista de modelos existentes.

\section{Vantagens:}

- O métodos baseia-se em teorias matemáticas bem conhecidas que lidam com a incerteza presente nas razões de probabilidade. 
- O modelamento probabilísticos permite emitir conclusões, ainda que parciais, sobre situações ambíguas.

- É possível reduzir a quantidade de processamento exigida por cada registro auditor, através de uma monitoração superficial em modo passivo, e depois monitorando ativamente numa operação mais refinada, quando algum evento for detectado numa primeira monitoração.

\section{Desvantagens:}

- O método é influenciado pela capacidade da pessoa que define as evidências de ocorrência dos eventos.

- Não é possível detectar situações que não tenham sido especificamente evidenciadas.

- Nenhum protótipo deste modelo foi implementado, e existem dúvidas sobre a eficiência de execução, em função dos cálculos envolvidos.

\subsection{Sistema híbridos}

Existem alguns sistemas que englobam técnicas de deteç̧ão estatística de anomalias e verificação de abusos, de maneira a cobrir, ou pelo menos minimizar, as deficiências mútuas. Por outro lado, esses modelos normalmente carregam muitas considerações que os tornam complexos ou limitados para uma implantação prática. Em geral ocorre que, apesar de serem freqüentemente implementados de forma parcial, estes modelos apresentam bons resultados. A seguir discutimos um modelo importante dessa técnica.

\subsubsection{Intrusion Detection Expert System (IDES)}

Um bom exemplo atual de sistema de deteç̧ão híbrida, por anomalia e abuso, é o Intrusion Detection Expert System (IDES) [Lun90, JV91], que além de utilizar métodos estatísticos para detectar comportamento atípico, possui também um sistema inteligente que reconhece intrusão e conhece as vulnerabilidades do sistema e as políticas de segurança do domínio. O IDES é um processo independente e analisa os dados de auditoria do sistema sob monitoramento, usando um perfil de atividade para determinar 
se o comportamento atual é normal com relação ao comportamento passado ou ao comportamento aceitável.

As atividades são monitoradas à medida que elas chegam nos registros de auditoria. Os perfis são atualizados se necessário, fornecendo capacidade de adaptar os modelos de comportamento. O IDES também inclue um sistema especialista capaz de descrever comportamento suspeito, que é independente dos modelos de comportamento passado. Este sistema possue regras que descrevem suspeita baseada no conhecimento de vulnerabilidades do sistema e políticas de segurança específicas do domínio. $O$ processamento e as decisões tomadas pelos dois componentes são independentes e cada módulo tende a suprir as deficiências e limitações deixadas pela outra parte.

\section{Vantagens:}

- A utilização de métodos conjuntos cobre pontos onde métodos isolados podem falhar.

- As codificação e funcionamento dos sistemas estatístico e especialista é totalmente independente.

\section{Desvantagens:}

- É necessário o tratamento de uma quantidade muito grande de dados.

- Os dados colhidos pelos processos auditores de diferentes sistemas operacionais necessitam ser padronizados.

- Processos auditores são freqüentemente atacados ou desligados.

- As técnicas estatísticas e de abuso, ao invés de se auxiliarem mutuamente, podem acabar acusando mais resultados falso positivos, caso todos os cenários possíveis não sejam bem considerados.

\subsection{Sistemas de detecção de intrusão baseados em redes}

Entre os sistemas mais atuais de detecção de intrusão estão aqueles que, além de utilizarem as técnicas de anomalia e abuso descritas anteriormente, incorporam estas técnicas à monitoração de um ambiente de rede e utilizam estes dados como parte dos algoritmos de deteç̧ão. 


\subsubsection{Network Security Monitor (NSM)}

O NSM [Heb90, Heb91, HLM91] ao invés de usar os registros de auditoria, analisa o tráfego de pacotes numa rede local para detectar o comportamento intrusivo. $O$ modelo NSM divide a rede e os hosts monitorados numa estrutura hierárquica denominada ICEM - Interconnected Computing Environment Model [HLM91], composta de 6 camadas, sendo que a mais baixa trata um fluxo de dados na rede, e a mais alta uma representação para o estado do sistema de rede como um todo. A camada mais baixa é chamada de camada de pacote e aceita como entrada um fluxo qualquer de bits de uma rede tipo broadcast, como por exemplo uma ethernet. Este fluxo é dividido em pacotes ethernet completos e um marcador horário (time stamp) é atrelado ao pacote, o qual é então passado para a segunda camada, chamada de thread layer. Nesta segunda camada os pacotes são correlacionados (associados numa relação de causa e efeito) em um fluxo de dados unidirecional. Cada fluxo consiste dos dados sendo transferidos de um host para outro, por um protocolo em particular, através de um conjunto de portas. Este fluxo, chamado thread, é mapeado dentro de um vetor chamado thread vector, que é então passado para a próxima camada, chamada de camada de conexão. Note que o thread vector é o mapeamento dos dados de uma conexão em particular (Figura 2.1)

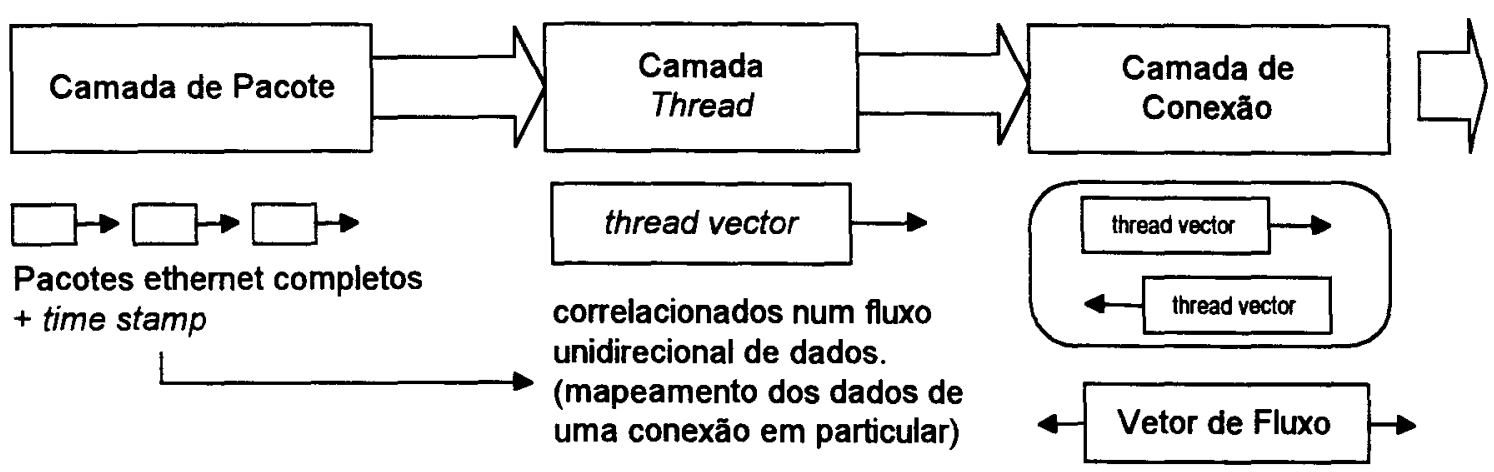

Figura 2.1 - Arquitetura do modelo ICEM com as 3 primeiras camadas 


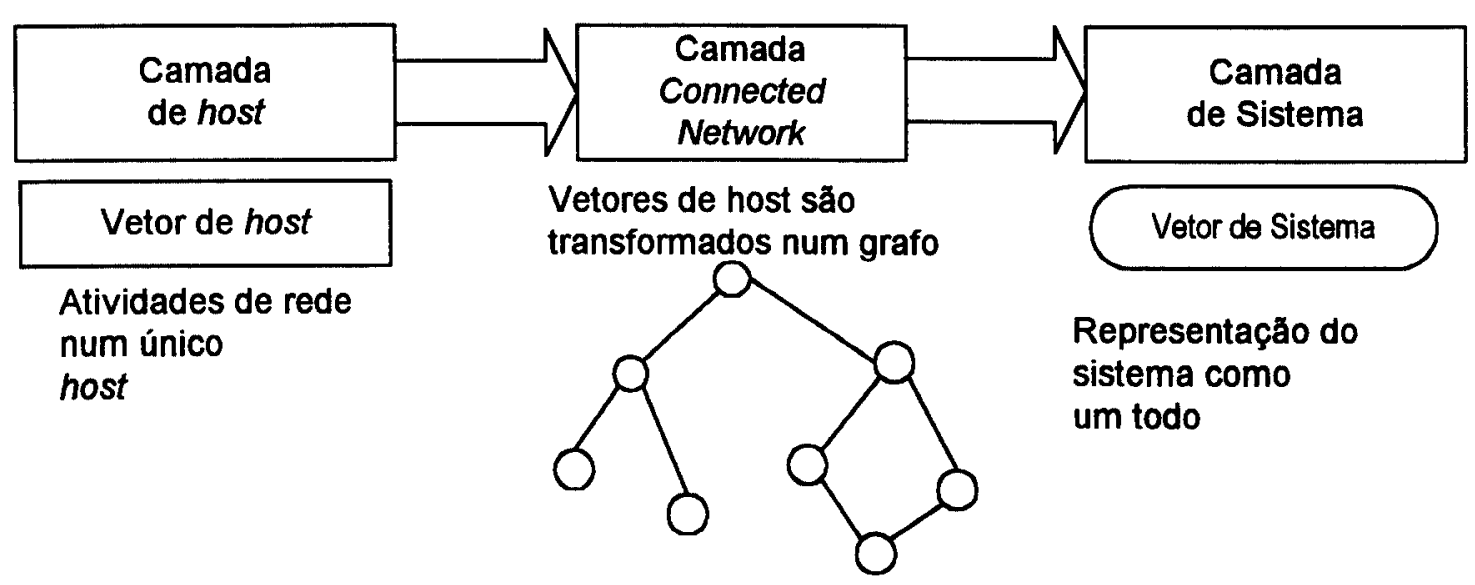

Figura 2.2 - Representação das 3 últimas camadas do modelo ICEM

Caso seja possível, são formados pares de thread vectors (um thread vector com outro da mesma conexão), de maneira a formar um fluxo bidirecional de dados, ou seja, uma conexão host-a-host. Os pares de thread vectors são representados por um vetor de conexão gerado pela combinação dos thread vectors individuais. Cada vetor de conexão é analisado, e uma representação reduzida, chamada vetor de conexão reduzido, é passada para a quarta camada, denominada camada de host (Figura 2.2). Na camada de host os vetores de conexão são usados para construir os vetores de host. Cada vetor de host representa as atividades de rede de um único host. São então passados para a quinta camada, denominada camada connected-network.

Nesta quinta camada os vetores de host são transformados num grafo $G$. Se $G(h o s t 1$, host $2, \operatorname{ser} 1)$ não é vazio, então há uma conexão, ou desvio, do host 1 para o host 2 pelo serviço serv1. O valor para a posição $G($ hostl, host 2 , servl) é não-vazio se o host vector para hostl possui (host2, servl) em seu caminho de conexão. A última camada usa os vetores connected-network para construir um único vetor de sistema que representa o comportamento global.

O tráfego na rede é analisado por um sistema especialista. O primeiro tipo de entrada recebida são os vetores do modelo ICEM; na implementação atual apenas os vetores de conexão e de host do modelo ICEM são produzidos. A segunda entrada são os perfis de comportamentos esperados, envolvendo serviços e caminhos de dados. A combinação dos perfis com o tráfego corrente, permite ao NSM detectar 
comportamentos estranhos na rede. $O$ terceiro tipo de entrada é o conhecimento sobre a capacidade oferecida por cada serviço de rede disponível (e.g. telnet fornece mais capacidades que FTP). O quarto tipo é o nível de autenticação exigida por cada serviço (e.g. telnet exige autenticação enquanto sendmail não). Como quinto tipo de entrada temos o nível de segurança das máquinas que pode ser obtido a partir de alguns padrões pré-determinados. A sexta entrada trata-se de assinaturas de ataques passados.

Os dados destas fontes são usados para identificar a probabilidade de uma sessão em particular representar comportamento intrusivo, ou se algum host foi comprometido. O nível de suspeita de uma sessão em particular é uma função de 4 fatores: anormalidade da sessão, nível de segurança do serviço usado pela sessão, nível de sensibilidade da direção da sessão e as assinaturas de ataques coincidentes nos fluxos de dados daquela sessão.

\section{Vantagens:}

- Apesar de existirem diversos sistemas de redes, existem certos protocolos padronizados, tais como TCP/IP e IPX. Estes padrões podem ser usados de maneira que o NSM monitore um conjunto heterogêneo de máquinas e sistemas operacionais.

- Os registros de auditoria muitas vezes não estão disponíveis instantaneamente, retardando o tempo de resposta. A própria natureza de broadcast das redes locais permite acesso aos dados assim que eles são transmitidos na rede, disparando imediatamente processo de detecção de ataque.

- Os processos e registros de auditoria são freqüentemente vulneráveis a ações de atacantes. O NSM passivamente vigia a rede e está logicamente protegido deste tipo de ataque. Sendo invisível e fisicamente seguro ao intruso, não pode ser desligado e seus dados não podem ser modificados.

- Freqüentemente a coleta dos registros de auditoria é desabilitada pelos gerentes, em virtude da perda de performance causada (de 5 a $20 \%$ ). Se a análise destes registros é realizada na própria máquina, mais degradação ocorre. Se os dados são transmitidos pela rede para análise em outra máquina, perde-se banda de passagem. A arquitetura do NSM não afeta os sistemas monitorados e não sofre a influência dos administradores, uma vez que é independente das configurações individuais das máquinas. 


\section{Desvantagens:}

- Implementação do modelo todo é complexa e deve considerar muitos aspectos.

- Como nos outros modelos, a especificação de limiares (thresholds) tem que ser feita com muito cuidado.

- Só é possivel detectar as assinaturas de ataque previamente codificadas.

$\mathrm{Na}$ implementação atual apenas as camadas que analisam o tráfego atual e os perfis de tráfego esperado foram implementadas como apresentado na Figura 2.3. No momento estão sendo realizados estudos para a codificação e definição das assinaturas de ataque.

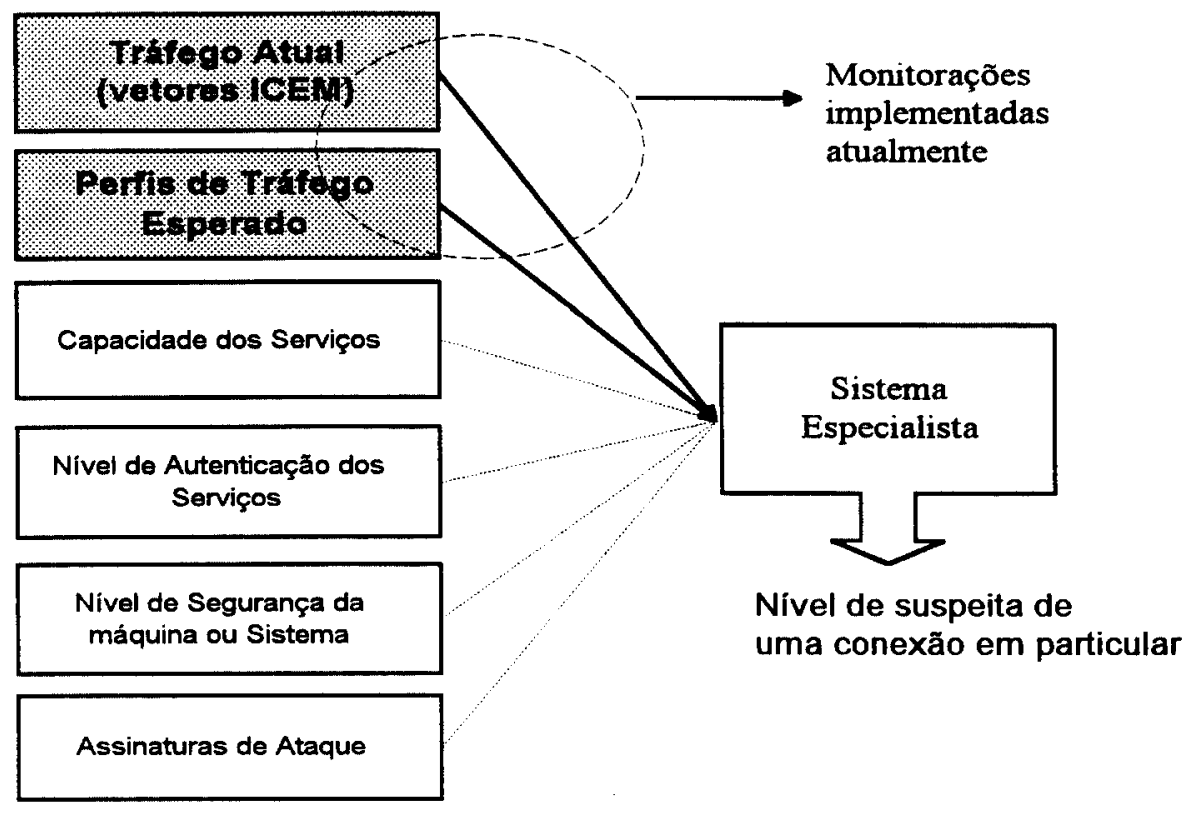

Figura 2.3 - Estrutura atual do sistema especialista do NSM

\subsection{Situação geral das técnicas de deteç̧ão de intrusão}

Diversos sistemas detetores foram testados e implementados. Muitos deles, inicialmente projetados para agir em computadores isolados, são baseados no modelo estatístico de detecção de intrusos de Denning [Den87], e utilizam dados de processos auditores gerados dentro do padrão de segurança C2 [DoDS85]. Entre estes podemos citar o NIDX [BK88], os algoritmos Haystak [Sma88], o já anteriormente citado IDES [LJL+89], e o Multics Intrusion Detection and Alerting System - MIDAS [SSHW88] e o 
sua evolução mais recente Computer Misuse Detection System - CMDS [Pro94]. Entre os que utilizam algoritmos para análise das conexões e fluxo de dados de rede, podemos destacar o NSM [HLM91], apresentado anteriormente, e o Network Anomaly Detection and Intrusion Reporter - NADIR [Hoc93], e o Network Level Intrusion Detection System - NICE [HLMS90].

Outro ponto de destaque atual, é um sistema denominado Distributed Intrusion Detection System - DIDS [MHL94]. Trata-se de um aprimoramemto do NSM, tendo sido desenhado de maneira a cobrir os pontos onde este falha. O DIDS possui uma arquitetura [SS91] que combina monitoramento distribuído e redução de dados com análise centralizada de informações, e este tratamento é único entre os sistemas detetores conhecidos. Cada host monitorado é equipado com um processo de monitoramento, que coleta e analisa registros de auditoria localmente. Estes monitores passam informação sobre eventos notáveis para um analisador, para processamento posterior. A rede local englobada pelo sistema é monitorada por um computador que possui um processo de monitoração, cuja implementação trata-se de um sub-conjunto do NSM. Esta máquina observa todo o tráfego ao longo da rede e relata ao analisador central as atividades relacionadas a segurança. $O$ analisador possui um sistema especialista que gerencia une todas as informações. As regras do sistema especialista derivam hierarquicamente de um modelo de detecção de intrusão denominado Intrusion Detection Model - IDM [Sma88]. Um protótipo deste sistema encontra-se em uso no Departamento de Defesa Americano, mas detalhes de sua implementação, ou mesmo sua utilização e eficiência não se encontram disponíveis.

Com relação aos modelos não estatísticos para detecção de intrusos, encontra-se o trabalho de Teng [TCL90] que analisa registros auditores individuais, e procura inferir a relação seqüencial entre eventos. Dentre os modelos baseados em detecção por abuso, encontra-se o modelo ASAX [HCMM92], capaz de representar e detectar intrusões. Há ainda o importante desenvolvimento de um conjunto de bibliotecas de funções, usadas para representar e detectar intrusões, apresentada no sistema STALKER [Sma95], além das máquinas de estado de alto nível, usadas para codificar e casar assinaturas, tais como STAT [PK92] e USTAT [Ilg92]. 
Entre os trabalhos em andamento, há uma promessa interessante. Trata-se de um modelo denominado Thumbprinting [Sta95]. Este sistema busca cobrir as deficiências do DIDS, citado acima, e permitir rastrear sessões suspeitas dentro de um ambiente de Intranets. Esta tecnologia envolve a formação de uma assinatura dos dados das conexões de rede em diversos pontos. A assinatura trata-se de um pequeno registro que não permite a completa reconstrução dos dados, mas permite comparação com outras assinaturas de outras conexões, de maneira a determinar com razoável confiança se os dados são ou não provenientes da mesma fonte. $\mathrm{O}$ processo envolve a captura $\mathrm{e}$ filtragem de pacotes, e formação de combinações lineares das freqüências com as quais diferentes caracteres ocorrem nos dados amostrados na rede. A otimização das combinações lineares é feita utilizando-se uma metodologia estatística, denominada análise componente principal. Trata-se da tecnologia mais recente, que se tem notícia, para tentar resolver o problema de rastreamento de intrusos em redes. Ainda encontra-se em implementação de protótipo.

Finalizando essa discussão, a Tabela 2.1 apresenta os principais sistemas detetores de intrusão atuais, classificados pela técnica utilizada e seu modo de atuação.

Tabela 2.1 - Principais sistemas detetores de intrusão atuais e suas características

\begin{tabular}{|c|c|c|c|c|}
\hline Modelo: & Técnicas: & Modo de atuação: & Situação: & Referência: \\
\hline NIDX & Anomalia estatístico & host-based & Implementado & [BK88] \\
\hline Haystack & Anomalia estatístico & host-based & Implementado & [Sma88] \\
\hline MUAS & Anomalia estatístico & host-based & Implementado & [SSHW88] \\
\hline IDES & $\begin{array}{l}\text { Híbrido: estatístico com } \\
\text { sistema especialista }\end{array}$ & host-based & Implementado & [JV91] \\
\hline NSM & $\begin{array}{l}\text { Hibrido: estatístico com } \\
\text { sistema especialista }\end{array}$ & $\begin{array}{l}\text { network-based com } \\
\text { análise central }\end{array}$ & $\begin{array}{l}\text { Implementado } \\
\text { parcialmente }\end{array}$ & [HLM91] \\
\hline STALKER & $\begin{array}{l}\text { Abuso por detecção de } \\
\text { assinatura }\end{array}$ & $\begin{array}{l}A P I \text { de detecção de } \\
\text { assinaturas em } \\
\text { registros auditores } \\
\text { host-based }\end{array}$ & Implementado & [Sma95] \\
\hline DWS & $\begin{array}{l}\text { Híbrido: estatístico com } \\
\text { sistema especialista, } \\
\text { detecção de assinaturas } \\
\text { e distribuído. }\end{array}$ & $\begin{array}{l}\text { host-based } \mathrm{e} \\
\text { network-based com } \\
\text { processos monitores } \\
\text { distribuidos. }\end{array}$ & $\begin{array}{l}\text { Implementado } \\
\text { parcialmente }\end{array}$ & [MHL94] \\
\hline Thumbp & $\begin{array}{l}\text { Abuso por detecção de } \\
\text { assinatura e distribuído }\end{array}$ & $\begin{array}{l}\text { host-based } \mathrm{e} \\
\text { network-based }\end{array}$ & $\begin{array}{l}\text { Modelado, em } \\
\text { implementação }\end{array}$ & [Sta95] \\
\hline
\end{tabular}




\section{Fundamentos Teóricos}

Este capítulo contém os principais fundamentos teóricos, necessário para o entendimento do modelo detector de intrusão. São discutidas as características básicas dos pacotes em redes TCP/IP, e os potenciais problemas de segurança envolvidos com este protocolo. Também é apresentada a biblioteca de captura de pacotes, utilizada em nosso sistema. Finalizando, há uma discussão sobre o uso de redes neurais no reconhecimento de padrões. Os desenvolvimentos apresentados são resumidos, e restritos ao âmbito deste trabalho.

\subsection{Redes de computadores com protocolo TCP/IP}

\subsubsection{Características básicas do protocolo TCP/IP}

O protocolo TCP/IP (Transmission Control Protocol / Internet Protocol) é formado por um conjunto de outros protocolos, cujos principais são [Ste94]:

IP

TCP

UDP

ARP

RARP

ICMP

\author{
Internet Protocol \\ Transmission Control Protocol \\ User Datagram Protocol \\ Address Resolution Protocol \\ Reverse Address Resolution Protocol \\ Internet Control Message Protocol
}

Este protocolo é implementado subdividido em camadas ou níveis, com os seguintes serviços de rede associados (Figura 3.1):

Nível:

Aplicação

Transporte

Rede

Enlace de Dados

Físico
Serviço de rede:

DNS, telnet, FTP, SMTP e outros

TCP, UDP

IP, ICMP

ARP, RARP e interface de rede

Cabo ou outro dispositivo 
Nível Físico: é o nível que tem contato direto com o hardware da máquina, tratando os sinais eletrônicos. Transmite e recebe os bits que dão origem à estrutura conhecida como pacote.

Nível de Enlace de Dados: os protocolos desse nível estão envolvidos com as controladoras de comunicação, seus microprocessadores e seus buffers. Dentro do conjunto TCP/IP existem dois protocolos denominados ARP (Address Resolution Protocol) [Plu82] e RARP (Reverse ARP) [BB92], que situam-se entre os niveis de Rede e de Enlace de Dados, para tratar o endereçamento quanto ao meio fisico.

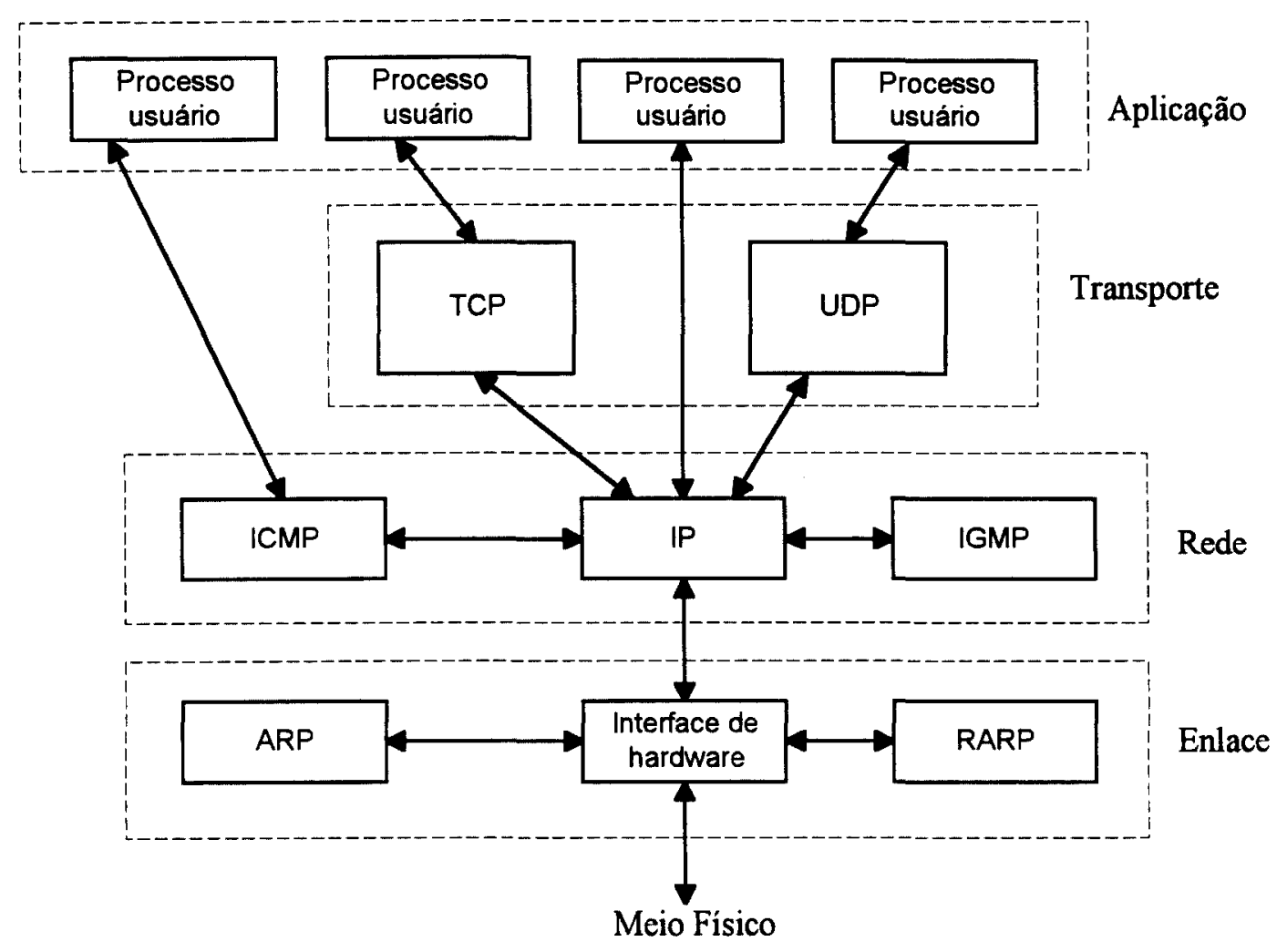

Figura 3.1 - Vários protocolos nas diferentes camadas do conjunto de protocolos TCP/IP [Ste94]

- ARP: é o protocolo que resolve os endereços fisicos, mapeia o endereço IP conhecido de 32 bits para o endereço físico na interface de rede. Por exemplo, em nosso caso, o IP é mapeado para um endereço fisico ethernet, composto de 48 bits.

- RARP: é o protocolo reverso do ARP, que resolve os endereços IP. Mapeia o endereço fisico conhecido (no nosso exemplo, ethernet) para um endereço IP. 
Nível de Rede: é onde está presente o protocolo IP. Permite a comunicação máquina a máquina. Mais significativamente, o IP realiza o roteamento da transmissão, determinando o caminho que esta deve seguir, baseando-se no endereço (número IP) recebido da camada inferior. Também permite serviços de formatação da transmissão, montando os dados dentro de um datagrama IP (Figura 3.2). Se o datagrama é de saída (i.e. recebido dos protocolos de níveis mais altos), o IP adiciona um cabeçalho (IP header) a ele. Este cabeçalho contém vários parâmetros, sendo os mais significativos os endereços IP das máquinas origem e destino. Outros parâmetros são o comprimento do datagrama e informação de identificação, no caso do datagrama exceder o tamanho em bytes permitido para pacotes de rede, indicando que deve ser fragmentado.

\begin{tabular}{|c|c|c|c|c|}
\hline \multicolumn{5}{|c|}{ † 32 bits } \\
\hline $\begin{array}{l}\text { 4-bit } \\
\text { version }\end{array}$ & $\begin{array}{c}\text { 4-bit header } \\
\text { length }\end{array}$ & $\begin{array}{l}\text { 8-bit type of servica } \\
\text { (TOS) }\end{array}$ & \multicolumn{2}{|c|}{ 16-bit total length (in bytes) } \\
\hline \multicolumn{3}{|c|}{ 16-bit identification } & $\begin{array}{l}\text { 3-bit } \\
\text { flags }\end{array}$ & 13-bit fragment offset \\
\hline 8-bit tim & $\begin{array}{l}\text { e to live } \\
\text { TL) }\end{array}$ & 8-bit protocol & & bit header checksum \\
\hline \multicolumn{5}{|c|}{ 32-bit source IP address } \\
\hline \multicolumn{5}{|c|}{ 32-bit destination IP address } \\
\hline \multicolumn{5}{|c|}{ options (if any) } \\
\hline \multicolumn{5}{|c|}{ data } \\
\hline
\end{tabular}

Figura 3.2 - Estrutura de um datagrama IP

Para um datagrama de chegada (vindos dos niveis de protocolo mais baixo), o IP usa a informação no cabeçalho para identificar a transmissão e determinar se ela está completa ou fragmentada. Se a transmissão foi fragmentada, o IP monta os fragmentos no datagrama original, o qual é passado para os niveis de protocolo mais altos.

No modo de operação normal do protocolo TCP/IP, todos os pacotes que chegam à máquina passam por esses três primeiros níveis, conforme representado na Figura 3.1. No nivel de rede, se o pacote for endereçado à própria máquina, ele é 
passado adiante para os níveis mais altos. Caso contrário o pacote é ignorado e o próximo é verificado.

Nivel de Transporte: habilita a comunicação entre processos executados em máquinas separadas. Os principais protocolos deste nível são TCP e UDP.

TCP (Transmission Control Protocol): habilita as aplicações a estabelecerem conexão entre si, como num circuito físico. O TCP envia dados na forma de circuitos virtuais, que são transmitidos entre hosts. A transmissão consiste de um ponto de partida, o qual abre a conexão, a transmissão interna ordenada por byte e um ponto de chegada, o qual fecha a conexão.

O TCP também adiciona um cabeçalho nos dados transmitidos, que contém um grande número de parâmetros e informações, que ajudam os processos na máquina origem a se comunicarem com seus processos pares na máquina destino (Figura 3.3). $\mathrm{O}$ TCP usa números de porta como seu método de endereçamento, o qual possibilita a diferenciação entre os participantes de uma transmissão. O TCP é um protocolo orientado à conexão e confiável, o que significa que qualquer dado escrito para uma conexão TCP será recebido por seu par, ou uma indicação de erro será retornada.

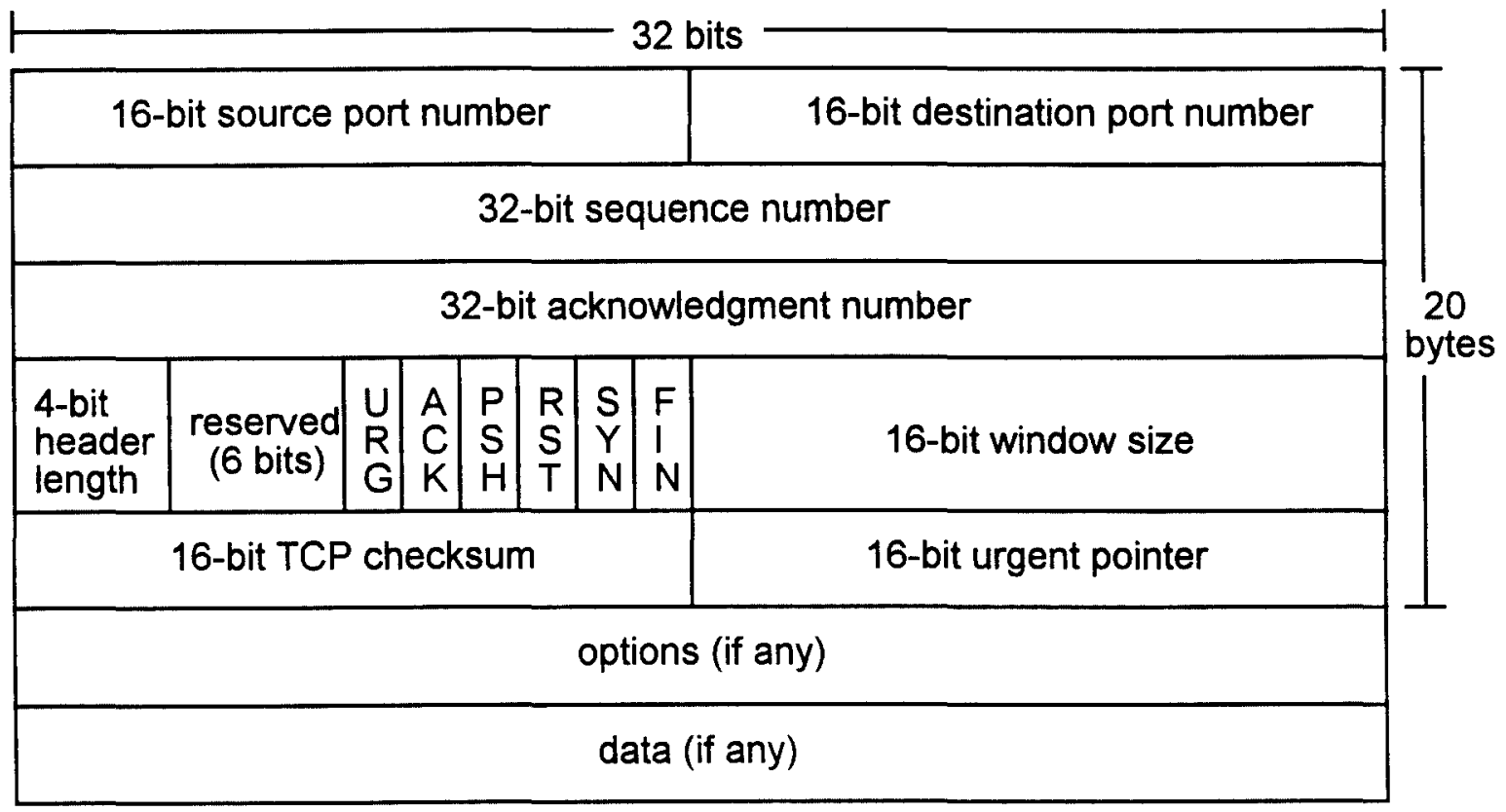

Figura 3.3 - Estrutura de um datagrama TCP 
UDP (User Datagram Protocol): é um protocolo alternativo presente no nível de Transporte. É um protocolo não orientado a conexão (connectionless), não confiável, baseado em datagramas (Figura 3.4). Esses datagramas são grupos de informações transmitidos como unidades de, e para, os protocolos dos níveis superiores nos hosts origem e destino. Datagramas UDP usam números de portas para especificar os processos de envio e recepção. Contudo, nenhuma tentativa é feita para se recuperar de uma falha ou perda; os pacotes podem ser perdidos sem nenhum retorno de indicação de erro.

O uso de TCP ou UDP depende da aplicação a ser utilizada pelo usuário, num nível mais alto. Por exemplo, se o usuário executar um aplicativo de conexão remota telnet [PR83], a aplicação passa a requisição do usuário para o TCP. Se a requisição do usuário envolve Domain Name Server (DNS) [Moc87], o UDP é quem recebe a requisição.

\begin{tabular}{|l|r|}
\hline 16-bit source port number & 16-bit destination port number \\
\hline 16-bit UDP length & 16-bit UDP checksum \\
\hline \multicolumn{2}{|c|}{ data (if any) } \\
\hline
\end{tabular}

Figura 3.4 - Estrutura de um datagrama UDP

Existe ainda um outro protocolo no nível de rede denominado ICMP (Internet Control Message Protocol) [Pos81]. Ele manipula os erros e fornece as mensagens relativas a estes erros, quando necessário.

Nível de Aplicação: É o nível onde são executadas as aplicações dos usuários, e é formado por um conjunto de outros protocolos, como por exemplo FTP (File Transfer Protocol) [PR85], usado para transferência remota de arquivos, http (Hipertext Transfer Protocol) [RGM+97] para transmissão de hipertexto, ou Telnet [PR83], usado para estabelecimento de conexões de terminal remotas, dentre diversos outros. 


\subsubsection{Problemas de segurança envolvendo redes TCP/IP}

Aqui são apresentados alguns aspectos relacionados com segurança dentro do conjunto de protocolos TCP/IP. Como o assunto é muito extenso para ser coberto em sua totalidade dentro deste texto, escolhemos alguns problemas mais significativos para nosso trabalho, que melhor representam os perigos envolvidos. Para um tratamento mais formal e detalhado deste tópico, recomenda-se as referências [GS96] e [Mor85]. A discussão a seguir é baseada no trabalho de Steven Bellovin [Bel89]. Alguns protocolos ou serviços, apesar de não possuirem vulnerabilidades inerentes, são apresentados por serem suscetíveis a ataques.

\section{- Captura de arquivos de senhas}

Apesar de não ser inerente, nem estar diretamente relacionado ao protocolo TCP/IP, trata-se de um dos métodos de ataque mais comuns e, portanto, digno de destaque. Neste cenário um atacante usa falhas nos processos que envolvem o TCP/IP para obter acesso a informações privilegiadas, principalmente com relação ao arquivo de senhas do sistema (normalmente o arquivo /etc/passwd ou equivalente). De posse destas informações, que compreendem o username e a senha criptografada, o atacante usa um programa de decriptografia (chamado genericamente de Cracker [GM84]), baseado em dicionários, para descobrir a senha dos usuários. Uma vez obtida a senha, o atacante ganha acesso ao sistema como um usuário legítimo e, a partir daí, utiliza os privilégios desse usuário para suas ações intrusivas, ou ainda explora vulnerabilidades conhecidas do próprio sistema operacional em questão, e que não tenham sido corrigidas pelos administradores.

\section{- Correio eletrônico}

O correio eletrônico, além de ser o serviço mais usado nas redes, e provavelmente o mais importante, está entre os mais vulneráveis a ataques e abusos. Em geral os servidores de correio eletrônico [Pos82, Cro82] não fornecem quaisquer mecanismos de autenticação ou validação. Além disso, é comum que a complexidade de código dos processos que manipulam mensagens (notadamente com relação ao sendmail) levem a falhas de segurança nas implementações. Essas falhas incluem desde a possibilidade de obtenção de informações e arquivos sensíveis, falsificação de mensagens, ou até mesmo a execução de comandos ou programas privilegiados. Até o presente, as falhas de 
segurança envolvendo processos do tipo sendmail têm estado entre as mais graves relatadas.

\section{- Finger e identd}

O Finger [Zim91] e o Identd [JR93] são utilizados para prover informações sobre usuários e propriedade de processos. Apesar de atualmente não apresentarem problemas sérios de falha de segurança, estes serviços acabam por fornecer informações importantes para os atacantes. Estas informações normalmente são usadas em tentativas de ataque a sessões interativas tipo telnet ou FTP, nas quais o atacante fornece um username válido e tenta advinhar a senha, manualmente ou com auxílio de um dicionário, por tentativa e erro (como discutido no capítulo 1, estes ataques são conhecidos como doorknob).

\section{- Servidores WWW}

Os servidores WWW, que fornecem serviços hipermídia sob protocolo http [RGM+97], tem apresentado falhas de segurança graves e freqüentes. Estas falhas tem sido relacionadas principalmente com execução privilegiada de scripts ou programas que permitem acesso a informações sensiveis já discutidas anteriormente, ou mesmo a execução de procedimentos restritos, que podem até mesmo serem executados na máquina servidora, a nível de kernel. Encaixam-se nesse grupo de risco as novas aplicações Java [GJS96] executadas por browsers de hipermídia, cujo código gerado pelo compilador (conhecido por bytecode) resulta numa máquina virtual.

\section{- O Domain Name System (DNS)}

O DNS [Moc87] trata-se de uma base de dados distribuída que permite a tradução dos nomes dos hosts para endereços IP. Um intruso que consiga interferir na operação do DNS pode montar uma variedade de ataques, incluindo obtenção de informações privilegiadas até comprometimento de recursos. Além disso, um atacante que tome o controle dos processos de DNS, pode confundir ou evitar mecanismos de segurança que sejam baseados em autenticação por intermédio de IP da máquina de origem. Para uma discussão mais detalhada sobre os problemas de segurança do DNS, recomenda-se uma consulta a $[\mathrm{KPN}+93]$. 


\section{- Telnet}

Apesar de não possuir problemas de segurança inerente, o telnet [PR83] é utilizado como meio intermediário para os ataques a outros protocolos ou processos. $\mathrm{O}$ processo de validação é baseado em uma única combinação de username e senha, o que faz com que os ataques normalmente sejam o tipo doorknob mencionado acima, ou então o atacante já possua uma senha válida, obtida por intermédio de decriptografia.

\section{- FTP}

As mesmas considerações mencionadas com relação ao telnet se aplicam ao FTP [PR85], com exceção de que alguns processos de FTP tem apresentado falhas que permitem a execução de comandos privilegiados. Além disso, especial atenção deve ser tomada na implementação de serviços de FTP Anonymous, para evitar que usuários alheios ao sistema tenham acesso a informações privilegiadas, ou executem operações reservadas.

\section{- Simple Network Management Protocol (SNMP)}

Por se tratar de um protocolo de gerenciamento, o acesso aos recursos do SNMP [CFSD90] deve ser apropriadamente protegido, e esta preocupação está estampada nas especificações do protocolo. Entretanto, estas mesmas especificações permitem serviço de autenticação nulo, o que é notadamente inseguro. Mesmo o modo read-only é perigoso, porque pode expor informações importantes.

\section{- Vulnerabilidades em redes locais}

Redes locais, principalmente tipo ethernet, são vulneráveis a espionagem ou falsificações. Em particular é possível interceptar, modificar e redirecionar pacotes, além de espionar e capturar o tráfego. Além disso é possível lançar ataques de comprometimento de recursos, como por exemplo através da geração de um alto fluxo ("tempestades") de pacotes tipo broadcast.

\section{- Portas reservadas}


Protocolos TCP e UDP possuem a noção de portas privilegiadas. Isto é, portas com numeração abaixo de 1024 somente podem ser alocadas por processos privilegiados. Esta restrição é usada como parte do mecanismo de autenticação. Entretanto, nem as especificações do TCP nem do UDP possuem este conceito. Além disso, este conceito não possui qualquer significado em computadores mono-usuário. Dessa forma, estes mecanismos de validação não são plenamente confiáveis.

\subsection{Captura e tratamento de pacotes de rede}

Muitas versões do Unix possuem ferramentas para captura de pacotes, tornando possível o uso de estações de trabalho para o monitoramento da rede. Como esses monitores são executados no nível de usuário, os pacotes devem ser copiados do núcleo do sistema operacional (kernel) para o nível do usuário antes de poderem ser analisados. Este processo de cópia pode ser minimizado desenvolvendo um agente no kernel chamado de filtro de pacotes (packet filter), que descarta os pacotes desnecessários o mais rápido possível. Os packet filter iniciais do Unix foram desenvolvidos sobre um filtro baseado em pilhas, e passaram a apresentar uma baixa performance nos então atuais processadores RISC. Entretanto, existe uma arquitetura mais otimizada para tratamento desse problema, denominada de BPF - BSD Packet Filtering [MJ93] desenvolvida por pesquisadores do Network Research Group do Lawrence Berkeley National Laboratory, USA.

O BPF usa uma nova abordagem, com um filtro baseado em registradores, e torna-se 20 vezes mais rápido do que os sistemas iniciais. O BPF também usa uma estratégia de straightforward buffering que torna sua performance até 100 vezes mais rápida do que a biblioteca de tratamento de pacotes denominada Network Information Tap - NIT [Sun90] da Sun Microsystems, executado na mesma máquina.

A arquitetura é composta de dois componentes principais: o interceptador de rede e o filtro de pacotes. O interceptador de rede coleta cópias dos pacotes do dispositivo de rede e as entrega às aplicações que monitoram a rede. $\mathrm{O}$ filtro decide se $\mathrm{O}$ pacote será aceito e em caso positivo, quanto do mesmo será copiado para a aplicação. 
Quando um pacote chega na interface de rede, o link-level device driver (Figura 3.5) o envia para uma pilha de protocolo do sistema. Mas quando o BPF está "escutando" esta interface, o driver inicialmente chama o BPF. Este por sua vez, envia o pacote para cada filtro associado com cada processo que se encontra monitorando a rede. Cada filtro decide se o pacote será aceito e quantos bytes deverão ser lidos. Para cada filtro que aceita o pacote, o BPF copia a quantidade de dados pedida para o buffer com o filtro. $\mathrm{O}$ controle então é devolvido ao dispositivo de rede e os procedimentos normais do protocolo de comunicação seguem adiante.

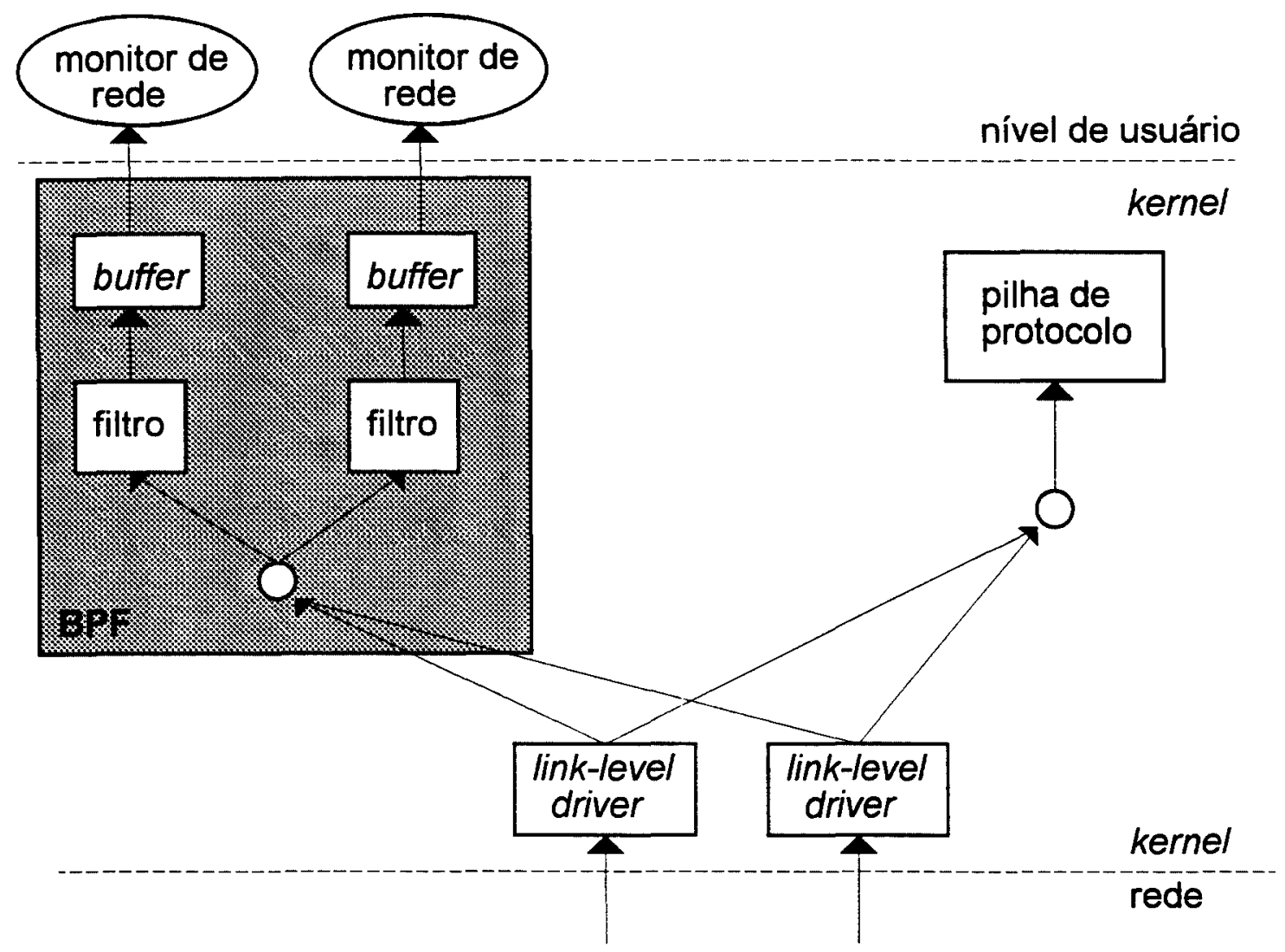

Figura 3.5 - Esquema de funcionamento do BSD Packet Filtering [MJ93]

Como normalmente os processos de monitoramento devem verificar cada pacote na rede e o tempo entre os pacotes pode ser de apenas alguns micro-segundos, não é possível fazer uma chamada de leitura do sistema por pacote. Assim o BPF coleta os dados de vários pacotes e os retorna como uma única unidade, quando o processo de monitoramento faz a leitura, encapsulando os dados capturados de cada pacote com um 
cabeçalho que inclui um marcador horário (time stamp), comprimento e deslocamento para o alinhamento dos dados.

Os processos de monitoramento necessitam de apenas um pequeno subconjunto do tráfego da rede. Um aumento de performance é conseguido a partir da filtragem dos pacotes indesejados diretamente na posição de DMA onde o dispositivo de rede os coloca, ao invés de copiá-los para algum outro buffer do kernel para posterior manipulação. Então, se o pacote não é aceito, somente os bytes necessários para processo de filtragem são referenciados.

Para a captura de pacotes, no sistema implementado, foi utilizada a biblioteca denominada libpcap v0.06 ${ }^{1}$. Esta biblioteca, que é uma implementação parcial ${ }^{2}$ do BPF, será discutida mais adiante, quando for apresentada a implementação do módulo de captura.

\subsection{Uso de redes neurais no reconhecimento de padrões}

\subsubsection{Introdução}

$O$ interesse no estudo de redes neurais tem crescido consideravelmente nos últimos anos. Os esforços de pesquisa têm se voltado para uma variedade de temas, tais como o estudo de novas arquiteturas de conexão, sistemas de processamento paralelo distribuido, computação neuromórfica e sistemas neurais artificiais, dentre outros.

Dentre várias possibilidades, o reconhecimento de padrões é a principal área de aplicação das redes neurais. Do ponto de vista humano, o reconhecimento de um padrão, seja ela qual for, compreende a técnica pela qual uma pessoa, uma vez havendo aprendido a reconhecer determinado assunto, poderá reconhecê-lo outra vez, mesmo que o que ela esteja observando novamente não seja exatamente igual ao que lhe foi

\footnotetext{
${ }^{1}$ A versão mais recente da biblioteca de captura libpcap encontra-se disponível em ftp://ftp.ee.lbl.gov/libpcap.tar.Z

2 Nota: a libpcap 0.0.6 trata-se de uma versão "Alfa", totalmente funcional, entretanto com algumas limitações com relação à proposta inicial do BPF. Durante a redação deste trabalho, aproximadamente em dezembro de 1996, foi lançada uma versão aprimorada do BPF, com novas possibilidades de filtragens em nível de kernel. Entretanto, não houve tempo hábil para uma atualização dos códigos do módulo de captura, de forma a utilizar a versão mais recente. O grupo de pesquisa tem trabalhado neste sentido.
} 
apresentado antes. $\mathrm{O}$ mesmo se aplica à uma rede neural, ou seja, uma vez que ela seja exposta a um conjunto de casos-padrão, possa reconhecer situações semelhantes.

Um exemplo clássico é a escrita. Como cada pessoa possui uma maneira peculiar de escrever, é impossível ter contato com todos os estilos de grafia de cada letra. Entretanto o ser humano necessita apenas ser apresentado a um pequeno conjunto de estilos diferentes, para que, por comparação, possa reconhecer quaisquer letras que estejam sendo lidas, ainda que não constem nos padrões de aprendizado. Uma aplicação semelhante é atualmente usada nos correios para reconhecimento óptico de caracteres [MM94]: os campos para anotação do Código de Endereçamento Postal (CEP) nas correspondências podem ser lidos por um computador, que identifica qual letra está em cada campo. Um sistema que pussuisse uma base de dados com milhares de formas de grafia da letra "1", e que fosse comparando a letra que foi grafada na correspondência com cada um desses exemplos, seria altamente custoso e provavelmente inviável. Então utiliza-se uma rede neural que, após treinada com alguns padrões de grafia da letra "1", poderá reconhecê-la na carta ainda que nunca a tenha visto, desde que não seja muito diferente daquelas com que ele foi treinada.

\subsubsection{Características gerais}

Um aspecto comum da implementação de redes neurais, é considerar o cérebro como um dispositivo computacional paralelo, muito diferente dos computadores seriais tradicionais. McCulloh e Pitts [MP43] propuseram uma unidade binária com limiar de ativação como um modelo computacional de um neurônio. O neurônio matemático calcula uma soma ponderada de $n$ sinais de entrada $x_{j}, \operatorname{com} j=1,2,3 \ldots, n$, e gera uma saída de $l$ se a soma está acima de um certo limiar $u$. Esse limiar é denominado threshold.

O processo computacional envolvido com uma rede neural artificial (RNA) é desenvolvido da seguinte maneira: um neurônio artificial (NA), ou elemento de processamento, recebe entradas de um grande número de outros NAs, ou de uma fonte de estímulo externo (Figura 3.6). Uma soma ponderada, chamada valor de ativação, dessas entradas constitui o argumento, para uma função de ativação (ou função de 
transferência). $\mathrm{O}$ valor de ativação $\eta_{k}$, para uma unidade de NA $k$ num tempo $t$ é dado por:

$$
\eta_{k}(t)=\sum_{j} w_{k j} x_{j}(t)+\beta_{k}
$$

onde , $w_{k j}$ é o peso na conexão (sinapse) do $j$-ésimo neurônio, $x_{j}$ é o valor de saída do neurônio $j$ e $\beta_{k}$ é um valor de ajuste que está relacionado com o limiar de ativação.

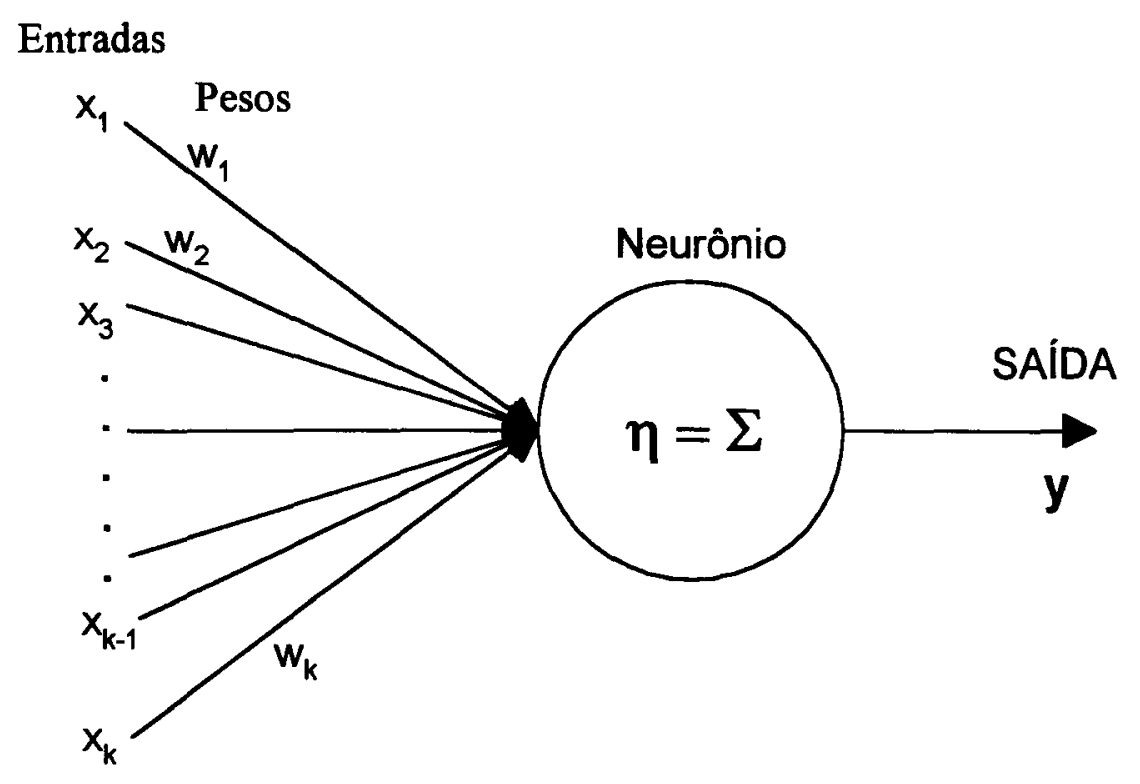

Figura 3.6 - Modelo de McCulloch-Pitts para um neurônio

O modelo neuronal de McCulloch-Pitts tem sido generalizado de muitas maneiras. Uma delas é a utilização de uma função de ativação que não seja necessariamente a função degrau. A função de ativação, que define as propriedades do neurônio, é geralmente não-linear. $O$ valor resultante da função de ativação é a saída do NA. A magnitude da saída, e o peso das conexões, determinam o efeito da unidade. Uma função não-linear típica, mais usada em redes neurais, é a função sigmoidal logística, dada por:

$$
y_{k}(t)=\frac{1}{1+e \frac{-\eta_{k}(t)}{T}}
$$

onde $T$ é um parâmetro de ajuste da declividade da função. 
Esta saída se distribui a outros NAs ao longo de conexões ponderadas, formando a topologia. A arquitetura da rede é a maneira na qual estas conexões são feitas, o que define o fluxo de informação. As RNAs podem ser vistas como grafos ponderados, nos quais os NAs são os nós, e as setas direcionais (com os pesos) são conexões entre saídas e entradas de neurônios. Baseado na arquitetura, ou seja, no modelo de conexão, as RNAs podem ser divididas em duas categorias [JMM96]:

- Redes tipo feedforward, nas quais os grafos não possuem loopings. Estas redes serão discutidas mais detalhadamente abaixo; $\mathrm{e}$

- Redes tipo feedback (ou recorrentes), nas quais os loopings ocorrem devido a conexões de realimentação.

$\mathrm{Na}$ família de redes feedforward mais comum, chamada Multilayer Perceptron, os neurônios são organizados em camadas que possuem conexões unidirecionais entre eles. Conectividades diferentes resultam em diferentes comportamentos para a rede. Genericamente falando, redes feedforward são estáticas, isto é, elas produzem, a partir de uma dada entrada, somente um conjunto de valores de saída, ao invés de uma seqüência de valores. Redes feedforward são ditas sem-memória, no sentido de que sua resposta para uma dada entrada é independente do estado anterior da rede. Por outro lado, redes recorrentes, ou tipo feedback, são sistemas dinâmicos. Quando um novo padrão de entrada é apresentado, as saídas do neurônio são calculadas e, devido aos desvios de realimentação, as entradas de cada neurônio são então modificadas, o que leva a rede a entrar num novo estado.

As conexões ponderadas das arquiteturas possuem um papel muito importante nas redes neurais. $O$ método usado para ajustar os pesos no processo de treinamento de uma rede é chamado de regra de aprendizagem. Diferentes arquiteturas requerem algoritmos de aprendizagem apropriados. A aprendizagem pode ser supervisionada ou não-supervisionada. A regra de aprendizagem supervisionada, mais amplamente utilizada, é o método de backpropagation. Outro tipo de aprendizagem, entretanto nãosupervisionada, é o método conhecido como auto-organização.

Em resumo, os três componentes essenciais de um sistema computacional baseado em redes neurais artificiais são: a função de ativação, a arquitetura e a regra de 
treinamento. Um dispositivo computacional para implementar simulações de cadeias neurais artificiais, de um modo parecido com o cérebro humano, consiste de diversas unidades neurais citadas acima, ricamente conectadas umas às outras.

\subsubsection{A aprendizagem da rede neural}

Não basta conectar neurônios para que eles forneçam um resultado útil. É necessário um método para treiná-los. Esse mecanismo deve ser tão simples quanto possível, de forma que o seu modelamento não se torne extremamente complexo. $O$ treinamento consiste basicamente em reforçar bons comportamentos, que devem ser repetidos, e reprimir os maus. $O$ princípio chave no processo de treinamento de uma rede neural é deixá-la aprender com seus próprios erros. Se ela produz uma saída incorreta, deve-se reduzir as chances desta se repetir, e caso produza um valor desejado, nenhuma medida é tomada.

O processo de treinamento, ou aprendizagem, de uma rede neural está relacionado com a atualização da arquitetura da rede e dos pesos das conexões, de forma que a rede possa realizar eficientemente uma determinada tarefa. A rede usualmente deve aprender os pesos das conexões, por intermédio de modelos de treinamento. As RNAs possuem a capacidade de aprender a partir de exemplos, ou seja, ao invés de seguir um conjunto de regras estabelecidas por especialistas humanos, elas podem aprender a partir de uma dada coleção de exemplos representativos. Esta é uma das maiores vantagens das redes neurais sobre os sistemas especialistas tradicionais.

Existem três paradigmas principais de aprendizagem [Hay94]: supervisionado, não supervisionado e híbrido. $\mathrm{Na}$ aprendizagem supervisionada é fornecida à rede a resposta correta para cada modelo de entrada. Os pesos são determinados de maneira que a rede produza respostas o mais próximo possível das respostas corretas conhecidas. Há uma variante da regra supervisionada, conhecida como aprendizagem reforçada, na qual são fornecidas à rede apenas as críticas (correções) às respostas de saída, e não as respostas corretas em si. Por outro lado, aprendizagem não supervisionada não requer uma resposta correta associada com cada modelo de entrada no conjunto de dados de treinamento. Ela explora a estrutura adjacente, ou correlações entre padrões dentro do conjunto de dados, e os organiza dentro de categorias, a partir daquelas correlações. Já o 
treinamento híbrido combina aprendizagem supervisionada e não supervisionada, com partes dos pesos sendo determinados através de cada método.

Os paradigmas são tratados a partir de teorias de aprendizagem, que resultam em regras para os algoritmos apropriados. Estes algoritmos, por vezes, possuem alta complexidade computacional. Existem quatro tipos básicos e regras de aprendizagem: regra de correção de erro, regra de Boltzmann, regra de Hebbian e regra de treinamento competitivo. Ambos os paradigmas, supervisionado e não supervisionado, empregam regras baseadas em correção de erros, regra de Hebbian e aprendizagem competitiva. Regras baseadas em correção de erro podem ser usadas para treinar redes feedforward, enquanto regras de aprendizagem de Hebbian tem sido usadas para todas as arquiteturas de rede. Entretanto cada algoritimo de aprendizagem é desenhado para treinar uma arquitetura específica. Desta forma, um algoritimo de aprendizagem, está associado com uma arquitetura particular. A seguir é descrita a regra de correção de erro, que está relacionada com o treinamento em backpropagation, utilizada neste trabalho. Para uma discussão apropriada das outras regras de aprendizagem, recomenda-se consulta à referência [JMM96] .

\subsubsection{Regras de correção de erro}

No paradigma de aprendizagem supervisionado, é fornecida uma saida desejada para cada padrão de entrada. Durante o processo de aprendizagem, a saída atual $y$ gerada pela rede pode não se igualar à saída desejada $d$. O princípio básico na regra de aprendizagem por correção de erro é usar o próprio desvio $(d-y)$ para modificar os pesos das conexões, de forma a reduzir gradualmente esse erro.

A regra de aprendizagem perceptron é baseada neste princípio de correção de erro. Um perceptron consiste de um único neurônio com pesos ajustáveis $w_{j}$, com $j=$ $1,2, \ldots, n$ e limiar $u$. Dado um vetor de entrada $x=\left(x_{1}, x_{2}, \ldots, x_{n}\right)^{t}$, a rede de entrada para o neurônio é:

$$
v=\sum_{j=1}^{n} w_{j} x_{j}-u
$$


A saída do perceptron é +1 se $v>0$ e 0 em outro caso. Note que a aprendizagem somente ocorre quando o perceptron produz um erro. Existe um procedimento para determinar os pesos e o limiar num perceptron, dado um conjunto de modelos de treinamento [Ros62]. Foi provado que quando os modelos de treinamento são desenhados a partir de duas classes linearmente separáveis, o procedimento de aprendizagem do perceptron converge após um número finito de interações. Este é o teorema de convergência do perceptron.

Entretanto, na prática, nem sempre é possível afirmar que os modelos são linearmente separáveis. Muitas variações deste algoritimo de aprendizagem foram propostos [HKP91]. Outras funções de ativação que levem a características de aprendizagem diferentes também podem ser usadas. Entretanto, um perceptron de camada única pode somente separar dois padrões linearmente separáveis quando é usada uma função de ativação monotônica. $\mathrm{O}$ algoritimo de aprendizagem de backpropagation também é baseado num princípio de correção de erro.

\subsubsection{Redes feedforward multicamada}

Rede feedforward multicamada é a designação dada a um modelo de redes neurais, com conjunto de neurônios interligados da seguinte forma: uma camada de entrada que tem suas entradas diretamente conectadas ao padrão de entrada, e suas saídas conectadas às entradas de outros neurônios. Outra classe são os neurônios de saída, que recebem as entradas de outros neurônios e produzem a saída resultante do sistema. Entre essas duas camadas podem existir quantas camadas intermediárias forem necessárias. O modo de conexão de uma camada à outra pode variar de totalmente conectada, caso em que a saída de cada neurônio de uma camada sirva de entrada para todos os outros da camada seguinte, até modelos em que há apenas algumas poucas ligações. Essas unidades conectam-se sucessivamente num único sentido, sem conexões entre unidades numa mesma camada e sem conexões reversas entre camadas.

A Figura 3.7 mostra um perceptron de 3 camadas, onde $w_{i j}^{(L)}$ é o peso sobre a conexão entre a $i$-ésima unidade na camada $(L-1)$ para a $j$-ésima unidade na camada $L$. 


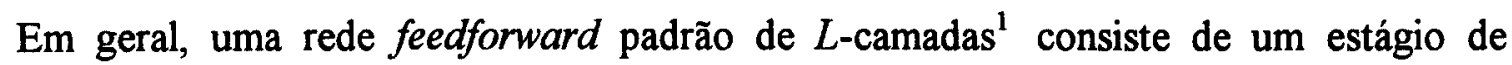
entrada, $L-1$ camadas ocultas, e uma camada de saída.

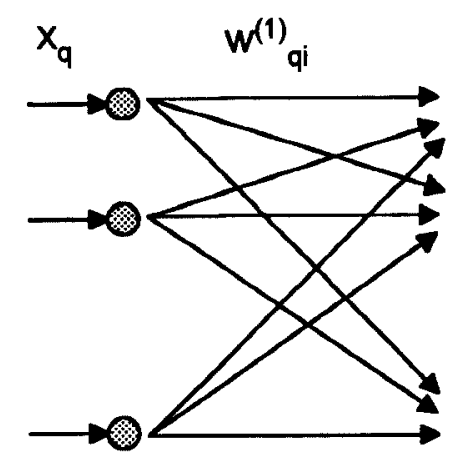

entrada

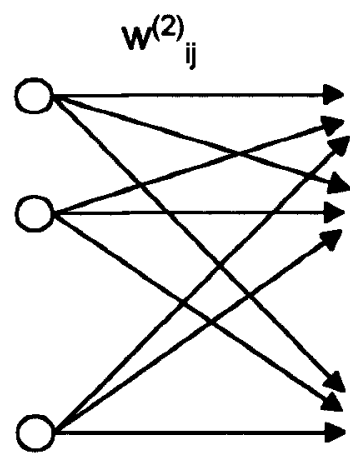

Camadas ocultas

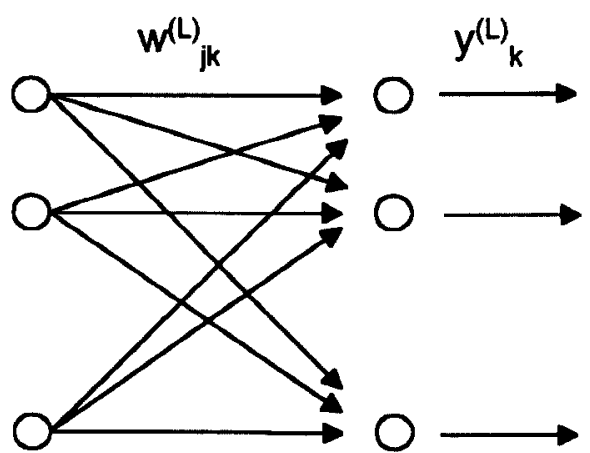

saida

Figura 3.7 - Uma típica arquitetura de rede tipo feedforward de 3 camadas [JMM96]

A classe mais popular de redes multicamada tipo feedforward é a rede de perceptrons multicamada (multilayer perceptrons), na qual cada unidade computacional utiliza a função degrau ou a função sigmoidal. Os perceptrons multicamada podem formar condições de contorno arbitrariamente complexas, e assim representar qualquer função boolena [MP69]. O desenvolvimento do algoritimo de aprendizagem em backpropagation, para determinação dos pesos num perceptron multicamada, popularizou o uso dessas redes. O termo backpropagation vem da aprendizagem que testa um valor de entrada e produz uma saída. $O$ erro gerado então é ajustado na camada de saída, sendo passado de volta para a camada anterior para que esta ajuste seu erro também, até que se chegue à camada de entrada. Ou seja, o erro é propagado para trás para ser ajustado.

Consideremos $w_{i j}^{(L)}$ como sendo o peso sobre a conexão entre a $i$-ésima unidade na camada $(L-l)$ para a j-ésima unidade na camada $L$. Seja $\left\{\left(x^{(1)}, d^{(1)}\right),\left(x^{(2)}, d^{(2)}\right), \ldots,\left(x^{(p)}, d^{(p)}\right)\right\}$ um conjunto de padrões de treinamento (pares entrada-saída), onde $x^{(i)} \in R^{n}$ é o vetor de entrada no espaço $n$-dimensional, e $d^{(i)} \in[0,1]^{m}$ um hipercubo $m$-dimensional. Para efeitos de classificação $m$ é o número de classes. A função erro quadrático mais freqüentemente usada nas RNAs é definida como:

\footnotetext{
1 Adota-se a convenção que os nós de entrada não são contados como camadas
} 


$$
E=\frac{1}{2} \sum_{i=1}^{p}\left\|y^{(i)}-d^{(i)}\right\|^{2}
$$

O algoritimo de backpropagation [RM86] é um método de gradiente para minimizar a função de erro quadrático da equação acima. $O$ processo de treinamento ainda envolve passos de validação. Esta validação é feita da seguinte forma: dado um conjunto de padrões e suas respectivas classificações, ele é apresentado à rede neural para treiná-la. Após todos os padrões terem sido mostrados à rede, pode ocorrer de um padrão haver comprometido ("estragado") o treinamento que outro tenha produzido, uma vez que o ajuste de pesos é feito independentemente para cada padrão apresentado. Para evitar que a rede não mais reconheça os primeiros padrões a que teve contato, é feita uma nova apresentação dos padrões e um novo ajuste de pesos. Isto é feito até que o erro médio encontrado nos padrões atinja um nível aceitável. Esses níveis podem ser mais rigorosos dependendo da aplicação que a rede terá.

\subsubsection{O re-treinamento e adaptabilidade da rede}

A capacidade de re-treinar uma rede neural fornece características muito interessantes. Sempre que se queira introduzir um novo padrão para que ela passe a reconhecê-lo, basta re-treiná-la, só que agora com este novo padrão fazendo parte do conjunto de padrões de treinamento. Esta característica fornece uma habilidade de adaptação que é necessária em algumas aplicações, notadamente quando o conjunto de padrões que a rede terá de reconhecer não é constante, mas pode apresentar variações no decorrer do tempo. Num sistema de reconhecimento de caracteres esta é uma propriedade não tão útil, já que é extremamente dificil ocorrer uma mudança nas letras que formam o alfabeto. Já num sistema de deteç̧ão de intrusão, esta característica é de fundamental importância, pois confere ao sistema este poder de adaptabilidade. 


\section{Um Modelo Adaptativo de Detecção de Intrusos}

Este capítulo apresenta uma proposta do modelo de deteç̧ão de intrusos em redes de computadores. O modelo é baseado em detecção por abuso, utilizando captura de pacotes para identificar assinaturas de ataque, que são posteriormente tratadas por uma rede neural.

\subsection{Introdução}

O modelo proposto neste trabalho trata-se de um sistema de segurança para redes de computadores que operem utilizando protocolo TCP/IP. Procura-se detectar o comportamento intrusivo, através da localização de assinaturas de ataque no fluxo de dados da rede. Trata-se de um modelo de deteç̧ão por abusos, que utiliza técnicas de captura de pacotes, aliadas a redes neurais, para além de descobrir o comportamento intrusivo, auditorar e fornecer elementos que auxiliem no processo de decisão sobre possíveis ações a serem tomadas pelo administrador. O sistema de detecção é composto por um ou mais sistema de captura de pacotes que, posicionados em locais estratégicos da rede, obtém as informações que são tratadas por um sistema de segurança.

\subsection{Descrição inicial}

Existem algumas técnicas de acesso, pelas quais as tentativas de ataque se desenvolvem. $\mathrm{Na}$ grande maioria dos cenários, o intruso se encontra fisicamente distante do sistema sob ataque [NP89], e assim utiliza algum ponto de rede durante sua ação. A Figura 4.1 ilustra quatro tipos de comportamentos básicos [KFG+93]. No ataque simples o intruso usa uma máquina na rede para acessar diretamente outra máquina. No ataque distribuído (também conhecido como doorknob), diversas tentativas de acesso (com ou sem sucesso) se desenvolvem a partir de uma única máquina. No ataque em cadeia, o 
intruso procura acessar diversas máquinas para dissimular sua verdadeira identidade, ou seu ponto de ataque inicial; no ataque em looping, a máquina atacada é a mesma originadora do ataque.
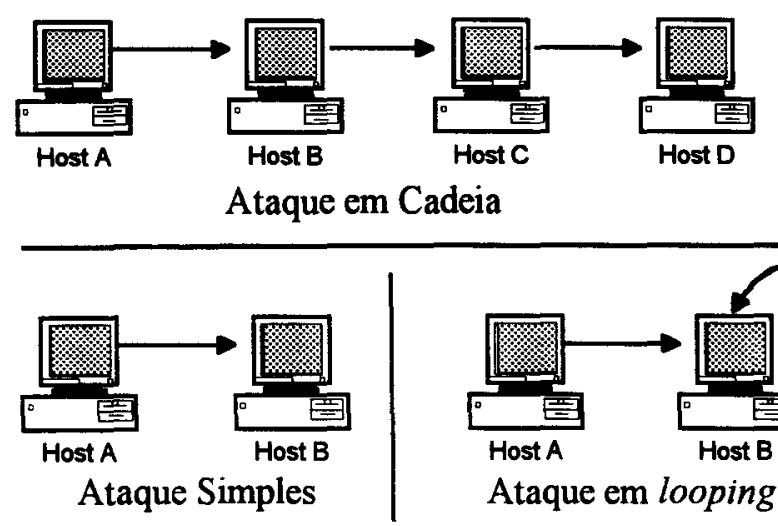

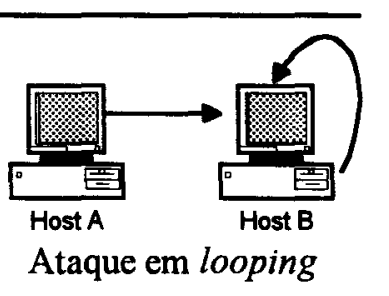

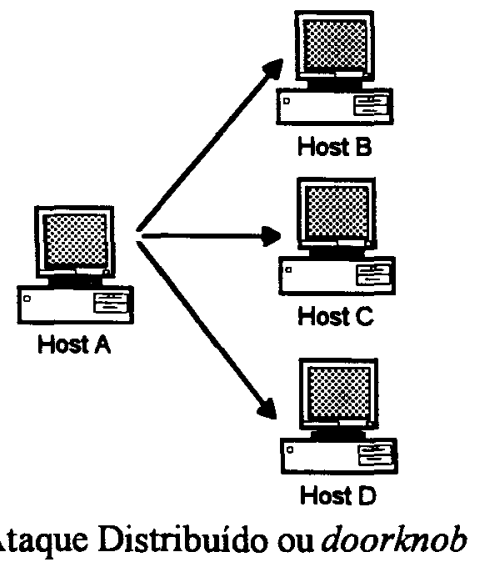

Ataque Distribuido ou doorknob

Figura 4.1 - Tipos básicos de ataque. Figura adaptada da referência [KFG+93]

Uma das propostas inovativas em nosso sistema, é a introdução de um mecanismo de segurança, capaz de detectar comportamento intrusivo em determinadas sessões de rede. Este mecanismo atua capturando e decifrando pacotes, que são transmitidos através da rede sob monitoração. Para realizar inferências acerca do estado de segurança das sessões, utiliza um sistema de pré-filtragem e uma rede neural. Como resultado, a rede neural fornece um número que, baseado em informações de assinaturas de ataques anteriores, indicará a gravidade de um determinado evento.

O sistema se baseia no fato de que um comportamento intrusivo pode ser detectado a partir da análise de padrões pré-determinados. Alguns destes comportamentos suspeitos [Den87] são, por exemplo:

- Alguém tentando acessar um determinado sistema deve gerar uma taxa anormal de falhas de password, seja com relação a um computador em particular ou o sistema como um todo;

- Alguém que ganhe acesso indevido ao sistema através de um account e password não autorizados deve desenvolver uma sessão diferente do usuário legítimo, em termos de tempo de login, localização do acesso ou tipo da conexão. Além disso o comportamento do intruso pode diferir consideravelmente do usuário legítimo em termos de acesso aos diretórios ou execução de utilitários do sistema; 
- Um usuário tentando penetrar em mecanismos de segurança num sistema operacional deve executar programas diferentes e disparar mais violações de proteção. Se há sucesso, ele terá acesso a programas e arquivos normalmente não permitidos a ele;

- Um usuário tentando acessar documentos sensíveis à segurança pode realizar logins em horários não usuais e rotear dados para discos ou impressoras normalmente não usados por ele;

- Um usuário tentando obter dados não autorizados de uma base de dados através de agregação e inferência deve recuperar mais registros que o normal;

- Um intruso capaz de monopolizar um recurso (por exemplo uma rede) deve possuir alta atividade anormal de pacotes com relação ao recurso, enquanto a atividade de todos os outros casos é, em contraste, normalmente baixa.

Essas ações, desde que devidamente observadas e tratadas, geram assinaturas de ataque que identificam um determinado padrão, que por sua vez pode ser identificado nos dados das sessões de rede. Nossa proposta é que a utilização de redes neurais fornece mecanismos eficazes de reconhecimento de ataque, além de inserir uma capacidade adaptativa que acompanhe as mudanças e variações nas técnicas existentes.

\subsection{Ambiente de abrangência}

O agente é implantado em uma máquina segura, ou seja, um computador logicamente invisível às outras máquinas, e que se encontra num local onde o acesso físico é restrito, podendo assim ser acessado apenas em determinadas condições especiais. Também podem ser utilizadas técnicas especiais de ocultação, utilizando por exemplo uma alocação dinâmica de números IP, ou ainda um conjunto de máquinas. Este sistema seguro é posicionado em pontos sensíveis do sistema de rede. Estes pontos sensiveis podem ser:

- Diretamente na subrede sob monitoramento (Figura 4.2);

- Junto a pontos de interconexão de subredes internas, ou compartilhando o backbone onde se ligam roteadores que forneçam, às subredes sob monitoração, acesso ao mundo exterior (Figura 4.3); 
- Avaliação de pontos de acesso de interconexão de WANs (linhas seriais). Neste caso estamos propondo o desenvolvimento de um sistema de monitoração que opere utilizando linhas seriais em conexões ponto-a-ponto, de maneira similar a um “grampo" telefônico (Figura 4.4). Note-se a importância desta configuração devido ao fato de que, geralmente, roteadores podem ter portas ligadas a mais do que uma subrede.

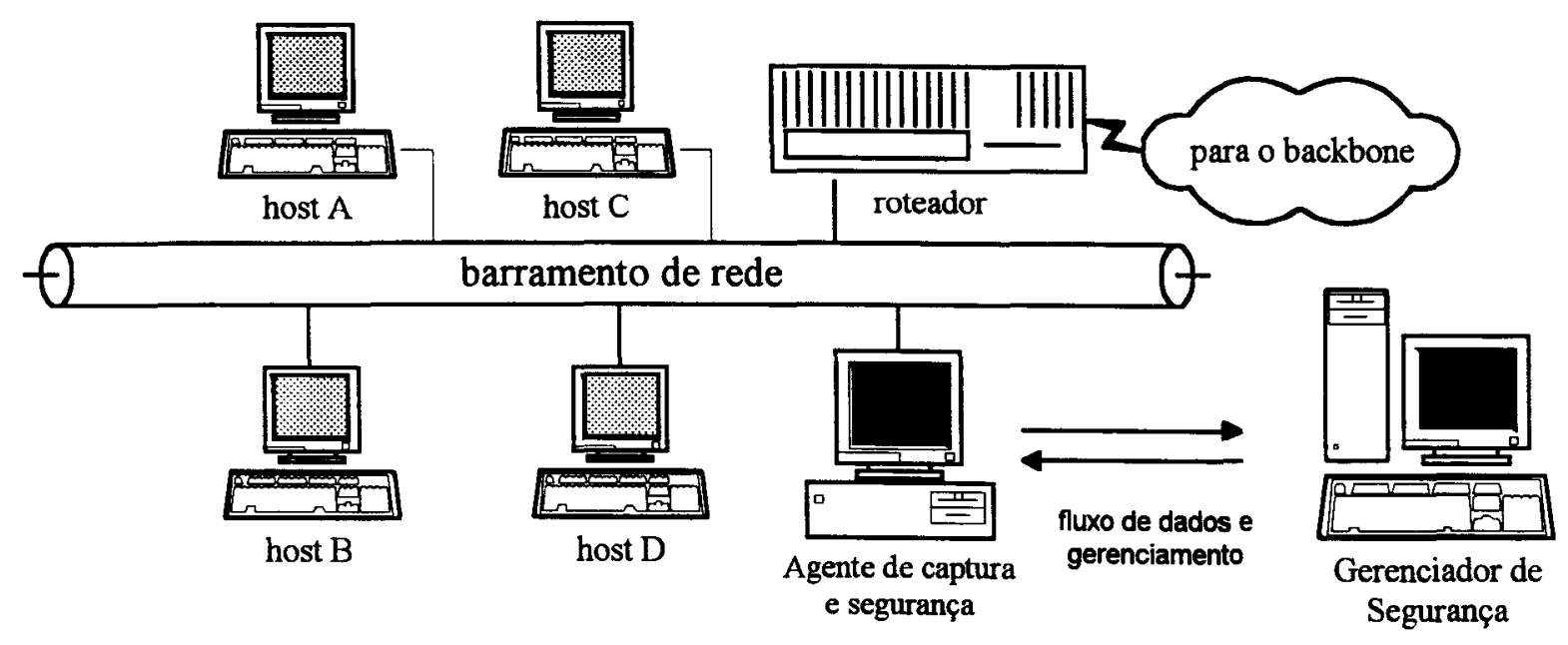

Figura 4.2 - Monitoração de sub-rede

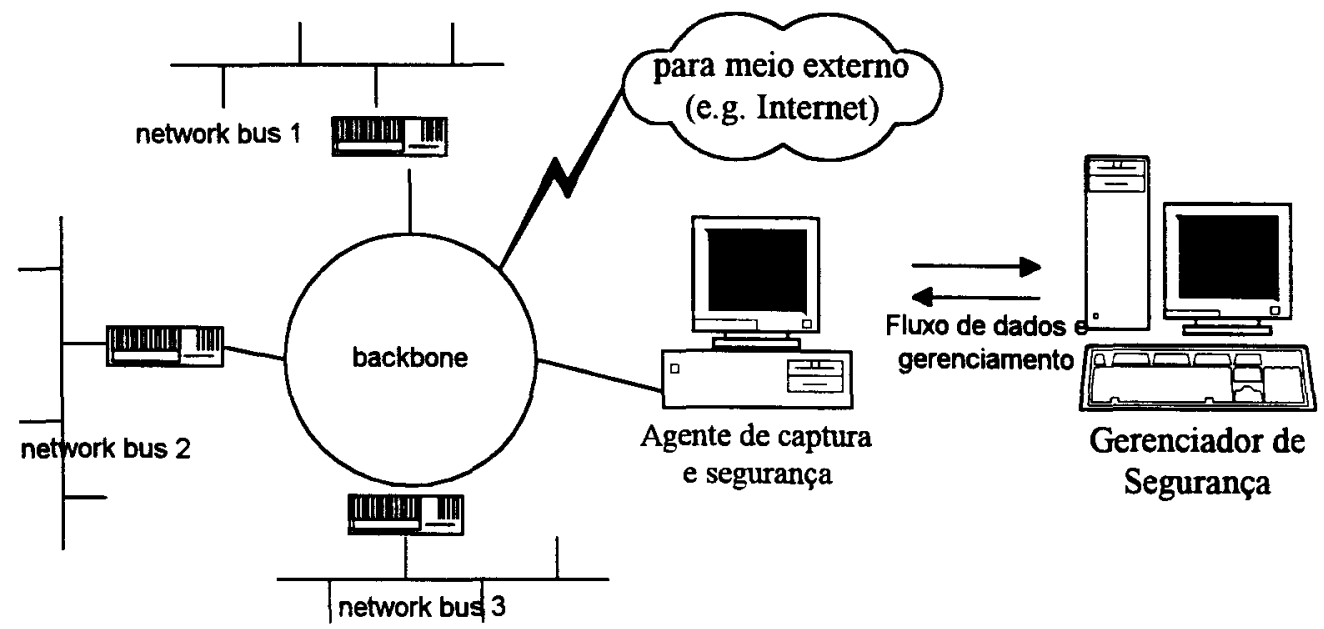

Figura 4.3 - Monitoração de um backbone 


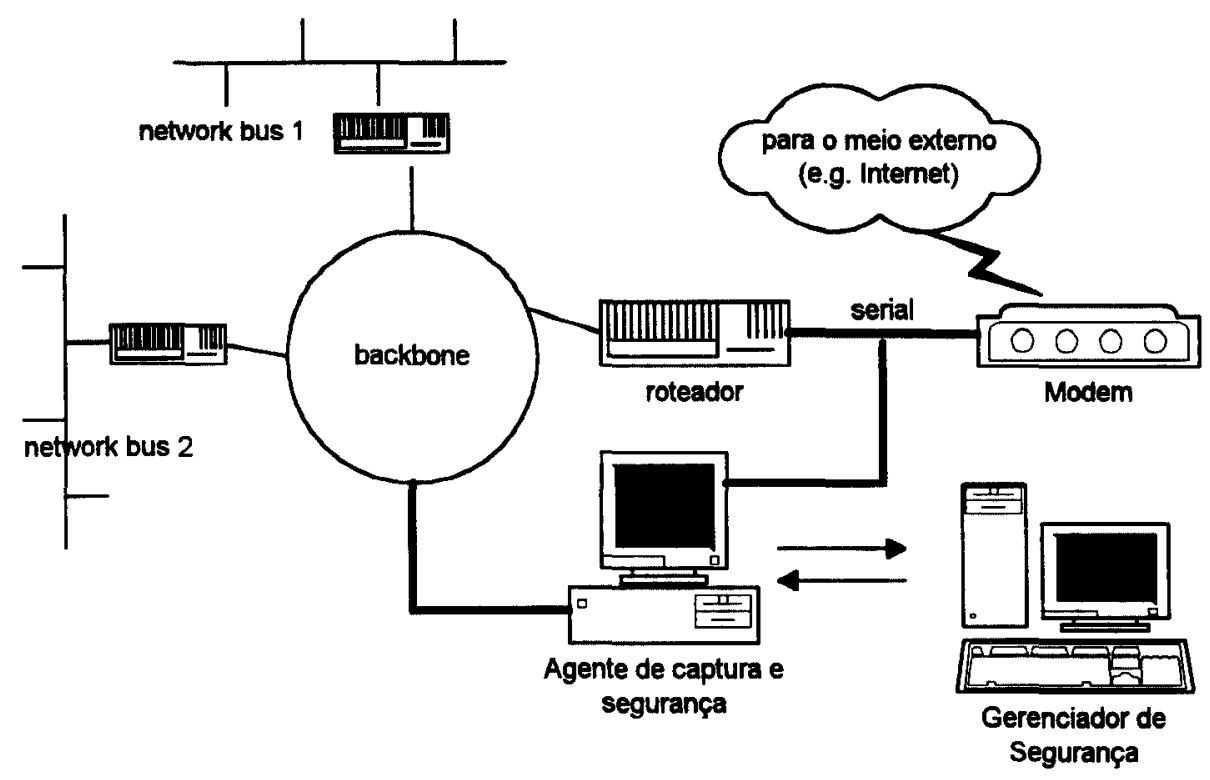

Figura 4.4 - Monitoração de backbone e linhas seriais

Em todas as situações anteriores, o agente de captura e segurança passivamente monitora a rede, e obtém um determinado fluxo de pacotes de interesse, através da utilização da interface de rede em modo promíscuo.

\subsection{Estrutura do modelo}

\subsubsection{Estrutura geral}

Nosso modelo de detecção de intrusão é formado por um sistema de captura e tratamento de pacotes, um sistema de rede neural, e um gerenciador de comunicações e interface com o usuário (Figura 4.5).
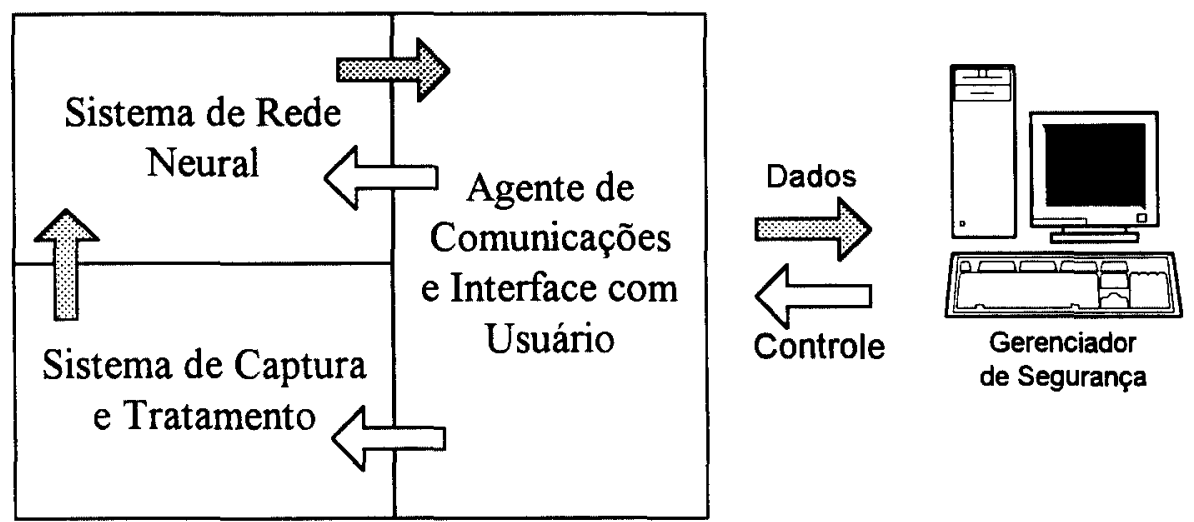

Sistema de Segurança

Figura 4.5 - Estrutura geral do modelo de segurança 
O sistema de captura e o sistema de rede neural podem ou não residirem na mesma máquina. Opcionalmente, o sistema de rede neural pode ser implantado na máquina central, gerenciadora de segurança (Figura 4.6). Dessa forma, devem haver agentes e gerentes de comunicação, utilizando protocolos que gerenciem a troca de informações entre estas máquinas.

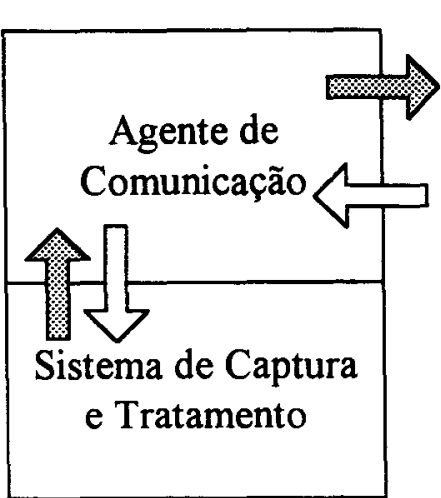

Estação Agente de Captura

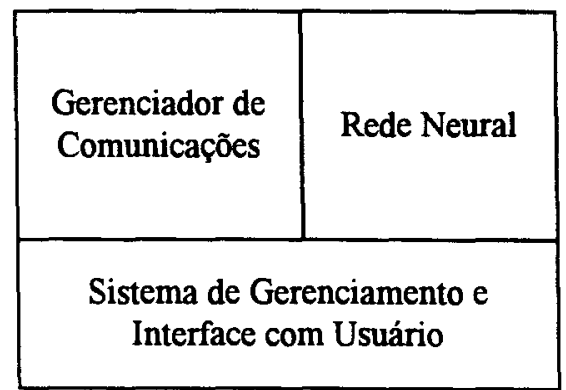

Estação Gerente de Segurança

Figura 4.6 - Estrutura geral alternativa do modelo de segurança

Esta distribuição do sistema como um todo, não influi no estabelecimento do modelo detector de intrusão, que discutiremos a seguir. Este assunto será abordado novamente, mais adiante, quando for discutida a implantação do protótipo de nosso modelo.

\subsubsection{Estrutura modular do sistema}

O sistema de captura e tratamento de pacotes é organizado em módulos (Figura 4.7), que tratam o fluxo de pacotes, e que terminam fornecendo o vetor de estímulo para a rede neural. O nível mais baixo apenas captura um fluxo de dados na rede e passa os pacotes ordenados para o módulo de conexão, sob controle do módulo de pré-seleção. 


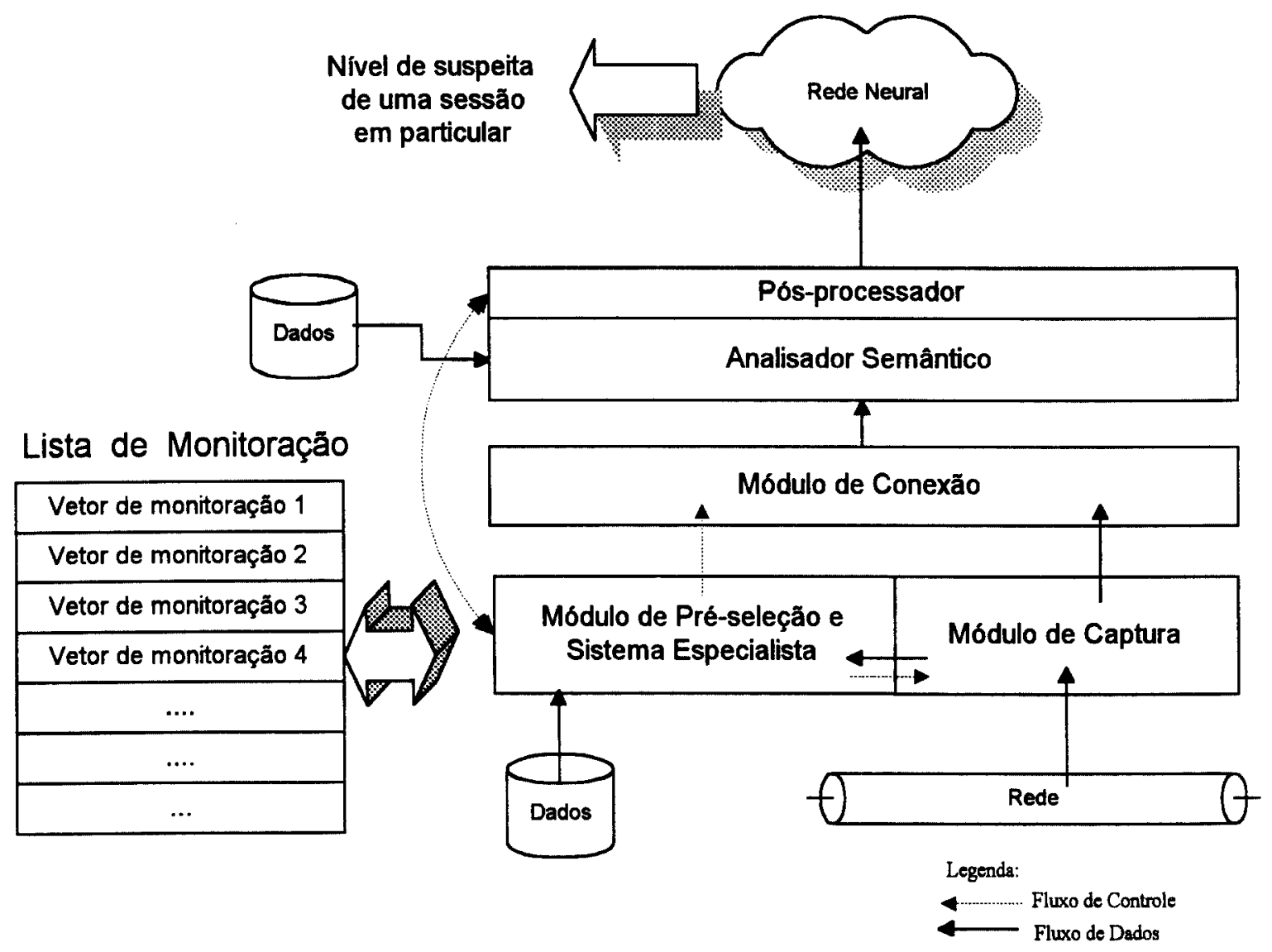

Figura 4.7 - Estrutura dos módulos do sistema de detecção de intrusos

\subsubsection{Módulo de captura e o módulo de pré-seleção}

$\mathrm{O}$ módulo de pré-seleção determina e realiza uma filtragem inicial dos eventos que possam representar interesse, como por exemplo, que tipo de protocolo deve ser monitorado, quais os serviços mais críticos, ou quais destinos ou origens devem ser considerados ou descartados. Os dados sobre estes eventos, provenientes dos pacotes previamente filtrados, são então enviados para análise pelo sistema especialista. $O$ sistema especialista proposto é baseado em regras de estruturas de decisão, como discutido na seção 2.3.2 [SS92], e utiliza as seguintes informações na tomada de decisões:

- Quais os caminhos esperados de sessão (origem e destino da sessão), e quais podem representar risco;

- Quais as portas de origem e destino e, por conseqüência, quais os serviços envolvidos; e 
- Sensibilidade das máquinas e confiabilidade dos domínios.

Estes dados servem como elementos de análise para monitoração dos eventos de risco, e vão determinar quando o sistema deve começar a capturar todos os dados de uma determinada sessão, para localizar as assinaturas de ataque. Estes eventos são armazenados numa lista de monitoração (Figura 4.7), que os mantêm durante um tempo definido. Os dados colocados nesta lista tratam-se de vetores (Figura 4.8) que incluem origem e destino da sessão, portas envolvidas, um "nível de segurança" (NS) e um indicador horário. Cada sessão ou evento provavelmente suspeito, é representada por um vetor na lista de monitoração

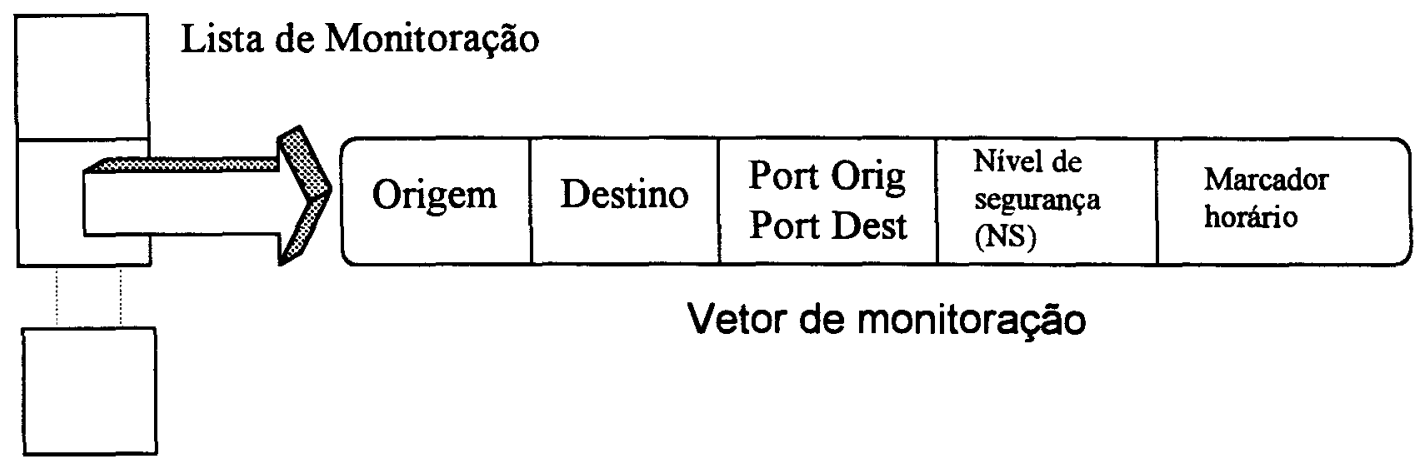

Figura 4.8 - Representação do vetor de monitoração

O nível de segurança (NS) é um valor numérico que vai sendo acrescido à medida que são monitorados eventos de interesse provenientes de uma dada origem. Esses eventos podem ser, por exemplo:

- Uma mesma origem acessando repetidamente um mesmo destino na rede sob monitoramento;

- Um mesmo domínio de origem (ou subconjunto deste domínio) acessando, ou tentando acessar, uma ou mais máquinas destino, na rede sob monitoramento;

- Sessões, ou tentativas de sessão, internas ou externas, ocorrendo em horários não esperados.

Um cenário a se considerar é o seguinte: o sistema detecta um finger vindo do host externo $A$ para o host $B$, na rede sob monitoramento, e inclui um vetor para este evento na lista de monitoração, com um valor de nível de segurança pré-determinado 
para o finger (NS $=10$, p.ex). Ao detectar um novo evento, por exemplo um telnet (NS $=15$, p.ex), a lista de monitoração é pesquisada e, encontrando-se uma entrada proveniente da mesma origem-destino, o nível de segurança deste vetor existente é acrescido do valor do nível de segurança do telnet, ficando com $N S=25$. Neste caso, não é criado um novo vetor na fila.

Pode ocorrer outra situação em que o evento detectado vem de um domínio (ou sub-rede) de onde já houve algum outro evento anterior (já registrado na lista), mas não necessariamente vindo da mesma máquina, nem possivelmente com mesmo destino dentro da rede sob monitoramento. Neste caso, um novo vetor é inserido na lista de monitoração, mas com o nível de segurança equivalente, acrescido de um peso que indica que já há alguma ocorrência vinda daquele domínio. Outras variações podem ser facilmente expandidas, conforme necessário, a partir das duas situações principais acima.

Continuando o processo, a lista de monitoração é ciclicamente verificada, dentro de um intervalo de tempo padronizado. Quando o campo do nível de segurança de um vetor atinge um limite pré-estabelecido, o sistema especialista determina que o módulo de captura passe a monitorar e capturar todos os dados daquela sessão ou, opcionalmente, de todas as sessões vindas daquele domínio. Há ainda a possibilidade de se realizar diferentes tipos de buscas e verificações na fila, considerando-se não apenas o limite do NS para um par origem-destino, mas também relativamente a domínios ou intervalos de endereços. Estas buscas podem resultar não apenas em atividades de monitoramento, mas também em ações de registro e auditoria, conforme a necessidade.

\subsubsection{Módulo de conexão}

Uma vez que o módulo de pré-seleção e o sistema especialista identificaram os acessos que diferem dos padrões inicialmente aceitáveis, todos os pacotes provenientes da conexão são enviados para o módulo de conexão.

Este terceiro módulo baseia-se no modelo hierárquico do Network Security Monitor (NSM) [Heb90, Heb91, HLM91] discutido anteriormente na seção 2.5.1. O módulo de conexão recebe os pacotes provenientes do sistema de captura, e os organiza numa relação de causa e efeito, identificando um fluxo de dados unidirecional. Isso é 
feito através da análise dos campos origem, destino, portas e número de seqüência dos pacotes, resolvendo assim o problema de fragmentação. Este tratamento pode ser realizado tanto a nível de IP como a nível de TCP.

Uma vez identificado e ordenado, o fluxo consiste dos dados sendo transferidos de uma máquina para outra, através de um dado conjunto de portas, por um determinado protocolo. Estes pacotes são mapeados num vetor de fluxo, que é a transcrição dos dados de uma conexão em particular. Se for necessário (e possível), são formados pares de vetores de fluxo, de modo a se representar bi-direcionalmente o tráfego de dados, de uma sessão ponto-a-ponto em particular (Figura 4.9).
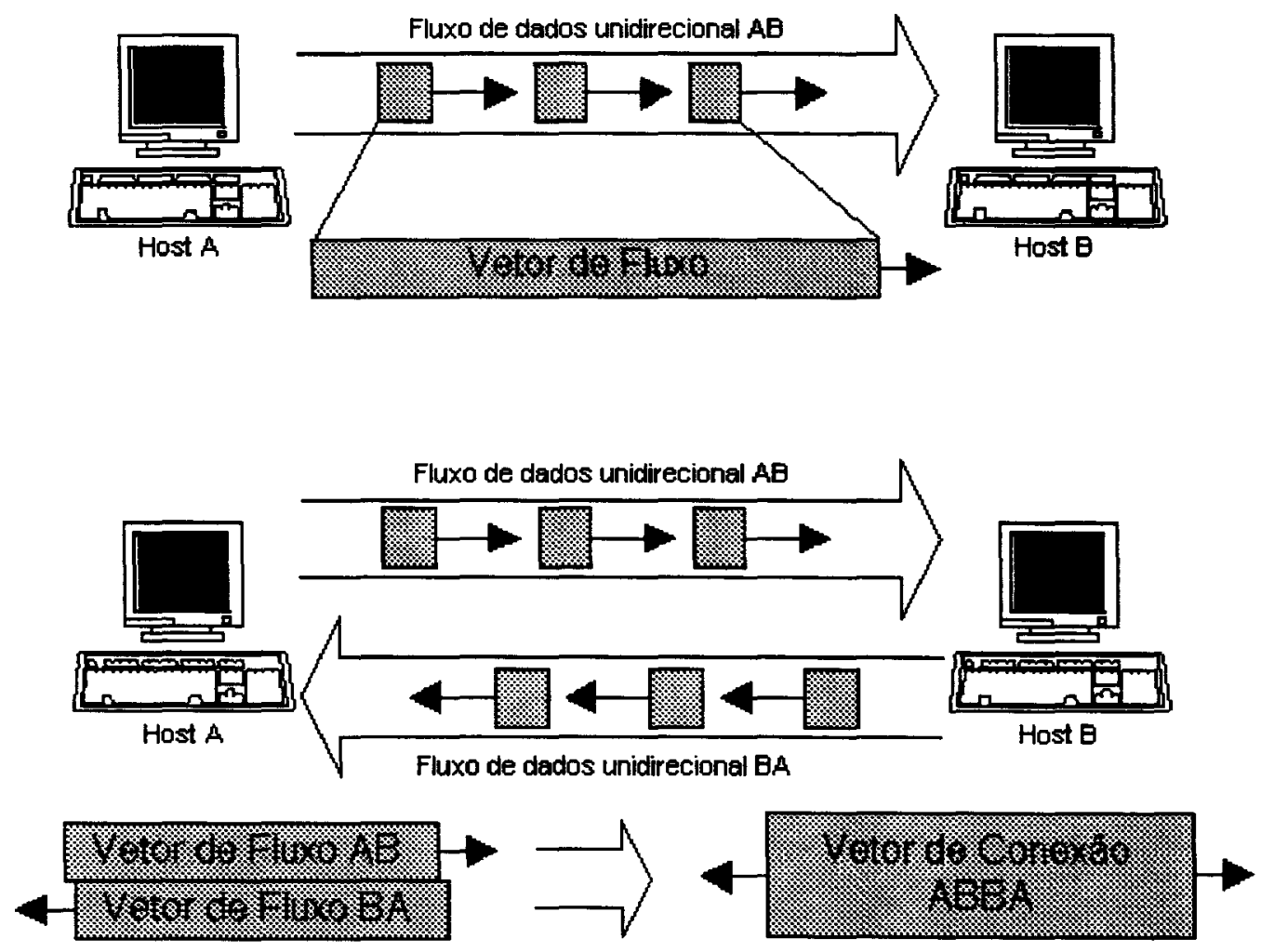

Figura 4.9 - Esquema de formação do vetor de conexão pelo módulo de conexão

Os pares de vetores de fluxo são representados por um vetor de conexão, que contém todos os dados transmitidos entre os 2 hosts através da sessão sob monitoramento. Os vetores de conexão são então enviados para a quarta camada, para serem tratados por um analisador semântico. 


\subsection{5 $O$ analisador semântico e o vetor de estímulo}

A função principal do analisador semântico é preparar o vetor de estímulo, que conterá os dados que serão analisados pela rede neural. Isto é feito para cada vetor de conexão que está sob monitoramento. É a partir deste vetor de estímulo que a rede neural fará a análise da existência, ou não, de assinaturas de ataque, buscando identificar o comportamento anômalo. $\mathrm{O}$ analisador semântico age sobre os vetores de conexão, fazendo uma filtragem e buscando dados de perfis de ataque que estejam presentes nos dados. Os perfis de ataque estão armazenados em uma base de dados, e são atualizados conforme a necessidade. Estes perfis tratam-se de strings de caracteres relevantes, pertencentes a assinaturas de ataque, e contém informações sobre como uma sessão suspeita se desenvolve. São analisados os dados contidos na sessão, e quantos e quais deles casam com os perfis.

Como exemplo, considere o desenvolvimento de uma sessão TCP com o processo de transmissão de correio eletrônico em protocolo SMTP, descrita a seguir [Cer95]. Esta sessão tenta explorar uma vulnerabilidade antiga, e bastante conhecida, do processo sendmail, a fim de capturar o arquivo de senhas do sistema vitima.algum.lugar.br e envia-lo para o endereço eletrônico intruso@outro.lado.br :

\section{[conexão tcp estabelecida]}

220 vitima.algum.lugar.br ESMTP Sendmail 8.7.5 ready.

mail from " | /bin/mail intrusoloutro.lado.br </etc/passwd "

250 " I / bin/mail intruso@outro.lado.br </etc/passwd "... sender ok.

rept to: nobody

250 Recipient ok.

354 Enter mail, end with "." on a line by itself

data.

250 QAA23003 Message accept for delivery

quit

221 vitima.algum.lugar.br closing connection.

[conexão encerrada]

O analisador semântico, baseado nos perfis de ataque, localiza os strings mais relevantes que correspondem a este tipo de comportamento, como por exemplo:

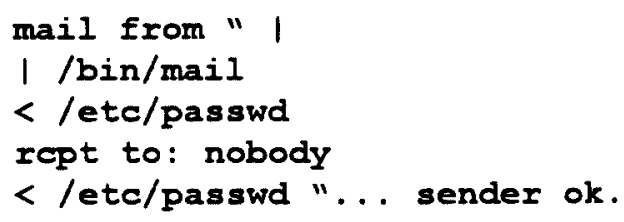


Utilizando-se uma base de dados previamente estabelecida, estes strings são convertidos num código binário. Esta conversão pode ainda considerar um peso, que indica a severidade daquele string na composição final da assinatura de ataque. Continuando o exemplo acima, os 5 componentes da assinatura de ataque, presentes na conexão, poderiam ser identificados da seguinte forma (Tabela 4.1):

Tabela 4.1 - Exemplo de conversão de cadeias de strings, formadores das assinaturas de ataque, em valores binários

\begin{tabular}{|l|l|}
\hline mail from " I & 010100101 \\
\hline I /bin/mail & 010001001 \\
\hline$<$ /etc/passwd & 111000110 \\
\hline rcpt to: nobody & 100101111 \\
\hline$</$ letc/passwd "... sender ok. & 111001111 \\
\hline
\end{tabular}

Estas informações são enviadas para um último pós-processamento. São agregadas a estas informações do analisador semântico, que contém os componentes das assinaturas de ataque encontrados, as informações do sistema especialista (sensibilidade dos serviços e sessões, dentre outros) provenientes da base de dados, todos também devidamente convertidos num código binário. Estes dados formam o vetor de estímulo para a rede neural. Cada sessão suspeita terá então um vetor de estímulo (Figura 4.10), que conterá, os seguintes dados:

- Nível de capacidade do serviço. Por exemplo, telnet oferece mais capacidades que FTP;

- Nível de autenticação do serviço, isto é, telnet exige mais autenticação do que SMTP;

- Nível de segurança das máquinas origem e destino, que pode ser um valor numérico fornecido por um sistema analisador padronizado, como por exemplo SATAN Security Administrator's Tool for Analysing Networks, ou ainda um valor default ou um valor referente ao sistema operacional, atribuído por organizações internacionais de segurança, tais como Computer Emergency Response Team (CERT) ou o United States Department of Energy's Computer Incident Advisory Capability (CIAC);

- Quantidade de dados transmitida, que pode ser um importante indicativo de ações suspeitas, se associado ao tipo de serviço utilizado; 
- Horário da sessão. Atividades, serviços e quantidades de dados transmitidos num determinado horário (por exemplo no horário comercial) podem ser suspeitas se ocorrerem em outro horário (por exemplo, à noite);

- E, finalmente, os strings suspeitos, componentes das assinaturas de ataque, localizados pelo analisador semântico nos dados, tal como descrito acima.

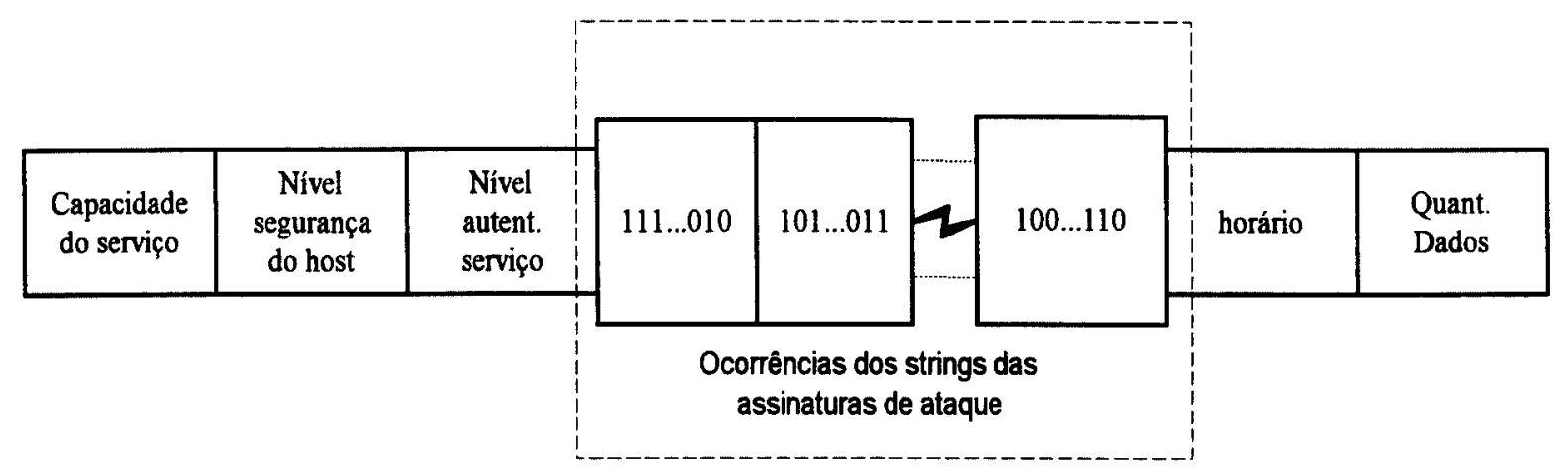

Figura 4.10 - Representação do vetor de estímulo para a rede neural

\subsubsection{Obtenção do nível de suspeita da sessão}

A rede neural analisa o vetor de estímulo de cada sessão, com os respectivos pesos que representam a importância da ocorrência dos eventos, e procura atribuir um grau de suspeita, que representa o estado de segurança da sessão. Antes que a rede neural possa identificar potenciais ataques, esta necessita ser treinada com um conjunto significativo e suficientemente grande de vetores de estímulo, que representem tanto o comportamento de sessões suspeitas e intrusivas quanto legítimas. Uma vez treinada, a rede deve utilizar sua propriedade de generalização para identificar corretamente usuários que apresentem características semelhantes àquelas presentes nas ações de intrusão utilizadas para treiná-la.

O sistema de gerenciamento (remoto ou não) recebe então o valor numérico que representa o estado de segurança das sessões suspeitas e as mapeia, classificando-as pelo grau de severidade, por intermédio de um código de cores. A partir deste ponto, várias ações podem ser tomadas, tais como emissão de vários níveis de alertas aos administradores (dependendo do nível de risco dos eventos detectados), disparo de processos de auditoria, ativação de contra-medidas para isolar o host ou o domínio originador do ataque, através do ajuste ativo de wrappers [Ven92], firewalls ou filtros. 
O sistema pode ainda sugerir ao administrador qual a melhor medida a ser tomada para sanar o problema, ou ainda, tentar localizar e contactar o administrador responsável pelo domínio de onde vem o ataque.

A rede neural também pode ser ajustada, de maneira a refletir as mudanças nos padrões de comportamento das ações de intrusão. Os administradores podem detectar comportamentos que são altamente intrusivos, mas que a rede neural ainda não está identificando corretamente, ou está identificando com uma gravidade inferior do que o esperado. Neste caso a rede pode ser alimentada com os novos padrões, e passar por um novo treinamento de maneira a aprender a reconhecer o novo padrão adequadamente, refletindo a mudança de comportamento. Esta capacidade adaptativa é a inovação mais importante e que não se encontra presente nos SDIs conhecidos até o momento. 



\section{Implementação de um Protótipo do Sistema}

Neste capítulo apresentamos o desenvolvimento da implementação de um protótipo do nosso sistema detector de intrusão em redes, baseado em captura de pacotes e redes neurais cujo modelo foi discutido no capítulo anterior.

\subsection{Introdução}

A fim de testar a funcionalidade do modelo de deteç̧ão de intrusos, proposto no capítulo anterior, foi o desenvolvido de um protótipo denominado SADI - Sistema Adaptativo de Detecção de Intrusão. Este protótipo possui algumas simplificações com relação ao modelo proposto, notadamente com relação ao módulo de pré-seleção de conexão, no qual o sistema especialista foi inicialmente aproximado e substituído por um conjunto simples de regras de filtragem. Além disso, algumas informações não foram incluídas no vetor de estímulo da rede neural, como por exemplo o nível de capacidade e autenticação do serviço e o nível de segurança das máquinas envolvidas, discutidos na seção 4.4.5. Este tratamento foi inicialmente incorporado ao módulo de pré-seleção, de forma que $o$ vetor de estímulo da rede neural possui essencialmente as possíveis ocorrências (strings) das assinaturas de ataque, obtidas pelo analisador semântico e convertidas em binários.

Optou-se por implantar todos os módulos do protótipo em uma única máquina, a fim de eliminar a necessidade de desenvolvimento de agentes e gerentes de comunicação de dados. $O$ ambiente de abrangência considerado trata-se do barramento de uma subrede ethernet (Figura 5.1), com tráfego de pacotes TCP/IP. 


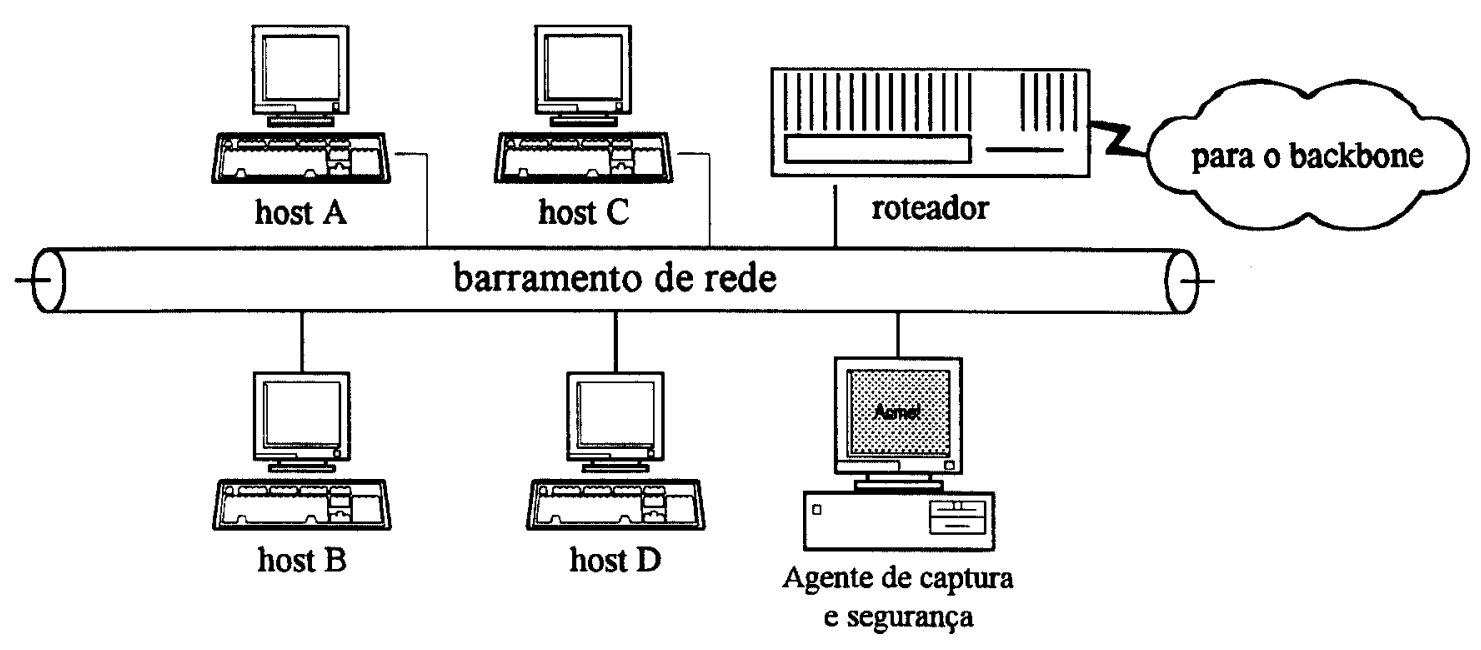

Figura 5.1 - Ambiente onde o protótipo realiza monitoração

\subsubsection{Equipamento utilizado}

O equipamento utilizado para implantação do protótipo trata-se de um microcomputador IBM-PC Valuepoint, com processador Intel 80486 DX2 de 66 Mhz, $256 \mathrm{~Kb}$ de memória cache, $20 \mathrm{Mb}$ de memória $\mathrm{RAM}, 430 \mathrm{Mb}$ de capacidade em disco rigido, e interface de rede ethernet de 16 bits em barramento ISA. Utilizou-se sistema operacional Linux versão 2.2.0, tendo sido aplicados todos os patches de correção de falhas de segurança internacionalmente recomendados. A máquina foi instalada num local fisicamente seguro, e todos os processos desnecessários, ou potencialmente inseguros, tais como sendmail, finger, identd e http, foram removidos, de maneira a protegê-la, minimizando as possibilidades de ataque. $\mathrm{O}$ desenvolvimento dos módulos foi realizado em linguagem $C A N S I$ e compilados com compilador $G N U C$. Estes módulos serão discutidos a seguir.

\subsection{O módulo de captura de pacotes}

\subsubsection{Características gerais}

A captura de pacotes é realizada por um módulo que se encontra entre o módulo de pré-seleção, que analisa os dados enviados, e o meio físico por onde trafegam todas as informações da rede. Através de uma biblioteca de captura de pacotes, o módulo tem acesso à interface de rede e aos pacotes que passam por ela, mapeando-os para uma estrutura em memória que segue o padrão de um datagrama IP. O módulo realiza três 
operações básicas: a captura preliminar de pacotes, análise inicial dos dados e captura intensiva dos pacotes.

\subsubsection{A biblioteca de captura de pacotes}

Para a captura de pacotes foi utilizada a biblioteca libpcap $v 0.06^{1}$, que na verdade trata-se de uma API (Application Program Interface) de implementação do BSD Packet Filter - BPF (discutido na seção 3.2) [MJ93], o que a torna rápida, eficiente, e de simples utilização. Esta API permite a captura não apenas de pacotes ethernet, mas também de pacotes PPP e SLIP, bastando para isso definições de código apropriadas.

O modo de operação normal do dispositivo de rede não permite o acesso a pacotes que não sejam destinados à máquina onde o sistema está executando. No entanto, existe um modo de operação, chamado de modo promiscuo, que permite que todos os pacotes sejam acessíveis. A execução de controle da interface de rede em modo promíscuo é reservada a processos que sejam executados com prioridade de root (UID zero). Dessa maneira, executadas com prioridade apropriada, as funções da biblioteca recebem uma cópia de cada pacote que passa pela interface de rede, independentemente do protocolo de alto nível. Tanto pacotes de entrada como de saída são acessíveis. A partir daí os pacotes são filtrados apropriadamente conforme programado, e assim o processo que fez a chamada, ou seja, o módulo de captura, recebe apenas os dados que foram solicitados. Esta filtragem é realizada em nível de kernel da máquina, conforme discutido na seção 3.2. Vários processos podem ser executados, todos utilizando a libpcap e especificando uma filtragem diferente no mesmo dispositivo de rede.

Além de especificar os parâmetros da filtragem desejada, discutidos a seguir, o processo originador da chamada (no caso, o módulo de captura) deve especificar um valor de timeout para a biblioteca. Como podem existir situações onde o tráfego de uma rede é intenso, ao invés de passar os pacotes um a um para o processo, a biblioteca tenta utilizar um buffer e retornar somente quando estiver cheio, ou quando o timeout definido pelo processo expirou.

\footnotetext{
${ }^{1}$ A versão mais recente da biblioteca de captura libpcap encontra-se disponivel em ftp://ftp.ee.lbl.gov/libpcap.tar.Z
} 


\subsubsection{As funções principais da biblioteca de captura libpcap}

A seguir são descritas as funções e estruturas mais importantes da biblioteca libpcap, usadas no módulo de captura:

- pcap_t *pcap_open_live (char *device, int snaplen, int promisc, int to_ms, char *ebuf)

pcap_open_live é usado para obter um descritor de captura de pacotes para monitorar os pacotes na rede. device é uma string que especifica o dispositivo de rede a ser aberto. snaplen especifica o número máximo de bytes a serem capturados. to ms especifica o timeout de leitura em milisegundos. ebuf é usado para retornar um texto de erro, somente quando a função falha e retorna NULL.

\section{- char *pcap_lookupdev(char *errbuf)}

pcap_lookupdev retorna um ponteiro para um dispositivo de rede apropriado, para ser usado com a pcap_open_live e pcap_lookupnet descrita abaixo. Se ocorrer um erro, retorna NULL e errbuf é preenchida com uma mensagem de erro apropriada.

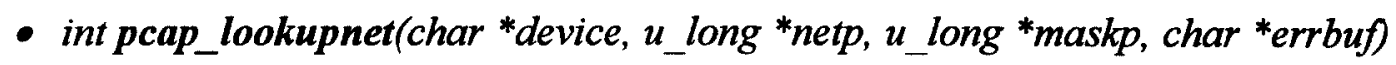

pcap_lookupnet é usada para determinar o endereço e a máscara (netp e maskp) de rede associados com o dispositivo de rede. Ambos são ponteiros u_long. Um retorno de -1 indica um erro e errbuf é preenchido com a mensagem de erro apropriada.

- int pcap_dispatch(pcap_t ${ }^{*} p$, int cnt, pcap_handler callback, u_char *user)

pcap_dispatch é usada para processar e coletar pacotes. cnt especifica o número máximo de pacotes a serem processados antes de retornar. Se $c n t$ for -1 processa todos os pacotes recebidos em um buffer; se cnt for 0 processa todos os pacotes até que ocorra um erro ou EOF é atingido. callback é um ponteiro para a função que efetivamente tratará os pacotes coletados pela pcap_dispatch.

Essa função que trata os pacotes deverá possuir três parâmetros: um ponteiro para $u_{-}$char o qual é passado pela pcap_dispatch (parâmetro user), um ponteiro para uma estrutura $p c a p \_p k t h d r$ apropriada, com relação ao pacote que se deseja tratar, e um 
ponteiro $u_{-}$char (que é o pacote). $O$ número de pacotes lidos é retornado (-1 indica erro).

As estruturas pcap_t e pcap_handler são internas à biblioteca e não serão discutidas aqui.

\subsubsection{Operações de captura}

Inicialmente utiliza-se a função pcap_lookupdev de maneira a procurar por um dispositivo de rede na máquina, associando-o a uma variável (device) no caso de sucesso. Como dito, este dispositivo deve ser aberto em modo promíscuo. Para isso, utiliza-se a função pcap_open_live, passando como parâmetros o nome do dispositivo (device), o tamanho do pacote (SNAPLEN), se o modo deve ser realmente promíscuo ou não (TRUE), e o intervalo entre os pacotes (PKTDELAY). Essa função retorna um ponteiro para o dispositivo, que vai ser usado para referências futuras (point_device).

Uma vez aberto o canal de comunicação com a rede, é necessário obter o endereço e a máscara de rede local, para referência em outros módulos. Isso é feito por intermédio da função pcap_lookupnet, passando o nome do dispositivo (device), e duas variáveis para o retorno dos dados, respectivamente localnet e netmask.

De posse dessas dados, é possivel analisar os pacotes que passam pela rede. A função pcap_dispatch passa os pacotes lidos da rede para a função que vai efetivamente processá-los. Os parâmetros são: o ponteiro para o dispositivo (point_device), o número de pacotes a serem processados (PACOTES), e um ponteiro para a função que receberá os pacotes, mapeando-os numa estrutura apropriada. Estas estruturas seguem a próprio formato dos cabeçalhos nos pacotes que estamos interessados em tratar, de modo a facilitar o mapeamento e localização dos campos apropriados. Estas estruturas são discutidas a seguir.

\subsubsection{Estruturas do sistema de captura}

Uma vez que a função principal pcap_dispatch da biblioteca libpcap retorna um ponteiro para o conteúdo do pacote que foi copiado da rede, temos disponíveis o cabeçalho ethernet, o cabeçalho IP e depois o pacote TCP, ICMP ou UDP. 
Para a análise de intrusão pelo SADI, são necessários somente os dados do cabeçalho IP em diante. Esta estrutura de interesse deve ser mapeada para um estrutura de dados na memória, que corresponde exatamente à estrutura do pacote. Isso facilita o manuseio das informações no decorrer do programa.

\section{- Estrutura IP_header}

struct IP_header \{

flag_offset;

unsigned char version_length, type; unsigned short length, D,

unsigned char TTL, protocol;

unsigned short checksum;

unsigned long int source, destination;

\}

Os valores mais importantes dessa estrutura são os campos source e destination, que contém os endereços das máquinas de origem e de destino, respectivamente. $O$ campo length contém o tamanho em bytes do cabeçalho IP, utilizado para se determinar exatamente onde termina o cabeçalho e onde começam os dados encapsulados.

Através do valor do campo protocol é possível saber de que tipo são os dados encapsulados no pacote e, a partir dai, mapeá-los para a outra estrutura de dados correspondente. Esses dados podem ser do tipo TCP, ICMP e UDP, que serão mapeados respectivamente para as estruturas TCP_header, ICMP_header e UDP_header, descritas a seguir:

\section{- Estrutura TCP_header}

struct TCP_header \{

unsigned short source, destination; unsigned long int seq_nr, ACK_nr; unsigned short offset_flag, window, checksum, urgent; \}

Nessa estrutura, os campos source e destination representam as portas da sessão sob monitoração. A partir do valor da porta de destino, pode-se determinar que tipo de serviço está em andamento na sessão. Por exemplo, se o destino é a porta 25, trata-se de uma sessão de sendmail; se o destino for a porta 23 é uma sessão remota via telnet, e assim por diante. A porta de origem pode ser qualquer valor, pois este é 
gerado em seqüência na máquina de origem. Este valor também é utilizado em nosso tratamento, com finalidade de se diferenciar várias sessões procedentes de uma mesma máquina.

- Estrutura ICMP_header

struct ICMP_header \{ unsigned char type, code; unsigned short checksum; \}

Esta estrutura é utilizada para se monitorar as transmissões de pacotes de ping, a partir dos valores de type e code. E finalmente, se o dado for UDP, a seguinte estrutura será utilizada:

\section{- Estrutura UDP_header}

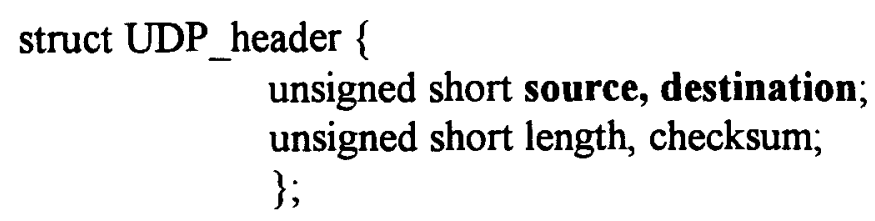

Dessa maneira, tornam-se disponíveis todos os dados que os pacotes TCP/IP podem fornecer. Agora é possível analisar o tipo de sessão que esses pacotes representam. Esta análise é feita pelo módulo de pré-seleção, que controla o módulo de captura, e será discutido a seguir.

\subsection{O módulo de pré-seleção}

\subsubsection{Considerações gerais}

A fim de simplificar alguns procedimentos de implantação, o módulo de préseleção de conexão não incorporou o sistema especialista, inicialmente proposto no modelo. O sistema especialista foi substituído por um pequeno conjunto de regras simples que, em síntese, decidem quais tipos de pacotes e sessões são inicialmente monitorados. Entretanto, esta generalização não implica nenhuma perda significativa na identificação do comportamento intrusivo. Inicialmente, optou-se por monitorar apenas 
pacotes provenientes de redes externas, ou seja, não pertencentes à rede local sob monitoração.

\subsubsection{Tipos de pacotes tratados}

Utilizando-se das estruturas descritas anteriormente, o módulo de pré-seleção faz as chamadas apropriadas ao módulo de captura, pré-analisando os pacotes. Além disso, determina-se que a análise somente se proceda quando o pacote contenha dados que correspondam a um conjunto de eventos de interesse. Para este procedimento apenas alguns campos dos pacotes são preliminarmente examinados, de modo a verificar se satisfazem essas características iniciais de pré-filtragem. Esses campos são:

- No cabeçalho IP: o endereço IP de origem e o endereço IP de destino;

- No cabeçalho TCP e UDP: a porta origem e a porta destino; e

- No cabeçalho ICMP: os campos de identificação type e code.

Algumas regras foram inicialmente adotadas para simplificar a implementação do módulo de pré-seleção:

- Pacotes provenientes da rede interna, ou seja, do mesmo barramento, são descartados;

- Pacotes TCP provenientes do meio externo são tratados se representam uma sessão do tipo FTP (porta 21), Telnet (porta 23), SMTP (porta 25), http (porta 80), finger (porta 79), pop3 (porta 110), exec (512), rlogin (porta 513), rsh (porta514) e 1 pr (porta 515);

- Pacotes UDP do meio externo são tratados, se representam uma sessão do tipo bootp (porta 67), sunrpc (porta 111), rwho (porta 513), syslog (porta 514), talk (porta 517), route (porta 520) e NFS (porta 2049);

- Os pacotes ICMP que não representem ping (cujo cabeçalho ICMP contém type=3 e $\operatorname{code}=3$ ) são descartados.

\subsubsection{Lista de monitoração e o disparo de captura}

Quando pacotes que representam eventos de interesse são detectados, é criada a lista de monitoração. Esta lista de monitoração, descrita na seção 4.4.3, trata-se de uma 
tabela de registro de sessões, ou suas tentativas. Esta lista, forma uma seqüência de entradas para representar o relacionamento entre uma máquina de uma rede externa, e a rede interna sob vigilância. Estas entradas, são os vetores de monitoração. Os dados principais sobre esse relacionamento são armazenados na seguinte estrutura de dados:

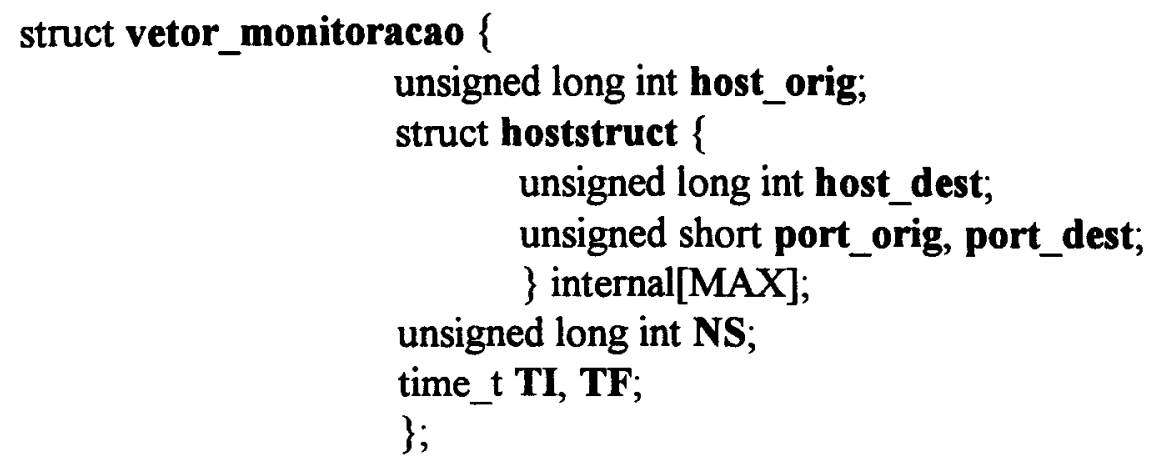

Cada entrada na lista de monitoração contém:

- O endereço do host de origem (host_orig), o qual é o índice da tabela, e

- Um vetor com os endereços dos hosts internos (host_dest) na rede sob monitoramento, aos quais este host externo estabeleceu, ou tentou estabelecer, sessões. Neste vetor são registradas as respectivas portas de origem e destino (port_orig, port_dest), tempo inicial (TI) no qual o primeiro pacote daquele evento foi detectado e tempo final (TF) do último pacote a ser detectado.

Conforme já mencionado, cada serviço de rede tem o seu nível de segurança próprio. Este nível de segurança (NS) é um valor numérico que vai sendo acrescido à medida que são monitorados eventos de interesse provenientes de uma dada origem. Esses eventos podem ser, por exemplo:

- Uma mesma origem acessando, ou tentando acessar, repetidamente um mesmo destino na rede sob monitoração;

- Um mesmo domínio de origem (ou subconjunto deste domínio) acessando, ou tentando acessar, uma ou mais máquinas destino, na rede sob monitoração; e

- Sessões, ou tentativas de sessão, internas ou externas, ocorrendo em horários não esperados. 
Aos serviços de rede são associados valores padrão para o NS, de acordo com a importância e sensibilidade de cada um. Os valores utilizados em nossa implementação atual são apresentados na Tabela 5.1.

Tabela 5.1 - Valores de NS, referentes às portas, adotados no módulo de préseleção para determinar o disparo automático de captura

\begin{tabular}{|l|c|l|}
\hline Porta / Protocolo & NS & Serviço: \\
\hline $21 /$ TCP & 15 & ftp \\
\hline $23 /$ TCP & 15 & telnet \\
\hline $25 /$ TCP & 5 & smtp \\
\hline $67 /$ UDP & 10 & bootp \\
\hline $79 /$ TCP & 2 & finger \\
\hline $110 /$ TCP & 5 & pop3 \\
\hline $111 /$ UDP & 10 & sunrpc \\
\hline $512 /$ TCP & 5 & exec \\
\hline $513 /$ UDP & 10 & rlogin \\
\hline $514 /$ TCP & 15 & rsh \\
\hline $515 /$ TCP & 10 & lpr \\
\hline $520 /$ UDP & 10 & route \\
\hline $2049 /$ UDP & 15 & NFS \\
\hline outras & 2 & Outras portas não listadas (default) \\
\hline
\end{tabular}

Exemplo: o sistema detecta um finger vindo do host $A$ (externo à rede em monitoração) para o host $B$ (interno à rede) e inclui um vetor para este evento na lista de monitoração, com um valor de nível de segurança pré-determinado para o finger $(\mathrm{NS}=2)$. Ao detectar um novo evento, por exemplo um telnet $(\mathrm{NS}=15)$, a lista é pesquisada e, encontrando-se uma entrada proveniente da mesma origem-destino, o nível de segurança deste vetor existente é acrescido do valor do nível de segurança do telnet, ficando com NS=25.

Outro tipo de registro implementado, considera o seguinte cenário: o evento detectado vem de um domínio (ou sub-rede) de onde já houve algum outro evento anterior (já registrado na lista), mas não necessariamente vindo da mesma máquina, nem com mesmo destino. Insere-se novo vetor na lista de monitoração, mas com o nível de segurança equivalente, acrescido de um peso que indica que já há alguma ocorrência vinda daquele domínio. E além disso, outras entradas provenientes da mesma rede em 
questão, já registradas na lista, também recebem o incremento do valor de NS, equivalente a este último evento.

A lista de monitoração passa por verificações cíclicas periódicas, verificando os valores de NS, TI e TF. O administrador do sistema estabelece um limiar para o valor máximo que NS pode assumir. Este limiar pode ser dependente do período do dia, ou dia da semana em questão. Caso o NS de um evento registrado (sessão ou tentativa) ultrapasse esse limiar, a localidade que gerou este evento passa a ser considerada potencialmente perigosa para a rede. Quando isso ocorre, ao realizar a verificação cíclica, o módulo de pré-seleção ativa o módulo de conexão (Figura 5.2) para que este comece a registrar, sem restrições, todos os pacotes vindos da rede onde está situada a máquina, ou as máquinas, suspeitas.

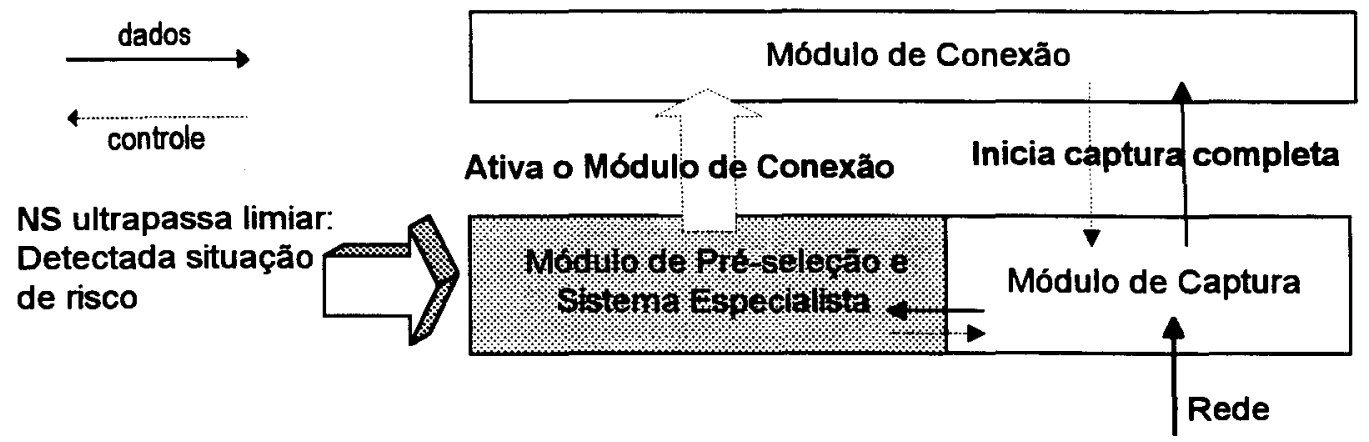

Figura 5.2 - Ativação do Módulo de Conexão pelo módulo Pré-seleção

Os valores de TI e TF são utilizados para se proceder a análise periódica e cíclica da tabela. Desta maneira, alguns eventos são removidos após um determinado tempo de vida, uma vez que não mais representem risco. Por razões de sigilo da implementação, já que se tratam fatores críticos do mecanismo de detecção, os tempos e a metodologia utilizada na verificação cíclica, bem como o limiar de NS adotado, não são discutidos explicitamente aqui. Informações adicionais podem ser obtidas diretamente com o autor.

\subsection{O módulo de conexão}

\subsubsection{Características gerais}

Quando o módulo de conexão recebe um sinal do módulo de pré-seleção, cria uma entrada em sua tabela de domínio suspeitos, onde encontram-se listados todos os 
endereços de computadores e redes que representem riscos em potencial. Em seguida, 0 módulo de conexão faz uma solicitação ao módulo de captura, para receber uma cópia de todos os pacotes vindos dos domínios que possuem entrada nessa tabela. $\mathrm{O}$ módulo passa a criar os vetores de conexão, ou seja, o mapeamento dos dados bidirecionais de uma conexão em particular. $\mathrm{O}$ módulo de conexão, foi inicialmente implementado em conjunto com o módulo de pré-seleção e captura. Depois, foi transformado em um processo independente dentro do sistema.

Na implementação atual, uma entrada só é retirada da tabela de domínios suspeitos quando a sessão termina, ou até que o módulo de pré-seleção, ao fazer as verificações cíclicas, decida que os eventos não são mais suspeitos. Há a intenção que o resultado obtido pela rede neural, sob o nível de suspeita de uma sessão em particular, também possa eliminar entradas da tabela de domínios suspeitos no módulo de conexão, interrompendo assim a captura de pacotes provenientes de sessões diagnosticadas como não intrusivas. Entretanto esse tratamento, ainda não foi adotado.

\subsubsection{Mapeamento dos dados}

O vetor de conexão é copiado em uma unidade de saída. Antes do mapeamento dos dados, o módulo de conexão gera um registro que contém, nesta ordem, tipo dos pacotes da sessão (se TCP, UDP ou ICMP), endereço IP da máquina origem, seguido da porta da máquina origem, e endereço IP da máquina destino, seguido da porta de destino. Estas informações são precedidas e finalizadas por alguns caracteres especiais (no caso estes caracteres são o string :::::::::::::: ), que serão utilizados pelo módulo analisador semântico. O uso desses caracteres será discutido mais adiante. Dessa forma, o identificador da sessão é escrito da seguinte maneira:

:::::::::::::::

protocolo:IPorigem-PortaOrigem _ IPdestino-PortaDestino ::::::::::::::

Por exemplo, considerando-se uma sessão em protocolo TCP da porta 1899 da máquina 143.107.228.1 (origem) para a máquina 200.17.28.8 (destino) na porta 21 (uma sessão FTP), teríamos um registro identificador de sessão inicial, da seguinte forma: 
TCP : 143.107.228.1-1899_200.17.28.8-21

::::::::::::::

Em seguida, os dados da sessão em ambos os sentidos são copiados. Como o vetor de conexão é um mapeamento seqüencial dos dados de uma sessão, é necessário demarcar de onde vem cada grupo de caracteres, ou seja, indicar quais grupos de caracteres são provenientes da origem ou do destino da sessão. Optou-se por preceder cada porção de fluxo de dados com dois pequenos marcadores (flags) que indicassem este sentido: SADI) e SADI( . Estes marcadores, que garantidamente não fazem parte de assinaturas de ataque, significam:

- SADI) : Os dados que seguem este marcador são provenientes do originador da sessão. Seguindo o exemplo a seguir, estes dados viriam de 143.107.228.1

- SADI ( : Os dados que seguem este marcador são provenientes do destino da sessão, no exemplo a seguir, vindos de 200.17.28.8

Assim teríamos:

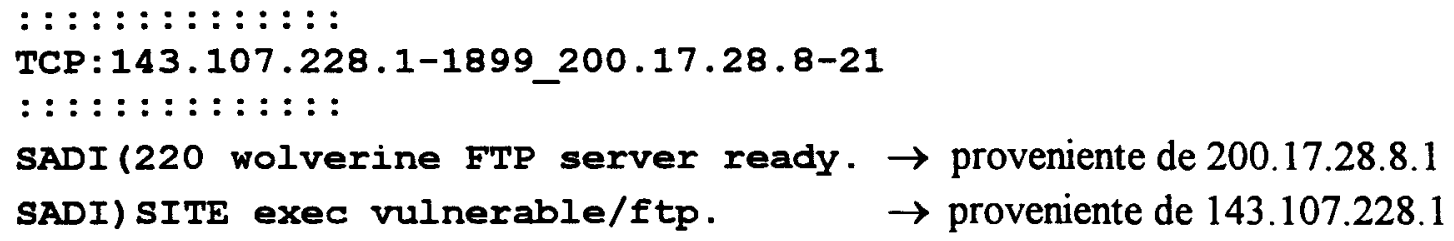

Como exemplo, considere o mapeamento do fluxo de dados de uma sessão FTP real, apresentada a seguir. Esta captura é característica de uma tentativa de intrusão, e foi obtida pelo módulo de conexão, utilizando apropriadamente o módulo de captura. $O$ marcador SADI), indica que os dados a seguir são provenientes de 143.107.228.1 (porta 1899) e o marcador SADI( indica dados provenientes de 200.17.28.8 (porta 21). 
$:::::::::::::$

TCP : 143.107.228.1-1899_200.17.28.8-21

$:::::::::::::::$ :

SADI (220 wolverine FTP server ready.

SADI) SITE exec vulnerable/ftp.

SADI (500 'SITE EXEC vulnerable/ftp': command not understood..

SADI) USER anONYMous.

SADI (331 Guest login ok, send e-mail address as password.

SADI (530 Please login with USER and PASS..

SADI) PASS -intrusolalgum. lugar.br.

SADI (230 Guest login ok, access restrictions apply..

SADI) PWD.

SADI (257 "/" is current directory..

SADI) MKD teste

SADI (550 teste: Permission denied. .

SADI) RMD teste

SADI(550 teste: No such file or directory..

SADI) LIST -Rlag.

SADI (150 Opening ASCII mode data connection for $/ \mathrm{bin} / \mathrm{ls}$.

SADI (226 Transfer complete. .

SADI) QUIT .

SADI $(221$ Goodbye. .

Este registro é, em essência, uma assinatura de ataque, que contém todo o desenrolar do comportamento de uma sessão suspeita. Entretanto, como há muitas informações desnecessárias, procede-se a uma redução desses dados, passando-os para um analisador semântico. É este analisador que irá filtrá-los, buscando pelos componentes principais das assinaturas de ataque, para finalmente produzir um vetor binário que traduz este comportamento suspeito, e que será interpretado pela rede neural.

O administrador possui ainda, a opção de determinar que o módulo de conexão, além de enviar dados para o analisador semântico, também faça um registro em disco de todas as sessões completas que estão sob monitoramento. Isto é útil para uma análise posterior dos eventos, para captura de evidências sobre atos ilícitos, ou mesmo para realizar estudos sobre o comportamento intrusivo. Neste caso, o módulo de conexão está apto a gerar um arquivo para cada evento capturado, e que contém toda a transcrição do fluxo de dados. Entretanto a aplicação principal deste recurso é possibilitar ao administrador capturar e analisar novos tipos de ataque, que poderão ser codificados e anexados ao analisador semântico, para obtenção de novas assinaturas de ataque. Essas 
assinaturas, por sua vez, podem ser utilizadas para re-treinar a rede neural, conferindo o poder de adaptabilidade a novos comportamentos intrusivos.

\subsection{0 analisador semântico e pós-processador}

\subsubsection{Características gerais}

O analisador semântico, trata-se de um sistema de reconhecimento e codificação de strings, e foi desenvolvido por José Maurício Bonifácio Jr. ${ }^{1}$, colaborador do projeto. A função básica deste módulo, é reconhecer componentes das assinaturas de ataque préestabelecidas, encontradas numa porção de texto, bem como identificar: que tipo de sessão se trata (TCP, UDP, ICMP), as portas envolvidas, o início e fim da sessão, e em que sentido está indo o string da assinatura reconhecida, com relação ao fluxo de dados (se do host $A$ para o host $B$ ou vice-versa). A entrada deste módulo é um registro de dados, gerado pelo módulo de sessão conforme discutido anteriormente. $\mathrm{O}$ analisador interpretará os grupos de caracteres de controle utilizados e os dados trafegados.

A codificação das assinaturas em binário, é feita através de um código decimal intermediário. Este código é um número inteiro positivo menor que 30000. Valores acima estão reservados para reconhecer inícios e finais de sessão, tipo de sessão, dentre outras operações de controle. Existe então, uma segunda tabela que mapeia estes códigos decimais em códigos binários (Figura 5.3). Todo este processo é feito visando uma maior simplicidade e independência das seções do módulo, facilitando inserções de novas assinaturas. Seguindo este raciocínio, é possível haver vários códigos inteiros que significariam perfis parecidos (por exemplo os strings /etc/passwd e /etc/shadow) e que poderiam possuir códigos binários iguais, porém, em alguma circunstância especial, poderiam ser diferenciados. A codificação das assinaturas e seus componentes, bem como a sua relação com a adaptabilidade do modelo, serão discutidos detalhadamente, mais adiante, neste capítulo.

\footnotetext{
${ }^{1}$ E-mail: boni@icmsc.sc.usp.br
} 


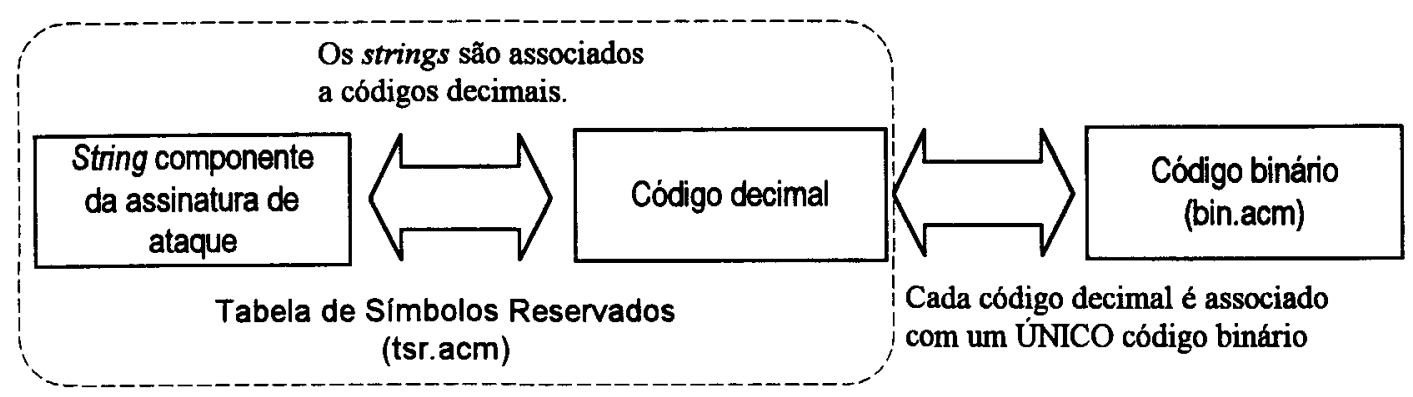

Figura 5.3 - Associação da Tabela de Símbolos Reservados com os valores binários

$\mathrm{O}$ arquivo de dados que contém os strings das assinaturas (tsr.acm), é composto da seguinte forma: a primeira linha contém um inteiro indicando quantos registros existem, e depois linha por linha, um inteiro, que é o código decimal, seguido do string componente da assinatura, de tamanho até 35 caracteres. Este arquivo é chamado de Tabela de Símbolos Reservados (TSR). Há ainda outro arquivo que codifica inteiros em binários (bin.acm), e contém um código inteiro o seu respectivo código binário, podendo mais de um código inteiro ser associado ao mesmo código binário, identificando strings semelhantes (o APÊNCICE B apresenta um trecho dos arquivos tsr.acm e bin.acm utilizados atualmente pelo SADI). Os strings das assinaturas, e seus respectivos códigos decimais e binários associados, são lidos e armazenadas numa tabela hash, uma única vez quando o módulo é carregado.

A função de busca na tabela hash retorna um código que indica se foi encontrada a assinatura completa, se o parâmetro passado é o início de uma assinatura válida, ou se há mais de uma ocorrência nas assinaturas válidas. Por exemplo, ao se procurar por login pode existir login root e login failure, ou apenas login, ou ainda não encontrar nada.

\subsubsection{Sub-módulo de reconhecimento de assinaturas}

Numa fase inicial, foi desenvolvido um autômato finito simples que percorre os caracteres, palavra por palavra, procurando-as na relação de componentes das assinaturas. $\mathrm{O}$ autômato foi incrementado para que tratasse outros casos, uma vez que as assinaturas podem ser constituídas por mais de uma palavra separada por espaço, ou ainda por outros caracteres como ( ) , : : / Estes caracteres, juntamente com o espaço em branco, podem tanto ser separadores como estarem inclusos entre os componentes das assinaturas. 
O autômato separa cada palavra do texto até encontrar algo que não seja letra ou dígito. Ao se encontrar um caractere diferente de letra ou dígito, identifica-se uma palavra. Esta palavra, que pode ser um componente da assinatura, é procurada nos dados da TSR. Se for encontrada completa, ela é imediatamente identificada e devolvida por este sub-módulo. Se o que está sendo procurado é o início de um ou mais componentes presentes na TSR (e.g. foi localizado login e na TSR há login root), armazena-se o início da segunda palavra, e continua separando-a, sem perder o início da primeira, de forma que possa tentar identificar as duas juntas. Este procedimento ocorre enquanto o que estiver sido localizado constituir o início de alguma assinatura válida. Isto é necessário pois, como mencionado, os componentes das assinaturas podem possuir um número indefinido de palavras ( e.g. o componente: sleep 2 ; echo quit).

Caso não encontre mais nada presente na TSR, retorna ao início da segunda palavra e começa a procurar de novo, isto é feito pois pode haver situações do tipo: na TSR existe sleep 2 ; echo quit e echo undefined e no texto encontra-se sleep 2 ; echo undefined. Neste caso o autômato tentaria localizar na TSR, um a um, os seguintes strings:

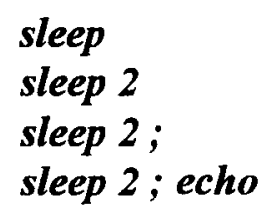

Entretanto sleep 2 ; echo undefined não é encontrado na TSR, pois não é componente de assinaturas de ataque. Então retorna-se ao início da segunda palavra, que no exemplo é o string “2", que por sua vez também não será encontrado sozinho na TSR. E assim sucessivamente até identificar todos os componentes presentes.

Com a experiência obtida no primeiro modelo, foi feito um segundo, mais otimizado e geral. O novo analisador, diferentemente do anterior, é implementado por inteiro como um autômato finito, ao invés de um autômato simples adicionado de "ifs" e "cases" para tratar os casos especiais (caracteres separadores que podem fazer parte da assinatura, e assinaturas com múltiplas palavras). Com isso foi obtido um autômato 
mais simples e mais genérico, abrangendo um número maior de casos possíveis, que não foram propostos na especificação de requisitos iniciais, mas que poderão ocorrer futuramente, devido a natureza mutante das assinaturas. Além disso, o novo modelo tratou alguns casos que passaram despercebidos ao anterior. Para uma discussão mais detalhada do autômato finito utilizado, consulte o APÊNDICE A.

\subsubsection{Sub-módulo de codificação binária}

Nem todos os símbolos encontrados são convertidos em binários. Existem ainda conjuntos de caracteres de controle, que foram codificados com valores entre 30000 e 30050, como por exemplo os marcadores :::::::::::::, SADI( e SADI). Estes casos são tratados separadamente.

No cabeçalho do registro da captura de dados encontram-se as informações sobre o tipo de protocolo, endereços IP e portas envolvidas, e essas informações necessitam ser codificadas. Por exemplo, quando um conjunto de caracteres :::::::::::::: é encontrado seguido de um código que indica o tipo de sessão (TCP, UDP, ICMP), ativase uma função que separa as portas envolvidas dos endereços IP. Assim ao encontrar o string TCP:200.17.28.3-21_200.17.28.8-34410, este deve ser separado em 21 e 34410. Este procedimento é adotado, para codificar as portas envolvidas. Os marcadores SADI( e SADI) podem ser usados para diferenciar determinados bits dos códigos binários dos strings componentes das assinaturas de ataque, de modo a indicar o sentido do fluxo de dados da sessão.

$\mathrm{O}$ analisador continua percorrendo o vetor de conexão identificando os strings presentes nos dados registrados pela captura. Ao encontrar um string que faça parte da TSR, seu correspondente valor decimal é armazenado num vetor, para posterior inserção do seu correspondente código binário. Assim, é obtido um conjunto de códigos binários, que será a entrada da rede neural, que por sua vez retorna um valor indicando $o$ quão suspeita é esta sessão. A Figura 5.4 apresenta um esquema do processo de transformação dos strings encontrados nas capturas em binários. 
Componentes das assinaturas

\begin{tabular}{|c|c|c|c|c|}
\hline mail from "I & /bin/mail & $</$ etc/passwd & rept to: nobody & $</$ etc/passwd \\
\hline \multicolumn{5}{|c|}{ Código decimal correspondente } \\
\hline 19 & 61 & 29 & 35 & 29 \\
\hline \multicolumn{5}{|c|}{ Código binário correspondente } \\
\hline 101011111001 & 011100111101 & 101010001000 & 000000110110 & 101010001000 \\
\hline
\end{tabular}

Figura 5.4 - Exemplo do esquema de codificação das assinaturas

\subsubsection{Esquemas de codificação das assinaturas para código binário}

A codificação dos conjuntos de caracteres suspeitos das assinaturas em códigos binários, descrita anteriormente, merece especial atenção. A forma de codificação é um importante aspecto no desenvolvimento e treinamento de redes neurais. Uma codificação bem estruturada pode levar a um ganho de rendimento tanto no treinamento, quanto na proporção de acertos que a rede apresentará. Uma codificação mal escolhida pode levar a rede a confundir padrões diferentes entre si, o que acarreta em um maior tempo de treinamento para que a rede consiga identificar os padrões corretamente. Além disso afetará na taxa de acertos que a rede apresenta, uma vez que sua capacidade de abstração pode ser prejudicada, ao ser exposta a um padrão novo tendo de classificá-lo em uma das classes treinadas. Será feito agora um estudo das técnicas propostas, abordando seus prós e contras.

A primeira técnica analisada, baseia-se na atribuição de um código binário diferente a cada componente distinto das assinaturas. Para as assinaturas que possuissem funções parecidas, ou que fossem variações de uma mesma assinatura, haveria códigos binários parecidos, de tal forma que a rede neural pudesse reconhecê-los como sendo mais semelhantes entre si do que com outras assinaturas. Isso é importante para o treinamento da rede neural.

Considerando como exemplo os strings letc/passwd e letc/shadow, que se referem a arquivos de senhas, e estão presentes em diversos cenários de ataque. Neste caso, as duas strings possuiriam valores binários parecidos. Por exemplo ${ }^{1}$ :

\footnotetext{
${ }^{1}$ Os códigos binários, associados com os componentes das assinaturas, que aparecem nessa seção são apenas ilustrativos, e não se tratam das codificações exatas adotadas pelo sistema.
} 


\section{/etc/passwd $\quad 0100100111$ \\ letc/shadow $\quad 0000101111$}

Neste exemplo, pode-se notar que ambos possuem apenas dois bits diferentes, e a rede aprenderia facilmente esta semelhança.

Esta abordagem, embora pareça interessante, acarreta certos problemas. A codificação inteira teria de ser feita manualmente, ou seja, seria necessário atribuir manualmente os códigos binários a cada tipo de assinatura diferente. Um problema encontrado neste método, é a possibilidade de se incorrer em erro, gerando duas assinaturas totalmente diferentes com códigos binários parecidos. Este procedimento gera outro problema: a cada novo comportamento intrusivo, seria necessário associar manualmente códigos binários aos strings componentes do novo ataque, fazendo-se as devidas verificações com relação às assinaturas já existentes. Isso compromete uma das requisições do sistema, que é a facilidade de adaptabilidade à identificação e codificação de novos ataques.

A segunda abordagem considerada, foi utilizar um pequeno programa de maneira a se produzir cada novo código, diferindo de todos os outros em no mínimo metade dos bits, ou seja, cada código poderia possuir, no máximo, metade de seus bits iguais a qualquer outro código existente. Isto resolve o problema da adaptabilidade, uma vez que não seria mais necessário associar os códigos manualmente, e novos códigos poderiam ser facilmente gerados automaticamente. Entretanto ainda, existe um problema. Considere a seguinte situação:

$\begin{array}{lllllllllll}\text { /etc/passwd } & 0 & 0 & 0 & 0 & 0 & 1 & 1 & 1 & 1 & 1 \\ \text { /etc/shadow } & 1 & 1 & 1 & 1 & 1 & 0 & 0 & 0 & 0 & 0 \\ \text { password incorrect } & 1 & 1 & 1 & 1 & 1 & 1 & 1 & 1 & 1 & 1\end{array}$

Se os códigos são atribuídos automaticamente, esta situação é totalmente factível de ocorrer. As duas primeiras strings, que são parecidas, e que deveriam ser codificadas de maneira semelhante (ou talvez igual), possuem códigos binários que as diferem em $50 \%$ uma da outra. Por outro lado, como todas as 3 diferem entre si por 5 bits seqüenciais, as 2 primeiras acabam se tornando parecidas com a última, o que não deveria ocorrer. Isso acontece em função da maneira como age a aprendizagem da rede neural, que tem características fortemente seqüenciais. A rede neural apresenta uma dada 
interpretação de aprendizagem para dois códigos binários que sejam diferentes entre si por metade de seus bits distribuídos aleatoriamente, e considera estes padrões como completamente distintos. Se os códigos forem diferentes entre si pelos mesmos 5 bits, mas que estejam dispostos numa seqüência como mostrada no exemplo acima, a interpretação adotada pela rede neural é outra, e os padrões podem ser considerados como semelhantes.

A terceira alternativa consiste, de se ter todos os códigos binários igualmente distantes qualitativamente, ou seja, cada código é diferente de todos os outros códigos em um número fixo de bits. Isso garante que todos os códigos são igualmente diferentes de todos os outros. A codificação de strings componentes semelhantes é resolvida fazendo-se com que elas tenham códigos decimais iguais, de forma que não há um código para cada string, mas sim um código para cada grupo de strings semelhantes. Este esquema exige uma quantidade maior de códigos binários, o que implica que cada código deverá possuir uma quantidade de bits maior do que nos outros esquemas, entretanto essa codificação é mais amigável, além de facilitar a inserção e codificação de novos padrões de ataque.

Um exemplo desta alternativa, em que cada código de 10 bits difere dos outros em 2 bits, é o seguinte:

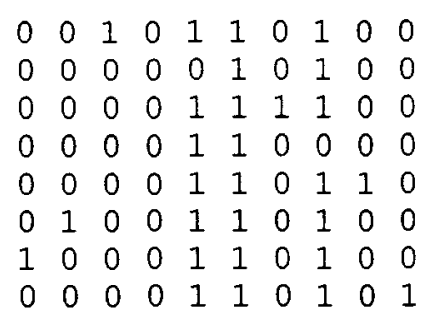

Todas as alternativas interferem de um modo ou de outro no rendimento e futura adaptabilidade da rede neural. Pelas discussões, problemas levantados e testes efetuados, optamos por adotar esta terceira e última alternativa, e desenvolvemos um programa assistente para gerar uma codificação binária na qual o usuário pode determinar quantos bits usar para a codificação, e em no mínimo quantos bits cada código deve diferir dos demais. Este programa é descrito a seguir. 


\subsubsection{O Assistente Adaptativo de Inserção de Assinaturas}

Em nossa implementação atual, a associação dos strings relevantes com os códigos inteiros na TSR, foi realizada com auxílio de um programa denominado Assistente Adaptativo de Inserção de Assinaturas (AAIA), desenvolvido para esta finalidade. Este programa lê num dispositivo de entrada os novos strings componentes de uma assinatura de ataque, e verifica se cada um dos novos strings a serem inseridos já não está associado com um valor decimal na tabela de símbolos reservados, ou seja, no arquivo tsr.acm. Além disso, apresenta os strings já anteriormente associados, permitindo que o administrador tenha a opção de associar strings semelhantes com o mesmo código decimal, representando um mesmo comportamento.

O AAIA pode ainda gerar uma combinação de código binário e, automaticamente, associar cada código com um único decimal, formando o arquivo bin.acm, discutido na seção 5.5.3. Para isso basta que o administrador especifique qual o tamanho em bits desejado para cada código, e por quantos bits cada código deve diferir, no mínimo, de todos os outros. Esse tratamento fornece uma grande independência entre os strings e a codificação binária, pois permite modificar facilmente os códigos binários associados, por exemplo, aumentando ou diminuindo a quantidade de bits utilizados, sem que para isso seja necessário qualquer modificação na codificação dos strings. Além disso também possibilita o crescimento do número de strings codificados, sem necessidade de modificações no código dos sub-módulos do analisador semântico.

Feita a codificação dos strings componentes de um novo comportamento intrusivo, o administrador pode utilizar o AAIA para transformar uma assinatura de ataque, capturada ou fornecida por órgãos de segurança, e codificá-la num vetor binário no formato que a rede neural possa interpretar no processo de aprendizagem. Para isso, o próprio AAIA conta com as mesmas características do analisador semântico, de maneira a transformar um conjunto de caracteres, fornecido num dispositivo de entrada, e codificá-lo com base na TSR, produzindo assim o vetor binário representante da assinatura. Este vetor binário pode então ser utilizado no re-treinamento da rede neural, para refletir o novo comportamento intrusivo. 
A idéia fundamental no desenvolvimento do AAIA foi fornecer ao administrador um mecanismo simples, rápido e flexível para codificar novos padrões de ataque, garantindo a adaptabilidade do sistema.

\subsection{O simulador de rede neural}

\subsubsection{Características gerais}

O interesse fundamental neste trabalho é testar a possibilidade de utilização do modelo proposto, como um método efetivo de detecção de intrusão. Deseja-se verificar se uma rede neural pode ser treinada com nosso modelo e, após o treinamento, passar a identificar corretamente o comportamento intrusivo em um conjunto de padrões capturado da rede. Dessa forma, optou-se por utilizar um simulador de rede neural, ao invés de se desenvolver um sistema de rede neural. Esta escolha visa facilitar e otimizar o trabalho com redes neurais, permitindo assim que os esforços fossem voltados para o estudo do comportamento intrusivo. Optou-se por um simulador de rede neural, de domínio público e de uso gratuito. Foram considerados alguns fatores, tais como:

- Suporta vários tipos de arquiteturas de redes, e possibilidades de treinamento.

- Possui uma interface gráfica amigável e portabilidade; e

- Possibilita a geração de um código em linguagem $C$, que implemente a rede, independentemente do simulador. Assim esse código poderia ser anexado ao sistema detector de intrusão.

Com base nestes requisitos, o simulador escolhido foi o Stuttgart Neural Network Simulator (SNNS) ${ }^{1}$. Outros simuladores considerados e analisados foram o GENESIS V.2.0 (General Neural Simulation System) ${ }^{2}$ e o Aspirin/MIGRAINES V.6.0 $0^{3}$.

O SNNS, versão 4.1, é um simulador de domínio público, desenvolvido pela Universidade de Stuttgart, e destinado a criar um ambiente eficiente e flexível para pesquisa e aplicação de redes neurais.

\footnotetext{
${ }^{1}$ O SNNS é disponível por FTP anônimo em ftp://ftp.informatik.uni-stuttgart.de/pub/SNNS

${ }^{2}$ Disponivel em ftp://genesis.bbb.caltech.edu/pub/genesis

${ }^{3}$ Disponível em ftp://pt.cs.cmu.edu/afs/cs/project/connect/
} 
Este simulador trata os neurônios como unidades simples com conexões entre si Cada unidade recebe um vetor entrada da rede que é saída das unidades de uma camada anterior. O tipo de cada unidade no simulador é determinado pela função de ativação e função de saída. O simulador é formado por diversos módulos que permitem realizar operações específicas na rede neural, nos arquivos ou nos gráficos produzidos, dentre outros recursos.

O funcionamento e operação é baseado numa interface gráfica, executada sobre ambiente $X$-Windows em sistema operacional Solaris 2.5. O usuário pode definir, criar e manipular redes neurais em diversas arquiteturas, e manipular conjuntos de dados facilmente, além de realizar definições e modificações dos processos de aprendizagem. Os processos de treinamento e validação podem ser acompanhados, em tempo real, através da visualização de gráficos que apresentam a evolução do erro cometido. Também existem opções que permitem imprimir e visualizar a estrutura da rede neural e dos pesos utilizados no processo de treinamento.

Por ser um assunto muito vasto, os diversos recursos disponíveis pelo SNNS não serão apresentados aqui, em sua totalidade. A seguir, é realizada uma explanação geral sobre a interface principal, que permite controlar a rede neural durante o processo de aprendizagem e testes. Também são relacionadas algumas características básicas do SNNS, importantes para o desenvolvimento deste trabalho. As discussões que seguem são baseadas na referência [DMC97], a qual deve ser consultada para uma melhor compreensão das funcionalidades do simulador.

\subsubsection{O controle da rede neural no SNNS}

As operações que o simulador pode realizar com a rede neural são controladas pelo Painel de Controle (Control Panel). Podem ser controlados a inicialização dos pesos da rede, o aprendizado, a atualização e validação, e os testes, dentre outras opções. Uma captura de tela do painel de controle é mostrada na Figura 5.5. 


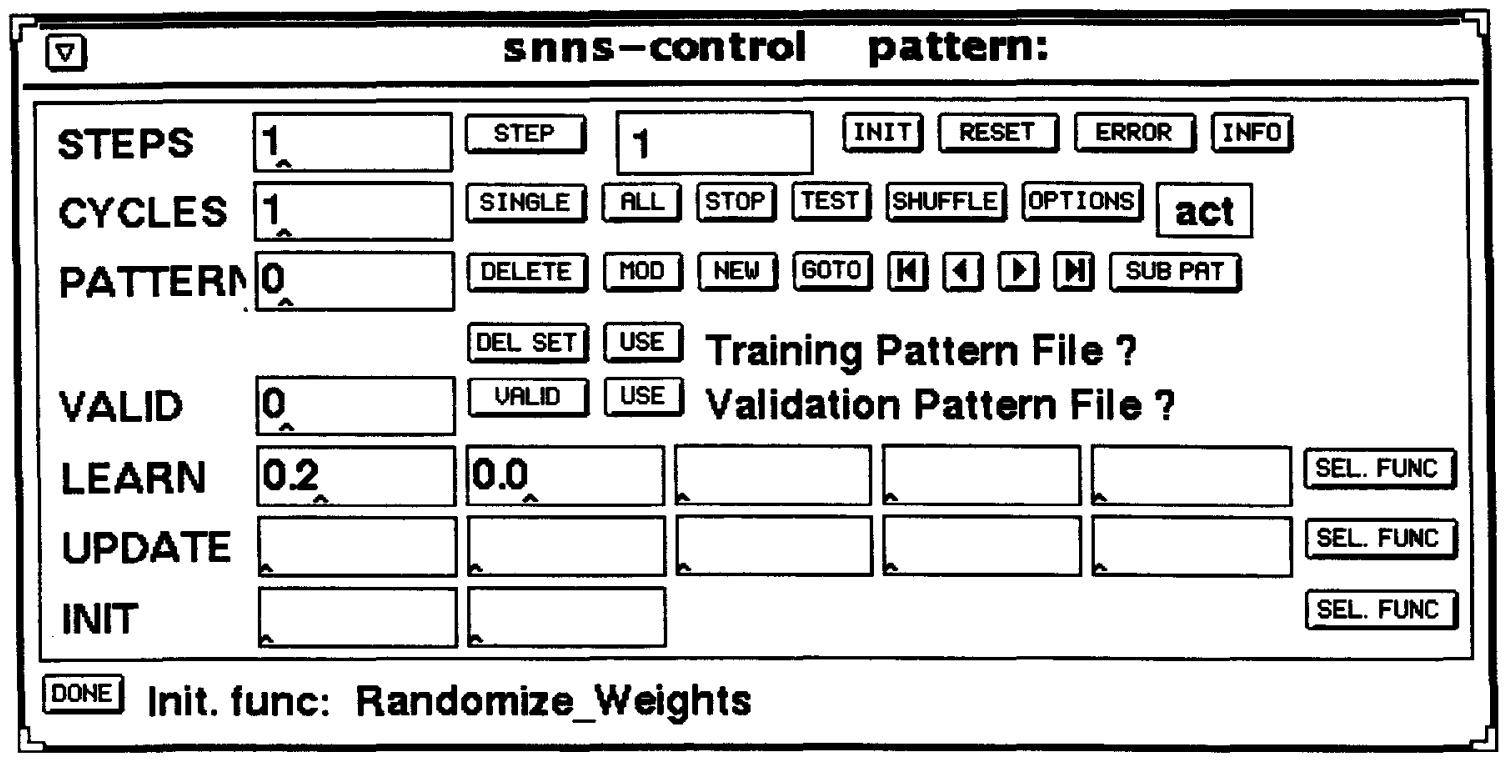

Figura 5.5 - Painel de controle do SNNS

Os recursos mais importantes deste painel, estão relacionados com a seção que controla a aprendizagem. Esta seção é composta por:

- Um campo de texto CYCLES, que especifica o número de ciclos de aprendizagem.

- Um botão SINGLE, que provoca o treinamento da rede com um único padrão para o número de ciclos definido em CYCLES. A janela de texto do simulador (não reproduzida aqui) relata o erro a cada CYCLES/10 ciclos. O erro é o somatório da diferença quadrática entre a saída real e a esperada pela rede, sobre todas as unidades de saída.

- Um botão $A L L$, que provoca o treinamento da rede com todos os padrões para o número de ciclos definido em CYCLES. O erro é o somatório da diferença quadrática entre a saída real e a esperada pela rede, sobre todas as unidades de saída somada sobre o número de padrões apresentados.

- Um botão STOP, que interrompe o ciclo de treinamento.

- Um botão TEST, que permite testar a performance da rede com todos os padrões utilizados no treinamento. Os valores de ativação das unidades de entrada e saída são copiados na rede. Depois, o número de passos de atualização especificados em STEPS são executados. 
- Um botão SHUFFLE para otimizar aprendizagem, fazendo vários padrões serem apresentados em diferentes ordens, em ciclos distintos. Uma seqüência randômica de padrões é criada automaticamente quando este botão é pressionado.

Outros controles, relacionados com a manipulação dos padrões no treinamento, também são de interesse:

- O campo de texto PATTERN, que mostra o número de seqüência do padrão corrente.

- O botão USE, que abre um menu com os padrões carregados a partir do gerenciador de arquivos de SNNS. O conjunto de padrões selecionado passa a ser o conjunto corrente.

- O campo CURRENT PATTERN SET que mostra o nome do conjunto de padrões de treinamento em uso. Quando não há nenhum, é mostrado a mensagem "Training Pattern File?".

Existe ainda um controle relacionado com a validação do conjunto de padrões durante o processo de aprendizagem. Este é formado principalmente por:

- O campo $V A L I D$, é utilizado para especificar o número de ciclos no qual o processo de treinamento é interrompido, para realizar a validação. $O$ valor zero inibe a validação. $O$ erro de validação é impresso e mostrado numa saída gráfica.

- Outro botão USE, com a mesma função citada acima.

- O campo VALIDATON PATTERN SET, que apresenta o nome do conjunto de padrões de validação atualmente utilizado. Quando não há nenhum, apresenta a mensagem "Validation Pattern File?".

- O botão SEL FUNC, que invoca um menu para selecionar a função de aprendizagem (procedimento de treinamento).

\subsubsection{Inserindo conjuntos de dados no SNNS}

O SNNS pode manipular conjuntos de dados de tamanhos fixos ou variáveis. Esses dados são os conjuntos utilizados nos procedimentos de aprendizagem e testes do 
simulador. Os dados são inseridos a partir de arquivos texto, obedecendo a uma gramática particular do simulador, com determinados caracteres e expressões de controle. Essa gramática não será discutida detalhadamente aqui, entretanto apresentamos abaixo um exemplo de arquivo de entrada de padrões. $O$ arquivo é constituído de um cabeçalho com informações sobre os padrões e, em seguida, aparecem os dados binários que representam os padrões.

O exemplo logo a seguir, retirado da referência [DMC97], trata-se de um conjunto de padrões de treinamento para uma rede neural resolver o problema de lógica $X O R$. O "padrão de entrada" (Input pattern) identifica o padrão que a rede deve reconhecer, e o "padrão de saída" (Output pattern) instrui à rede como ela deve responder àquele padrão. São utilizados quatro padrões para um rede com duas unidades (neurônios) de entrada e uma unidade de saída. Os dados que aparecem após "\#” são comentários. O padrão de entrada é sempre seguido do respectivo padrão de saída, sendo ambos codificados em binários.

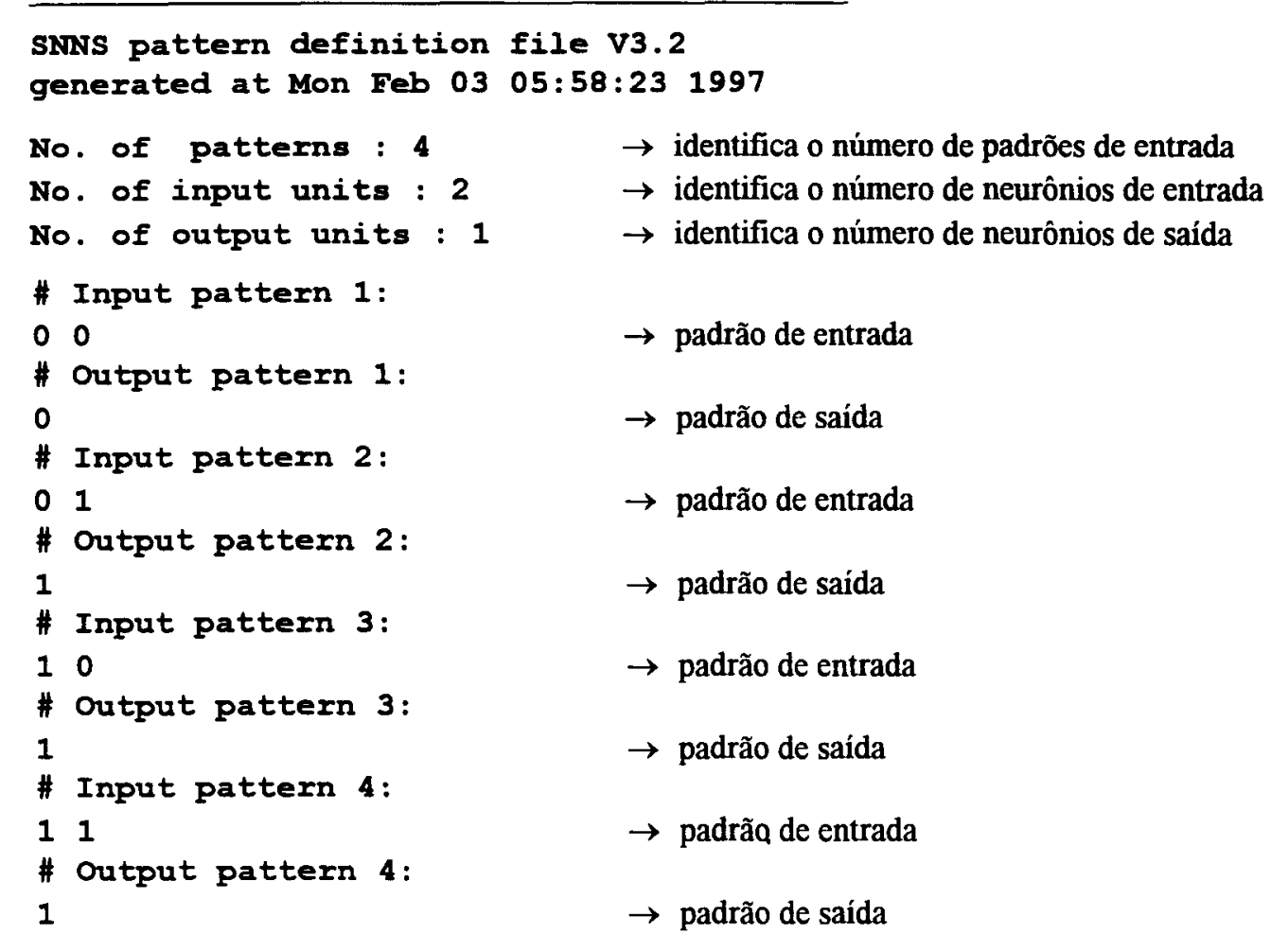




\subsubsection{Saída de resultados do SNNS}

A partir dos procedimentos de aprendizagem, e baseando-se na função de ativação escolhida, quando o simulador recebe um padrão para análise, ele responde com um valor real variando entre 0,0 e 1,0 . Isso acontece tanto para os dados de treinamento e validação, quanto para os dados de teste. Durante o treinamento e validação, os resultados determinados pela rede neural são comparados com os resultados prédefinidos para os padrões utilizados. Assim, calcula-se o erro cometido pela rede, conforme discutido na seção 3.3.5. O comportamento do erro é um indicativo importante do correto funcionamento do processo de aprendizagem. Além disso, o erro cometido sobre um conjunto de testes, com o qual a rede não teve contato durante a fase de aprendizagem, indica como está se comportando a capacidade de generalização da rede.

No sistema proposto, o valor real emitido pela rede para um determinado comportamento indica o nível de suspeita daquele conjunto de dados capturados. Quanto mais próximo de 1 , mais a sessão se aproxima de um comportamento intrusivo.

\subsubsection{Monitoração do processo de aprendizagem}

Ao iniciar o processo de aprendizagem, o usuário pode solicitar que o simulador construa um gráfico do erro em função dos ciclos, tanto para o conjunto de dados treinamento como de validação anteriormente mencionados. Este gráfico, cujo exemplo encontra-se reproduzido na Figura 5.6, é fundamental para avaliar se a rede está sendo corretamente treinada e se o processo de generalização está ocorrendo satisfatoriamente. A linha tracejada é referente à validação, e a contínua é referente ao treinamento. 


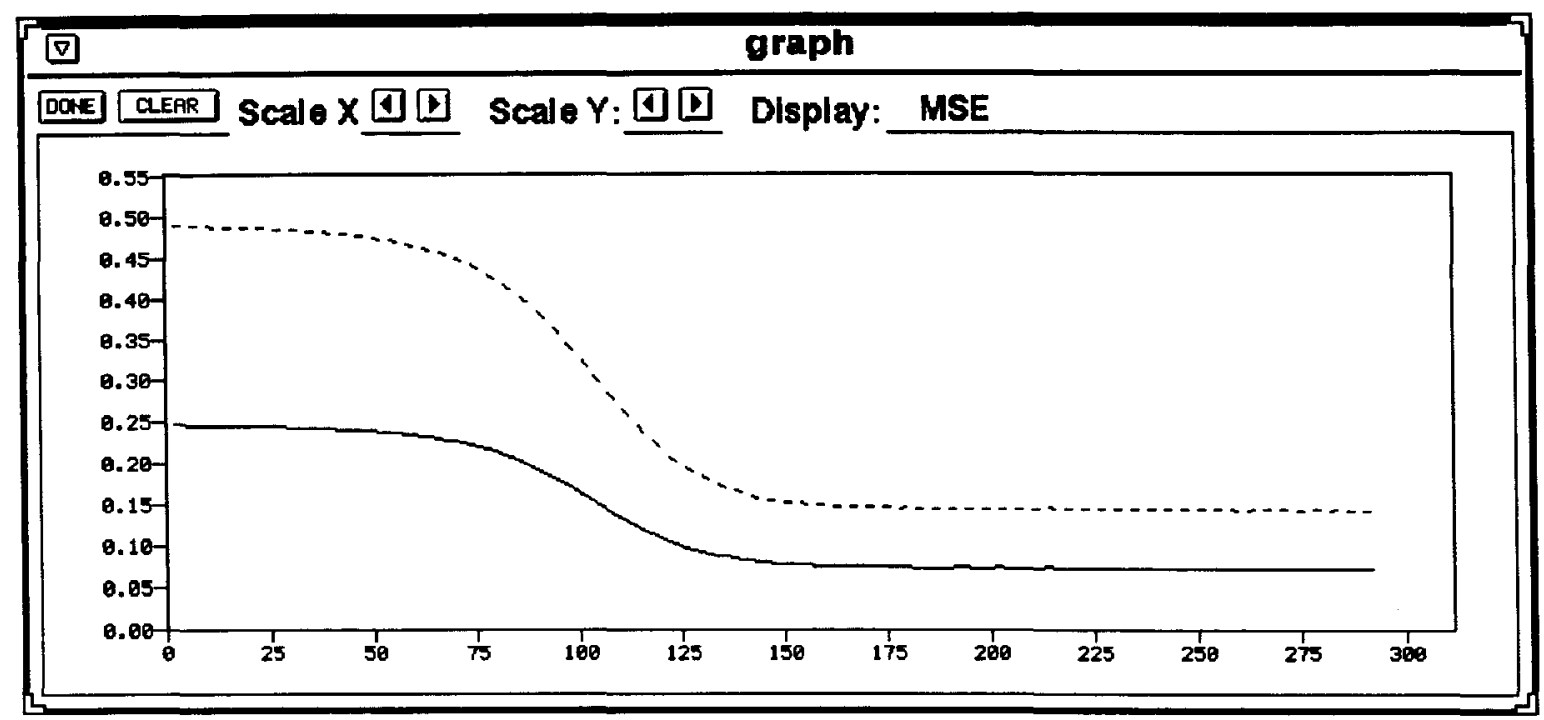

Figura 5.6 - Reprodução de uma tela do gráfico do erro cometido pela rede neural

Após a realização de alguns testes, certificou-se que este simulador atende todas as necessidades do SADI. Uma vez que a programação e manipulação de uma rede neural, do início da sua aprendizagem até o final dos testes, é uma tarefa complexa, o uso desse simulador permite diminuir os esforços de implementação, possibilitando centralizar esforços no problema da captura, definição e codificação dos padrões, e na detecção do comportamento intrusivo.

\subsection{Resumo do fluxo de informações}

Finalizando este capítulo, é apresentada a Figura 5.7, que mostra o fluxo simplificado de informações tratadas pelo SADI, desde a captura e verificação inicial de pacotes, passando pelo módulo de conexão e pelo analisador semântico, até a posterior codificação dos strings num código binário que é enviado para a rede neural. 


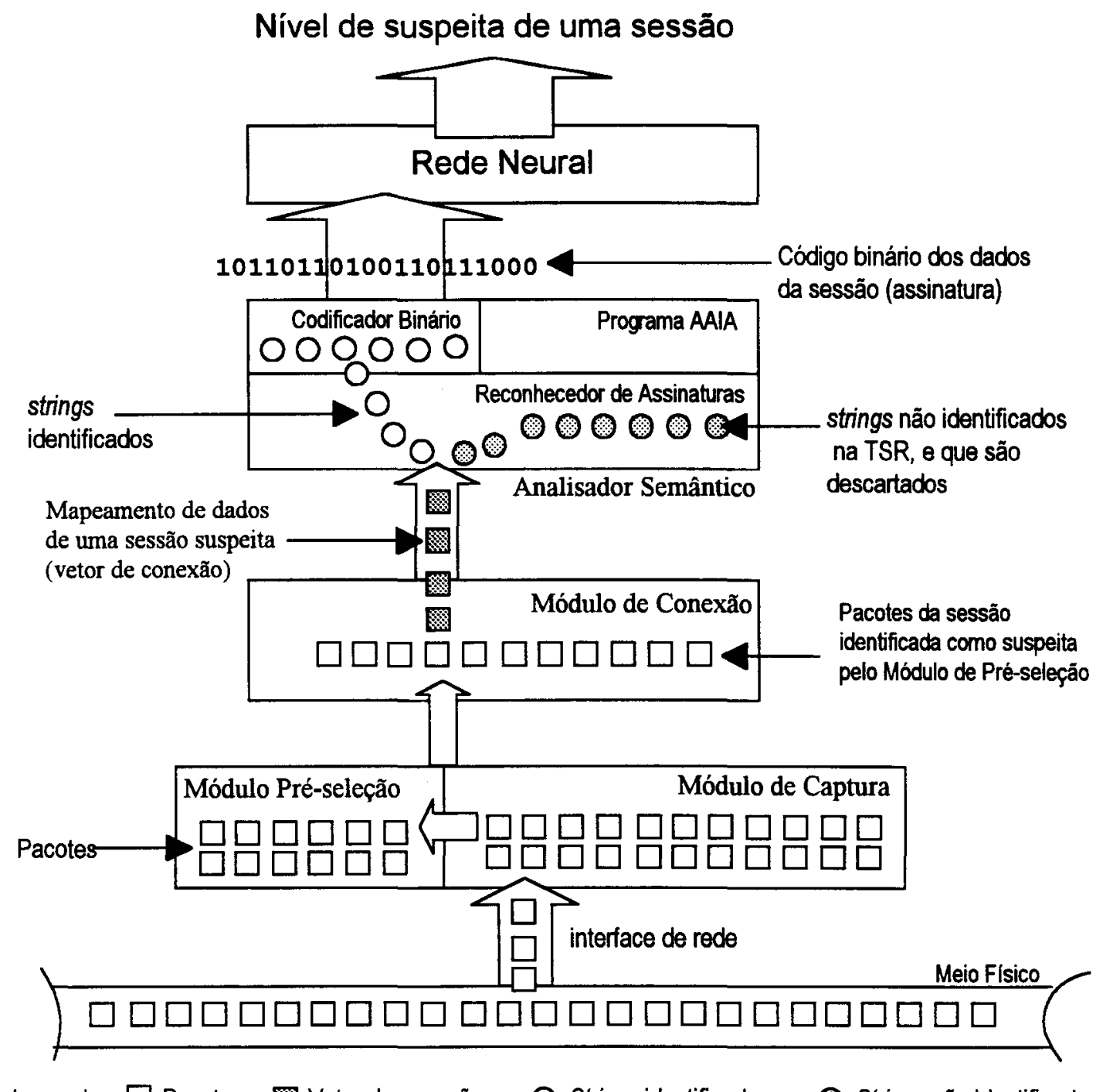

Legenda: $\square$ Pacotes 屬 Vetor de conexão $\bigcirc$ Strings identificados $\quad$ Strings não identificados

Figura 5.7 - Esquema do fluxo de informações no SADI 


\section{Resultados Obtidos}

Este capítulo apresenta os resultados obtidos pelo SADI. São discutidos a elaboração dos perfis intrusivos, os comportamentos simulados, e as assinaturas de ataque capturadas. Os dados submetidos e os resultados fornecidos pelo simulador de rede neural são mostrados em diversas situações de treinamento. $O$ capítulo contém ainda algumas particularidades de configuração dos módulos do sistema, relacionadas com a obtenção e análise dos perfis, e que não foram propositadamente discutidas no capítulo anterior.

\subsection{Introdução}

Para testar o SADI, foram simulados ataques sobre estações de trabalho dentro de uma rede. Estes ataques foram feitos a partir de uma máquina, que se encontrava externa à rede local sob monitoração. A partir dessas simulações, foi capturado um bom conjunto de assinaturas de ataque, que foram convertidas em vetores binários para serem utilizados no treinamento e validação da rede neural.

De modo a comprovar a eficiência do protótipo com relação à sua habilidade em capturar informações da rede, os módulos do sistema foram testados independentemente uns dos outros, antes das simulações efetivas de ataque. Foram testados nesta ordem:

- O módulo de captura e de conexão, em conjunto, para que fosse determinado se os dados referentes a uma sessão poderiam ser total e efetivamente reconstituídos;

- O módulo de pré-seleção junto com o módulo de captura, para verificar se o disparo automático, corretamente, o momento de começar a capturar todos os dados de uma sessão; 
- O analisador semântico, para verificar a filtragem e interpretação da captura dos componentes das assinaturas de ataque;

- O funcionamento conjunto destes 3 módulos acima, com a simulação de cenários de intrusão, e a captura das assinaturas de ataque;

- O AAIA, para verificar a facilidade da codificação das assinaturas e seus componentes;

- E, finalmente, o simulador de rede neural com o treinamento, validação e ajustes.

\subsection{Testes do módulo de captura e de conexão}

Os módulos de captura e de conexão foram testados independentemente. A idéia básica consiste em enviar uma série de dados conhecidos de uma estação $A$ para outra estação $B$, e verificar se a totalidade dos dados pode ser reconstruída pelo agente de captura que monitora a rede. Outro teste realizado foi monitorar as sessões de diversas estações transmitindo para uma mesma estação destino, e novamente verificar a reconstituição das sessões. Isso foi feito para se determinar a eficiência de captura.

Estes testes foram realizados dentro de um ambiente real, em um laboratório de ensino de computação ${ }^{1}$, onde o agente de captura observava 12 estações de trabalho UNIX e 25 microcomputadores, ligados numa rede local, de cabeamento em par trançado, que utiliza protocolo TCP/IP e IPX Netware. Apenas as sessões que transmitiam os dados das estações de origem e destino foram controladas, para analisar se o que era transmitido, era também capturado pelo agente.

Além disso, para se determinar como o sistema se comporta, em condições de fluxo de dados diferentes, os testes foram ainda realizados em duas situações bastante diferentes: durante horários de uso intenso do laboratório e durante períodos de inatividade.

O agente de captura foi inicialmente preparado de forma que, a partir da linha de comando de chamada do processo, fosse possivel especificar quais origens e destinos (e

\footnotetext{
${ }^{1}$ Os testes foram realizados nos Laboratórios de Ensino de Computação, do Instituto de Biociências, Letras e Ciências Exatas da UNESP, em São José do Rio Preto, SP, onde o autor é docente.
} 
quais portas ou serviços) deveriam ser monitorados. Os dados de cada captura foram então gravados em arquivos, e assim puderam ser posteriormente comparados com aqueles efetivamente transmitidos. Isso foi possivel pois os dados trocados pelas máquinas de teste também eram controlados e registrados em arquivos em suas origens. Em resumo, cada sessão de teste tinha os dados reconstituídos localmente, e estes eram comparados com os dados obtidos pelo agente de captura.

A Tabela 6.1, a seguir, mostra a perda de dados em 5 diferentes cenários de monitoração, sob 3 condições de tráfego. A coluna à esquerda mostra as situações sob testes, e as colunas à direita mostram a perda de dados na reconstituição das sessões, nas condições de tráfego no ambiente monitorado. Estas situações de tráfego foram determinadas de maneira qualitativa, a partir de nossa experiência, em razão de não dispormos de equipamento adequado para quantifica-lo.

Tabela 6.1 - Eficiência da captura de pacotes

\begin{tabular}{|l|c|c|c|}
\cline { 2 - 4 } \multicolumn{1}{c|}{} & \multicolumn{3}{c|}{$\begin{array}{c}\text { Porcentagem de perdas na captura, em diversas } \\
\text { condicões de tráfego na rede }\end{array}$} \\
\hline Situação de teste : & Inatividade & Uso reduzido & Uso intenso \\
\hline Host $A$ transmite para host $B$ & $0 \%$ & $0 \%$ & $0 \%$ \\
\hline 5 hosts transmitem para host $B$ & $0 \%$ & $0 \%$ & $0 \%$ \\
\hline 20 hosts transmitem para host $B$ & $0 \%$ & $0.3 \%$ & $0.5 \%$ \\
\hline 20 hosts transmitem para 5 hosts & $0 \%$ & $0.3 \%$ & $1 \%$ \\
\hline 20 hosts transmitem para 10 hosts & $0 \%$ & $0.5 \%$ & $1.5 \%$ \\
\hline
\end{tabular}

A partir dos dados obtidos, foi possivel comprovar que os módulos de captura e de conexão do SADI são muito eficientes na reconstituição das sessões monitoradas. Este bom rendimento, decorre principalmente em razão da escolha adequada da biblioteca de captura de pacotes libpcap, conforme discutido na seção 5.2.2, e em função de sua arquitetura BPF [MJ93] discutida na seção 3.2

Ao se analisar estes resultados, deve-se considerar também que a máquina utilizada no protótipo é bastante simples. Conforme discutido na seção 5.1.2, trata-se de um microcomputador IBM-PC, com processador Intel 80486 DX2 de $66 \mathrm{Mhz}, 20 \mathrm{Mb}$ de memória RAM, e interface de rede ethernet de 16 bits em barramento ISA. Certamente a eficiência de captura pode ser ainda melhorada, a partir da utilização um processador 
mais rápido, com uma interface de rede em barramento mais eficiente, como por exemplo, uma ethernet em barramento PCI. Entretanto, dentro da proposta de implantação do protótipo, os resultados obtidos para a captura de pacotes foram extremamente satisfatórios.

\subsection{Testes do módulo de pré-seleção}

O módulo de pré-seleção, que é responsável pelo disparo de captura de pacotes de uma sessão inicialmente suspeita, também foi testado de maneira independente. $O$ valor do nível de segurança NS de cada serviço de rede, foi configurado por meio de um pequeno arquivo texto, que é lido durante a ativação do módulo. Este, permite a rápida modificação dos valores de NS, sempre que o administrador do sistema julgar necessário. Este arquivo é formado por linhas que identificam a porta referente ao serviço, seguida do nível de segurança definido. Há ainda um valor default para sessões com destino a eventuais portas não listadas. Os valores de NS adotados foram aqueles apresentados na seção 5.3.3 (Tabela 5.1) .

Opcionalmente, o SADI admite mais de um arquivo de configuração, para ser utilizado em função do horário no qual a monitoração está ocorrendo. Por exemplo, pode haver uma configuração de valores de NS para ser utilizada entre 8 e 18 horas, outra para ser utilizada entre 18 e 23 horas, e uma terceira entre 23 e 8 horas. É recomendável adotar esse tratamento, porque acessos a determinado serviços podem ser mais ou menos suspeitos dependendo do horário em que ocorrem.

O módulo de pré-seleção foi testado por intermédio de acessos que violavam as regras que determinam o disparo da captura. Ao atingir o valor do limiar de NS, o módulo inicia a captura dos dados das sessões vindas do domínio suspeito, e o módulo de conexão passa a preparar os vetores de conexão. O módulo de pré-seleção, só determina a interrupção da captura após haver um determinado período de inatividade de tráfego, vindo da localidade suspeita. Da mesma forma, as entradas da tabela de monitoração que não resultaram em captura também são removidas automaticamente, após um tempo especificado pelo administrador. 
Também seria apropriado que o próprio resultado do nível de suspeita obtido pela rede neural para uma dada sessão, fosse utilizado para determinar quando a captura de dados desta deve ser interrompida. Por exemplo, uma sessão está sendo capturada, mas a rede neural decidiu que ela não é suspeita, então a captura pode ser momentaneamente interrompida. Entretanto, para efeitos de simplificação na implementação, esta opção não foi anexada ao SADI. A captura só é interrompida quando a sessão termina, ou quando o módulo de pré-seleção julgar que ela não é mais suspeita.

$\mathrm{Na}$ implementação atual, o módulo de pré-seleção só se ocupa com pacotes que sejam provenientes de fora da rede local sob monitoração. Em todos os testes realizados, o módulo determinou a captura de maneira correta para os eventos suspeitos, quando o NS atinge o limiar especificado.

Havendo sido testados e validados o módulo de captura, de pré-seleção e conexão, foram iniciadas as simulações de ataques, captura e codificação das assinaturas, o que será discutido a seguir

\subsection{Formação das assinaturas de ataque}

\subsubsection{Técnicas de simulação de ataque}

Os procedimentos de ataques na rede em teste, foram simulados sempre de maneira igual, ou muito próxima, aos verdadeiros comportamentos intrusivos. Isso foi feito a partir da análise de um conjunto de estudos de casos relatados nas publicações especializadas, e também a partir de consultas a diversas fontes na Internet. Por razões óbvias da necessidade de se manter um determinado nível de sigilo sobre o comportamento intrusivo estudado, as técnicas de simulação não serão discutidas profundamente aqui, mas poderão ser obtidas diretamente com o autor. Elas foram conduzidas de três maneiras básicas:

- Manualmente, através de diversas técnicas baseadas em artigos sobre segurança, e documentos técnicos disponíveis na Internet, que descrevem métodos e "receitas" para se explorar vulnerabilidades de sistemas operacionais. 
- Por intermédio do programa SATAN - Security Administrator's Tool for Analysing Networks (versão 1.1.1). O SATAN ${ }^{1}$ é um sistema de domínio público que realiza varreduras nas máquinas componentes de uma rede, buscando por vulnerabilidades conhecidas. Ele coleta informações que estão disponíveis a qualquer pessoa com acesso a rede e, para cada vulnerabilidade encontrada, oferece um tutorial que explica o problema e o impacto que ele pode acarretar. $O$ tutorial também explica o que pode ser feito para corrigir o problema.

- Usando o sistema comercial ISS - Internet Security Scan, adquirido para esta finalidade, e que possui características semelhantes ao SATAN, mas que testa algumas vulnerabilidades diferentes. $\mathrm{O}_{\text {ISS }}{ }^{2}$ também realiza varreduras, que podem ser programadas em diversos níveis, e emite relatórios sobre os problemas encontrados. A versão comercial utilizada foi a V.3.3 . Entretanto, também utilizamos uma versão pública ${ }^{3}$ V.1.3 (mais antiga e atualmente descontinuada) deste sistema, que realiza algumas variações de varreduras interessantes.

Em algumas situações, os três diferentes métodos de simulação acima, testavam a mesma vulnerabilidade. Porém o faziam através de ações diferentes, o que se mostrou muito útil na observação e captura de variações dos comportamentos intrusivos para a formação das assinaturas de ataque. Em muitos casos, as variações foram forçadas manualmente, para enriquecer possiveis cenários de intrusão.

\subsubsection{Ambiente de testes dos ataques}

Os ataques foram lançados sobre três máquinas controladas: uma estação de trabalho Sun Sparc LX, com sistema operacional SunOS 4.1.3_U1, uma estação IBMPC, com sistema operacional Linux V.2.2.0, e uma estação de trabalho IBM Risc6000, com sistema operacional AIX 3.2.5. Estas máquinas, possuíam todos os serviços de rede mais relevantes. $O$ sistema de captura foi previamente preparado para capturar e registrar as sessões que tivessem destino para estas máquinas. Os ataques partiram de outra estação de trabalho Sun Sparc LX, com sistema operacional SunOS.

\footnotetext{
${ }^{1}$ Disponivel por FTP anônimo em ftp://ftp.win.tue.nl/pub/security/

${ }^{2}$ Comercializado por Internet Security Svstems Inc. - Atlanta, Georgia, USA. Informações disponíveis em $h$ ttp://www.iss.net/

${ }^{3}$ Disponível por FTP anônimo em ftp://coast.cs.purdue.edu/pub/tools/unix/iss/
} 
Sobre estas máquinas, as simulações de ataque foram realizadas em duas situações diferentes. Numa primeira etapa, quando possível, estas máquinas foram deixadas com diversas vulnerabilidades conhecidas (que chamamos genericamente de "buracos") em seus sistemas operacionais, de forma que os ataques obtivessem sucesso. Isso foi feito omitindo-se a implantação de correções (patches) recomendadas por órgãos de segurança, ou pelos fornecedores dos sistemas. Entretanto essa situação não foi alcançada para todos os casos desejados, pois alguns sistemas operacionais utilizados já possuíam algumas vulnerabilidades originalmente corrigidas.

Numa segunda etapa, foram aplicadas todas as correções recomendadas, pertinentes ao sistema operacional em uso, de forma que as falhas fossem bloqueadas e as máquinas se tornassem, em tese, seguras.

Isto permitiu capturar as assinaturas de ataque do comportamento intrusivo em duas situações diferentes: uma em que grande parte dos ataques resultam em sucesso, e outro onde os ataques se desenvolvem, entretanto, sem se consolidar. Ambos são importantes para o treinamento de nossa rede neural, pois representam técnicas intrusivas com evoluções diferentes. Posteriormente, com o andamento da pesquisa e com os resultados da rede neural, foi possivel inferir que as ações do atacante já são suficientes para determinar o comportamento intrusivo. Entretanto este é um detalhe que não será tratado aqui.

Obedecendo algumas limitações de monitoração, discutidas anteriormente, dentro das quais o SADI foi implementado, foram simulados e testados os seguintes tipos de ataques em protocolo TCP:

- Diversas variações de ataques distribuído do tipo doorknob com FTP, Telnet, rlogin e rsh dentre outros.

- Vulnerabilidades antigas e recentes do Sendmail (até versão 8.8.3);

- Falhas em processos de FTP nativos (fornecidos com o SO) ou não-nativos (e.g. WuFTP daemon);

- FTP anônimo com tentativa de escrita em diversos níveis;

- Busca de informações através de finger; 
- Tentativas de acesso arbitrário a diversos arquivos sensíveis através de FTP anônimo;

- Falhas em processos de finger e identd;

- Ataque a servidores WWW (http) para obtenção de informações privilegiadas através de execução de scripts.

Estas vulnerabilidades foram escolhidas porque, apesar de bem conhecidas e extensivamente descritas por órgãos de segurança e na literatura especializada, têm sido exploradas com freqüência e sucesso por atacantes em todas as partes e em diversas situações. Num primeiro momento, estas vulnerabilidades podem parecer simples, mas nem por isso os riscos e os danos referentes a elas podem ser menosprezados. Relatórios recentes do CERT e de órgãos especializados mostram que cerca de $93 \%$ dos ataques na Internet ocorrem através da exploração de vulnerabilidades bem conhecidas [Pow96b], e que não foram corrigidas a tempo ou adequadamente. As simulações de ataque foram baseadas, em grande parte, nestas notificações do CERT, e órgãos correlatos, abrangendo assim as vulnerabilidades bem conhecidas da Internet, e suas variações.

A partir dos tipos de vulnerabilidade enumeradas acima, foram simulados cerca de 40 cenários diferentes de ataque, com variações de evolução e seqüência. Isto permitiu capturar 117 sessões de comportamentos intrusivos diferentes, distribuídos nos ambientes atacados, ou seja, nas diversas máquinas especialmente preparadas com, e sem, as falhas de segurança esperadas. $\mathrm{Na}$ verdade a quantidade de ataques e ensaios realizados foi da ordem de 240 , mas, em muitos casos, as diferentes máquinas respondem da mesma maneira para um mesmo ataque, resultando assim num único resultado utilizável. A Tabela 6.2 apresenta os ataques simulados aproveitáveis, com relação às portas.

Tabela 6.2 - Distribuição dos ataques simulados utilizáveis, com relação às portas

\begin{tabular}{|l|c|}
\hline Porta: & Simulações de ataque: \\
\hline Porta 21 (ftp) & 50 \\
\hline Porta 23 (telnet) & 04 \\
\hline Porta 25 (SMTP) & 26 \\
\hline Porta 513 (rlogin) & 09 \\
\hline Porta 514 (rsh) & 05 \\
\hline Outras portas diversas & 23 \\
\hline TOTAL: & $\mathbf{1 1 7}$ \\
\hline
\end{tabular}


Finalizando as capturas no ambiente simulado, foi monitorado e registrado, em igual quantidade, um conjunto de sessões que não se tratavam de comportamentos intrusivos. Essas sessões também são importantes para o treinamento e aprendizagem da rede neural.

As sessões capturadas foram enviadas para o analisador semântico, para serem filtradas e desmembradas, de maneira a se determinar os componentes das assinaturas de ataque. Isso será discutido a seguir.

\subsubsection{Formação das assinaturas}

O passo seguinte para a elaboração do conjunto inicial de assinaturas de ataque, foi enviar todas as sessões simuladas e capturadas para o autômato finito do analisador semântico, discutido na seção 5.5.2. Dessa maneira, todos os componentes de cada um dos ataques foram desmembrados em strings completos. Estes strings foram analisados manualmente e determinou-se quais eram os mais relevantes na formação das assinaturas.

Considerando novamente a vulnerabilidade do processo sendmail [Cer95] utilizada como exemplo na seção 4.4.5, capturada diretamente através do sistema:

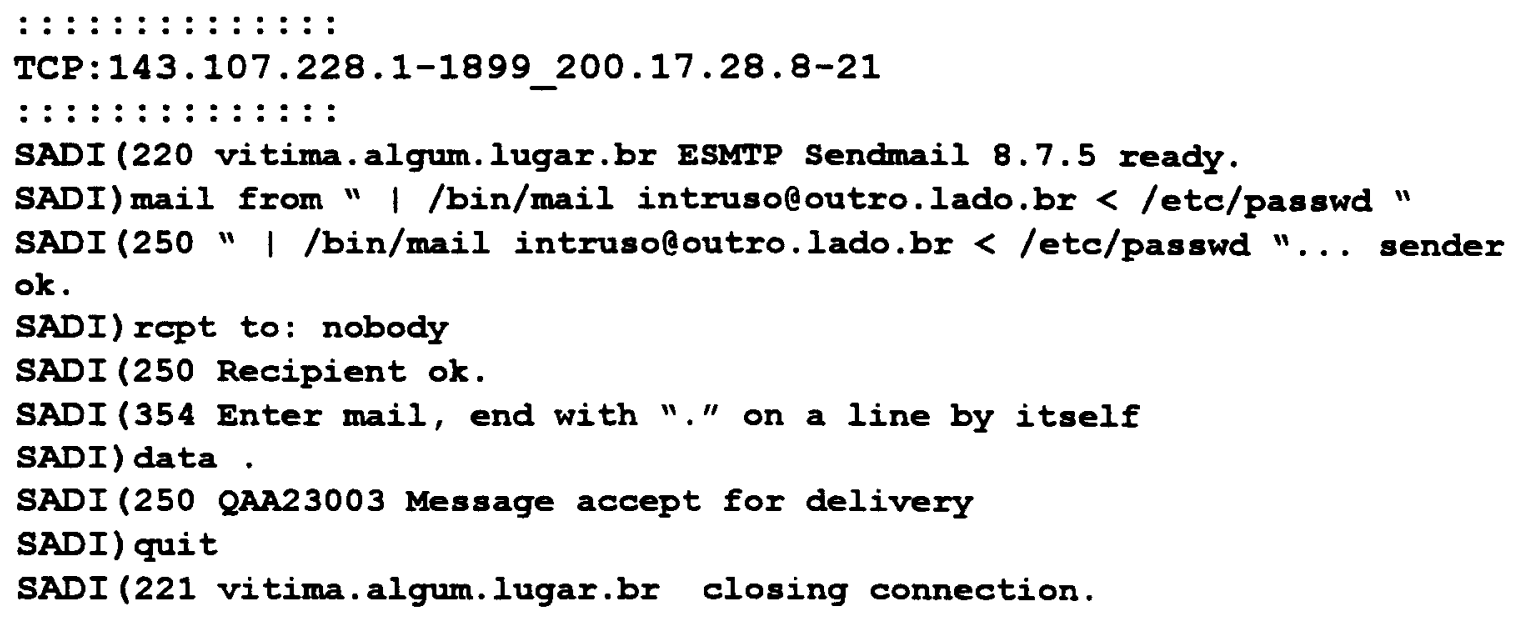

A partir de uma análise dos dados capturados, determinou-se que os componentes mais relevantes deste comportamento intrusivo, e que farão parte da assinatura, são os strings: 


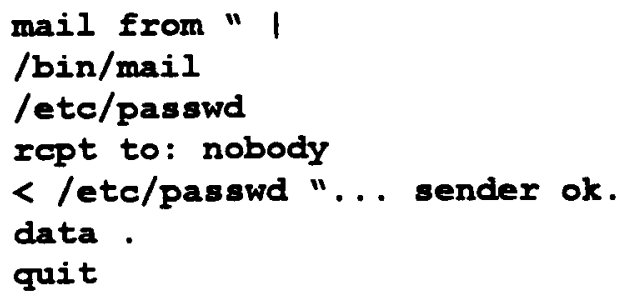

Em seguida, utilizando-se o sistema assistente de codificação AAIA discutido na seção 5.5.5, cada um dos strings formadores da assinatura de ataque foi associado com um valor inteiro, e assim passaram a fazer parte da tabela de símbolos reservado (arquivo tsr.acm). Isso foi feito para cada um dos 117 comportamentos monitorados.

Neste ponto, cabe uma constatação importante decorrente da pesquisa: de uma maneira geral, não existem muitos strings a serem codificados. Isso ocorre basicamente por duas razões: primeiro porque, apesar dos ataques acontecerem de diversas maneiras diferentes, existe um certo número limitado - e muitas vezes repetitivo e constante - de acontecimentos que estão presentes em todos os cenários de ataque. Ou seja, os ataques não se concretizam sem essas determinadas ações limitadas, e é isso que permite analisar o comportamento intrusivo. A segunda razão, é que muitas ações podem ser codificadas da mesma maneira, como já discutido anteriormente. Por exemplo, os strings letc/passwd e /etc/shadow podem ser codificados como iguais, pois representam o mesmo tipo de ação de ataque.

A partir da análise de todos os ataques simulados, foram identificados 71 grupos diferentes de strings, que estão presentes nos comportamentos intrusivos, e que foram associados a 71 valores inteiros diferentes (o APÊNDICE B apresenta parte da codificação atual adotada). É chamado genericamente de "grupo", os conjuntos de caracteres que são muito semelhantes e que representam a mesma ação. Em muitos casos há "grupos" que possuem um único string, mas que no futuro poderão possuir outros semelhantes, que representem o mesmo comportamento. Além disso, também foram codificados alguns caracteres de controle dos registros das sessões, tais como o tipo da sessão e as portas mais importantes envolvidas, haja visto que estes dados também fazem parte da assinatura de ataque, conforme discutido na seção 5.5.1.

Cada valor inteiro é então associado com um único código binário (arquivo bin. $\mathrm{acm}$ ). A criação dos códigos binários e a associação com os valores decimais inteiros 
também é realizada facilmente pelo AAIA. Estes códigos serão finalmente usados pelo sub-módulo de codificação binária do analisador semântico, para produzir os vetores binários das assinaturas.

\subsubsection{Preparação das assinaturas de ataque em vetores binários}

Dando continuidade à preparação dos vetores para o treinamento da rede neural, cada um dos valores decimais dos strings foi associado com um valor binário. Foi adotado um tratamento no qual cada código binário deveria diferir do outro, em pelo menos 3 bits. A partir de alguns testes de interpolações sucessivas, utilizando o AAIA, determinou-se que uma escolha adequada, seria uma codificação de 12 bits, o que permite definir pelo menos 90 códigos binários que diferem pelo menos 3 bits de todos os outros. Nesta fase de teste do SADI, essa codificação é adequada para acomodar os dados que, como mencionado acima, totalizam 71 grupos de componentes das assinaturas de ataque. Além disso, essa codificação pode ser alterada facilmente, porque é independente dos componentes, que já foram proposital e adequadamente associados com códigos decimais independentes para permitir futuras modificações.

Os códigos binários foram gerados pelo AAIA por interpolações sucessivas, descartando-se os que não atendiam à definição, e cada um deles foi associado com um decimal da tabela de símbolos reservados.

Além disso, foi criada uma codificação especial para as portas em uso nas sessões, que são associadas aos caracteres de controle dos vetores de conexão. Este código binário, que é o primeiro componente da assinatura de ataque foi definido de acordo com a Tabela 6.3. 
Tabela 6.3 - Codificação em binários para as portas das sessões

\begin{tabular}{|l|l|}
\hline Código: & Porta: \\
\hline 100000 & Porta 23 (telnet) \\
\hline 010000 & Porta 21 (ftp) \\
\hline 001000 & Porta 25 (SMTP) \\
\hline 000100 & Outras portas não listadas (default) \\
\hline 000010 & Porta 514 (rsh) e 512 (exec) \\
\hline 000001 & Porta 513 (rlogin) \\
\hline 000000 & sem porta especifica (sessões ICMP) \\
\hline
\end{tabular}

Tendo sido devidamente codificadas todas as informações necessárias, procedeuse à formação das assinaturas de ataque propriamente ditas. Os dados simulados foram novamente submetidos ao analisador semântico incorporado ao AAIA, com todos os sub-módulos em funcionamento. O analisador semântico, sob controle do AAIA, produziu as assinaturas em código binário. $\mathrm{O}$ mesmo foi feito para as sessões não intrusivas capturadas.

Para se chegar ao melhor modelo para a assinatura de ataque, foram observados e estudados diversos comportamentos intrusivos e não intrusivos, obtidos pelas simulações. A partir dessa análise, foi definido que a assinatura binária adequada seria formada por um total de 11 campos: um campo de 6 bits para identificar a porta de destino da sessão, e mais 10 campos de 12 bits com as ocorrências dos strings componentes da assinatura, totalizando assim 126 bits.

Em alguns casos, esses 11 campos não são preenchidos, porque a assinatura não possui esta quantidade de componentes. Neste caso, os campos restantes são preenchidos com zero. Isso também acontece algumas vezes com as sessões não intrusivas. Como a sessão não é uma intrusão, o vetor resultante da submissão desta ao analisador semântico, possui diversos campos preenchidos por zero. Eventualmente, o analisador semântico encontra algum string, componente de assinaturas de ataque, presente nos dados de uma sessão sabidamente não intrusiva. Este também é um dado importante no treinamento da rede, pois permite que ela seja treinada para não acusar falsos-positivos. Considerando esse fato, esta situação foi simulada durante a captura dos 
dados não intrusivos, ou seja, foram inseridos manualmente alguns strings componentes das assinaturas de ataque nas sessões não intrusivas.

A seguir, apresentamos a codificação do ataque à vulnerabilidade do processo sendmail [Cer95], que está sendo utilizado nos exemplos anteriores. A saída, produzida pelo analisador semântico, já está formatada adequadamente para simulador de rede neural. O que aparece após os sinais de “\#” são comentários para identificar a assinatura. Os componentes da assinatura de ataque binária, propriamente dita, estão intercalados no texto com tipos não sublinhado e sublinhado, para facilitar a visualização:

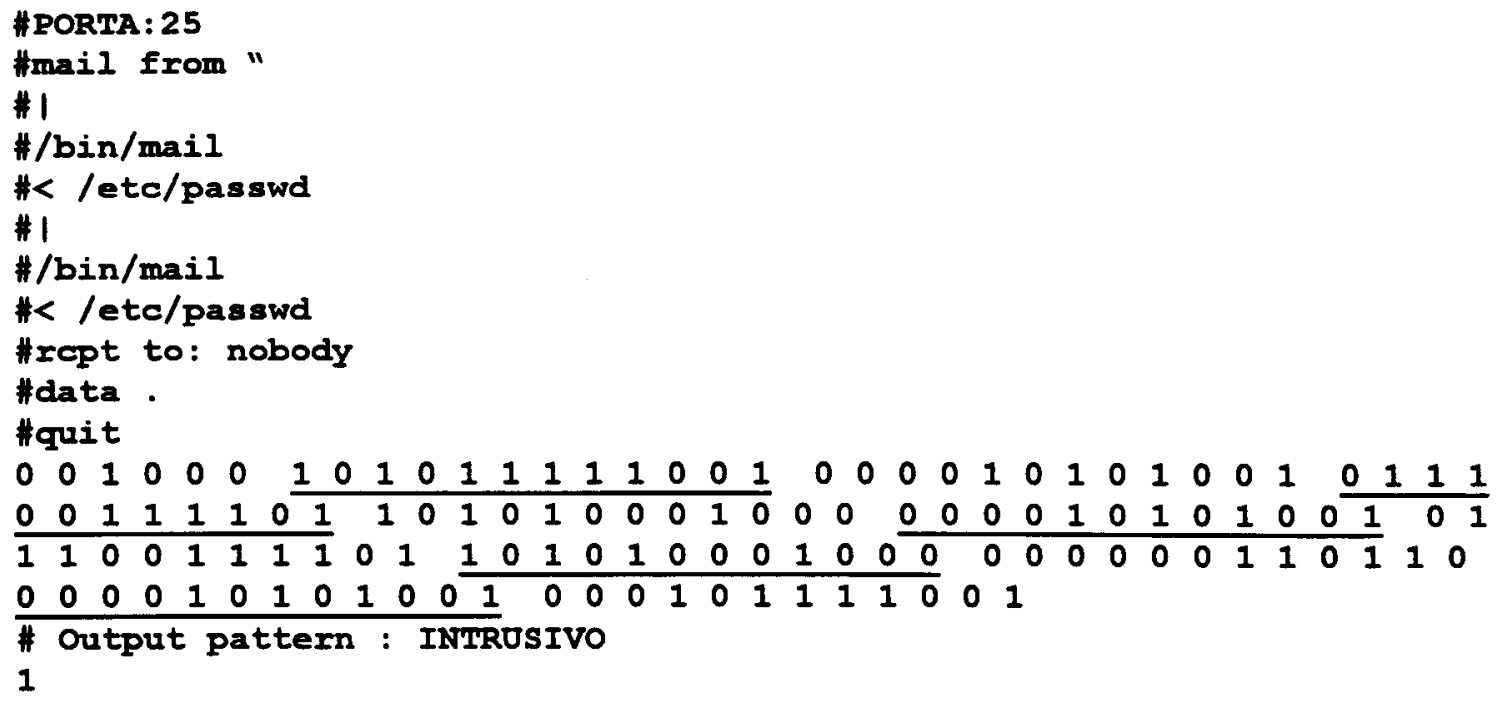

O valor 1 no final, indica para o simulador de rede neural que este padrão se trata de uma intrusão. Os componentes binários anteriores, seguidos desse valor 1 , formam o vetor que a rede neural efetivamente utiliza e interpreta em seus procedimentos

Analogamente, para uma sessão não intrusiva, na mesma porta 25 (SMTP), onde foi forçada a ocorrência dos strings User unknown e Invalid sender address, foi obtida a seguinte saída:

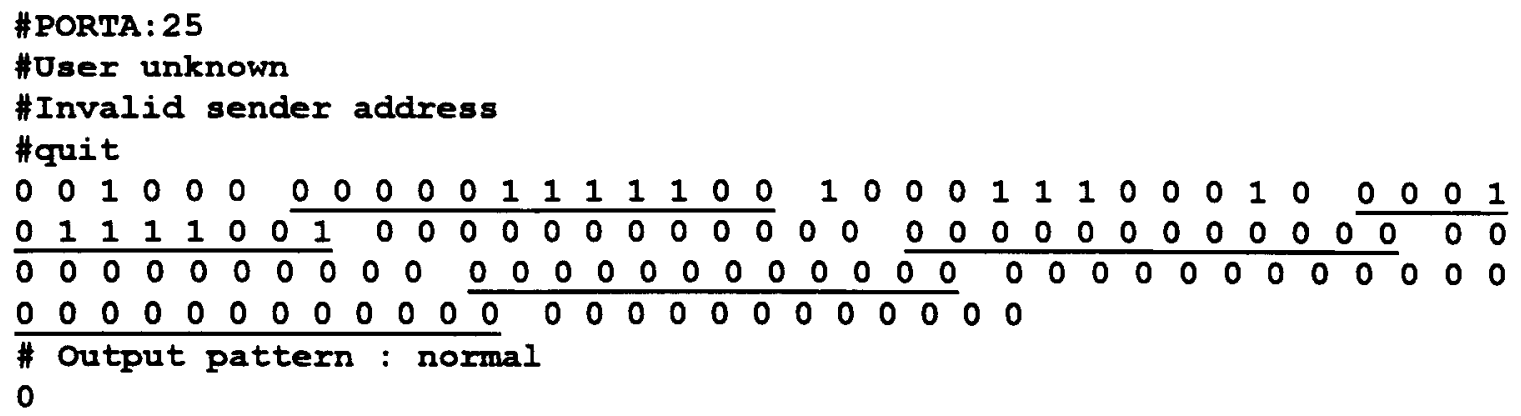


E o valor 0 no final, indica que se trata de um vetor referente a um comportamento não intrusivo.

Assim foram obtidas 117 assinaturas de comportamentos de ataque codificadas dessa maneira, e outros 117 assinaturas que identificam comportamentos não intrusivos.

\subsection{Dados para o treinamento da rede neural}

As 117 assinaturas binárias de ataque, e as 117 de não-ataque, foram divididas em 3 conjuntos: treinamento, validação e testes. $O$ conjunto de treinamento é utilizado no aprendizado da rede e o conjunto de validação serve para ajustar a rede neural. Este procedimento é conhecido como validação cruzada [RWL94]. O conjunto de teste é usado para submeter à rede valores que ela ainda não viu durante a fase de aprendizagem, e assim verificar qual o erro cometido. A Tabela 6.4 mostra a divisão dos dados de ataque usados nos 3 conjuntos. A mesma divisão foi utilizada para os dados não intrusivos. Para que a rede neural não seja induzida a resultados falsos, ou submetida a uma situação onde tendesse a diagnosticar melhor uma situação do que outra, um dado presente em um dos conjuntos não aparece nos outros dois. Isso também minimiza a possibilidade da rede passar a conseguir identificar corretamente apenas um tipo de comportamento.

Tabela 6.4 - Distribuição dos dados de ataque usados na aprendizagem e teste da rede neural, em função das portas. Um dado presente num conjunto não se repete em outro

\begin{tabular}{|l|c|c|c|c|}
\hline \multicolumn{1}{|c|}{ Porta } & Treinamento & Validação & Teste & Total \\
\hline Porta 21 & 26 & 12 & 12 & 50 \\
\hline Porta 23 & 2 & 1 & 1 & 04 \\
\hline Porta 25 & 14 & 6 & 6 & 26 \\
\hline Porta 113 & 5 & 2 & 2 & 09 \\
\hline Porta 512 & 3 & 1 & 1 & 05 \\
\hline Outras portas & 11 & 6 & 6 & 23 \\
\hline TOTAL: & $\mathbf{6 1}$ & $\mathbf{2 8}$ & $\mathbf{2 8}$ & $\mathbf{1 1 7}$ \\
\hline
\end{tabular}

Numa segunda etapa da preparação, todos os dados de treinamento, validação e testes foram juntados em um único arquivo, que passou a possuir todos os 117 padrões 
de intrusão. Em seguida, por intermédio de um pequeno programa, foram formados novamente os arquivos de treinamento (61 padrões), validação e testes ( 28 padrões cada), mas de maneira aleatória, garantindo-se ainda que os dados presentes em um deles não se repetisse em outro. $O$ processo de formação dos arquivos aleatórios foi repetido 3 vezes, utilizando o mesmo arquivo com os 117 padrões totais. Assim foram obtidos outros 3 conjuntos de dados para utilizar na rede neural. Novamente, o mesmo foi feito para os dados não intrusivos. Este procedimento foi adotado para se determinar o erro médio cometido pela rede, quando exposta a diferentes situações de treinamento e assim, mais uma vez, garantir que ela não apresenta resultados tendenciosos, em função de vícios de treinamento.

Resumindo, foram 4 conjuntos de dados submetidos à rede neural: um conjunto com uma distribuição equilibrada entre os ataques às diversas portas testadas e 3 conjuntos com distribuições aleatórias.

\subsection{Resultados da rede neural}

\subsubsection{Rede neural utilizada}

Utilizando-se o SNNS, foram definidas duas redes neurais tipo Multilayer Perceptron: uma com uma camada de saida e nenhuma camada intermediária, que foi chamada de Rede MLP126-1 ${ }^{1}$ e outra com uma camada de saída e uma camada intermediária com 10 neurônios, denominada MLP126-10-1. A função utilizada foi a Backpropagtion padrão, já discutida anteriormente. Esta configuração das redes neurais é totalmente empírica.

\subsubsection{Condições de aprendizagem da rede neural}

O processo de aprendizagem ocorre em ciclos; em cada ciclo os dados de treinamento são percorridos e os pesos dos neurônios são ajustados. Para isso a rede se baseia no erro cometido entre o resultado esperado e o resultado que ela determinou, levando-se em consideração a função escolhida. A cada número de ciclos especificado pelo usuário, o simulador faz o que se chama de validação: submete à rede, treinada até

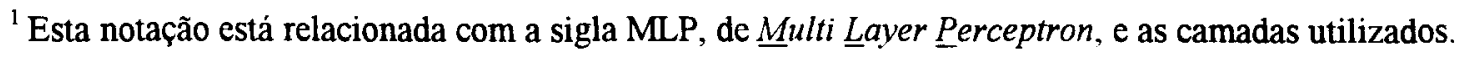


o momento, um conjunto de dados que ela ainda não viu, verificando novamente o erro cometido e ajustando os pesos conforme necessário. Assim, os processos de validação e treinamento vão acontecendo alternadamente. Para que a rede tenha aprendido a reconhecer os padrões, é necessário que ambos os erros, de treinamento e validação, apresentem resultados que decaiam com o passar dos ciclos.

Após a rede haver sido considerada treinada, submete-se um terceiro conjunto de testes, ao qual ela ainda não teve contato, e determina-se o erro cometido sobre esse conjunto.

Em todos os casos foi usado o simulador SNNS, com 200 ciclos de treinamento e validação a cada 20 ciclos. A aprendizagem foi otimizada automaticamente pelo simulador (através da opção Shuffle discutida anteriormente na seção 5.6.2), fazendo com que vários padrões fossem apresentados em diferentes ordens em ciclos distintos, de forma que uma seqüência aleatória de padrões fosse criada automaticamente a cada ciclo.

\subsubsection{Procedimentos de aprendizagem e testes}

Cada um dos 4 conjuntos de dados foi utilizado da seguinte maneira: o conjunto de treinamento e o de validação são usados durante a aprendizagem, produzindo um gráfico do erro quadrático médio em função dos ciclos, tanto para a validação quanto para o treinamento. Esse gráfico, cuja saída de tela foi capturada diretamente do simulador de rede neural, indica como a rede está se comportando durante a fase de aprendizagem, e qual o erro que está sendo cometido ao longo dos ciclos.

Após o processo de aprendizagem, a rede foi submetida ao conjunto de testes, de modo a determinar o erro quadrático médio cometido com relação a dados ainda não vistos. Este resultado é o que melhor representa se a rede está conseguindo cumprir seus objetivos de generalização, ou seja, se tornando adaptativa a situações às quais ainda não teve contato.

Todos os 4 conjuntos de dados, discutidos anteriormente, foram submetidos às duas redes definidas, e assim foram obtidos os resultados dos processos de aprendizagem e testes 


\subsubsection{Resultados dos processos de aprendizagem e validação}

As figuras a seguir são gráficos capturados diretamente do simulador neural, e apresentam os resultados do erro quadrático médio cometido pelo treinamento e pela validação, durante o processo de aprendizagem, para as redes neurais MLP126-1 e MLP126-10-1. Os comportamentos de cada processo de aprendizagem são comentados logo após os resultados apresentados pelos gráficos.

NA.: Restante desta página intencionalmente em branco, para organizar a visualização das figuras. 


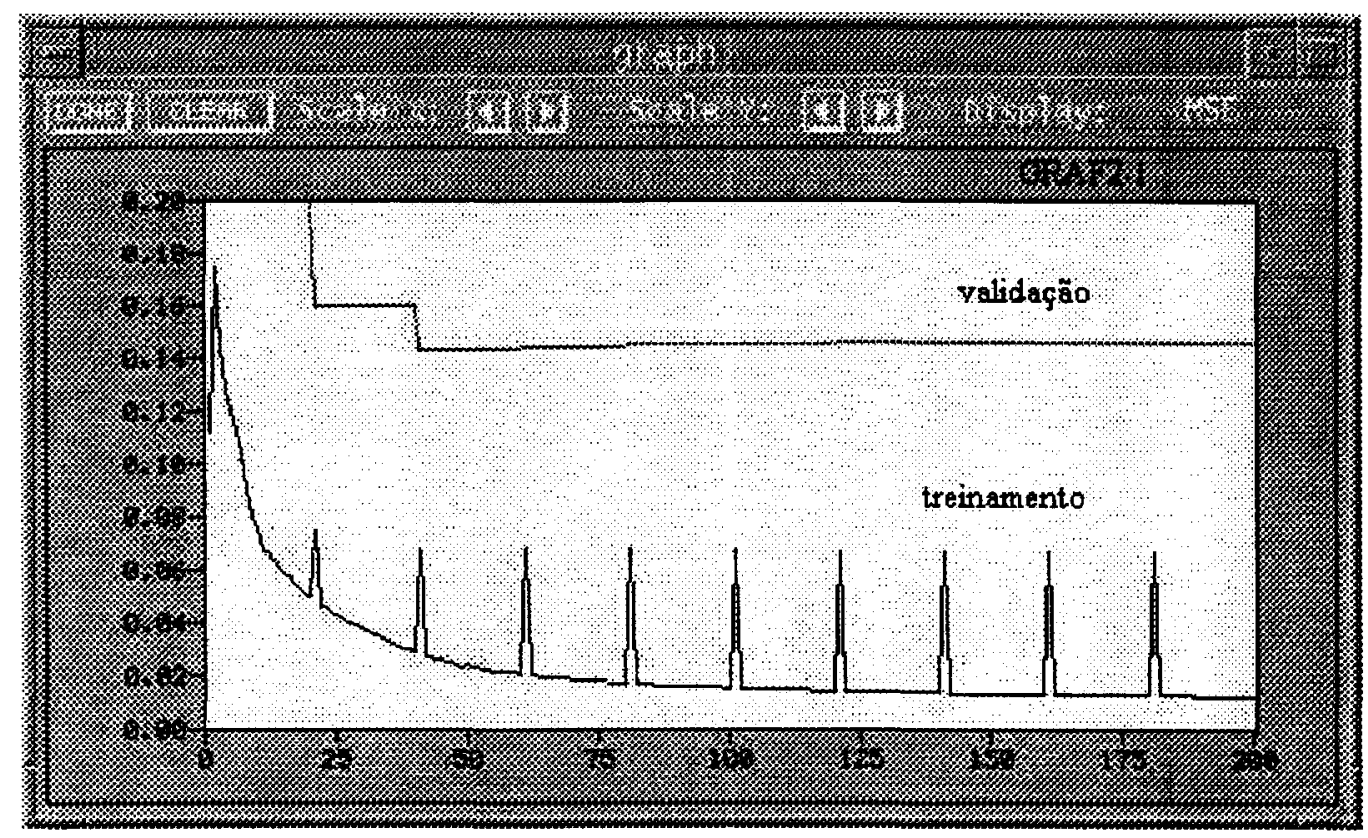

Figura 6.1 - Erro ao longo dos ciclos. Conjunto de dados 1 e rede MLP126-1

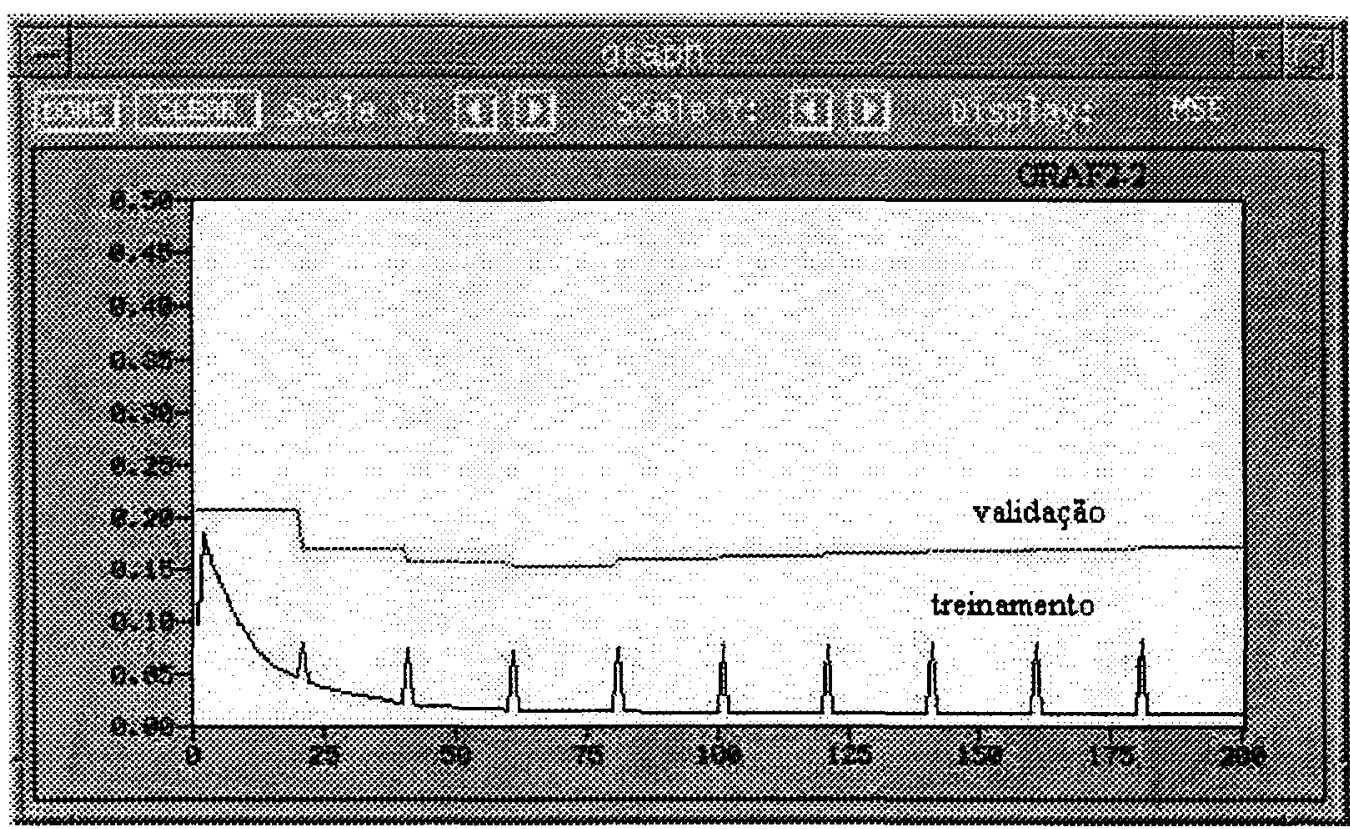

Figura 6.2 - Erro ao longo dos ciclos. Conjunto de dados 1 e rede MLP126-10-1

Os gráficos das Figuras 6.1 e 6.2 foram obtidos utilizando-se o conjunto de dados 1 , que distribui igualmente os ataques às portas nos dados de treinamento, validação e testes. Pode-se perceber que ambas as redes neurais definidas estão se comportando da maneira esperada, ou seja, o erro de treinamento cai assintóticamente até um valor mínimo ao longo dos ciclos, e o erro de validação se torna estacionário. Isso indica que a rede está aprendendo a reconhecer e generalizar os padrões. 


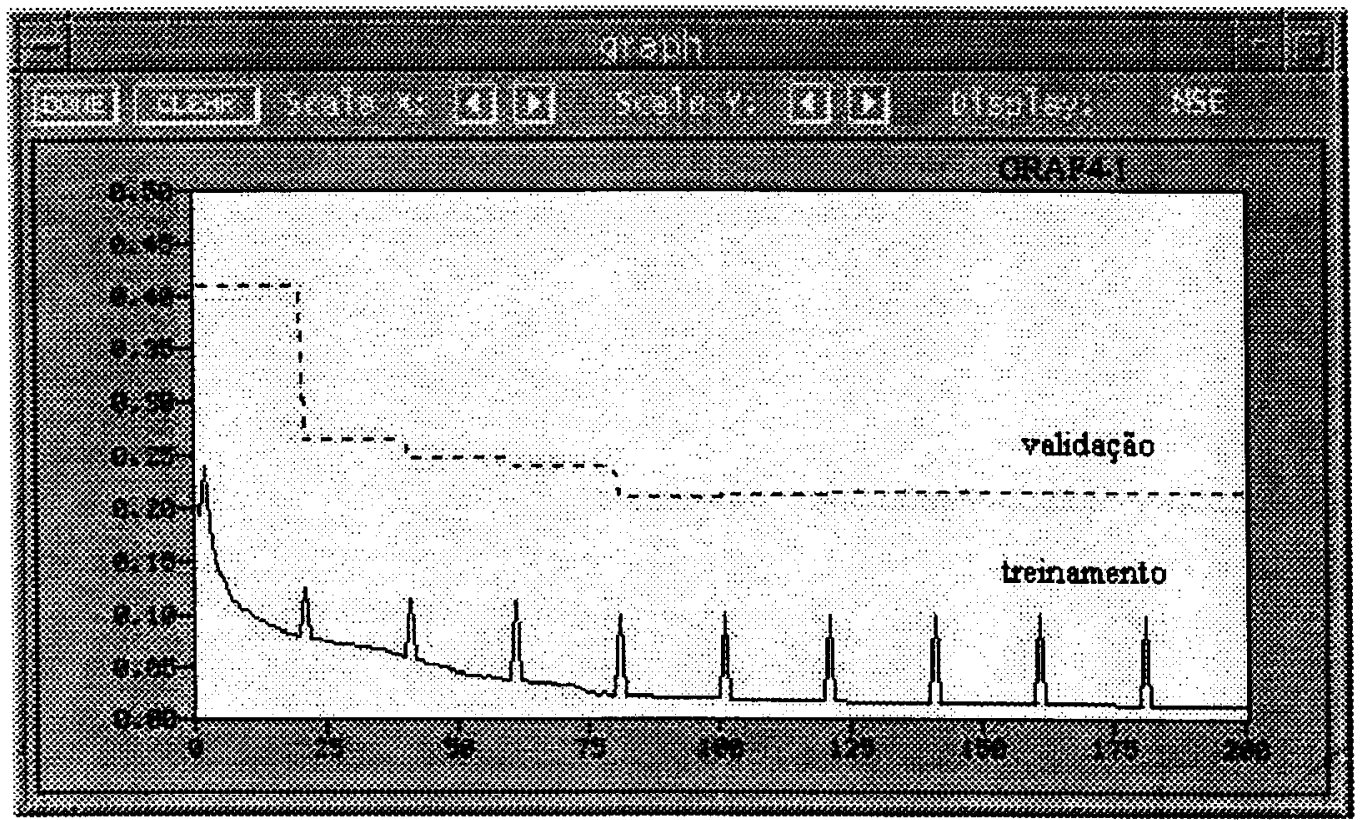

Figura 6.3 - Erro ao longo dos ciclos. Conjunto de dados 2 e rede MLP126-1

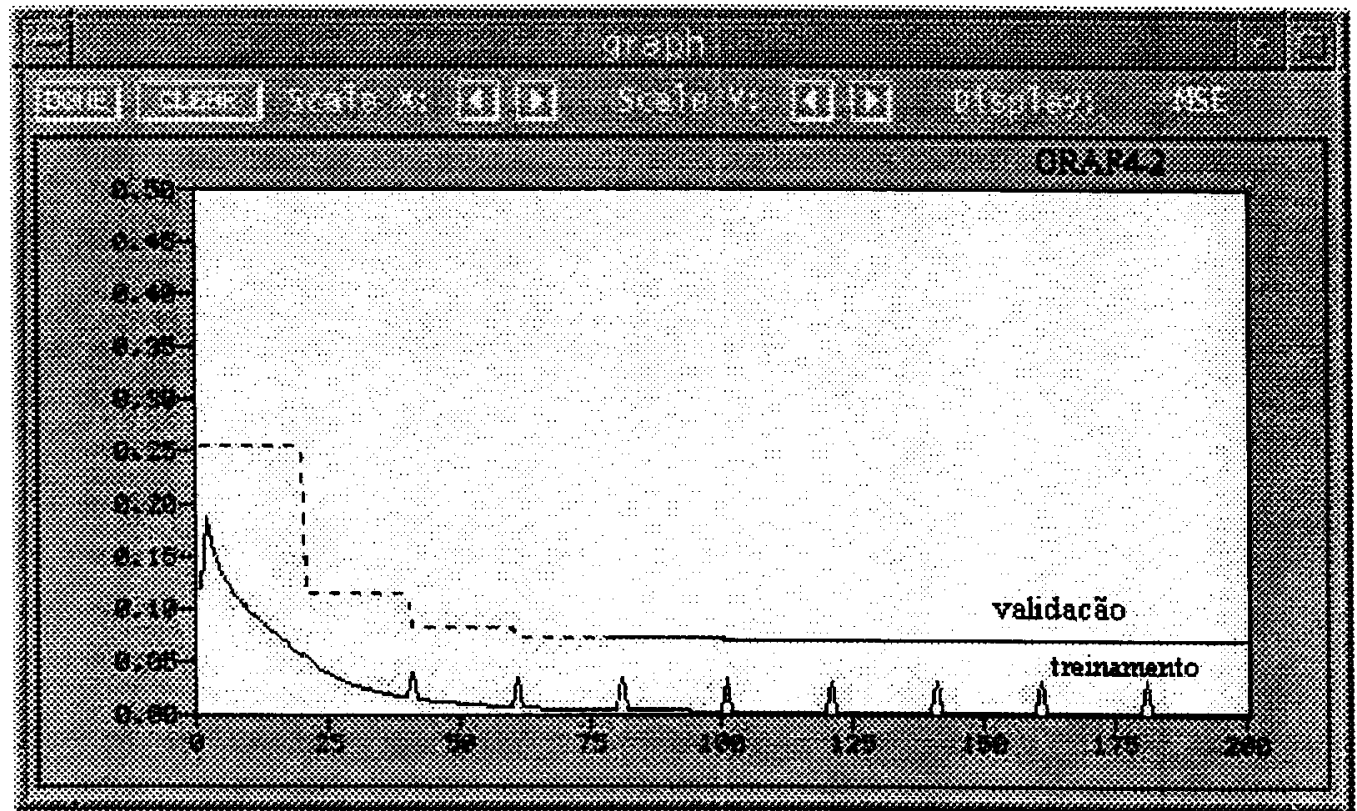

Figura 6.4 - Erro ao longo dos ciclos. Conjunto de dados 2 e rede MLP126-10-1

Os gráficos das Figuras 6.3 e 6.4 foram obtidos utilizando-se o conjunto de dados 2 , que é uma distribuição aleatória de ataques às diversas portas, conforme explicado na seção 6.5. Praticamente não há diferença de comportamento em comparação com o conjunto 1 , no qual os ataques são igualmente distribuídos. Pode-se perceber que ambas as redes neurais definidas estão se comportando da maneira esperada, ou seja, o erro de treinamento cai assintóticamente até um valor mínimo ao longo dos ciclos, e o erro de validação se torna estacionário. Novamente, este comportamento indica que a rede está aprendendo a reconhecer e generalizar corretamente os padrões. 


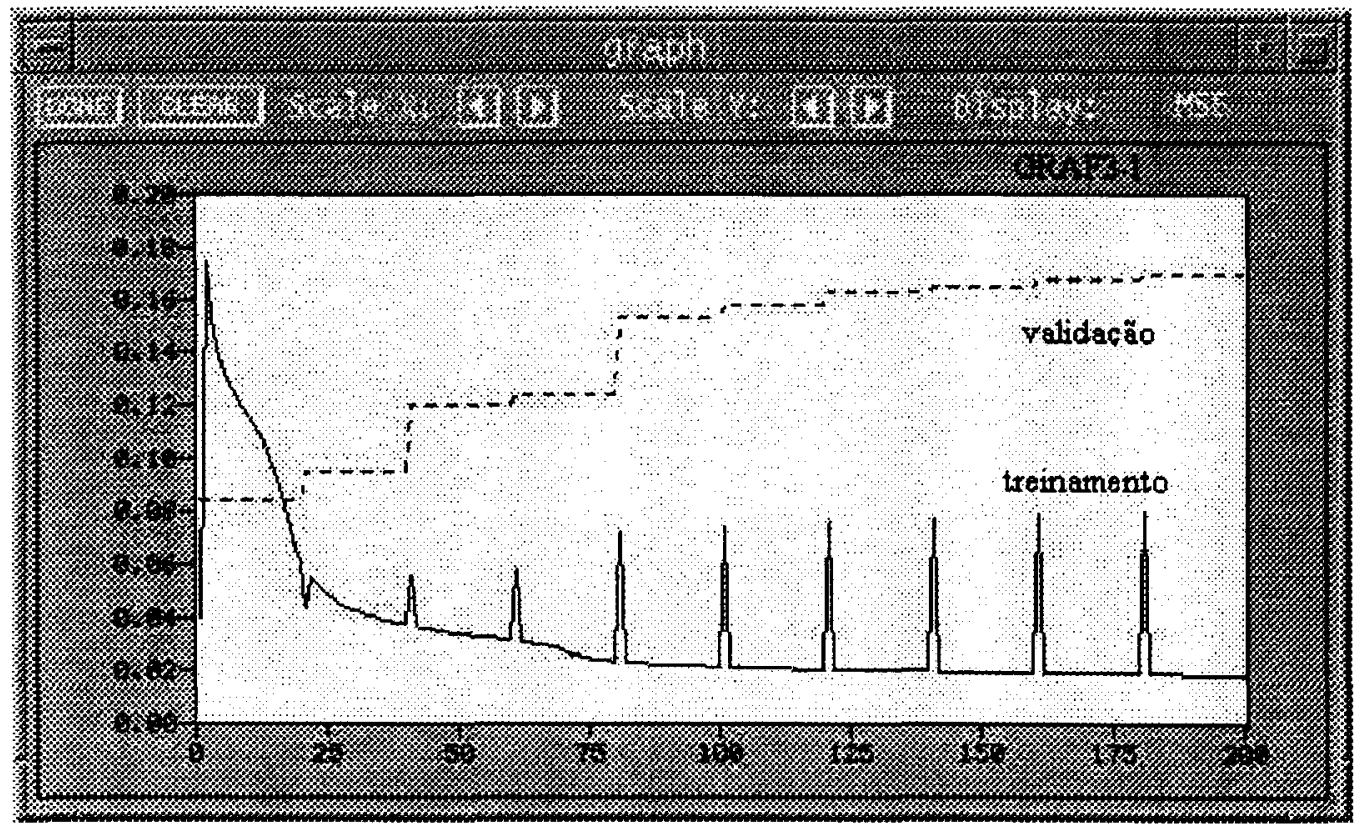

Figura 6.5 - Erro ao longo dos ciclos de. Conjunto de dados 3 e rede MLP126-1

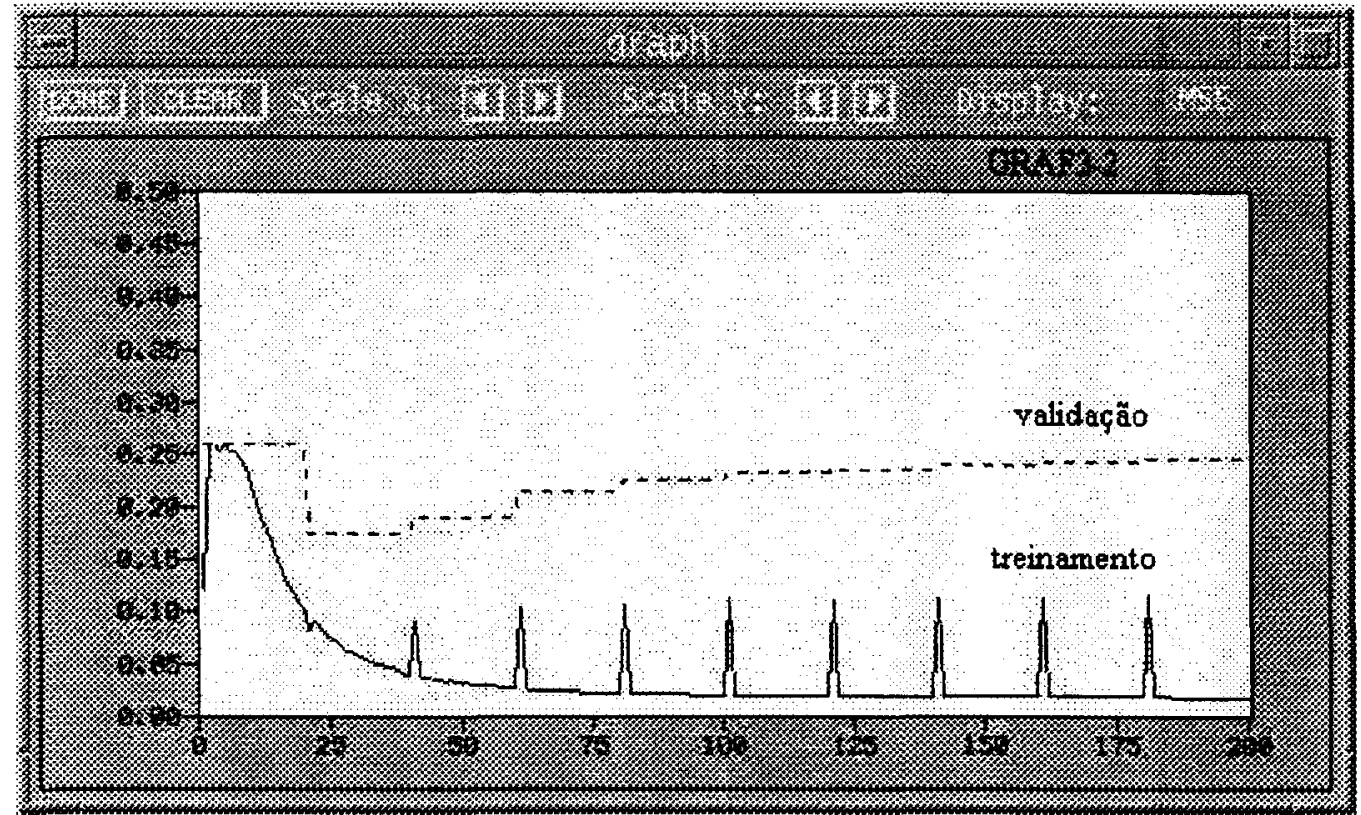

Figura 6.6 - Erro ao longo dos ciclos de. Conjunto de dados 3 e rede MLP126-10-1

Os gráficos das Figuras 6.5 e 6.6 foram obtidos utilizando-se o conjunto de dados 3 , que é também é uma distribuição aleatória de ataques às diversas portas (Tabela 6.2). Entretanto observa-se que, apesar do treinamento apresentar um comportamento assintótico satisfatório, o erro de validação cresce ao longo dos ciclos, o que indica que a rede neural está perdendo a capacidade de generalização. Isso ocorre em função de conjuntos de dados que contém uma ocorrência maior de um determinado tipo de padrão, o que acarreta resultados tendenciosos. Este comportamento, e suas implicações, voltarão a ser discutidos detalhadamente, mais adiante neste capítulo 


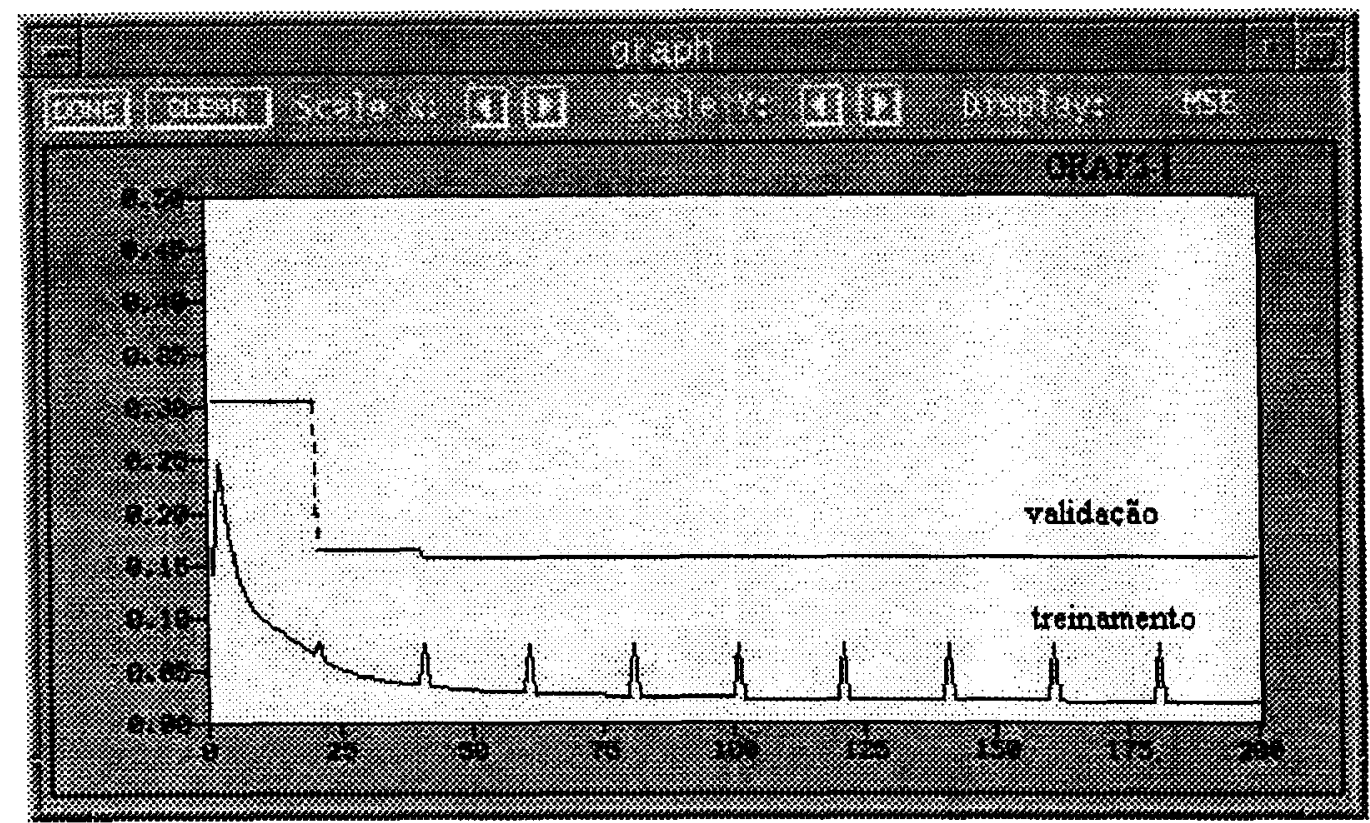

Figura 6.7 - Erro ao longo dos ciclos de. Conjunto de dados 4 e rede MLP126-1

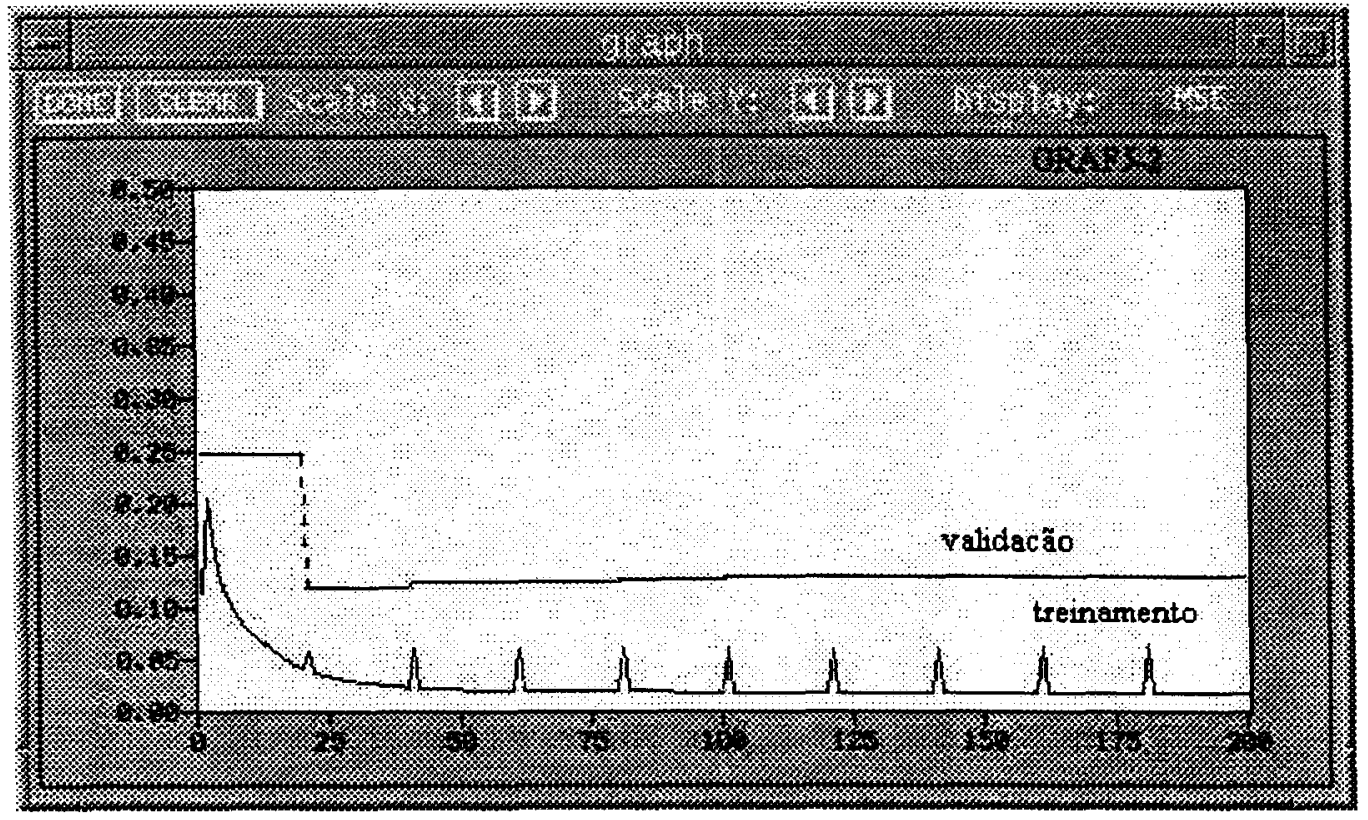

Figura 6.8 - Erro ao longo dos ciclos de. Conjunto de dados 4 e rede MLP126-10-1

Os gráficos das Figuras 6.7 e 6.8 são provenientes de aprendizagem com o conjunto de dados 4 , que também é uma distribuição aleatória de ataques às diversas portas (Tabela 6.4). Neste caso também não há diferença de comportamento em comparação com o conjunto 1 , no qual os ataques são igualmente distribuídos, e com o conjunto 2, no qual a distribuição de padrões também é aleatória. Pode-se perceber que ambas as redes neurais definidas estão se comportando da maneira esperada, ou seja, o erro de treinamento cai assintóticamente até um valor mínimo ao longo dos ciclos, e o erro de validação se torna estacionário indicando aprendizagem e generalização satisfatórios. 
Cumpre ressaltar que os pequenos picos que aparecem nos gráficos de treinamento (em todos os gráficos anteriores) são normais dentro do processo de validação cruzada [RWL94]. Observando os gráficos com cuidado, nota-se que os picos aparecem quando o processo de aprendizagem faz uma validação (no caso, a cada 20 ciclos), e os pesos da rede neural são reajustados. Neste ponto o erro de treinamento sofre uma pequena variação em função deste reajuste.

\subsubsection{Tempos de aprendizagem}

O tempo gasto pelo simulador neural no treinamento das redes é relativamente pequeno. Com o SNNS sendo executado em uma estação de trabalho Sun Sparc 5, compartilhada com outros usuários e processos, foram gastos em média 3 minutos para realizar 200 ciclos de aprendizagem com a rede MLP126-1. A rede MLP126-10-1, com os mesmos 200 ciclos, leva em média 8 minutos para ser treinada.

\subsubsection{Resultados dos processos de teste a generalização}

Como mencionado anteriormente, para cada processo de aprendizagem, foi submetido à rede já treinada, um conjunto de testes, e assim foi obtido um valor de erro quadrático médio para a determinação dos padrões desse conjunto. Os resultados dos testes para os 4 conjuntos de dados estão apresentados na Tabela 6.5.

\section{Tabela 6.5 - Resultados dos erros quadráticos médios}

\begin{tabular}{|l|l|l|l|l|c|}
\cline { 2 - 6 } \multicolumn{1}{c|}{} & \multicolumn{4}{c|}{ Conjuntos de dados de treinamento utilizados } \\
\hline Rede Neural & Conjunto 1 & Conjunto 2 & Conjunto 3 & Conjunto 4 & Média \\
\hline MLP126-1 & 0,07137 & 0,15295 & 0,20820 & 0,12746 & $\mathbf{0 , 1 3 9 9 5}$ \\
\hline MLP126-10-1 & 0,09166 & 0,13198 & 0,09074 & 0,12422 & $\mathbf{0 , 1 0 9 6 5}$ \\
\hline
\end{tabular}

Pode-se observar que o erro médio, referente aos 4 conjuntos de dados, apresentado para a rede neural sem camadas intermediárias foi de aproximadamente $14 \%$, e para a rede neural com uma camada intermediária de 10 neurônios ficou em cerca de $11 \%$.

A resposta produzida pela rede neural para os padrões de testes, é a mais importante. A capacidade de adaptação e generalização do modelo é avaliada pelos 
resultados obtidos com os padrões de testes, haja visto que estes se tratam de assinaturas com as quais a rede neural não teve contato durante a fase de aprendizagem. Isto significa que os resultados que ela determina para estes padrões, são inferidos a partir do processo de aprendizagem. Em outras palavras, tomando como base os comportamentos que lhe foram apresentados como intrusivos, a rede neural consegue reconhecer comportamentos ainda não vistos, e ainda determinar o quanto eles se aproximam ou não de uma intrusão.

A Tabela 6.5 evidencia a excelente capacidade de generalização do SADI: as redes neurais treinadas erraram a deteç̧ão de padrões ainda não vistos, em apenas cerca de 11 a $14 \%$. Isso significa que a rede neural treinada tem excelentes condições de generalizar, e detecta corretamente em torno de $86 \%$ dos padrões com os quais ainda não teve contato. Como as simulações de ataque cobrem a grande maioria das vulnerabilidades conhecidas, notificadas pelo CERT e órgãos similares, conforme discutido na seção 6.4 , pode-se concluir que a abrangência do método é muito boa.

\subsection{Resultados de generalização e adaptabilidade}

Para confirmar a capacidade de generalização do modelo, ou seja, a capacidade de determinar corretamente comportamentos ainda não vistos, foram realizadas ainda outras verificações sobre as redes treinadas, além daqueles testes com os conjuntos de dados mencionados em 6.6.6. Estes novos testes consistiram basicamente em submeter à rede neural treinada, a variações de um mesmo ataque ou de não-ataques, e assim observar a capacidade de generalização. Dois resultados mais ilustrativos destes testes, são mostrados a seguir.

\subsubsection{Resultados de variações de ataque}

A seguir são apresentadas os resultados inferidos para três variações de um mesmo ataque ao processo sendmail, com as quais a rede neural não teve contato durante a aprendizagem. As saídas foram obtidas diretamente dos arquivos produzidos pelo SNNS, tendo sido adicionados apenas alguns comentários para facilitar a interpretação. Antes da saida produzida pela rede neural, aparece a assinatura de ataque e a codificação binária que foi fornecidos como entrada. 
- Padrão de ataque 1

Assinatura submetida à rede:

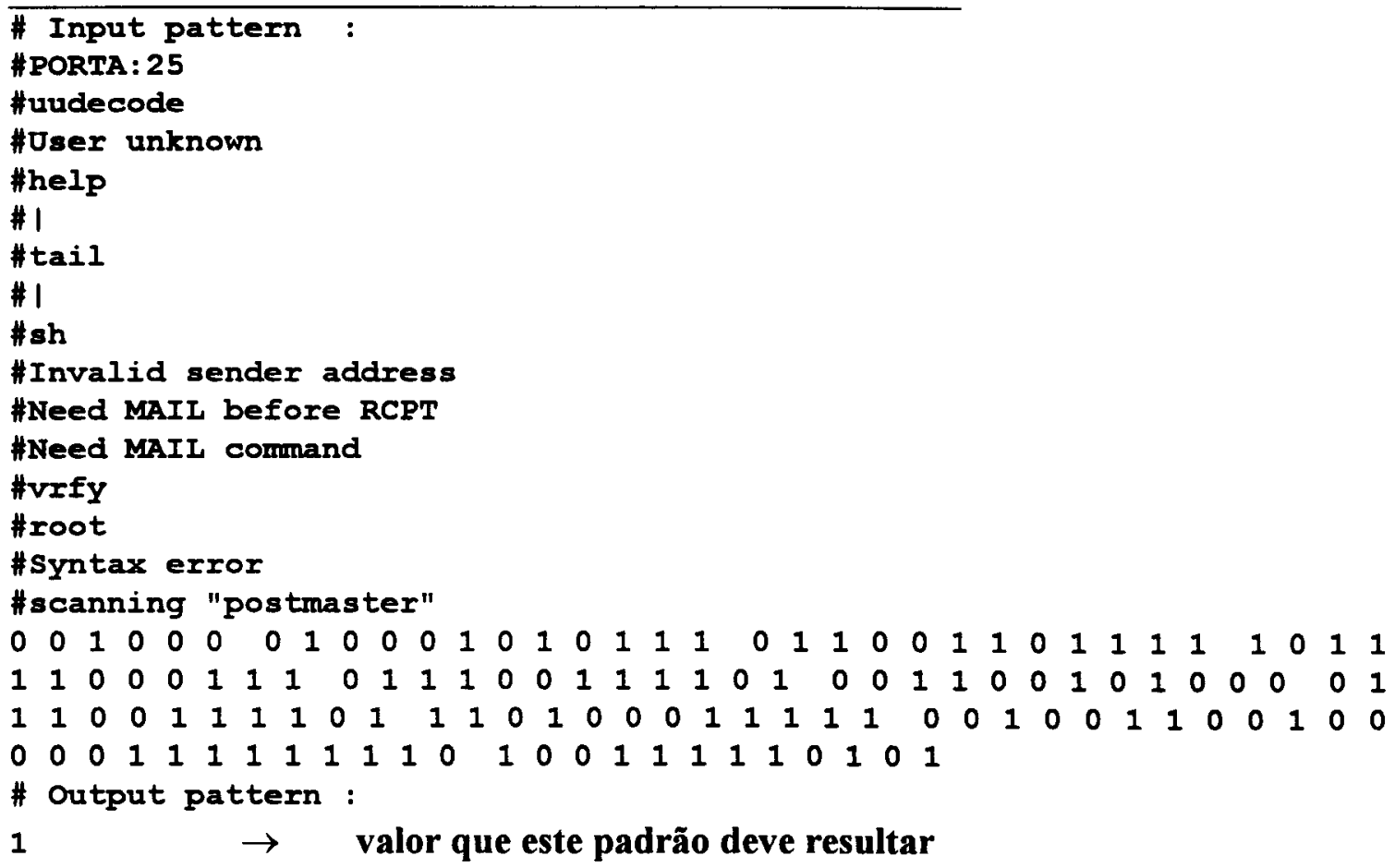

Padrão determinado pela rede neural para esta assinatura:

\#

$\begin{array}{llllllllllllllllllll}0 & 0 & 1 & 0 & 0 & 0 & 0 & 1 & 0 & 0 & 0 & 1 & 0 & 1 & 0 & 1 & 1 & 1 & 0 & 1\end{array}$

$\begin{array}{llllllllllllllllllll}1 & 0 & 0 & 1 & 1 & 0 & 1 & 1 & 1 & 1 & 1 & 0 & 1 & 1 & 1 & 1 & 0 & 0 & 0 & 1\end{array}$

$\begin{array}{llllllllllllllllllll}1 & 1 & 0 & 1 & 1 & 1 & 0 & 0 & 1 & 1 & 1 & 1 & 0 & 1 & 0 & 0 & 1 & 1 & 0 & 0\end{array}$

$\begin{array}{llllllllllllllllllll}1 & 0 & 1 & 0 & 0 & 0 & 0 & 1 & 1 & 1 & 0 & 0 & 1 & 1 & 1 & 1 & 0 & 1 & 1 & 1\end{array}$

$\begin{array}{llllllllllllllllllll}0 & 1 & 0 & 0 & 0 & 1 & 1 & 1 & 1 & 1 & 0 & 0 & 1 & 0 & 0 & 1 & 1 & 0 & 0 & 1\end{array}$

$\begin{array}{llllllllllllllllllll}0 & 0 & 0 & 0 & 0 & 1 & 1 & 1 & 1 & 1 & 1 & 1 & 1 & 0 & 1 & 0 & 0 & 1 & 1 & 1\end{array}$

$\begin{array}{llllll}1 & 1 & 0 & 1 & 0 & 1\end{array}$

$\#$

$0.9961 \rightarrow$ valor determinado pela rede para este padrão 


\section{- Padrão de ataque 2}

Assinatura submetida à rede:

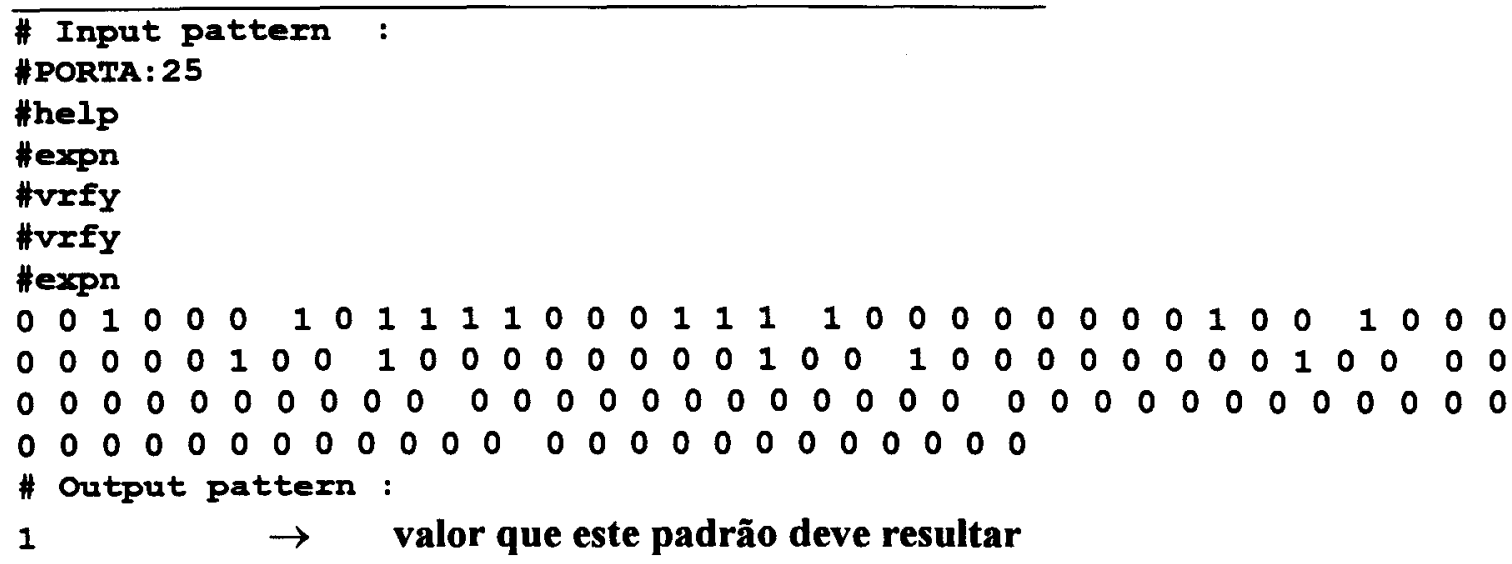

Padrão determinado pela rede neural para esta assinatura:

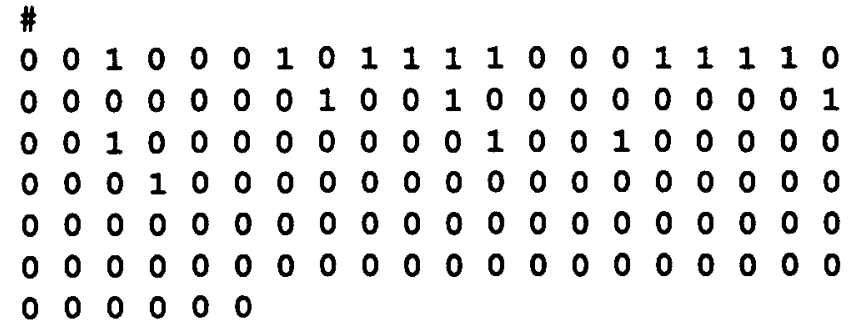

\section{- Padrão de ataque 3}

Assinatura submetida à rede:

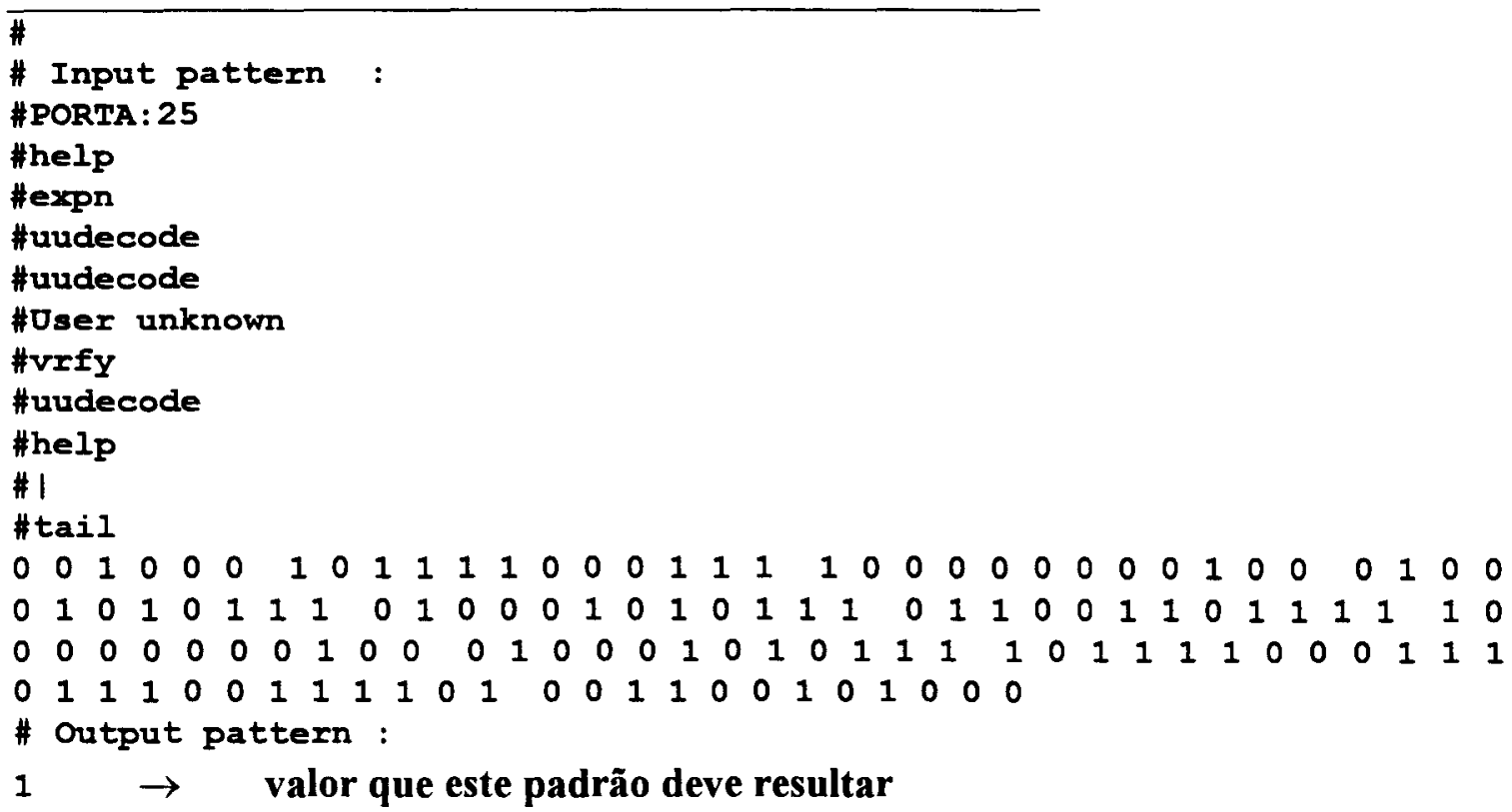


Padrão determinado pela rede neural para esta assinatura:

\#

$\begin{array}{lllllllllllllllllllll}0 & 0 & 1 & 0 & 0 & 0 & 1 & 0 & 1 & 1 & 1 & 1 & 0 & 0 & 0 & 1 & 1 & 1 & 1 & 0\end{array}$

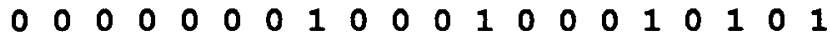

$\begin{array}{lllllllllllllllllllll}1 & 1 & 0 & 1 & 0 & 0 & 0 & 1 & 0 & 1 & 0 & 1 & 1 & 1 & 0 & 1 & 1 & 0 & 0 & 1\end{array}$

$\begin{array}{lllllllllllllllllllll}1 & 0 & 1 & 1 & 1 & 1 & 1 & 0 & 0 & 0 & 0 & 0 & 0 & 0 & 0 & 1 & 0 & 0 & 0 & 1\end{array}$

$\begin{array}{llllllllllllllllllll}0 & 0 & 0 & 1 & 0 & 1 & 0 & 1 & 1 & 1 & 1 & 0 & 1 & 1 & 1 & 1 & 0 & 0 & 0 & 1\end{array}$

$\begin{array}{lllllllllllllllllllll}1 & 1 & 0 & 1 & 1 & 1 & 0 & 0 & 1 & 1 & 1 & 1 & 0 & 1 & 0 & 0 & 1 & 1 & 0 & 0\end{array}$

$\begin{array}{lllllll}1 & 0 & 1 & 0 & 0 & 0\end{array}$

$0.98031 \rightarrow$ valor determinado pela rede para este padrão

\subsubsection{Resultados de variações de um não-ataque}

Neste segundo teste de generalização foi utilizada uma assinatura de ataque a um processo FTP (porta 21), mas esta assinatura foi propositalmente modificada, trocandose os binários que identificam a porta, para que ela fosse codificada como um ataque ao processo de sendmail (porta 25). Ou seja, todos os componentes da assinatura são indicativos de um ataque ao processo de FTP, mas uma vez provenientes de uma atividade na porta 25 , não fazem sentido como um ataque.

Isso fez com que todo o corpo da assinatura se tornasse muito parecido com uma assinatura de ataque válida, diferindo em alguns poucos bits iniciais. Além disso, a rede não recebeu aquela assinatura original de ataque ao FTP durante o processo de treinamento. Se a rede consegue generalizar corretamente, ela deve identificar essa assinatura como pouco suspeita, apesar de grande parte de seus bits consistirem de uma seqüência de ataque válida, entretanto, em outra porta. A seguir, pelo resultados que seguem estas variações, podemos observar que ambos foram detectados como pouco suspeitos, o que novamente confirma a capacidade de generalização. 
- Padrão de não-ataque 1

Assinatura submetida à rede:

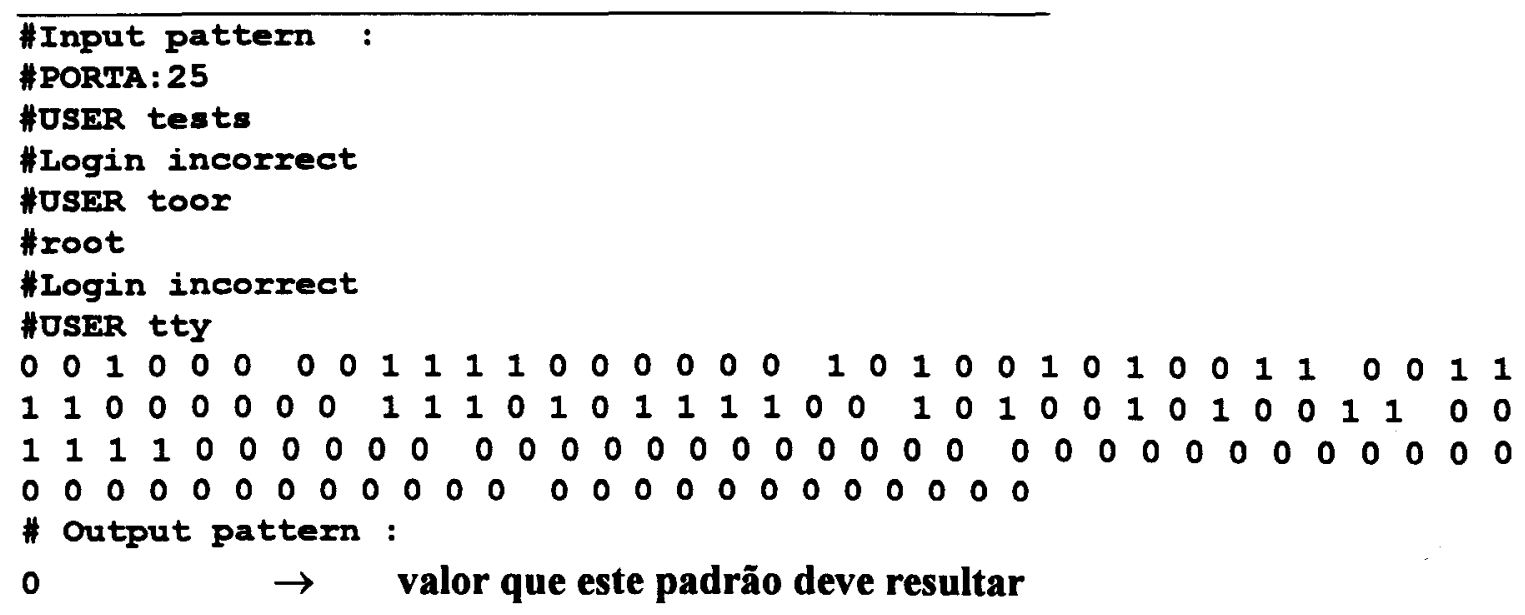

Padrão determinado pela rede neural para esta assinatura:

$\#$

$0 \begin{array}{llllllllllllllllllll}0 & 0 & 1 & 0 & 0 & 0 & 0 & 0 & 1 & 1 & 1 & 1 & 0 & 0 & 0 & 0 & 0 & 0 & 1 & 0\end{array}$

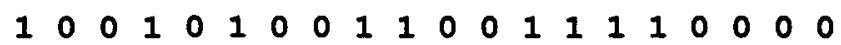

$\begin{array}{lllllllllllllllllllll}0 & 0 & 1 & 1 & 1 & 0 & 1 & 0 & 1 & 1 & 1 & 1 & 0 & 0 & 1 & 0 & 1 & 0 & 0 & 1\end{array}$

$\begin{array}{llllllllllllllllllll}0 & 1 & 0 & 0 & 1 & 1 & 0 & 0 & 1 & 1 & 1 & 1 & 0 & 0 & 0 & 0 & 0 & 0 & 0 & 0\end{array}$

$0 \begin{array}{lllllllllllllllllll}0 & 0 & 0 & 0 & 0 & 0 & 0 & 0 & 0 & 0 & 0 & 0 & 0 & 0 & 0 & 0 & 0 & 0 & 0\end{array}$

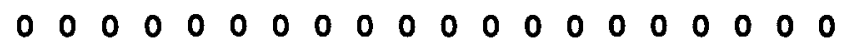

$\begin{array}{lllllll}0 & 0 & 0 & 0 & 0 & 0\end{array}$

$0.2615 \rightarrow$ valor determinado pela rede para este padrão

\section{- Padrão de não-ataque 2}

Assinatura submetida à rede:

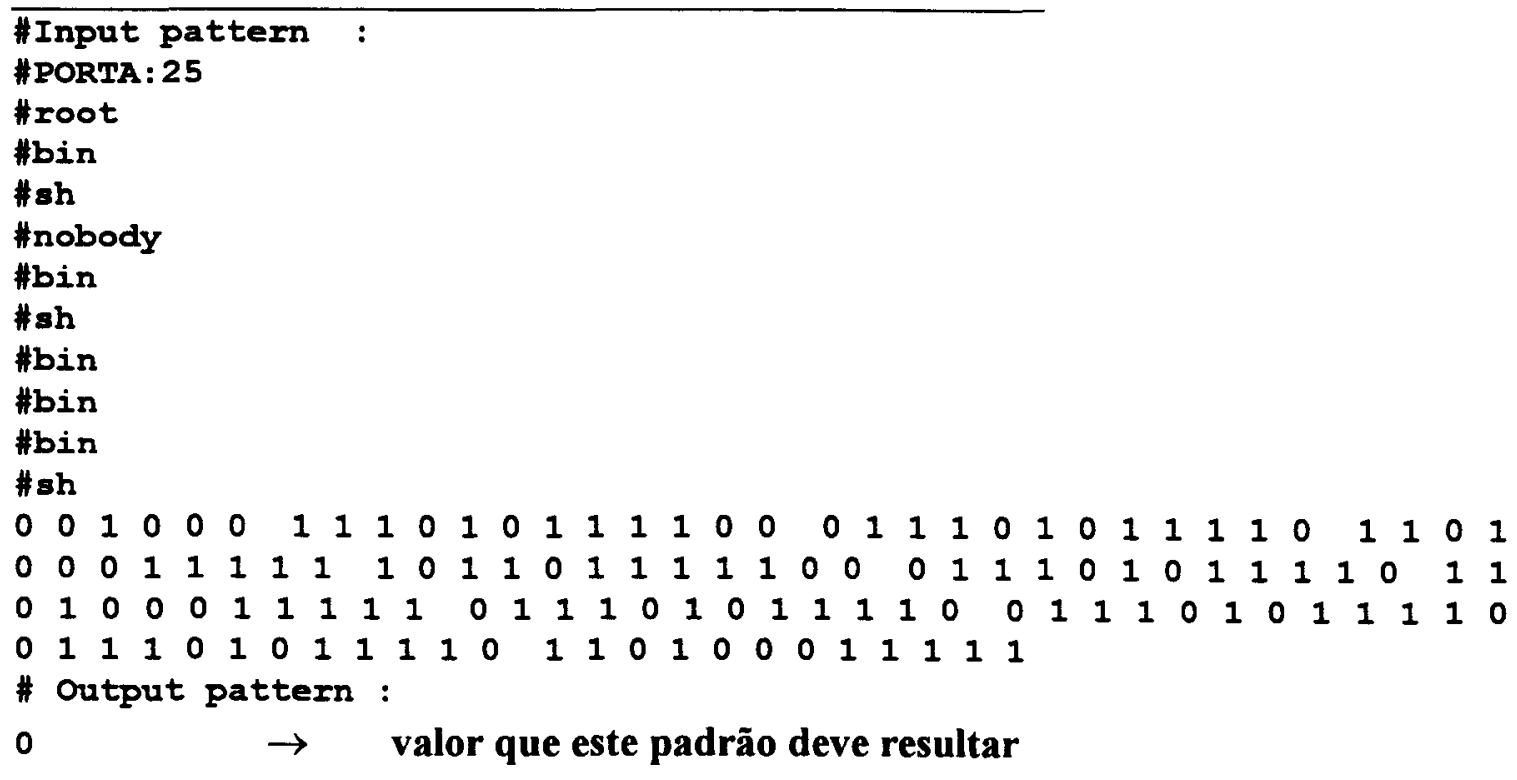


Padrão determinado pela rede neural para esta assinatura:

$\#$

$\begin{array}{llllllllllllllllllll}0 & 0 & 1 & 0 & 0 & 0 & 1 & 1 & 1 & 0 & 1 & 0 & 1 & 1 & 1 & 1 & 0 & 0 & 0 & 1\end{array}$

$\begin{array}{llllllllllllllllllll}1 & 1 & 0 & 1 & 0 & 1 & 1 & 1 & 1 & 0 & 1 & 1 & 0 & 1 & 0 & 0 & 0 & 1 & 1 & 1\end{array}$

$\begin{array}{llllllllllllllllllll}1 & 1 & 1 & 0 & 1 & 1 & 0 & 1 & 1 & 1 & 1 & 1 & 0 & 0 & 0 & 1 & 1 & 1 & 0 & 1\end{array}$

$\begin{array}{llllllllllllllllllll}0 & 1 & 1 & 1 & 1 & 0 & 1 & 1 & 0 & 1 & 0 & 0 & 0 & 1 & 1 & 1 & 1 & 1 & 0 & 1\end{array}$

$\begin{array}{llllllllllllllllllll}1 & 1 & 0 & 1 & 0 & 1 & 1 & 1 & 1 & 0 & 0 & 1 & 1 & 1 & 0 & 1 & 0 & 1 & 1 & 1\end{array}$

$\begin{array}{llllllllllllllllllll}1 & 0 & 0 & 1 & 1 & 1 & 0 & 1 & 0 & 1 & 1 & 1 & 1 & 0 & 1 & 1 & 0 & 1 & 0 & 0\end{array}$

$\begin{array}{llllll}0 & 1 & 1 & 1 & 1 & 1\end{array}$

$0.03344 \rightarrow$ valor determinado pela rede para este padrão

\subsection{O assistente de adaptabilidade}

Utilizando o AAIA, foram realizados vários testes de inserção e codificação de novos comportamentos intrusivos, que surgiram durante o desenvolvimento do trabalho. A codificação binária utilizada, que permite a independência de códigos já discutida, mostrou-se muito adequada e de fácil utilização. As novas assinaturas podem ser codificadas à medida que surgem novos alertas de segurança.

O novo comportamento é simulado em rede e capturado diretamente por uma parte do módulo de captura e conexão, que foi incorporada ao AAIA. Dessa forma, a sessão especificada, com a assinatura de ataque completa, é registrada num dispositivo de saída, (normalmente em disco). Depois, ainda com o auxilio do AAIA, o comportamento é separado em strings relevantes, e o administrador pode verificar se esses strings já foram ou não codificados e assim proceder os ajustes necessários. Finalizando, o AAIA permite que a assinatura capturada seja novamente verificada, filtrada e transformada em seu correspondente vetor binário, por intermédio do módulo analisador semântico incorporado. Há ainda a possibilidade do administrador não necessitar simular o comportamento direto na rede, mas apenas gerar um arquivo texto com os elementos componentes do ataque notificado ou observado, e proceder apenas ao processo de codificação e formação da assinatura binária.

Durante o andamento deste trabalho, cada string componente das assinaturas de ataque foi inicialmente codificado com 11 bits. Esses 11 bits permitem codificar cerca de 40 códigos binários que sejam diferentes entre si por 3 bits. À medida que o trabalho se desenvolveu, houve a necessidade de modificar esta codificação, em função de novos 
tratamentos adotados e novas assinaturas codificadas, de maneira a acomodar um número maior de strings. A codificação foi então modificada para 12 bits, que permite definir cerca de 90 códigos binários diferindo por no mínimo 3 bits. Essa modificação foi feita sem nenhum problema com o auxilio do AAIA e não foi necessário executar qualquer modificação nos módulos dos programas, nem redefinir os strings já codificados. Foi necessário apenas que as sessões com assinaturas anteriormente capturadas fossem codificadas novamente para 12 bits, mas isso pode ser realizado rapidamente com o AAIA. Uma vez que as assinaturas foram recodificadas, a rede neural pode ser rapidamente treinada para incorporar a interpretação dos novos comportamentos.

\subsection{Considerações gerais sobre os resultados das redes neurais}

De uma maneira geral, as predições do comportamento intrusivo pelas redes neurais foram bastante satisfatórias e comprovam a eficiência do modelo implantado pelo SADI. Mais importante é observar que o comportamento apresentado, tanto pelos erros de treinamento como de validação, decaem ao longo do tempo e tendem a se estabilizar em um valor assintóticamente pequeno. Isso é satisfatório, e ocorre em todos os resultados dos conjuntos de dados utilizados, com exceção dos resultados apresentados com o conjunto número 3, conforme discutido anteriormente junto às Figuras 6.5 e 6.6. Nesses casos, ainda que o erro de treinamento diminua, o erro de validação vai aumentando ao longo dos ciclos, notadamente quando os dados são submetidos à rede MLP126-1 (sem camadas intermediárias). Isto é chamado de over-fitting (ou ainda, over-trainning) e significa que a rede neural está ficando tendenciosa, passando a perder sua capacidade de generalização.

O over-fitting ocorre, em geral, porque os dados que estão sendo usados no conjunto de treinamento são tendenciosos, ou seja, estão mal distribuídos com relação à variedade de padrões possíveis. Uma inspeção no conjunto de dados 3 , que foi aleatoriamente montado, mostra que é exatamente essa a razão. Nos dados há mais casos referentes a uma porta ou a um tipo de intrusão particular do que outros. A melhor maneira de se evitar este problema é garantir uma melhor distribuição dos padrões. Outro procedimento que pode ser adotado, é interromper o processo de treinamento, 
antes que o over-fitting comece a se manifestar nos dados, ou seja, submetendo a rede a um número menor de ciclos de treinamento. Entretanto, observando os gráficos das Figuras 6.5 e 6.6, essa opção não parece viável.

Se os resultados obtidos com o conjunto 3 forem desconsiderados, a média dos erros de teste de ambas as redes neurais ficam em torno de $12 \%$, conforme pode ser observado na Tabela 6.6 .

Tabela 6.6 - Resultados dos erros quadráticos médios, desconsiderando-se 0 conjunto 3

\begin{tabular}{|c|c|c|c|c|}
\hline \multirow[b]{2}{*}{ Rede Neural } & \multicolumn{4}{|c|}{ Conjuntos de dados de treinamento utilizados } \\
\hline & Conjunto 1 & Conjunto 2 & Conjunto 4 & Média \\
\hline MLP126-1 & 0,07137 & 0,15295 & 0,12746 & 0,12746 \\
\hline MLP126-10-1 & 0,09166 & 0,13198 & 0,12422 & 0,12422 \\
\hline
\end{tabular}

Esse também é um resultado interessante, porque mostra que ambas as redes neurais sem camada intermediária (MLP126-1), e com uma camada intermediária (MLP126-10-1), possuem um comportamento satisfatório, e muito próximo, na determinação de um padrão ao qual ainda não tiveram contato. Isso está de acordo com a discussão de [WRH91], onde os autores mostram que redes mínimas apresentam um resultado de generalização melhor ou igual a redes mais complexas. Por outro lado, esse valor de $12 \%$ pode representar um limite prático para o sistema, em função dos dados de treinamento utilizados. Para uma melhor interpretação desse resultado, é necessária uma investigação mais profunda do comportamento de diversas redes neurais, com outras funções e ativação e outros procedimentos de treinamento. Entretanto, este estudo não foi realizado por se encontrar fora dos propósitos deste trabalho, o qual concentra esforços em mostrar a eficácia do método de detecção proposto. 


\section{Conclusões e Sugestões para Trabalhos Futuros}

Este capítulo apresenta as conclusões, através da sintese da experiência obtida com este trabalho. Também são feitas algumas propostas para dar continuidade à linha de pesquisa em segurança e detecção de intrusos em redes de computadores.

\subsection{Conclusões gerais}

Este trabalho, apresentou um modelo de deteç̧ão de intrusos, que utiliza padrões intrusivos capturados na rede. Os resultados obtidos a partir do protótipo SADI, indicam que o uso de identificação de padrões, para representar e detectar intrusões em redes de computadores é adequado. Os sistemas detetores de intrusão não obtiveram até hoje uma ampla aceitação, principalmente pelas exigências de armazenamento, padronização e tratamento de dados, e também devido ao impacto causado sobre a performance dos computadores envolvidos. De uma maneira oposta, o SADI pode ser utilizado sem grandes exigências de equipamentos ou recursos e, principalmente, sem causar interferência ou exigir configurações especiais no ambiente sob monitoração.

Além disso, a capacidade adaptativa e de generalização é um avanço significativo. Os resultados mostram que a rede neural, adequadamente treinada, pode detectar corretamente os comportamentos aos quais ainda não teve contato. Além disso, a inserção e adequação de novos comportamentos pode ser facilmente obtida por intermédio da codificação de novas assinaturas e do re-treinamento da rede. Para isso, basta que o novo comportamento intrusivo seja simulado e capturado, ou mesmo inserido a partir de dados fornecidos por agências de segurança públicas ou privadas, ou a partir de um órgão centralizador de segurança da localidade. Isto permite que o 
detector permaneça utilizável em diversas situações, sem que haja necessidade de modificações significativas, ou mesmo de pessoal especializado em segurança.

A capacidade de generalização e adaptação é um diferencial importante, se compararmos o SADI com métodos estatísticos, baseados em detecção por anomalias. Estes métodos estatísticos, amplamente utilizados com sucesso na análise de dados de auditoria de sistemas isolados, possuem dificuldade em detectar comportamentos fortemente dependentes da seqüência de ocorrência, ou mesmo eventos interrelacionados, como são a maioria das ações intrusivas em sistemas de rede. Ao contrário desses sistemas, este é um ponto forte no SADI, e isto é proveniente exatamente dos mecanismos de generalização da rede neural, baseando-se para isso num bom conjunto de treinamento, e numa filtragem adequada de pacotes.

É interessante notar que a aplicação da detecção de assinatura de ataques, e análise por rede neural, fornece um mecanismo simples, elegante e confiável na detecção de intrusos em redes de computadores. A representação dos ataques em assinaturas foi feita de uma maneira natural, próxima da qual os administradores estão habituados a interpretar os eventos de segurança. A não interferência na rede de computadores, monitorada como um todo, ou mesmo em outros mecanismos de segurança ou auditores já existentes, é um atrativo a mais para a utilização do método. Inclusive, esta característica permite que o SADI seja utilizado em conjunto com outras técnicas, aumentando assim a segurança global do ambiente.

O desenvolvimento do protótipo, baseado no modelo proposto, resultou em diversos subsistemas importantes, que podem possuir aplicações específicas dentro do gerenciamento de segurança, ou mesmo em outras situações. Estas contribuições, inovações e possibilidades de utilização são discutidas a seguir.

\subsection{Contribuições específicas deste trabalho}




\subsubsection{Determinação do comportamento intrusivo}

A análise do comportamento intrusivo, e a possibilidade de estabelecer um mecanismo de captura de assinaturas de ataque dentro das sessões de rede, é uma das contribuições mais importantes deste trabalho. Esta característica foi extensamente discutida, quando foram apresentados os resultados da formação das assinaturas, ao longo da seção 6.4. A união da observação deste comportamento, com a análise por intermédio de uma rede neural, é que faz com que este método seja inovador e, principalmente, eficaz. Os comportamentos observados podem ser usados em outras aplicações, como por exemplo, o treinamento de pessoal especializado em segurança de redes de computadores, ou até mesmo no desenvolvimento de sistemas tutoriais automáticos, para preparar os administradores para agirem em situações de emergência. Podem ainda, servir como base para o desenvolvimento de outros mecanismos de segurança, ou mesmo detectar e alertar para a necessidade de correções de falhas em sistemas operacionais ou softwares específicos.

\subsubsection{Determinação e codificação de um conjunto de assinaturas de ataque}

Outro resultado muito positivo deste trabalho foi a possibilidade de obter um conjunto de assinaturas de ataque de uma variedade de comportamentos intrusivos. Foram pesquisadas, em diversas fontes, referências sobre conjuntos de assinaturas de ataque. Ao se iniciar debate sobre este tema nos grupos de Usenet News, especificamente comp.security.unix e comp.security.misc, no início de 1996, ficou claro que as assinaturas de ataque tratam-se de dados altamente sigilosos, não normalmente disponibilizados por quem os possui. Assim, informações públicas sobre estas assinaturas e a maneira de obtenção, são praticamente inexistentes, mesmo no meio acadêmico. Este trabalho também oferece uma contribuição importante neste sentido, ou seja, prover um modelo e uma técnica eficiente, e principalmente independente, de determinação e codificação de comportamentos intrusivos e eventos de segurança em redes de computadores, ou mesmo em sistemas isolados. Este método pode ser usado não somente para o estudo e aplicação em sistemas de segurança de rede, mas também, por exemplo, para análise de ações ilícitas e interpretação de evidências criminais por intermédio de agências de combate ao crime. 


\subsubsection{A captura e o tratamento de sessões}

A contribuição dos mecanismos de captura e tratamento de sessões reside principalmente na escolha de uma biblioteca apropriada para a realização dos procedimentos desejados. O módulo de captura e o módulo de conexão podem ser facilmente modificados e utilizados, de forma independente, para outras análises de comportamento intrusivo e, por conseqüência, para obtenção de assinaturas de ataque. Além disso são indicados em outras aplicações e finalidades que não sejam apenas aquelas relacionadas com segurança. Como exemplo, podemos citar o desenvolvimento de mecanismos de controle de tráfego e análise e determinação de falhas em redes.

Um grande atrativo é que os mecanismos de tratamento de pacotes, formados pelo módulo de captura e pelo módulo de conexão, não exigem grandes recursos de processamento, e são altamente portáveis, haja visto que a biblioteca libpcap também está disponível para diversos sistemas operacionais. O SADI, desenvolvido originalmente sobre Linux 2.2.0, foi portado e testado com sucesso sobre os sistemas operacionais FreeBSD 2.1.6, SunOS 4.1.3_U1, Solaris 2.5 e IBM AIX 4.0. O desenvolvimento, permite que o sistema seja facilmente implantado em um micro-computador portátil, tipo notebook, com sistema operacional Unix para processadores da linha $80 x 86$, o que o faz independente de recursos locais, e fornece uma grande mobilidade e agilidade. Isso permite, por exemplo, que um administrador geral de segurança possua sempre pronta uma máquina de sua confiança, para rapidamente analisar redes que eventualmente estejam sob suspeita de comprometimento dentro de uma determinada localidade.

\subsection{Sugestões para continuidade e aprimoramento deste trabalho}

\subsubsection{Considerações gerais}

A primeira necessidade para a continuação deste trabalho é interligar os módulos do sistema, fazendo com que eles se comuniquem, de maneira independente. Conforme discutido anteriormente, para facilitar o desenvolvimento, os módulos foram produzidos e testados independentemente. É interessante que os módulos de captura e pré-seleção, possam residir numa máquina separada do analisador semântico e da rede neural, com 
um sistema de gerenciamento. Isso permite monitorar diversas redes, cada qual com um sistema de captura de pacotes, e juntar a análise e as informações de alerta num agente central de segurança. Assim também seria possível inter-relacionar eventos acontecendo em sub-redes distintas e, eventualmente, possuir um módulo global de pré-seleção. Por exemplo: se uma sub-rede identificou eventos de segurança vindos de uma determinada origem, e disparou a captura, esta informação é enviada para o centralizador de segurança, que determina que todos os sistemas de captura, de todas as sub-redes, passem a capturar dados daquela origem, mesmo que ainda não tenham havido eventos significativos nestas sub-redes. Em seguida, são discutidas algumas dessas propostas para esta unificação do sistema.

\subsubsection{Sistema de Gerenciamento}

É proposto o desenvolvimento de um módulo de gerenciamento, independente do módulo de segurança. Os dois módulos se comunicam via TCP/IP, o que fornece a capacidade do gerente ser colocado em qualquer ponto da Internet. Entretanto, por outro lado possibilita o uso de ferramentas do tipo sniffers que, uma vez comandadas pelo próprios atacantes, podem interceptar informações importantes. No entanto, a possibilidade de colocar o módulo de gerência em qualquer lugar é uma característica fundamental, inclusive para que o agente possa servir a uma comunidade de administradores (e.g. numa grande empresa, com vários departamentos e setores). Neste sentido, o sistema de gerenciamento deve possuir um subsistema que tenha como objetivo disponibilizar todas as funções que tratem dos aspectos de segurança do gerenciamento de dados, como por exemplo as técnicas SSL, MD5, DES, RSA e S/Key, discutidas em [GS96].

Há uma proposta de que o módulo de gerenciamento seja desenvolvido como uma ferramenta extra no sistema NetTracker [MMM97], desenvolvido no ICMSC/USP, e que, além de aplicações de detecção de intrusão, pode incorporar o monitoramento de outras informações e dados da rede, também oriundos ou não do agente de segurança:

- Qual a utilização da conexão externa;

- Quais as máquinas, redes ou domínios mais acessados interna e externamente; 
- Quais os horários de pico de utilização;

- Quais os serviços mais utilizados e por quem.

O NetTracker, cuja estrutura é reproduzida na Figura 7.1, trata-se de um sistema gerenciador, e usa a arquitetura SNMP [Cas90] e SNMPv2 [Cas93a, Cas93b] para busca e troca de informações de gerenciamento. $O$ sistema permite a utilização de recursos multimídia, através dos quais podem ser apresentadas ou capturadas imagens (fotos digitalizadas de pessoas - normalmente administradores - e equipamentos, imagens fornecidas por câmeras de monitoração localizadas em pontos estratégicos, videoconferência para comunicação gerente-gerente e gerentes-usuários, etc) e áudio (e.g. mensagens de alerta gravadas, sinais sonoros, e conversação on-line).

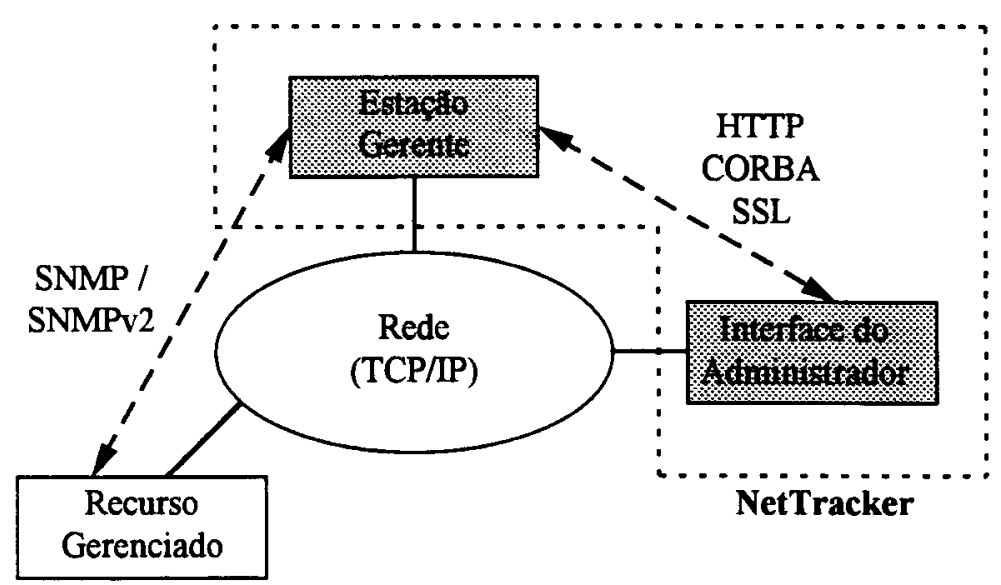

Figura 7.1 - Estrutura de funcionamento do sistema NetTracker [MMM97]

As informações e dados relativos à rede podem ser apresentados ao administrador graficamente, onde os elementos de redes são diferenciados por figuras (hosts, gateways, rede, etc) e cores diferentes que caracterizam os estados dos elementos de rede (up, down, não-gerenciável, suspeito de intrusão, etc) de forma a simplificar a visualização e facilitar o acesso as informações de monitoramento.

Desta forma, o agente de segurança irá se comunicar com o sistema de gerenciamento através do envio de notificações sobre a ocorrência de algum evento importante (detecção de intrusão), ou por pedido explícito do sistema de gerenciamento. 
A notificação ao responsável pela rede atacada poderia ser feita automaticamente, em função da gravidade dos eventos, por intermédio do controle via Internet, de pagers, geradores de faxes ou similares. $\mathrm{O}$ administrador de uma rede qualquer, poderia então visualizar, em determinado momento, o estado de cada sessão que passa pelo agente de segurança, podendo filtrar aquelas que mais lhe interessem. Através de um sistema gradativo de coloração, pode-se indicar quais sessões são consideradas normais (por exemplo tendendo para verde), e quais são vistas pelo sistema de segurança como potencialmente perigosas (tendendo ao vermelho). A cor seria derivada do parâmetro do nível de suspeita, determinado pela rede neural, baseando-se na deteç̧ão das assinaturas de ataque.

Adicionalmente, se o administrador, através do monitoramento tradicional da rede (ou por alguma notificação), conhecer alguma tentativa inovadora de intrusão que o agente não tenha detectado, ele poderá inseri-lo na base de dados do agente de segurança, e retreinar a rede neural, de forma a atualizar todo o sistema.

\subsubsection{Módulo de pré-seleção}

Com relação ao módulo de pré-seleção, seria importante agregar outras informações que auxiliem a determinar o disparo automático de captura e, conforme propõe o modelo, estabelecer um sistema especialista com um conjunto de regras mais abrangente, como discutido na sessão 4.4.3. As regras poderiam tratar a sensibilidade das máquinas envolvidas, as portas de maior e menor risco e fatores de segurança relacionados aos sistemas operacionais acessados.

\subsubsection{Aprimoramento das assinaturas de ataque}

Estas informações, mencionadas acima, referentes ao módulo de pré-seleção também podem ser anexadas às assinaturas de ataque. Por exemplo, o valor do nível de segurança NS, discutido na seção 4.4 .3 que, em síntese, identifica a quantidade de eventos provenientes de uma dada origem, pode ser um dado relevante para $o$ treinamento da rede neural. 
A assinatura de ataque deve conter também um marcador horário, que identifica o periodo do dia no qual o evento está ocorrendo. Conforme discutido anteriormente, o horário do evento é um indicativo importante sobre a possibilidade de se tratar ou não de uma intrusão.

\subsubsection{Aprimoramento da rede neural}

Apesar dos resultados obtidos pela rede neural terem sido satisfatórios, muito ainda pode ser feito em seu aprimoramento e otimização. Uma das propostas principais, é codificar as assinaturas de ataque com, por exemplo, 2 ou 3 neurônios de saída, ao invés de 1 neurônio na implementação atual. Isso provavelmente permitirá um melhor treinamento e generalização da rede, além da possibilidade de tornar a detecção mais sensível, refinando o nível de segurança apresentado para uma intrusão em particular. Além disso, outras informações podem ser agregadas à saída da rede neural, como por exemplo: uma base de dados que relacione o nível de segurança do evento com as possíveis medidas a serem tomadas pelo administrador para sanar ou minimizar o ataque. Outros estudos podem ser feitos com outras funções de ativação da rede neural, o que provavelmente permitirá a otimização do treinamento.

A rede neural também necessita ser incorporada ao sistema de segurança, por intermédio de uma função ou biblioteca em linguagem $C$, que receba os vetores de conexão e devolva o nível de segurança. O simulador atual pode ser utilizado, pois tem a capacidade de produzir a função, e a rede treinada adequadamente. Entretanto, é necessário desenvolver um método mais amigável e simples para o administrador inserir novos padrões, realizar o treinamento e produzir a rede neural e a função a ser utilizada no sistema de segurança, sem que para isso seja necessário conhecer as interfaces e recursos do simulador. Isso pode ser desenvolvido com recursos de processamento em batch do simulador neural. Por outro lado, pode ainda ser produzido um sistema específico e otimizado de rede neural para tratar o problema de intrusão, dentro do SADI, ao invés de se utilizar o simulador SNNS. 


\subsubsection{Obtenção de contra-prova ou dupla verificação (double-checking)}

Para minimizar a possibilidade de notificações de resultados falsos-positivos, no caso da rede neural detectar uma possível intrusão, é proposto que exista um mecanismo capaz de realizar uma reavaliação do evento, de maneira a confirmar ou não o ataque, obtendo assim uma contra-prova ou dupla verificação (double-checking). Esta pode ser realizada, por exemplo, com a utilização de uma outra rede neural, treinada para realizar uma reavaliação dos padrões.

Pode ainda ser utilizado um tratamento baseado em métodos estatísticos conhecidos, como por exemplo o gerador automático de prognósticos de padrões [TCL90], discutido na seção 2.2.2. Este método, utilizando informações do sistema de captura de pacote, poderia analisar informações tais como quantidade de dados trafegados, horários envolvidos, localidades acessadas, dentre outros, para auxiliar no processo de reverificação de um ataque.

\subsubsection{Determinação do sucesso de um ataque}

Outra preocupação é informar ao administrador se uma tentativa de intrusão teve ou não sucesso. Segundo as análises realizadas, este tratamento também pode ser implantado de uma maneira relativamente simples e eficiente, utilizando duas redes neurais treinadas: uma para analisar o comportamento da ação externa, e outra para analisar a resposta do sistema atacado. A princípio, apenas as ações do atacante são suficientes para se determinar a tentativa de ataque. A ação de uma rede para cada sentido da sessão pode indicar se o ataque teve ou não sucesso, e ainda fornecer informações para sanar o problema, analisando casos específicos. A utilização deste método também pode ser indicada para reduzir a possibilidade de alertas de intrusão falsos-positivos.

\subsection{Conclusão final}

De uma maneira geral, entende-se que este trabalho forneceu uma contribuição efetiva no aprimoramento dos mecanismos de detecção de intrusos em redes de computadores. Através da unificação de técnicas relativamente simples, foi possível 
especificar e testar um novo modelo para tratar um problema importante, atual e de dificil solução. Por se tratar de um assunto extremamente vasto, também houve uma preocupação no sentido de que nossos desenvolvimentos possam servir como referência para a continuidade desses estudos. Com relação às vantagens e desvantagens do modelo, pode-se considerar as seguintes:

\section{Vantagens:}

- Consegue detectar novos ataques, com os quais ainda não teve contato;

- Não causa impacto de perda de performance nos sistemas monitorados;

- Possui custo reduzido, pois não exige grandes recursos computacionais;

- Apresenta facilidade para codificar rapidamente novos tipos de ataque;

- Apresenta melhor tratamento em casos onde os usuários manifestam uma variação muito grande de comportamento, mas que possuem fortes características seqüenciais;

- Apresenta boa sensibilidade na detecção de violação de políticas, pois atacantes que tentem dissimular o sistema podem ser detectados, em função das características semânticas e seqüenciais envolvidas no sistema.

\section{Desvantagens:}

- Só age sobre ataques em rede, isto é, não detecta usuários legítimos ou não, com comportamento intrusivo dentro de um único computador;

- O estabelecimento de limiares (threshold) do sistema de pré-seleção é bastante crítico e depende de uma análise rigorosa;

- Necessita de pessoal especializado para determinar os componentes de novos comportamentos intrusivos, ou necessita receber esta codificação de algum órgão ou entidade. Se não há pessoal especializado, neste último caso cria-se uma dependência nem sempre indicada para mecanismos de segurança;

- A análise de dados criptografados dentro dos dados pode ser muito complexa, ou mesmo inviável.

Em resumo, a maior contribuição reside na observação, entendimento e codificação de comportamentos intrusivos, em redes de computadores, a partir da sua manifestação ao longo das sessões. Entretanto, de modo algum é sugerido que o SADI 
possa ser uma solução genérica para o problema de deteç̧ão de intrusos em redes de computadores. Ele pode ser usado com sucesso em diversas situações, mas recomendase que sua aplicação seja realizada em conjunto com outros mecanismos, de modo a aprimorar a segurança das instalações.

Finalizando, cumpre ressaltar que a segurança de um sistema computacional deve ser tratada com um conjunto de técnicas eficazes, que vão desde o uso de sistemas computacionais apropriados, passando pelo adequado treinamento de recursos humanos para lidar com o problema, e chegando até a educação dos usuários. 



\title{
ANEXO A - Artigo publicado
}

\author{
A.M. Cansian. Técnicas de Segurança para Redes Acadêmicas. \\ Proceedings of II WAIS - Workshop em Administração e \\ Integração de Sistemas / Simpósio Brasileiro de Redes de \\ Computadores, Fortaleza, CE, 20 a 23 de maio de 1996.
}

\section{Técnicas de Segurança para Redes Acadêmicas}

\author{
Adriano Mauro Cansian \\ Departamento de Ciências da Computação e Estatística \\ UNESP - Universidade Estadual Paulista, Câmpus de São José do Rio Preto \\ R. Cristóvão Colombo, 2265 - 15055-000 São José do Rio Preto - SP \\ Tel. (017) 224-4966 R.232 Fax: (017) 224-8692 \\ E-mail: adriano@nimitz.ibilce.unesp.br
}

\begin{abstract}
Resumo
Este trabalho apresenta as técnicas de segurança utilizadas no sistema de rede da UNESP, em São José do Rio Preto. É realizada uma breve descrição da rede de computadores e laboratórios de informática do Câmpus, e em seguida são apresentadas as ferramentas de dominio público utilizadas para a proteção do sistema. Pretende-se mostrar que uma grande parte dos eventos de segurança e ações de hacking, normalmente presentes numa rede acadêmica aberta $e$ heterogênea, podem ser evitadas com procedimentos básicos $e$ amplamente conhecidos, que não influenciam no rendimento nem na utilização $e$ padronização, e que podem ser implantados e mantidos a um custo muito baixo.
\end{abstract}

\begin{abstract}
This work presents network security technologies being used in São José do Rio Preto's Campus at UNESP (São Paulo State University). There is an introduction with a brief description about our networks and computer laboratories, and a report with public domain tools used to protect our systems. We intend to show that a significative amount of events envolving security and hacking actions, actually current in a opened and heterogeneous academic network, can be avoided with basic and well-know procedures, with no act on performance and standartization, and that can be established and maintained at low costs.
\end{abstract}




\title{
ANEXO B - Artigo publicado
}

\author{
A.M. Cansian, E.S.Moreira, A.C.P.L.F. de Carvalho and J.M.Boni. \\ Network Intrusion Detection Using Neural Networks. \\ Proceedings of International Conference on Computacional \\ Intellingence and Multimedia Applications, Griffith \\ University, Australia, de 10 a 12 de fevereiro de 1997.
}

\section{Network Intrusion Detection Using Neural Networks}

\author{
Adriano M. Cansian \\ UNESP - Universidade Estadual Paulista - IBILCE S.J.Rio Preto \\ Po Box 136 - CEP 15970-001 - São José do Rio Preto - SP - Brazil (E-mail: adriano@ibilce.unesp.br) \\ Edson S.Moreira, André C.P. de L.F. de Carvalho e José M. Bonifácio Jr. \\ USP - Universidade de São Paulo / Instituto de Ciências Matemáticas de São Carlos \\ Po Box 668 - CEP 13560-970 - São Carlos - SP - Brazil (E-mail: edson, andre, boni@icmsc.sc.usp.br)
}

\begin{abstract}
A significative number of network computer security intrusions can't be prevented or dealed with simple access control and auditing being executed at standalone computers. Therefore advanced and distributed intrusion detection techniques can play an important role, preventing abuses and protecting information over a networked environment. This work presents current development status of a system which, positioned at key points of the network, will keep looking at the passing packets, in search of suspicious connections. Neural networks are used to look for profiles of intrusion within the analysed data streams. The assessment is done through comparison with well known profiles of intrusion. The system is highly adaptive, since new profiles can be added to the data base and the neural network retrained to consider them.
\end{abstract}

Keywords: security, intrusion, neural, network, packets

\section{Introduction}

The recent increase in the use of networks has been followed by concerns about computers misuse and security. Additionally, an ever-increasing number of essential activities are performed through networks (especially over the Internet), and hence a correct and reliable operation is vital. On the other hand, piracy acts, intrusion attempts, consummate invasions and break-in actions are becoming frequent and involve an increasingly high number of computers [1,2]. This scenario brings up the need for special security techniques in modern computer systems; ones which go beyond the traditional "locking up the doors" practice.

This paper describes the actual status project of a network-based security system that uses techniques of Packet Filtering and Capture and Neural Networks to find out intruders, to register and learn about their mode of operation and then to provide elements that help the system administrator take action against them. The detection system is formed by one or more security agents, which are placed at strategic points in the network and that provide information to the managing personnel or systems. 


\title{
ANEXO C - Artigo aceito para publicação
}

\author{
A.M.Cansian, E.S.Moreira,R.B.Mouro,F.T.Morishita and A.C.P.L.F. \\ de Carvalho. An Adaptative System for Detecting Intrusion \\ on Netwoks. Aceito para III International Congress on \\ Informatic Engineering, Universidade de Buenos Aires, \\ Argentina, dias 16 e 17 de abril de 1997.
}

An Adaptive System For Detecting Intrusion On Networks

Adriano M. Cansian (adriano@ibilce.unesp.br)

Edson S.Moreira, Rogério B.Mouro, Fábio T.Morishita, André C.P.de L.F. de Carvalho (edson, mouro, teruo, andre@icmsc.sc.usp.br)

\begin{abstract}
As the Internet expands both in number of hosts connected and in terms of the number of services provided, security has become a key issue for the technology developers. This work presents current development status of a system which, positioned at key points of the network, will keep looking to the passing packets, searching for suspicious connections. It provides a list of such connections for the administrator, enabling him/her to take the proper action in the early stage of the intrusion. Neural Networks are used to look for profiles of intrusion within the data streams analised. The assessment is made by comparison to well known profiles of intrusion. The system is highly adaptive, since new profiles can be added to the data base and the Neural Network re-trainned to consider the new profile.
\end{abstract}

\section{Introduction}

The recent increase in the use of networks has been followed by an increase concern about the security of information stored in the computers interconnected. Besides, an everincreasing number of essential activities is performed through networks (specially over the Internet), and hence correct and reliable operation is vital. On the other hand, piracy acts, intrusion attempts, consumate invasions and break-in actions are becoming frequent and involve an increasing number of computers [1-2]. This scenario brings up the need for special security techniques in modern computer systems.

Various Intrusion Detection Systems (IDS) have been developed and some of them have been introduced experimentally. These systems are divided into host-based [3-7] and network-based [8-10]. Host-based systems use audit trails (which are usually daemons) as the main action to detect intrusions, while network-based systems build up their own set of information using network trafic.

This paper describes the project of a network-based security system that uses techniques of Artificial Intelligence and a Neural Network to find out intruders, register them and provide elements to help the system administrator to take decisions. The detection system is formed by one or more security agents, which placed at strategic points in the network, give information to managing personnel. 


\title{
ANEXO D - Artigo aceito para publicação
}

\author{
A.M. Cansian, J.M.Bonifáfio Jr., E.S.Moreira e A.C.P.L.F. de \\ Carvalho. Um Modelo Adaptativo Para Deteç̧ão de \\ Comportamento suspeito em Redes de Computadores. Aceito \\ para o XV Simpósio Brasileiro de Redes de Computadores, São \\ Carlos, SP, maio de 1997.
}

Um Modelo Adaptativo Para Detecção de Comportamento Suspeito em Redes de Computadores

\author{
Adriano M. Cansian \\ (adriano@ibilce.unesp.br)
}

UNESP - Universidade Estadual Paulista - IBILCE / S.J.Rio Preto

Po Box 136 - CEP 15970-001 - São José do Rio Preto - SP - Brasil

José M. Bonifácio Jr, Edson S. Moreira e André C. P. de L. F. de Carvalho. (boni, edson, andre@icmsc.sc.usp.br)

Instituto de Ciências Matemáticas de São Carlos - ICMSC/USP

Po Box 668 - CEP 13560-970 - São Carlos - SP - Brasil

\section{Resumo}

Todos os sistemas computacionais, notadamente aqueles ligados à Internet, são suscetiveis a ação de atacantes, sejam eles internos ou externos. Neste trabalho apresentamos um modelo de deteç̧ão de intrusos em redes de computadores que operam sobre protocolo TCP/IP. O sistema consiste do reconhecimento de assinaturas de ataque, baseando-se em captura de pacotes. A identificação do comportamento intrusivo é realizada por intermédio de uma rede neural, o que confere grande adaptabilidade $e$ permite acompanhar as modificações das técnicas de ataque. É descrito um modelo de detecção de intrusos, e apresentada a situação atual de implementação de um protótipo do sistema.

\section{Abstract}

All computer systems, mainly those connected to the Internet are vulnerable to attacking attempts, both from internal and external sources. In this work we present a TCP/IP based network intrusion detection model. The system consists of a pattern recognizer of attacks, based in capture of packets. The identification of intrusion behavior is realized by a neural network, that provides high adaptability and allows for following up modifications in the attacking techniques. We describe the intrusion detection model and present the current status of the implementation of a prototype. 


\section{Referências Bibliográficas}

[And80] J. P. Anderson. Computer Security Threat Monitoring and Surveillance. Technical Report, James P. Anderson Co. , Fort Washington, Pennsylvania, USA, April, 1980.

[Bac94] R. Bace. A New Look at Perpetrators of Computer Crime. In Proceedings of 16th Department of Energy Computer Security Conference, 1994.

[BB92] T. Bradley and C. Brown. Inverse Address Resolution Protocol. Request for Comments RFC-1293, 1992.

[Bel89] S.M. Bellovin. Security Problems in the TCP/IP Protocol Suite. Computer Communications Review, 19(2):32-48, April 1989.

[Bib77] K.J. Biba. Integrity Constraints for Secure Computer Systems. Technical Report ESD-TR-76-372, USAF Electronic Systems Division, Bedford, Massachussets, April, 1977.

[BK88] David S. Bauer and Michael E. Koblentz. NIDX - An Expert System for Real-Time Network Intrusion Detection. In Proceedings of the Computer Networking Symposium, pp. 98-106. IEEE, New York, NY, USA, April 1988.

[BL73] D.E.Bell \& L.J. LaPadula. Secure Computer Systems: Mathematical Foundations and Model. Technical Report M74-244, The MITRE Corporation, Bedford, Massachussets, May 1973.

[Cer95] Computer Emergency Response Team. Vulnerabilities in /bin/mail. CERT Advisory CA-95:02. January , 26, 1995.Uniform Resource Locator :

ftp://info.cert.org/pub/cert_advisories/CA-95:02.binmail.vulnerabilities

[Cas90] J. Case. A Simple Network Management Protocol (SNMP), Internic Network Working Group, Request for Comments RFC-1157, 1990.

[Cas93a] J. Case. Introduction to version 2 of the Internet-standard Network Management Framework. SNMP Research, Inc., Hughes LAN System, Dover Beach Consulting, Inc., Carnegie Mello University, Request for Comments RFC-1441, 1993.

[Cas93b] J. Case. Manager-to-Manager Management Information Base. SNMP Research, Inc., Hughes LAN System, Dover Beach Consulting, Inc., Carnegie Mello University, Request for Comments RFC-1451, 1993.

[CFSD90] J. Case, M. Fedor, J. Schoffstall and J. Davin. A Simple Network Management Protocol (SNMP). RFC-11157, 1990. 
[Cha91] Eugene Charniak. Bayesian Networks Without Tears. AI Magazine, pp. 50-63, Winter 1991.

[Che88] K. Chen. An Inductive Engine for the Acquisition of Temporal Knowledge. Ph.D. Thesis, Departament of Computer Science, University of Illinois at Urbana-Champaign, 1988.

[CHS91] P. Cheeseman, R.Hanson and J.Stutz. Bayesian Classification with Correlation and Inheritance. In 12th International Joint Conference on Artificial Intellingence, August 1991.

[CKS+88] P. Cheeseman, J. Kelly, M. Self, J.Stutz, W.Taylor and D.Freeman. Autoclass: A Bayesian Classification System. In Proceedings of the Fifth Internacional Conference on Machine Learning, pp. 54-64. Morgan Kaufmann, USA, June 1988.

[Coh87] Fred Cohen. Computer Viruses - Theory and Experiments. Computers \& Security, 6:22-35, 1987.

[Cro82] D. Crocker. Standart for the Format of ARPA-Internet Text Messages. Request for Comments RFC-822, 1982.

[CSI96] Computer Security Institute. 1996 Computer Crime and Security Survey. URL http:/hww.gocsi.com/iss_t.htm\#Computer_Crime. San Francisco, California, USA, 1996.

[Den87] D.E. Denning. An Intrusion-Detection Model. IEEE Transactions on Software Engginering , Number 2, Vol. SE-13, pp. 222-232, February 1987.

[DMC97] H.Diniz, E.F. Mendes Filho e A.C.P.L.F. de Carvalho. SNNS Stuttgart Neural Network Simulator - Manual de Referência Rápida. Relatório Interno. Instituto de Ciências Matemática de São Carlos, USP, 1997.

[DoDS85] Department of Defense Standard. Department of Defense Trusted Computer System Evaluation Criteria. Number DOD5200.28-STD. U.S. Government Printing Office, USA, December 1985.

[FIR] FIRST - Forum of Incident Response Teams. http://www.first.org/first/

[Gia92] Joseph C. Giarratano. CLIPS Version 5.1 User's Guide. NASA, Lyndon B. Johnson Space Center, Information Systems Directorate, Software Technology Branch, March, 1992.

[GJS96] J.Gosling, B.Joy and G. Steele. The Java Language Specification, Addison-Wesley Publishing Co., USA, 1996.

[GL91] T.D.Garvey and T.F.Lunt. Model-based Intrusion Detection. In 
Proceedings of the 14th National Computer Security Conference, $\mathrm{pp}$ 372-385, Washington, DC, USA, October 1991.

[GM84] F.T.Gramp and R.H.Morris. Unix Operating System Security. AT\&T Bell Laboratories Technical Journal, 63(8), part 8, October 1984

[GS96] Simson Garfinkel \& Gene Spafford. Pratical Unix and Internet Security 2nd Edition.O'Reilly and Associates, Sebastopol, California, 1996.

[Hay94] S. Haykin. Neural Networks: A Comprehensive Foundation. MacMillan College Publishing Co., New York, NY, USA, 1994.

[HCMM92] N. Habra, B. Le Charlier, A.Mounji and I.Mathieu. ASAX: Software Architeture and Rule-based Language for Universal Audit Trail Analysis. In Proceedings of ESORICS'92, Toulouse, France, November 1992.

[Heb90] L.T. Heberlein et al. A Network Security Monitor. In Proceedings of 1990 IEEE Symposium on Research in Security and Privacy, pp 296304, Oakland, CA, USA, May 1990

[Heb91] L.T. Heberlein et al. Towards Detecting Intrusions in a Networked Environment. In Proceedings of 14th DOE Conference on Computer Security, pp 17-47. Concord, CA, USA, May 1991.

[HKP91] J. Hertz, A. Krogh and R.G. Palmer. Introduction to the Theory of Neural Computtation. Addisin-Wesley Reading, Massachussets, USA, 1991.

[HLM91] L.T. Heberlein, K.N. Levitt and B. Mukherjee. A Method to Detect Intrusive Activity in a Networked Environment. In Proceedings of 14th National Computer Security Conference, pp 362-371. Washington, DC, USA, October 1991.

[HLMS90] R.Heady, G.Luger, A.Maccabe and M.Servilla. The Architeture of a Network Level Intrusion Detection System. Technical Report, Department of Computer Science, University of New Mexico, USA, August 1990.

[Hoc93] J. Hochberg. NADIR: An Automated System for Detecting Network Intrusion and Misuse. Computers and Security, 12(3):235-248, May 1993.

[Ilg92] Koral Ilgun. USTAT: A Real-Time Intrusion Detection System for UNIX. Master Thesis, Computer Science Department, University of California, Santa Barbara, USA, July 1992.

[JMM96] A.K. Jain, J.Mao and K.M.Mohiuddin. Artificial Neural Networks: A Tutorial. IEEE Computer, pp. 31-44, March 1996. 
[JR93] M. St. Johns and M. T. Rose. Identification MIB. Request for Comments RFC-1414, 1993.

[JV91] H.S. Javitz and A.Valdez. The SRI IDES Statistical Anomaly Detector. In Proceedings of 1991 IEEE Symposium on Research in Security and Privacy, Oakland, CA, USA, 1991.

[KFG+93] C. Ko, D.A.Frincke, T. Goan Jr., L.T. Heberlein K.Levitt, B.Mukherjee and C. Wee. Analysis of an Algorithm for Distributed Recognation and Accountability. In Proceedings of First ACM Conference on Computer and Communicatons Security, pp 154-164, Fairfax, VA, USA, November 1993.

[KS94] S. Kumar and E.H.Spafford. An Application of Pattern Matching in Intrusion Detection. COAST Projet Technical Report CSD-TR-94-013. Purdue University, USA, July, 1994.

[KPN+93] A. Kumar, J. Postel, C. Neuman, P. Danzig and S. Miller. Common DNS Implementation Errors and Suggested Fixes. Request for Comments RFC-1536, 1993.

[Lam74] B.W. Lampson. Protection. Operating Systems Review, 8(1):18-24, January 1974.

[LJL+89] T.F.Lunt, R.Jagannathan, R.Lee, A.Whitehurst and S.Listgarten. Knowledge-Based Intrusion Detection. In Proceedings of the Annual AI Systems in Government Conference, Washington, DC, USA, March 1989.

[LS87] Dennis Longley and Michael Shain. Data and Computer Security: Dictionary of Standards, Concepts, and Terms. Stockton Press, New York, New York, 1987.

[LTG+92] T. F. Lunt, A.Tamaru, F.Gilhan, R.Jagannathan, P.G.Neumann, H.S.Javitz, A.Valdes and T.D.garvey. A Real-Time Intrusion Detection Expert System (IDES) - Final Technical Report. Computer Science Laboratory, SRI International, Menlo Park, California, USA, February 1992.

[Lun90] Teresa F. Lunt et al. IDES: A Progress Report. In Proceedings of Sixth Annual Computer Security Applications Conference. Tuscon, AZ, USA, December 1990.

[Lun93] Teresa F. Lunt. A Survey of Intrusion Detection Techniques. Computers and Security, 12(4):405-418, June 1993.

[MHL94] B.Mukherjee, L.T.Heberlein and K.N.Levitt, Network Intrusion Detection. IEEE Network, pp.26-41, May/June 1994. 
[MJ93] S. McCanne and V. Jacobson. The BSD Packet Filter: A New Architecture for User-level Packet Capture. In Proceedings of the 1993 Winter USENIX Technical Conference, San Diego, CA, USA. January 1993.

[MM94] K. Mohiuddin and J.Mao. A Comparative Study of Different Classifiers for Handprinted Character Recognition. In Pattern Recognation in Practice IV, pp. 437-448, Edited by E.S.Gelsema and L.N.Kanal, Elsevier Science, The Netherlands, 1994.

[MMM97] R. B. Mouro, F. T. Morishita e E. S. Moreira. NetTracker: Uma Arquitetura Operacional Extensível para Ferramentas de Gerenciamento de Redes. Aceito para o XV Simpósio Brasileiro de Redes de Computadores - SBRC, São Carlos, SP, Brasil, 1997.

[Moc87] P.Mockapetris. Domain Names - Concepts and Facilities. Request for Comments RFC-1034, 1987, e Domain Names - Implementation and Specifications. Request for Comments RFC-1035, 1987.

[Mor85] R.T.Morris. A Weakness in the 4.2BSD Unix TCP/IP Software. Computer Science Technical Report No.117, AT\&T Laboratories, Murray Hill, New Jersey, USA, 1985.

[MP43] W.S. McCulloch and W. Pitts. A Logical Calculus of Ideas Immanet in Nervous Activity. Bulletin of Mathematical Biophysics, Vol.5, pp. 115133, 1943.

[MP69] M. Minsky and S. Papert. Percepetrons: An Introduction to Computacional Geometry. MIT Press, Massachussets, USA, 1969.

[NP89] P. Neumann \& D. Parker. A Summary of Computer Misuse Techniques. In Proceedings of the 12th National Computer Security Conference, pages 396-407, Washington, DC, USA, October 1989.

[PK92] Phillip A. Porras and Richard A. Kemmerer. Penetration State Transition Analysis - A Rule-Based Intrusion Detection Approach. In Eighth Annual Computer Security Applications Conference, pp. 220-229. IEEE Computer Society Press, USA, December 1992.

[Plu82] D.C. Pullmer. An Ethernet Address Resolution Protocol. Request for Comments RFC-826, 1982.

[Pos81] J.B.Postel. Internet Control Message Protocol (ICMP). Request for Comments RFC-792, 1981.

[Pos82] J.B.Postel. Simple Mail Transfer Protocol. Request for Comments RFC$821,1982$.

[Pow96a] R.Power. Follow the Money. Lan Magazine, 11(11):54-60, October 1996. 
[Pow96b] R.Power. Current and Future Danger: A Primer on Computer Crime and Information Warfare. Computer Security Institute, San Francisco, California, USA, 1996.

[PR83] J.B.Postel and J.Reynolds. Telnet Protocol Specifications. Request for Comments RFC-854, 1983.

[PR85] J.B.Postel and J.Reynolds. File Transfer Protocol. Request for Comments RFC-959, 1985.

[Pro94] Paul Proctor. Audit Reduction and Computer Misuse Detection. In Sixth Annual Computer Security Incident Handling Workshop. San Franciso, CA, USA, October 1994.

[Rap97] P. Rapalus. CSI roundtable explores Intranet security. Uniform Resource Locator (URL) http://www.gocsi.com/intranet.htm. Computer Security Institute, San Francisco, CA, USA, 1997.

[RGM+97] R. Fielding, J. Gettys, J. Mogul, H. Frystyk and T. Berners-Lee. Hypertext Transfer Protocol - HTTP 1.1. Request for Comment RFC2068, 1997.

[RM86] D.E.Rumelhart and J.L.McClelland. Parallel Distributed Processing: Exploration in the Microstructure of Cognition. MIT Press, Cambridge, Massachussets, USA, 1988.

[Ros62] R. Rosenblatt. Principles of Neurodynamics. Spartan Books, New York, 1962.

[RS91] D. Russell \& G. T. Gangemi Sr. Computer Security Basics. O'Reilly and Associates, Sebastopol, California, December, 1991.

[RWL94] D.E.Rumelhart, B. Widrow and M.A.Lehr. Neural Networks. Communications of the ACM, 37(3): 87-92, March 1994.

[SH82] John F. Schoch and John A Hupp. The "Worm" Programs - Early Experience with a Distributed Computation. Communications of the $A C M, 25(3): 172-180$, March 1982.

[Sma88] Stephen E. Smaha. Haystack: An Intrusion Detection System. In Fourth Aerospace Computer Security Applications Conference, pp. 37-44, Tracor Applied Science Inc., Austin, Texas, USA, December 1988.

[Sma92] Steve Smaha. Questions About CMAD. In Proceedings of the Workshop on Future Directions in Computer Misuse and Anomaly Detection, pages 17-21, Davis, California, March 1992.

[Sma95] Steve Smaha. Advances in Misuse Intrusion Detection Systems. In 
Proceedings of Third Computer Misuse and Anomaly Detection Workshop, Sonoma, CA, USA, January 1995.

[Spa89] Eugene Spafford. Crisis and Aftermath. Communications of The ACM, 32(6): 678-687, June 1989.

[SS91] Steven R. Snapp and Stephen E. Smaha. DIDS (Distributed Untrusion Detection System) - Motivation, Architeture, and an Early Prototype. In Proceedings of 14th National Computer Security Conference, Washington, DC, USA, October 1991.

[SS92] Steven R. Snapp and Stephen E. Smaha. Signature Analysis Model Definition and Formalism. In Proceedings of the Fourth Workshop on Computer Security Incident Handling, Denver, CO, USA, August 1992.

[SSHW88] M.Sebring, E.Shellhouse, M.Hanna and R.Whitehurst. Expert Systems in Intrusion Detection: A Case Study. In Proceedings of the 11th National Computer Security Conference, Washington, DC, USA, October 1988.

[Sta95] S.G.Staniford-Chen. Distributed Tracing of Intruders. M.S.Thesis. Divison of Computer Science, University of California, Davis, CA, USA. 1995.

[Ste94] W.R.Stevens. TCP/IP Illustraded, Volume 1: The Protocolas. AddisonWesley Publishing Company, Reading, Massachusettsm, USA, 1994.

[Sun90] Sun Microsystems Inc. Network Information Tap - NIT (4P) ; SunOs 4.1.1 Reference Manual, October 1990.

[TCL90] H.S.Teng, K.Chen and S.C.Lu Security Audit Trail Analysis Using Inductively Generated Predictive Rules. In Proceedings of the Sixth Conference on Artificial Intelligence Applications, pp. 24-29, Piscataway, NJ, USA, March 1990 (IEEE Society Press).

[Ven92] W.Z.Venema. TCP Wrapper: Networking Monitoring, Access Control and Booby Traps. In Proceedings of Third UNIX Security Symposium, Baltimore, USA, September 1992.

[Zim91] D. Zimmerman. The Finger User Information Protocol. Request for Comments RFC-1288, 1991.

[WRH91] A.S.Weigend, D.E. Rumelhart and B. Hubberman. Generalization by Weight-elimination with Applications in Forecasting. Advances in Neural Information Processing. Vol. 3, pp. 875-882 (Edited by R.P.Lippman, J.Mody and D.S. Touretsky). Morgan Kaufman, San Mateo, California, USA, 1991. 


\section{APÊNDICE A - Autômato Finito}

O autômato implementado é composto de estados (S) e transições (T), de um estado inicial (S0) e de estados finais (S6 e S7), representados por um círculo duplo. É apresentado na figura a seguir.

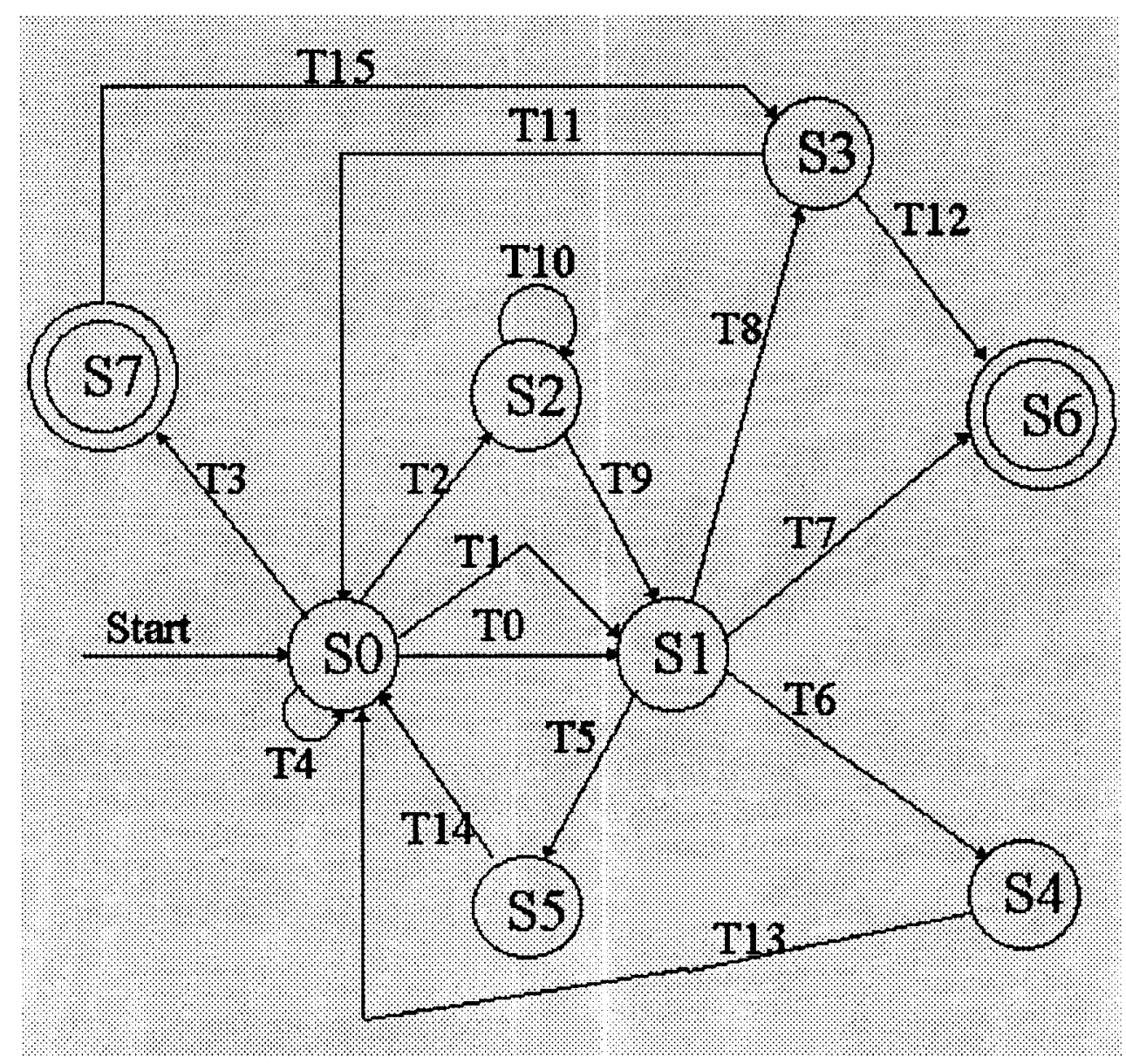

Esquema do autômato finito reconhecedor de assinaturas

Este autômato é composto por 7 estados e 14 tansições e controlado por algumas variáveis globais a todos os estados:

- ini e fim - ponteiros para o início e fim das palavras a serem localizadas;

- fim2 - Se o que estiver sendo procurado é identificado como sendo componente de assinatura, e também é por si só uma assinatura, é este ponteiro que guarda o fim desta primeira assinatura encontrada. Se nenhuma assinaturafor encontrada, esta é retornada e a análise léxica continua a partir deste ponto;

- segunda parte - ponteiro para a segunda palavra que estiver sendo procurada;

- carac_especial - Um flag indicando se encontrou um caractere especial, que deva ser tratado de forma diferente das letras e dígitos; 
- ultimo hash achado - índice na tabela hash em que se encontra a assinatura entre ini e fim 2 ;

- primeira parte - flag que indica se o que está sendo procurado é a primeira parte da assinatura, para que se possa ignorar os espaços (já que uma assinatura nunca começa por espaços). Tem finalidades de otimização.

Os estados são descritos a seguir:

- S0 - Estado inicial, que percorre e ignora símbolos como enter, form-feed, tab, line-feed, ou espaços (T4). Se encontra letra ou dígito (T2) vai para S2. Se encontra um caractere especial (T1), ou se a variável carac_especial estiver setada (T0), vai para S1. Esta transição T0 é necessária para que, se no texto houver, por exemplo, $\underline{\operatorname{login}} ;$, então seja possível procurar por $\underline{\operatorname{login}}$ sozinho e, em seguida, por $\underline{\text { login; }}$. Se encontrar um fim-de-arquivo vai para S7 (T3)

- S1 - É o estado que faz as buscas na tabela hash. Se encontrou a assinatura, vai para S6 (T7), e se não encontrou nada, vai para S3 (T8). Se encontrou apenas início(s) de assinatura(s) vai para $\mathbf{S 4}$ (T6). Se achou inícios, e também uma assinatura completa, vai para S5 (T5)

- S2 - Percorre letras e dígitos (T10), até que encontre um caractere especial e vá para S1 (T9)

- S3 - Trata os casos em que a busca na hash não encontrou nada. Verifica se uma parte da string que está sendo procurada, já foi encontrada na hash. Por exemplo: na TSR existe sync.sync.echo e sync.sync.echo logged in, e a string a ser procurada é sync.sync.echo logged out, que gerará um retorno de não encontrada na busca. Entretanto uma vez que sync.sync.echo já foi previamente localizada, vai para S6 (T12), de forma que retorne sync.sync.echo . Caso não tenha encontrado nada previamente, ajusta ini para fim2, se estiver procurando por mais de uma palavra. Ou então ajusta para fim, caso esteja procurando por apenas uma palavra. Em seguida volta ao estado S0 (T11).

- S4 - Apenas testa se é a primeira palavra que está sendo procurada, e ajusta primeira_parte para 0 , e segunda_parte para onde fim aponta, indo em seguida para S0 (T13)

- S5 - Seta fim2 para fim, para que possa retornar esta parte que já foi localizada como sendo uma assinatura, e voltar a busca a partir deste ponto, indo para S0 (T14)

- S6 - Retorna a assinatura encontrada. Este estado foi usado para facilitar a compreensão do grafo e para algum uso futuro (ao invés de retornar apenas a assinatura, fazer alguma operação a mais).

- S7 - Trata do caso em que se encontra um fim-de-arquivo. Se ainda houver algo que possa ser procurado, vai para o estado S3 (T15). Por exemplo, no caso em que o estado $\mathbf{S} 0$ esteja no início da terceira palavra, é possível que a segunda palavra sozinha seja uma assinatura; então retorna para não perdê-la. 


\section{APÊNDICE B - Exemplo da TSR}

O Arquivo TSR.ACM que se trata da Tabela de Símbolos Reservados, com os exemplos dos strings codificados mais importantes, é apresentado a seguir.

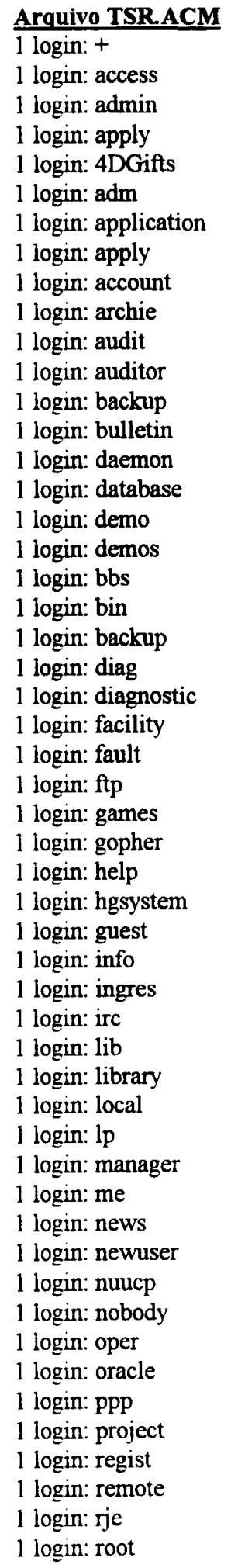

1 login: school

1 login: server

1 login: service

1 login: slip

1 login: sundiag

1 login: supervisor

1 login: sybase

1 login: sync

1 login: sys

1 login: sysdiad

1 login: sysinfo

1 login: sysman

1 login: sysmrg

1 login: sysop

1 login: telnet

1 login: temp

1 login: test

1 login: tests

1 login: toor

1 login: tour

1 login: tty

1 login: tutor

1 login: uucp

1 login: visitor

1 USER +

1 USER access

1 USER admin

1 USER apply

1 USER 4DGifts

1 USER adm

1 USER application

1 USER apply

1 USER account

1 USER archie

1 USER audit

1 USER auditor

1 USER backup

1 USER bulletin

1 USER daemon

1 USER database

1 USER demo

1 USER demos

1 USER bbs

1 USER bin

1 USER backup

1 USER diag

1 USER diagnostic

1 USER facility

1 USER fault

1 USER $\mathrm{ftp}$

1 USER games

1 USER gopher

1 USER help
1 USER hgsystem

1 USER guest

1 USER info

1 USER ingres

1 USER irc

1 USER lib

1 USER library

1 USER local

1 USER lp

1 USER manager

1 USER me

1 USER news

1 USER newuser

1 USER nuucp

1 USER nobody

1 USER oper

1 USER oracle

1 USER ppp

1 USER project

1 USER regist

1 USER remote

1 USER rje

1 USER root

1 USER school

1 USER server

1 USER service

1 USER slip

1 USER sundiag

1 USER supervisor

1 USER sybase

1 USER sync

1 USER sys

1 USER sysdiad

1 USER sysinfo

1 USER sysman

1 USER sysmrg

1 USER sysop

1 USER telnet

1 USER temp

1 USER test

1 USER tests

1 USER toor

1 USER tour

1 USER tty

1 USER tutor

1 USER uucp

1 USER visitor

2 Croot

3 ( sleep 2 ; echo quit)

4 SITE

5 su

6 command unrecognized

6 ? Invalid command 
7 Permission denied

8 Login incorrect

9 uudecode

9 decode

10 User unknown

11 tail

12 Invalid sender address

13 Need MAIL before RCPT

14 Need MAIl command

15 syntax error

15 Syntax error

16 Malformed from address

$17 \mathrm{sh}$

18 command not understood

19 Command not understood

19 access denied

20 debug

20 Debug

20 DEBUG

20 wiz

$20 \mathrm{WIZ}$

$20 \mathrm{Wiz}$

21 LIST -Rlag

$22 \mathrm{Bad}$

23 Login with USER first

$24 / \mathrm{bin} / \mathrm{mail}$

$25 \mid$

26 Invalid request

$27 /$ etc/passwd

27 /etc/shadow

28 /etc/aliases

28 /etc/inetd.conf

28 /.rhosts

28 /etc/skeykeys

28 /etc/hosts.equiv

28 /etc/services

28 /etc/hosts

28 /etc/uucp/Systems

29 cat /etc/passwd

29 cat /etc/shadow

30 cat /etc/inetd.conf

30 cat /.rhosts

30 cat /etc/skeykeys

30 cat /etc/hosts.equiv

$30 \mathrm{cat} / \mathrm{etc} / \mathrm{services}$

30 cat /etc/hosts

30 cat /etc/uucp/Systems

31 telnet

$32>$

$33 \mathrm{"/"}$

$33 \mathrm{~cd} /$

$34 \mathrm{MKD}$

$34 \mathrm{mkd}$

$34 \mathrm{rmd}$

34 RMD

35 Entering Passive Mode

36 scanning "postmaster"

37 /usr/lib/lpd

$37 \mathrm{lpr}$

38 user read

39 uucp.uucp.echo logged in

39 sysdiag.sysdiag.echo logged in

39 sys.sys. echo logged in
39 sync.sync.echo logged in

39 root.root.echo logged in

39 nobody.nobody.echo logged

in

39 news.news.echo logged in

39 ingres.ingres.echo logged in

$39 \mathrm{ftp}$.ftp.echo logged in

39 bin.bin.echo logged in

39 audit.audit.echo logged in

40 logged in

40 PASSWORD FILE

40 ALIASES

40 INETD.CONF

40 . RHOSTS

40 SKEY

40 HOSTS.EQUTV

40 SERVICES

40 HOSTS

40 UUCP

40 SHADOW

40 SYSTEM

40 NNTERFACE

40 ROUTE

41 login:

41 USER

42 passwords

43 exec

43 EXEC

44 sleep 2; echo quit

45 echo

$45 \mathrm{ECHO}$

45 Echo

46 Sorry

46 sorry

47 chmode 777

47 chmode 666

47 chomde a+rwx

47 chmode ugotrux

48 root

$49 \sim$ root

40 chown

51 Not owner

52 can't change

$53 \mathrm{Mprog}$

$54 / \mathrm{bin} / \mathrm{sh}$

$55 \mathrm{~F}=1 \mathrm{sDFMeu}$

$56 \mathrm{~A}=$ sh

57 Mlocal

$58 \mathrm{P}=/ \mathrm{bin} / \mathrm{sh}$

59 telnet

$60 \mathrm{sh}$

61 |mail

61 /mail

$61 / \mathrm{bin} / \mathrm{mail}$

62 /bin/echo

$63 \mathrm{sh} \gg$

6434363,25

65 EXPN

65 expn

65 VRFY

65 vify

66 cat $>/$ tmp

67 help

67 HELP
$68 /$ dev/null

69 nobody

70 command successful

70 Command successful

71 Unknown user name after 


\section{APÊNDICE C - Principais URLs utilizados}

Para facilitar a pesquisa, são apresentados a seguir os pricipais endereços (URLs Uniform Resource Locators) utilizados durante a realização deste trabalho.

\begin{tabular}{|l|l|}
\hline \multicolumn{2}{|l|}{ URLs relativos a segurança (utilitários, documentação, artigos e correlatos): } \\
\hline 8lgm Eletronic Mailing List & http://www.8lgm.org/ \\
\hline Bugtraq Eletronic Mailing List & http:/www.geek-girl.com/bugtrag/ \\
\hline CERT - Computer Emergency Response Team & http://www.cert.org/ \\
\hline CIAC Security Web Site & http://ciac.llnl.gov/ciac/ \\
\hline Computer Security Institute & http://www.gocsi.com/ \\
\hline Computer underground Digest WWW Site & http://www.soci.niu.edu/ cudigest \\
\hline FIRST - Forum of Incident Response Teams & http://www.first.org/first/ \\
\hline Internet Security Systems Inc. (ISS) & http://www.iss.net// \\
\hline Raptor Systems Security Library & http://www.raptor.com/library/library.html \\
\hline SAIC Security - Security Documents & http://mls.saic.com/docs.html \\
\hline SATAN & ftp://ftp.win.tue.nl/pub/security/ \\
\hline The COAST Projet & http://www.cs.purdue.edu/coast \\
\hline USA Computer Incident Advisory Capability & http://ciac.llnl.gov/ciac/ \\
\hline Wietse's collection of tools and papers & ftp://ftp.win.tue.nl/pub/security/index.html \\
\hline The Acme! Security Project & http://www.ibilce.unesp.br/Acme \\
\hline
\end{tabular}

\begin{tabular}{|l|l|}
\hline \multicolumn{2}{|l|}{ URLs Diversos utilizados durante o desenvolvimento deste trabalho: } \\
\hline Biblioteca de Captura de Pacotes Libpcap & ftp://ftp.ee.lbl.gov/libpcap.tar.Z \\
\hline InterNIC Internet Documentation & http://www.internic.net/ds/dspglintdoc.html \\
\hline LBNL Network Research Group & http://ee.lbl.gov/ \\
\hline SNNS Stuttgart Neural Network Simulator & ftp://ftp.informatik.uni-stuttgart.de/pub/SNNS \\
\hline Steven McCanne (co-autor da Libpcap) & http://HTTP.CS.Berkeley.EDU/ mccanne/ \\
\hline Unix NetworkMonitoring Tools & http://ciac.llnl.gov/ciac/ToolsUnixNetMon.html \\
\hline
\end{tabular}




\section{APÊNDICE D - Como contactar o autor}

Adriano Mauro Cansian pode ser contactado em:

UNESP - Universidade Estadual Paulista

Instituto de Biociências, Letras e Ciências Exatas de São José do Rio Preto

http://www.ibilce.unesp.br/

Depto. de Ciências da Computação e Estatística

R. Cristóvão Colombo, 2265 - Jd. Nazareth

15055-000 São José do Rio Preto, SP - Brasil

Tel. +55 (017) 224-4966 Fax: +55 (017) 224-8692

E-mail: adriano@ibilce.unesp.br 


\section{GLOSSÁRIO}

Account Uma autorização para um usuário utilizar um sistema de rede ou computador multi-usuário. Estão geralmente associados à account, um username, uma senha, e um espaço em disco em um computador.

Advisory Um boletim ou alerta contendo, geralmente, notificações de falhas de segurança e recomendando medidas ou ações para sanar o problema. São emitidos pelos produtores de softwares ou por orgãos de segurança como CERT ou CIAC.

API

Application Program Interface. É usada para simplificar a programação de uma tarefa. Uma API é formada por uma ou mais bibliotecas que contêm todos os procedimentos necessários para solucionar um determinado problema, possibilitando um aumento no nível de abstração. É escrita para ser usada por uma determinada linguagem de programação, sob um sistema operacional específico.

Backbone Uma conexão de rede, geralmente de alta velocidade, que interliga outros segmentos; também usado para referenciar uma rede que age como uma centralizadora.

CERT Computer Emergency Response Team. É uma organização não governamental Americana, sem fins lucrativos, que fornece auxílio em situações que envolvem segurança de computadores e redes. Consulte http://www.cert.org/

CIAC Computer Incident Advisory Capability. Orgão do United States Department of Energy, que fornece auxilio em situações que envolvem segurança de computadores e redes. Consulte http:/twww.ciac.gov/

Cliente $\quad \mathrm{O}$ usuário de um serviço de rede; também usado para descrever um computador ou programa que utiliza recursos de outro.

Conta O mesmo que account (vide acima).

DNS Domain Name System. Método usado para converter nomes de endereços na rede Internet para seus correspondentes números IP.

FTP File Transfer Protocol. Protocolo padrão, de alto nível, usado para transferência de arquivos entre computadores na Internet.

Internet Uma concatenação de diversas redes individuais, que operam sobre protocolo TCP/IP, e que seguem um conjunto específico de padrões, compartilhando um mesmo esquema de endereçamento.

IP Internet Number. Um número de endereçamento na rede Internet, formado 
por 4 grupos de decimais separados por pontos no formato: aaa.bbb.ccc.ddd

Kernel O nível de um sistema operacional que contém todas as instruções internas, ou todas as funções ocultas aos usuários. Comporta as rotinas de gerenciamento de memória, o escalonador de tarefas e as chamadas de sistema.

login Operação de acesso e entrada em um sistema computacional, onde o usuário fornece o seu username e sua senha.

Password O mesmo que senha.

patch Uma correção ou atualização aplicada a um sistema computacional ou software, para sanar uma falha, um erro de projeto ou uma situação não prevista. Também referenciado freqüentemente como "remendo".

Protocolo Uma descrição dos formatos de mensagens, e regras que computadores devem obedecer para trocar estas mensagens entre si. Podem descrever detalhes de baixo nível nas interfaces das máquinas, ou condições de alto nível para comunicação entre os programas. Na Internet são definidos por intermédio de um RFC.

RFC Request for Comments. Um documento técnico que define ou formaliza um padrão dentro da rede Internet. É identificado por um número de ordem de sua publicação, na forma $R F C-x x x x$.

root

Supervisor, administrador ou super-usuário responsável por um sistema computacional. Possui privilégios para realizar determinadas operações especiais ou reservadas.

script Um pequeno programa de processamento de lote, que realiza operações seqüenciais, que são geralmente comandos de um sistema operacional.

Sendmail Programa para manipulação de correio eletrônico, amplamente utilizado em sistemas UNIX

Senha Conjunto de caracteres secretos que o usuário fornece para ganhar acesso a um recurso do sistema.

shell Um tipo de interface de interação entre o usuário e o sistema operacional de um computador. Define o ambiente de utilização, e os recursos disponiveis.

SMTP Simple Mail Transfer Protocol. Protocolo padrão na Internet para transferência de mensagens de correio eletrônico entre computadores.

string Uma cadeia de caracteres ASCII.

syscall Chamada de sistema. Um recurso fornecido pelo kernel do sistema operacional UNIX, e utilizado pelos processos para se obter serviços deste mesmo kernel. 
TCP/IP Transmission Control Protocol / Internet Protocol. Um conjunto de protocolos, desenvolvido a partir de um projeto do Departamento de Defesa Americano, e que têm como finalidade fornecer serviços de rede, tais como conexões remotas e transferência de arquivos e correio eletrônico, dentre outros.

Telnet Protocolo padrão na Internet, para conexão de terminal remoto interativo.

Threshold Um valor limite ou limiar.

userid Código de identificação, geralmente numérico, de um usuário dentro de um sistema computacional. Está sempre associado a um username e um account.

username Nome de identificação de um usuário, associado a um userid.

Worm Um programa de computador, geralmente danoso ou destruidor, que se replica por si próprio, independente de outros programas. 